\title{
SEA SURFACE TEMPERATURES FROM OXYGEN ISOTOPES IN MARINE MOLLUSCS IN MIDDLE AND LATER STONE AGE SITES, SOUTH AFRICA
}

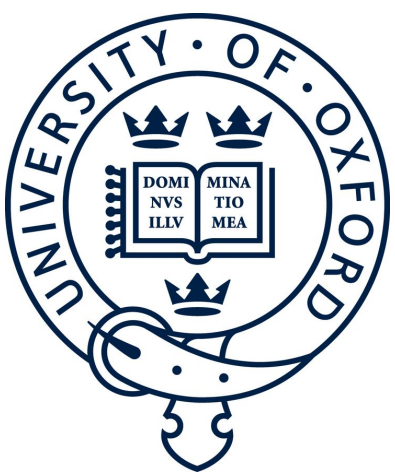

Emma Loftus

Merton College

University of Oxford

A thesis submitted for the degree of

Doctor of Philosophy

Trinity 2016 


\section{Abstract}

The southernmost coast of South Africa has been proposed to have been a uniquely important region in later human evolution, in part due to the abundance of nutritious and dense coastal resources. Yet, strong contrasts in the Middle Stone Age (MSA) and subsequent Later Stone Age (LSA) archaeological records cast uncertainty on the significance of shellfish utilisation for processes of human evolution. Further, climatic shifts are frequently advanced as drivers of widespread technological change but few climate proxy records correspond adequately to the archaeological evidence at a temporal or spatial level to be unambiguously linked to human cultural activity. This thesis presents a temporally and spatially distributed record of near-shore seasonal sea surface temperatures (SSTs) from serial $\delta^{18} \mathrm{O}$ shell measurements of archaeological Turbo sarmaticus opercula. In addition, the annual timing of shellfish harvesting captured in the temperature signal of the shells' final few growth increments is indicative of the scheduling of foraging behaviours and social organisation.

A non-destructive method for evaluating the preservation of the original aragonitic shell carbonate using Fourier transform infrared spectrometry with an attenuated reflectance attachment is presented, allowing for robust SST reconstructions. Nearshore SST reconstructions are presented from the LSA levels of Nelson Bay Cave and Byneskranskop 1, with new radiocarbon chronologies spanning the terminal Pleistocene and the Holocene, and the MSA deposits at Pinnacle Point 5-6 and Klasies River Main site, dated to periods in Marine Isotope Stage (MIS) 5 and across the MIS5/4 transition. These reconstructions confirm the utility of near-shore SST records for terrestrial climate reconstructions, indicating summer rainfall shifts during the Holocene and across MIS5/4. The annual timing of shellfish foraging is shown to be markedly different between the MSA and LSA, and more nuanced assessments of foraging behaviours within the MSA and LSA emerge. 


\section{Preface}

I am indebted to the research of Nick Shackleton, Anne Cohen and Mariagrazia Galimberti, who separately sought to reconstruct seasonal sea surface temperatures from southern African archaeological mollusc shells. Shackleton and Galimberti demonstrated the reliability of Turbo sarmaticus for palaeotemperature reconstructions, and Cohen provided a novel framework for the interpretation of such records. That said, upon beginning this thesis several methodological challenges remained for the development of robust temperature records from the opercula of Turbo. The complex growth patterns evident on the surface of the opercula confound sampling, and standard sclerochronological techniques, as applied by Galimberti, provided frustratingly few insights. Here I benefited from an observation made to me by Prof. Chris Richardson of Bangor University, who noted that growth increments on the opercula appear to shift the direction of growth discretely, rather than continuously, probably as the mollusc rotates the operculum to fit the growing top shell aperture. Prof. Richardson and Prof. James Scourse also kindly hosted me at their laboratory in Bangor where they and Drs. Paul Butler, David Reynolds and Alejandro Román González trained me to use a micromill for high resolution sampling, which improved the possibilities for seasonal temperature reconstructions.

A further problem I encountered was in demonstrating the preservation of the original aragonitic carbonate - using XRD, Galimberti's study had observed high rates of recrystallisation in archaeological shells, disqualifying many shells for analysis, and confirming that an evaluation of recrystallisation is essential for robust temperature studies. However, I did not have routine access to an XRD instrument and some limited experiments with Dr Matthew Cliffe of the Department of Chemistry had emphasised to me how highly specialist, destructive and time consuming the method is - hardly suitable for routine screening of small powder samples. Consequently, I researched the 
capabilities of two instruments within RLAHA, FTIR-ATR and SEM, and noted the good potential for FTIR to provide quantitative measures of calcite contamination. I developed a method for evaluating small powder samples (described below in 3.3.2), published with Prof. Keith Rogers of Cranfield University, who assisted with comparative XRD analyses, as "Loftus E, Rogers KD, Lee-Thorp, JA. 2015. A simple method to establish calcite:aragonite ratios in archaeological mollusc shells. Journal of Quaternary Science. 30(8): 731-735."

Another methodological issue only became apparent gradually during the first 18 months of my DPhil - the newly-acquired Sercon carbonate device in RLAHA could not analyse small samples with the precision necessary for palaeotemperature research. I had been analysing samples using the Kiel Device in the Department of Earth Sciences, Oxford, with the help of Dr. Chris Day, but that instrument was heavily utilised and experiencing recurring break-downs during this period. I also visited the Division of Archaeological, Geographical and Environmental Sciences of the University of Bradford and analysed some samples on the Gasbench system there, but the laboratory was scheduled to close for over a year in January 2015. Consequently, Prof. Lee-Thorp and I applied for a NERC Isotopes Geosciences Laboratory grant (IP-1543-0515) to analyse 800 samples on the Isoprime system at the British Geological Services facility in Keyworth. We also applied for a NERC Radiocarbon Facility grant for AMS dates for Byneskranskop 1 and Nelson Bay Cave (NF/2015/1/11), as upon closer examination the existing chronologies for these two sites were somewhat insecure and improved dating would allow me to refine the climate reconstructions from the shell data. Given the role of Nelson Bay Cave, in particular, in establishing the lithic sequence framework for South Africa, the new chronologies also provide impetus for a timely re-evaluation of the Later Stone Age technological sequence, relevant to the broader archaeological community in South Africa. The new dates, provided here in Chapter 4, were published as "Loftus E, Sealy J, Lee-Thorp JA. 2016. New radiocarbon dates and Bayesian models for Nelson Bay Cave and Byneskranskop 1: implications for the South African Later Stone Age sequence. Radiocarbon. 58: 365- 381."

Except where indicated, all figures and photographs are my own. In addition to the grants mentioned above, this research was supported primarily by a Clarendon Fund Scholarship from the Oxford University Press, with further support from Merton College, Boise Fund (Oxford), the Quaternary Research Association, the Palaeontological Scientific Trust (South Africa), and a Department of Science and Technology and the National Research Foundation South African Research Chairs Initiative award to Judith 
Sealy. Samples were obtained and exported under permits from Heritage Western Cape (case numbers 15021902AS0219E and 14072110GT0730E), the Eastern Cape Provincial Heritage Resources Authority (2/2/APM-PERMIT/14/09/003) and the South African Heritage Resources Agency (Permit ID 1924).

Acknowledgements. I would like to thank several people who have helped me in various ways during the last few years. In addition to those mentioned above, I am grateful to Vincent Hare, Amy Jeffrey, Michaela Ecker, Harvey Lederman, Hayley Sula, Christophe Snoeck, Katerina Douka, Patrick Roberts, Maciej Wencel, Chris Doherty, Richard Staff, Mike Dee, David Chivall, Andy Gledhill, Hilary Sloane, Andrew Smith, Melanie Leng and especially Peter Ditchfield, for help in the laboratory and in discussing isotopes and South African archaeology. Especial thanks are due to Chris Day for help with the Kiel. Thank you also to those at UCT and in Cape Town who helped me with practical matters - Nick Zachariou, Louisa Hutten, Wendy Black and others. Access to the Pinnacle Point and Klasies River collections was kindly facilitated by Curtis Marean and Sarah Wurz, respectively. I am privileged in having two exceptional thesis advisers, Prof. Julia Lee-Thorp at Oxford, and Prof. Judy Sealy, in Cape Town, who created the opportunities for me to do this project, and patiently helped me puzzle through the intricacies of it all. I am always grateful to the opportunities given by the University of Oxford, RLAHA and the Institute of Archaeology, which enabled me to study and live in such a magnificent city. I would also like to thank Merton College and the staff and students thereof, who provided friendship and financial support over five years of my masters and doctorate - I am grateful to my college advisor Prof. Irene Lemos, for support in the final stretch. I have met many of my best friends at Merton (Nikki, Jess, Josh, Jamie, Kat, Emil, Rob, Ruth, Rosalind, Jason), and they make Oxford the wonderful place that it is for me. Love and thanks to Laurent, who turned everything around. I owe everything to my mother, Anne, who has given me all the opportunities to do what I love. 


\section{Contents}

$\begin{array}{ll}\text { Abstract } & \text { i }\end{array}$

$\begin{array}{ll}\text { Preface } & \text { ii }\end{array}$

1 Introduction $\quad 1$

2 Archaeological and environmental context $\quad 8$

2.1 Climate and environments . . . . . . . . . . . . . . . . 9

2.1 .1 Regional climate systems _. . . . . . . . . . . . . . . 9

2.1.2 Southern Cape environments and the Agulhas Current . . . . . 12

2.1.3 Modern SST, air temperature and rainfall along the south coast . 13

2.1.4 South African palaeoclimate . . . . . . . . . . . . . . 18

2.1.5 Interpretive framework for near shore SST records . . . . . . . . . 19

2.2 Archaeology . . . . . . . . . . . . . . . . . . . 23

2.2.1 Southern African Stone Age archaeology . . . . . . . . . . . . 23

2.2 .2 The sites . . . . . . . . . . . . . . . . . . . . . . 32

3 Methods 43

3.1 Turbo sarmaticus and modern calibration data . . . . . . . . . . . 44

3.1.1 Shell growth and palaeotemperature archives . . . . . . . . . 45

3.1 .2 Turbo ecology and growth . . . . . . . . . . . . 47 
3.1.3 Galimberti (2010) modern calibration study . . . . . . . . . . . 48

3.2 Micromill sampling and $\delta^{18} \mathrm{O}$ analysis . . . . . . . . . . . . . . 50

3.2.1 Sampling strategies for Turbo opercula . . . . . . . . . . 50

3.2.2 Micromill sampling strategy . . . . . . . . . . . . . . 53

$3.2 .3 \quad \delta^{18} \mathrm{O}$ analyses $\ldots \ldots \ldots \ldots \ldots$

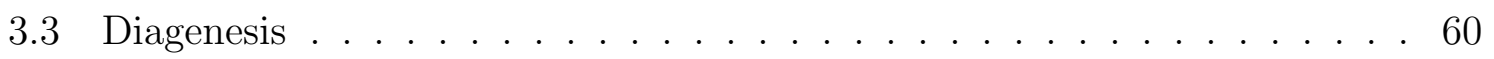

3.3.1 Pretreatment for organic contaminants . . . . . . . . . 61

3.3.2 FTIR analyses for recrystallisation . . . . . . . . . . . 63

3.4 Seawater $\delta^{18} \mathrm{O}$ variability ......................... 74

4 Chronology of Nelson Bay Cave and Byneskranskop $1 \quad 77$

4.1 Introduction . . . . . . . . . . . . . . . 78

4.2 Previous chronological research . . . . . . . . . . . . . . 79

4.2.1 Nelson Bay Cave . . . . . . . . . . . . . . . . . . 79

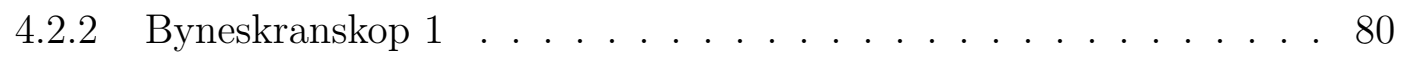

4.3 Materials and methods .................. . 80

4.3.1 Principles of radiocarbon dating . . . . . . . . . . . . . . 80

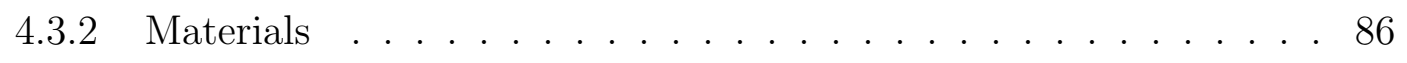

4.3.3 Laboratory Methods ................. . 86

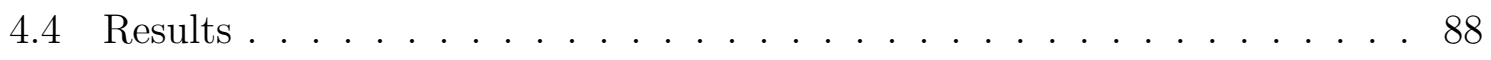

4.4 Nelson Bay Cave ... . . . . . . . . . . . . . . . 88

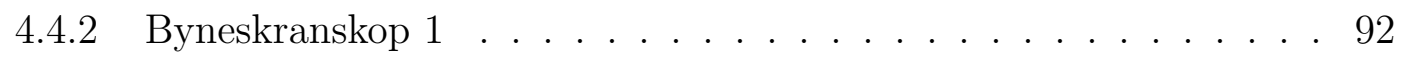

4.5 Bayesian models and discussion . . . . . . . . . . . . . . . 95

4.5.1 Nelson Bay Cave . . . . . . . . . . . . . . . . . . 95

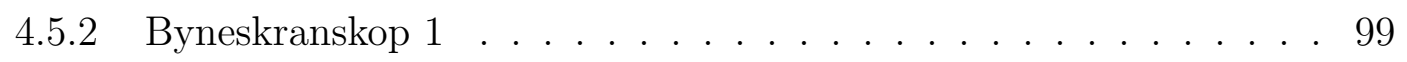

4.5.3 Correspondence with the overall southern African LSA chronology 102

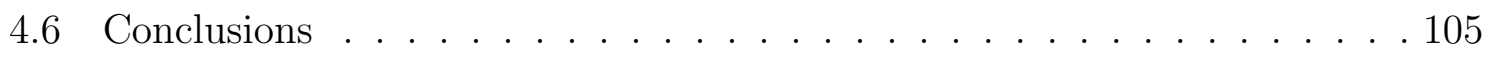


5 Shell isotope data: climate trends and seasonality 107

5.1 Assessing physiological effects on seasonal amplitude . . . . . . . . . . 108

5.2 Alternative correction for changes in seawater $\delta^{18} \mathrm{O}$. . . . . . . . 109

5.3 Holocene study . . . . . . . . . . . . . . . . . . . . . 110

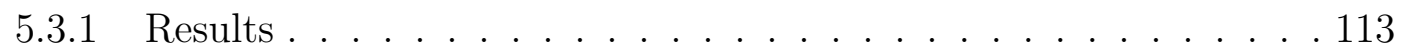

5.3.2 Discussion of LSA $\delta^{18} \mathrm{O}$ and $\delta^{13} \mathrm{C}$ sample results . . . . . . . . . 119

5.4 MIS4 and MIS5 study . . . . . . . . . . . . . . . . . . . 122

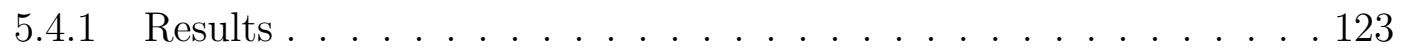

5.4 Discussion of MSA sample results . . . . . . . . . . . . . 137

5.5 Comparison with other estimates of seasonality . . . . . . . . . . . 140

5.5.1 Comparison with shell records of SST seasonality . . . . . . . . 140

5.5.2 Comparison with an offshore core record of SST seasonality . 142

5.5.3 Comparison with modelled estimates of SST seasonality . . . . . . 144

5.6 Conclusions . . . . . . . . . . . . . . . . . . . 147

6 Harvesting strategies through the MSA and LSA 150

6.1 Shellfish and seasonality . . . . . . . . . . . . . . . . 151

6.2 Season of harvest results . . . . . . . . . . . . . . . . . . . . 152

6.2.1 Method for evaluating season of collection . . . . . . . . . . 152

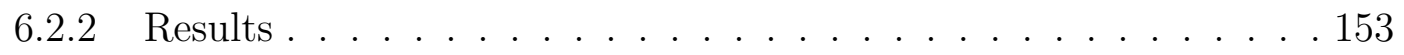

6.3 Turbo growth rates during the MSA and LSA . . . . . . . . . . . . 158

6.4 Discussion . . . . . . . . . . . . . . . . . . 163

$\begin{array}{lll}7 & \text { Discussion and conclusions } & 168\end{array}$

7.1 Near-shore SSTs and regional climate patterns . . . . . . . . . . . . 170

7.2 Subsistence and cultural patterns . . . . . . . . . . . . . . 172

7.2.1 Subsistence . . . . . . . . . . . . . . . . . . 172

7.2.2 Cultural and environmental change . . . . . . . . . . . . 176

7.3 Future research . . . . . . . . . . . . . . . . . . 179

7.4 Summary of conclusions . . . . . . . . . . . . . . . . 180 
A Raw data

B Line plots and shell photographs

C Statistical test results 


\section{List of Figures}

1.0.1 Two views of a Turbo sarmaticus shell, with operculum drawn into shell. 3

1.0.2 Inner and outer view of T. sarmaticus operculum. . . . . . . . . . . 5

2.1.1 Map of southern Africa showing the three rainfall zones, summer (SRZ), winter (WRZ) and year-round (YRZ), and the approximate positions of the major atmospheric features, including the easterly and westerly winds, and the high pressure systems. . . . . . . . . . . . . . 10

2.1.2 Map of Southern African biomes. . . . . . . . . . . . . . . 11

2.1.3 Topographical map of southernmost Africa with graphs of mean monthly climate indicators, including minimum and maximum air temperatures and precipitation. . . . . . . . . . . . . . . 15

2.1.4 Schematic showing the chronological relationships between the changes in global climate, including relative sea level (RSL) and $\delta^{18} \mathrm{O}$ of the global ocean, and South African archaeology. . . . . . . . . . . . 17

2.1.5 Diagrammatic sketches of the conceptual model that correlates surface SSTs in the Agulhas Current to regional wind anomalies and precipitation. 21

2.2.1 Map of southernmost Africa, showing the locations of the four archaeological sites in this study . . . . . . . . . . . . . . . 32

2.2.2 Photograph of the entrance to Nelson Bay Cave. . . . . . . . . . . . . . 33

2.2.3 Generalised site stratigraphy for Nelson Bay Cave. . . . . . . . . . . . . 35

2.2.4 Photograph of Byneskranskop 1 and nearby sites. . . . . . . . . . . . . 37

2.2.5 Stratigraphy of squares 29 and 30 at Byneskranskop 1. . . . . . . . . 38

2.2.6 Photograph of Klasies River Mouth Main site. . . . . . . . . . . . . . . . 38

2.2.7 Stratigraphy of Klasies River Main site . . . . . . . . . . . . . . . . 39 
2.2.8 Photographs of Pinnacle Point sea cliffs and PP5-6 Long Section . . . . 41

2.2.9 Stratigraphy of the Long Deposit of Pinnacle Point 5-6 . . . . . . . . . . 42

3.1.1 Scanning electron microscope image of the needle-like, fan shaped aragonite crystal structure of a modern T. sarmaticus operculum. . . . . . . 46

3.2.1 The drilling strategies of four previous researchers. . . . . . . . . . . . 51

3.2.2 Schematic of cross section through a T. sarmaticus operculum. . . . . . . 53

3.2.3 Modern operculum CP One (from Cape Point) showing micromill sampling. 54

3.2.4 Series of $\delta^{18} \mathrm{O}$ measurements across one operculum. . . . . . . . . . 55

3.3.1 FTIR spectra of aragonite and calcite . . . . . . . . . . . . . . 66

3.3.2 Eight replicate measurements of FTIR spectra of $100 \%$ Iceland spar. . . . 67

3.3.3 Ratios of five aragonite and calcite peaks against the ratio of calcite in each sample . . . . . . . . . . . . . . . . . 70

3.3.4 All peaks for the half the calibration set composed of artificial mixtures of ground oyster shell (calcite) and aragonitic Turbo sarmaticus shell. $\quad$ • 72

3.3.5 FTIR spectra between $800-900 \mathrm{~cm}^{-1}$ for the complete calibration set. . . 73

4.3.1 OxCal 4.2 plot of IntCal09 and SHCal13 calibration curves. . . . . . . . . 83

4.5.1 Bayesian model of radiocarbon dates from Nelson Bay Cave, including new AMS dates (in green). . . . . . . . . . . . . . . 96

4.5.2 Modelled age ranges of the stratigraphic levels at Nelson Bay Cave, (top) based on the dates published in Deacon (1984) and (bottom) incorporating fourteen AMS dates from this study. . . . . . . . . . . . . . . 97

4.5.3 Bayesian model of radiocarbon dates from Byneskranskop 1. . . . . . . . 100

4.5.4 Modelled age ranges of the stratigraphic levels at Byneskranskop 1. . . . 101

4.5.5 Modelled start and end boundaries for the major Later Stone Age technocomplexes, separated according to region. . . . . . . . . . 105

5.1.1 Scatterplots of average $\delta^{18} \mathrm{O}$ for each shell against the range of $\delta^{18} \mathrm{O}$ values per shell. . . . . . . . . . . . . . . . . . . 109 
5.3.1 Individual boxplots of $\delta^{18} \mathrm{O}$ for 27 serially sampled Turbo opercula from NBC, BNK1 and HRC, spanning from c. 2 kcalBP to c. 14 kcalBP. . . . 116

5.3.2 Boxplots of $\delta^{18} \mathrm{O}$ for the Holocene dataset, aggregated according to broad time period. . . . . . . . . . . . . . . 117

5.3.3 Boxplots of $\delta^{13} \mathrm{C}$ for the Holocene dataset, aggregated according to broad time period . . . . . . . . . . . . . . . 120

5.4.1 Individual boxplots of $\delta^{18} \mathrm{O}$ for 24 serially sampled Turbo opercula from Pinnacle Point 5/6, spanning deposits dating from c. 62 to 81 ka. . . . . 129

5.4.2 Individual boxplots of $\delta^{18} \mathrm{O}$ for 21 serially sampled Turbo opercula from Klasies River Main site, spanning deposits dating from c. 70 to $>115 \mathrm{ka}$, and two late Holocene aged shells from Klasies River Cave 5. . . . . . 130

5.4.3 Boxplots of serially sampled opercula $\delta^{18} \mathrm{O}$ from Pinnacle Point 5-6, aggregated according to depositional unit (top), and Klasies River Main and Cave 5, aggregated according to technological unit (bottom). . . . . 133

5.4.4 Boxplot of $\delta^{18} \mathrm{O}$ values from Pinnacle Point 5-6 in chronological order, analysed by sub-aggregate unit. . . . . . . . . . . . . . 135

5.4.5 Boxplots of $\delta^{13} \mathrm{C}$ for the Pleistocene aged samples, aggregated by site and depositional or technological units. . . . . . . . . . . . 136

5.4.6 Annual range of temperatures across the entire period of study. . . . . 138

5.5.1 Climate parameters for the last 120 ka. A: Relative sea level changes from modern. B: Insolation seasonality (June-December insolation) at $30^{\circ} \mathrm{S}$. C: Plot of reconstructed Agulhas Current seasonal SSTs from a marine sediment core. D: Averaged maximum, mean and minimum reconstructed temperatures from this study. . . . . . . . . . . . . . . . 145

5.5.2 Anomaly plots of sea surface temperatures for mid Holocene conditions simulated by three Earth Systems Models. . . . . . . . . . . . . . 148

5.5.3 Anomaly plots of sea surface temperatures for Last Glacial Maximum conditions simulated by three Earth Systems Models. . . . . . . . . . . 149

6.2.1 Schematic showing the method for evaluating the season of harvest. . . . 153

6.2.2 Warm vs cold and seasonal counts for each period considered in this study. 158

6.2.3 Warm vs cold and seasonal determinations A. for the entire LSA assemblage, according to cultural period, and B. separated according to site location for the post Wilton and Wilton periods. . . . . . . . 160 
6.2.4 Percentage of warm vs cold season and interquartile seasonal determinations for the entire set of shells, according to broad age category, MIS5, MIS4 and the Holocene. . . . . . . . . . . . . . . . . . . . . . . 161

6.2.5 Percentage of warm versus cold season and interquartile seasonal determinations for MIS5, 4 and Holocene aged shells according to site location. . . . . . . . . . . . . . . . . . . 162

7.1.1 Map of modern (1950-2000) aridity index (Mean Annual Precipitation/Mean Annual Evaporation) across southern Africa . . . . . . . . . . . . . 171

7.2.1 Bathymetric map of the southern coastal plain, South Africa. . . . . . . . 174

7.2.2 Proportion of quartzite and non-quartzite lithics at Nelson Bay Cave; Pinnacle Point 5-6 and Klasies River main site, compared to the serial $\delta^{18} \mathrm{O}$ values and harvest season results per level . . . . . . . . . . 177

B1 Individual line plots of each Holocene aged shell in alphabetical order. . . 219

B2 Individual line plots of each shell from Pinnacle Point 5-6 in alphabetical order. . . . . . . . . . . . . . . . . . . . . 221

B3 Individual line plots of each shell from Klasies River in alphabetical order.223

B4 Individual photographs of each sampled shell from NBC and HRC. . . . 225

B5 Individual photographs of each sampled shell from PP5-6. . . . . . . . . 227

B6 Individual photographs of each sampled shell from KRM. . . . . . . . . 229 


\section{List of Tables}

2.1 Key quarterly SST statistics for five locations on the south coast, South Africa . . . . . . . . . . . . . . . . . . 16

2.2 Southern African lithic cultural sequence, with key characteristics and approximate age range. . . . . . . . . . . . . . . . . 24

3.1 Comparison of predicted temperatures from $\delta^{18} \mathrm{O}$ measurements of Turbo opercula collected between 2004-2007 and observed SSTs at Mossel Bay.

3.2 Micromill settings and estimated conversion to calcite according to FTIR

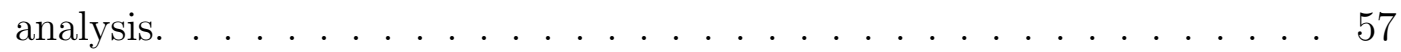

3.3 FTIR-ATR and pXRD analyses of calcite:aragonite mixtures compared. . 68

3.4 Sources of calcite and aragonite used in calibration mixtures. . . . . . . . 71

3.5 Stable isotope values of seawater samples collected along the south coast of South Africa. . . . . . . . . . . . . . . . . . 76

4.1 Previously published radiocarbon dates from Nelson Bay Cave with sample material details. . . . . . . . . . . . . . . . . 81

4.2 Previously published radiocarbon dates from Byneskranskop 1. . . . . . . 82

4.3 Samples selected for radiocarbon dating from Nelson Bay Cave and Byneskranskop 1. . . . . . . . . . . . . . . . . 87

4.4 AMS dates on bone collagen (bovid long bone shaft fragments) from Klein's excavation at Nelson Bay Cave, with $\% \mathrm{C}$ and $\delta^{13} C$. Dates are calibrated using the SHCal13 curve (Hogg et al., 2013). . . . . . . . . . 91

4.5 AMS dates on bone collagen (tortoise carapace fragments) from Byneskranskop 1 , with $\% \mathrm{C}$ and $\delta^{13} C$. Dates are calibrated using the SHCal13 curve (Hogg et al., 2013). . . . . . . . . . . . . . . . . . . 94 
4.6 Two sets of modelled age results in calibrated years BP for levels and boundaries at NBC, based on the previously published dates only and with the new AMS ages incorporated. . . . . . . . . . . . . 98

4.7 Modelled age results in calibrated years BP for levels and boundaries at BNK1, based on the previously published and new AMS dates. . . . . . . 101

4.8 Differences in years between the modelled boundaries of lithic industries in three regions, based on several hundred radiocarbon dates from across 54 sites. . . . . . . . . . . . . . . . . 106

5.1 Holocene shells corrected using Simon et al. (2015) foraminiferal $\delta^{18} \mathrm{O}$ record. . . . . . . . . . . . . . . . . . . . . . 110

5.2 Holocene and terminal Pleistocene operculum samples. . . . . . . . . . . 112

5.3 Summary statistics of $\delta^{18} \mathrm{O}$ and converted temperature values for each Holocene and terminal Pleistocene operculum. . . . . . . . . . . . . . . 115

5.4 Statistics for $\delta^{18} \mathrm{O}$ values aggregated by broad time period (the terminal Pleistocene and early, middle and later Holocene). . . . . . . . . . . . . . 118

5.5 Statistics for $\delta^{13} \mathrm{C}$ values aggregated by broad time period (the terminal Pleistocene and early, middle and later Holocene). . . . . . . . . . . . . 119

5.6 Opercula samples from Pinnacle Point 5/6. . . . . . . . . . . . . . . 124

5.7 Opercula samples from Klasies River Main site. . . . . . . . . . . . . . 125

5.8 Summary statistics of $\delta^{18} \mathrm{O}$ and converted temperature values for each operculum from Pinnacle Point 5/6. . . . . . . . . . . . . . . . 127

5.9 Summary statistics of $\delta^{18} \mathrm{O}$ and converted temperature values for each operculum from Klasies River Mouth. . . . . . . . . . . . . . . . . . . . 128

5.10 Statistics for serially sampled opercula $\delta^{18} \mathrm{O}$ and converted temperature values from Pinnacle Point 5-6, aggregated by depositional unit. . . . . . 131

5.11 Statistics for serially sampled opercula $\delta^{18} \mathrm{O}$ and converted temperature values from Klasies River Main site and Cave 5, aggregated by technological unit. . . . . . . . . . . . . . . . . . . . . . . . . 132

5.12 Statistics for the aggregated $\delta^{13} \mathrm{C}$ values from Pinnacle Point 5-6 and Klasies River Main site and Cave 5. . . . . . . . . . . . . . . . . 136

5.13 Statistics for $\delta^{18} \mathrm{O}$ and converted temperature values from Cohen and Tyson (1995) (early, middle and later Holocene all from Nelson Bay Cave) and Galimberti (2010) (Pinnacle Point sites) shells, aggregated by time period. . . . . . . . . . . . . . . . . . . . . 143 
5.14 Comparison of seasonality estimates for key periods during the Holocene and Pleistocene . . . . . . . . . . . . . . . . . 146

6.1 Interquartile ranges for $\delta^{18} \mathrm{O}$ values aggregated according to period, used to evaluate the season of harvest. . . . . . . . . . . . . . . . 154

6.2 Warm vs cool season and interquartile seasonal determinations for the Holocene shells from BNK1 and NBC. . . . . . . . . . . . . . 155

6.3 Warm vs cool and interquartile seasonal determinations for the shells from Pinnacle Point $5-6 \ldots$. . . . . . . . . . . . . . 156

6.4 Warm vs cool and interquartile seasonal determinations for the shells from Klasies River Main site. . . . . . . . . . . . . . . . . 157

6.5 Growth rates in mm of annual cycles in individual Turbo opercula as identified from serial $\delta^{18} \mathrm{O}$ analyses. . . . . . . . . . . . . . . 159

A1 Measured $\delta^{18} \mathrm{O}(\mathrm{O})$ and $\delta^{13} \mathrm{C}(\mathrm{C})$ values for each Late and Mid Holocene shell. . . . . . . . . . . . . . . . . . . . . . . . . 214

A2 Measured $\delta^{18} \mathrm{O}(\mathrm{O})$ and $\delta^{13} \mathrm{C}(\mathrm{C})$ values for each Early Holocene and Late Pleistocene shell . . . . . . . . . . . . . . . . . . . 215

A3 Measured $\delta^{18} \mathrm{O}(\mathrm{O})$ and $\delta^{13} \mathrm{C}(\mathrm{C})$ values for each Pinnacle Point 5/6 shell 216

A4 Measured $\delta^{18} \mathrm{O}(\mathrm{O})$ and $\delta^{13} \mathrm{C}(\mathrm{C})$ values for each Klasies River shell. . . . 217

C1 Post-hoc TukeyHSD multiple comparisons test results for raw Holocene $\delta^{18} \mathrm{O}$ results, grouped into four periods. . . . . . . . . . . 230

C2 ANOVA results for corrected Holocene $\delta^{18} \mathrm{O}$ results, grouped into four periods. . . . . . . . . . . . . . . . 230

C3 Post-hoc TukeyHSD multiple comparisons test results for corrected Holocene $\delta^{18} \mathrm{O}$ results, grouped into four periods. . . . . . . . . . . 231

C4 Post-hoc TukeyHSD multiple comparisons test results for corrected Holocene $\delta^{18} \mathrm{O}$ results, grouped into six groups. . . . . . . . . . . 231

C5 Post-hoc TukeyHSD multiple comparisons test results for Holocene $\delta^{13} \mathrm{C}$ results, grouped into four periods. . . . . . . . . . . . . . 232

C6 Post-hoc TukeyHSD multiple comparisons test results for uncorrected Pinnacle Point $5 / 6 \delta^{18} \mathrm{O}$ results. . . . . . . . . . . . . . . . . 232 
C7 ANOVA results for corrected Pinnacle Point 5/6 $\delta^{18} \mathrm{O}$ results . . . . . . . 232

C8 Post-hoc TukeyHSD multiple comparisons test results for corrected Pinnacle Point $5 / 6 \delta^{18} \mathrm{O}$ results. . . . . . . . . . . . . . . . 233

C9 Post-hoc TukeyHSD multiple comparisons test results for uncorrected Klasies River Main site $\delta^{18} \mathrm{O}$ values. . . . . . . . . . . . . . 233

C10 ANOVA results for corrected Klasies River Main site $\delta^{18} \mathrm{O}$ values. . . . . 233

C11 Post-hoc TukeyHSD multiple comparisons test results for corrected Klasies River Main site $\delta^{18} \mathrm{O}$ values. . . . . . . . . . . . . . . . . . . 234

C12 Post-hoc TukeyHSD multiple comparisons test results for Pinnacle Point 5-6 and Klasies River $\delta^{13} \mathrm{C}$ results, by site and according to depositional or technological unit. . . . . . . . . . . . . . . . . . 234 


\section{Chapter 1}

\section{Introduction}

The southernmost coast of South Africa boasts a long record of human occupation, with some of the earliest robust evidence for the emergence of complex behaviours characteristic of modern humans (e.g. Rightmire and Deacon, 1991; Henshilwood and Sealy, 1997; Henshilwood et al., 2002; Marean et al., 2007; Marean, 2016). The region has been proposed to have been uniquely important as a stable refugium for human populations under glacial conditions (Compton, 2011), and archaeological sites contain early and abundant evidence for the exploitation of coastal resources, notably shellfish (Marean et al., 2007). This combination of ecological context and archaeological record suggests an important role for the habitats and resources of the southernmost coast in later modern human evolution (Parkington, 2010; Marean, 2014). Yet, although ecological interpretations have great intuitive appeal for understanding the southern African archaeological record, there is currently little consensus on if and how the shifts seen in the archaeological sequence of the region relate to global and regional climate trends (e.g. Jacobs and Roberts, 2008; Ziegler et al., 2013; Roberts et al., 2016). Moreover, trends in the exploitation of coastal habitats throughout the Middle and Later Stone Ages are still ambiguous and their significance is heavily debated (Steele and Klein, 2008; Jerardino, 2016; Marean, 2016).

The landscape of the southernmost coastal region has varied enormously over the period of human occupation as shorelines advanced and retreated in response to global sealevel fluctuations and multiple interlinked and competing climate dynamics stimulated environmental and ecological shifts. That humans living along the southernmost coast witnessed and responded to climatic and environmental changes is not in doubt. Yet, palaeoclimate proxies typically offer only crude approximations of single climatic variables. 
The nature of local environmental change during this time is uncertain, as is the significance of the strong shifts in lithic style, ornamental and symbolic objects and subsistence behaviours that are evident in the cultural records. The two categories of evidence about the human past, environmental and cultural, do not neccessarily complement one another at either the spatial and temporal scales of analysis. A robust test of the hypothesis that cultural change ultimately reflects climatic influences is needed.

At a regional scale, the southernmost coast lies at the intersection of the tropical, easterly and temperate, westerly circulation systems that lie to the north and south respectively (Tyson and Preston-Whyte, 2000). These systems determine the strongly seasonal rainfall gradient across the country, from summer-dominated in the northern and eastern regions to a winter rainfall regime in the south-west (see Figure 2.1.1). The southernmost coast experiences a gradient of rainfall seasonality from east to west that reflects the relative dominance of these two systems, which have shifted in relation to one another in the past (Van Zinderen Bakker, 1967; Tyson, 1986; Cockcroft et al., 1987; Chase and Meadows, 2007), driving ecosystem shifts in conjunction with global temperature trends (Chevalier and Chase, 2016). Locally, the southernmost coast is a strongly maritime environment, with the Agulhas Current effectively moderating daily and seasonal air temperature fluctuations (Lutjeharms, 2006). Moisture and heat fluxes off the warm Agulhas waters stimulate atmospheric dynamics that affect the coastal region exclusively, partially buffering the region from the climatic events occurring across southern Africa. Thus, clear understandings of past ecological shifts, and the consequent effects for ancient human populations, require high-resolution, time-matched palaeoenvironmental and palaeoclimatic records of regional conditions.

This study aims to reconstuct seasonal resolution records of near-shore sea surface temperatures spanning the last glacial cycle using archaeological Turbo sarmaticus shells (see Figure 1.0.1) from sites located along the southernmost coast. These molluscs were collected by foraging people living along this coast and their shells were discarded as refuse, which gradually accumulated in deposits that span tens of thousands of years of occupation. Turbo sarmaticus shells are a reliable seasonal palaeoenvironmental archive as the $\delta^{18} \mathrm{O}$ values of the calcium carbonate growth increments reflect the temperatures of the waters in which they grew. Additionally, the shells of Turbo record aspects of the foraging behaviour of ancient humans - the season of collection is recorded in the $\delta^{18} \mathrm{O}$ value of their final growth increment. Thus, Turbo shells are archives of both environmental and social information, enabling the twin objectives of this thesis: to 

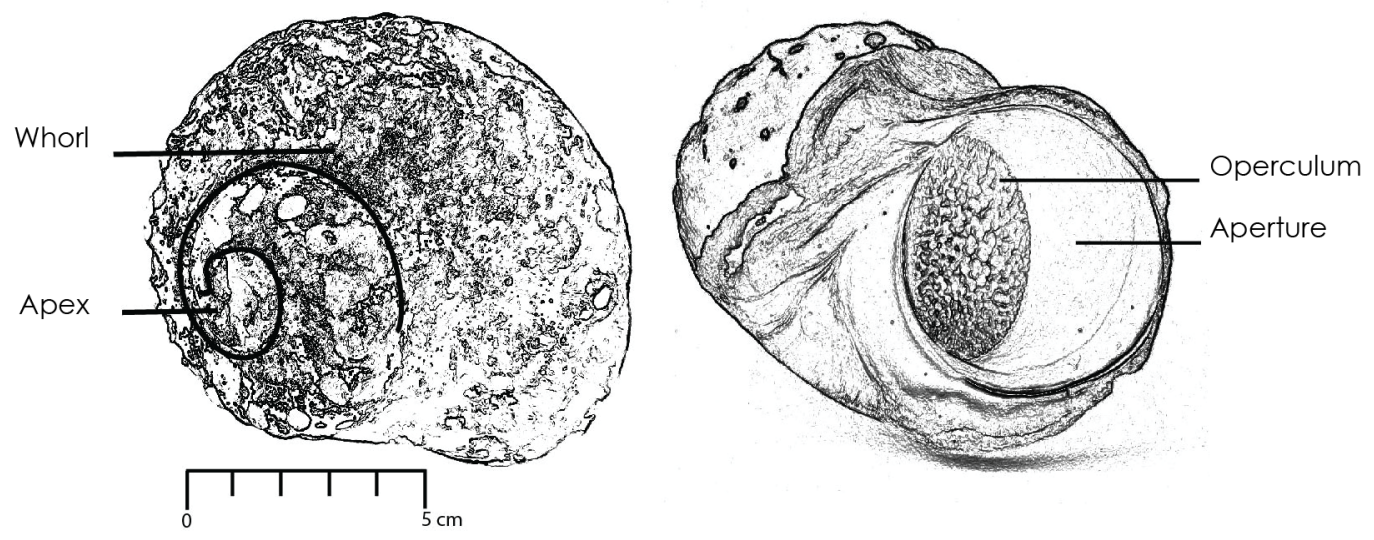

Figure 1.0.1: Two views of a Turbo sarmaticus shell, with operculum drawn into shell.

produce a long term record of environmental change interbedded with the archaeological record of cultural change across the Middle and Later Stone Ages (MSA and LSA) within the setting of a single coastal environment and to evaluate the seasonal timing of shellfish harvesting (and by proxy the season of site occupation) across this period.

Although by no means a perfect palaeoenvironmental recorder, mollusc shells present some unique advantages for those interested in past people and environments (see Andrus, 2011 and Thomas, 2015a, 2015b for recent comprehensive reviews of this burgeoning field of study). Mollusc shells preserve well compared to many types of organic remains and are often abundant in coastal archaeological sites. While many records of past ocean temperatures come from spatially and temporally averaged deposits of planktic and benthic organisms accumulated in deep ocean sediments, shells reflect seasonal sea surface temperatures (SSTs) directly at the coast, and so can be better proxies for the local environmental conditions experienced by ancient populations. Moreover, as noted above, not only do the shells capture key climatic parameters such as SSTs at unusually high-resolution, but the same record can also reveal details of the subsistence practices of ancient populations, such as the timing of mollusc harvesting, which speaks to settlement strategies and social organisation. And as food refuse, shells are interbedded with the human cultural record, sidestepping many of the problems of chronological control that arise when comparing archaeological and environmental records from different contexts.

However, despite the promising advantages of shells as palaeoenvironmental and palaeoclimatic archive, and many years of research into the topic (e.g. Epstein and Mayeda, 1953; Epstein and Lowenstam, 1953; Emiliani and Mayeda, 1964; Emiliani et al., 1964; 
Keith and Parker, 1965; Shackleton, 1969, 1973, 1982), the isotopic study of marine shells is not yet routine in archaeology. Extensive research is required to establish the utility and reliability of a particular species for geochemical investigation, and the methodological and technical considerations discourage casual investigations. But the advancement of sclerochronological techniques (the study of accretionary growth layers in biogenic hardparts) in combination with stable isotope analyses has enabled highly resolved intra-annual records of mollusc growth and environmental parameters to be developed from the increments of a mollusc shell and the field is steadily expanding within archaeology (e.g. Mannino et al., 2003; 2007; Stephens et al., 2008; Carré et al., 2009; Ferguson et al., 2011; Surge and Barrett, 2012; Prendergast et al., 2015). Indeed, much of the research in this field has taken place under the aegis of archaeological projects, where shells are found in stratified and datable deposits and in close association with human cultural materials and other environmental archives.

Turbo sarmaticus opercula are one of the most common components of archaeological shell assemblages on the southernmost coast and are frequently the best preserved the hard, flat disk of the operculum does not fragment as easily as hollow, thin-walled topshells and bivalves and opercula were preferentially transported back to residential sites once the heavy top-shell was discarded at the site of collection (Langejans et al., 2012). This offers the extraordinary opportunity for SST reconstructions spanning the entire last glacial cycle along the southernmost coast using the same species. But Turbo opercula present some unique sclerochronological problems for palaeoenvironmental reconstructions. Typically in sclerochronological studies, shells are sectioned and ground smooth to provide a suitably flat and uniform surface to study and sample the growth increments. However, this is not possible for Turbo opercula, where the growth increments lie at the surface and are only a few millimeters thick - the naturally ridged and complex growth spiral must be sampled without polishing. Further, many sclerochronological studies rely on either very long-lived (e.g. Schöne et al., 2005; Butler et al., 2013) or comparatively large, fast-growing species (e.g. Fenger et al., 2007; Surge and Barrett, 2012), allowing for either robust multi-year or highly detailed SST reconstructions. The small, slow-growing, comparatively short-lived Turbo requires a different strategy for sampling and interpretation.

Shackleton (1982) first showed the promise of Turbo sarmaticus for palaeoclimatic and archaeological research: he matched the oxygen isotope ratios of opercula from Klasies River Main site against the global ocean isotope curve for use as a crude dating tool, believing that the global changes in oceanic $\delta^{18} \mathrm{O}$ dominated the shell isotope signal 


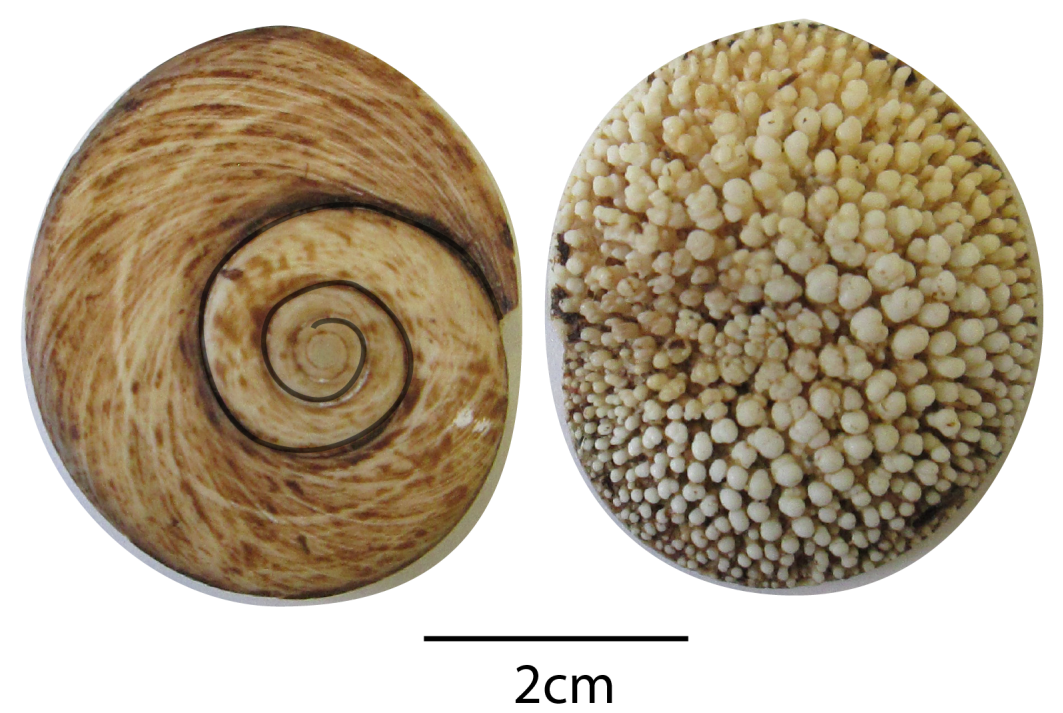

Figure 1.0.2: Inner and outer view of T. sarmaticus operculum. Note that the operculin, an organic "skin" on the inner surface, has been removed.

over long timescales (as opposed to local temperature effects). Prior to this, he had assessed the season of collection of LSA Scutellastra tabularis shells from Nelson Bay Cave, demonstrating the clear relevance of shell-focussed research to South African archaeological research questions (Shackleton, 1973). Subsequently, Cohen (Cohen et al., 1992; Cohen and Branch, 1992; Cohen, 1993) demonstrated the environmental utility of southern and western coast limpet species, and developed a theoretical model for the interpretation of near-shore SSTs derived from shell oxygen isotope measurements that is key for the interpretation of this thesis's results (Cohen and Tyson, 1995: see section 2.1.5). Most recently, Galimberti undertook a comprehensive study of Turbo sarmaticus for palaeotemperature reconstructions, with both a modern study demonstrating the utility of this species and a limited palaeotemperature study using opercula from archaeological sites Pinnacle Point 13B and 9B, dating largely to Marine Isotope Stage (MIS) 5 .

However, previous projects, although demonstrating proof-of-concept, were limited in sample size, and in temporal and spatial scope. A study applying these methods and frameworks to a broad set of archaeological materials has yet to be undertaken. Consequently, the goal for this project was to apply these methods to an expanded set of samples to create a longer narrative of subsistence practices throughout the MSA and LSA and of the role of climate fluctuations for the human cultural record over the last 
glacial cycle. Samples come from the LSA levels at Nelson Bay Cave and Byneskranskop 1, and the MSA levels at Klasies River Mouth and Pinnacle Point 5-6, using the better dated and contextualised LSA material as a vital reference framework for the MSA temperature records. The design of this project allows me to address the following research objectives:

\section{Research Aims and Objectives}

1. Evaluate changes in near-shore SSTs between and within MIS5, MIS4 and the Holocene and the different site locations and determine any correspondence with global and regional climate events.

2. Evaluate changes in the seasonality of SSTs (i.e. the annual temperature range) between and within these periods and sites and determine any correspondence with global and regional climate events.

3. Examine correspondences between the interbedded SST and archaeological records.

4. Examine evidence for changes in the annual timing of shellfish harvesting within and between the MSA and LSA and between sites.

Organisation of this thesis Following this introduction, Chapter 2 provides the contextual information for the archaeological and environmental questions that motivate this study. First, I describe the modern climatic and environmental context, both regionally and for the southernmost coast, and briefly establish a framework for investigating palaeoclimate change in southern Africa. Then, I present the relevant archaeological context regarding environmental and cultural intersections and changing subsistence behaviours throughout the MSA and LSA, and also describe the four archaeological sites studied in this thesis. Chapter 3 is concerned with the methodological considerations of deriving seasonal sea surface temperatures from archaeological shells. I begin by considering the utility of Turbo sarmaticus as a palaeotemperature recorder, including discussions of the ecology and behaviour of the species, and the results of a modern calibration study. Next, the method for high resolution sampling of opercula to capture seasonality and a brief consideration of the possible diagenetic effects of micromilling is presented. The following section discusses the twin problems of pretreatment and diagenesis and presents a method to evaluate recrystallisation of aragonite shells by 
Fourier transform infrared spectrometry. Finally, I provide a brief discussion of variation in seawater $\delta^{18} \mathrm{O}$ through time and along the coast, as this is a key variable of the temperature conversion equation.

Chapter 4 presents a largely self-contained radiocarbon study for the two LSA sites, Nelson Bay Cave and Byneskranskop 1, and explores the implications of these updated chronologies for the regional archaeological sequence. Chapters 5 and 6 contain the core results for this thesis - the seasonal sea surface temperatures and climatic implications are presented in Chapter 5, while the analyses in Chapter 6 of season of harvest and growth rate data explore changes in exploitation of shellfish through time. A final summary discussion and concluding comments are presented in Chapter 7, in which the overall contribution of this research to southern African palaeoclimate studies and archaeology is outlined and some of the avenues for future research are detailed. 


\section{Chapter 2}

\section{Archaeological and environmental context}

\section{Contents}

2.1 Climate and environments .............. 9

2.1 .1 Regional climate systems _. . . . . . . . . . . . 9

2.1.2 Southern Cape environments and the Agulhas Current . . . . 12

2.1.3 Modern SST, air temperature and rainfall along the south coast 13

2.1.4 South African palaeoclimate. . . . . . . . . . 18

2.1.5 Interpretive framework for near shore SST records . . . . . . 19

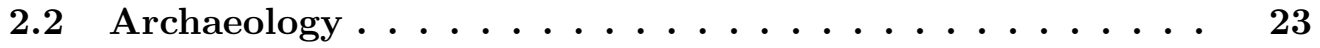

2.2.1 Southern African Stone Age archaeology . . . . . . . . . . 23

2.2.1.1 Cultural and environmental change . . . . . . 25

2.2.1.2 MSA and LSA marine subsistence strategies . . . . 28

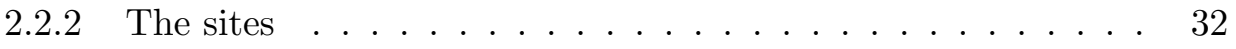

2.2.2.1 Nelson Bay Cave . . . . . . . . . . . . . . . . 33

2.2.2.2 Byneskranskop 1 . . . . . . . . . . 36

2.2.2.3 Klasies River Main site . . . . . . . . . . . . 37

2.2.2.4 Pinnacle Point 5-6 . . . . . . . . . . 40 
In this chapter, I describe the archaeological and palaeoenvironmental background to this study. In the first half of the chapter, the key features of southern African climate and ocean systems are presented, alongside a discussion of key models for understanding trends in Pleistocene climate, particularly those explaining the role of the Agulhas Current and the westerly wind system, and the debate surrounding the question of seasonality across the region.

In the second half of this chapter, I begin with a brief introduction to the southern African archaeological sequence, and briefly outline the major archaeological debates for this region. I then provide descriptions of the four main sites included in this thesis: two Later Stone Age sites, Nelson Bay Cave and Byneskranskop 1, and two Middle Stone Age sites, Klasies River Mouth and Pinnacle Point 5-6.

\subsection{Climate and environments}

\subsubsection{Regional climate systems}

Southern Africa is affected by both tropical and temperate circulation systems that lie to the north and south respectively, and the region experiences a diverse set of climatic conditions. Situated in the band of semi-permanent high pressure that characterises the Southern Hemisphere subtropics (Tyson and Preston-Whyte, 2000), the region is dominated by high pressure cells (see Figure 2.1.1), stable subsiding systems that generally bring clear, fine weather to much of the region, particularly in winter. Yet, the position of the anticyclonic systems varies considerably with the seasons, driving the pronounced seasonality in rainfall across the region. Much of the sub-continent, to the north and east, receives most ( $>66 \%$ ) of its precipitation during summer, between October and March, when tropical disturbances associated with the Intertropical Convergence Zone (ITCZ) facilitate moisture transport from the Indian Ocean. During winter, temperate frontal systems embedded in the westerly wind systems situated to the south of the subcontinent migrate northwards over South Africa's south-western coast, forcing the South Atlantic anticyclone north. These low-pressure westerly waves bring rainfall to the Cape region and the south coast. Consequently, while much of the country receives most precipitation during summer, the south-west receives most rainfall in winter (April to September), creating quite distinct climatic and environmental conditions from the rest of the country. The south coast, at the intersection of the winter and summer 


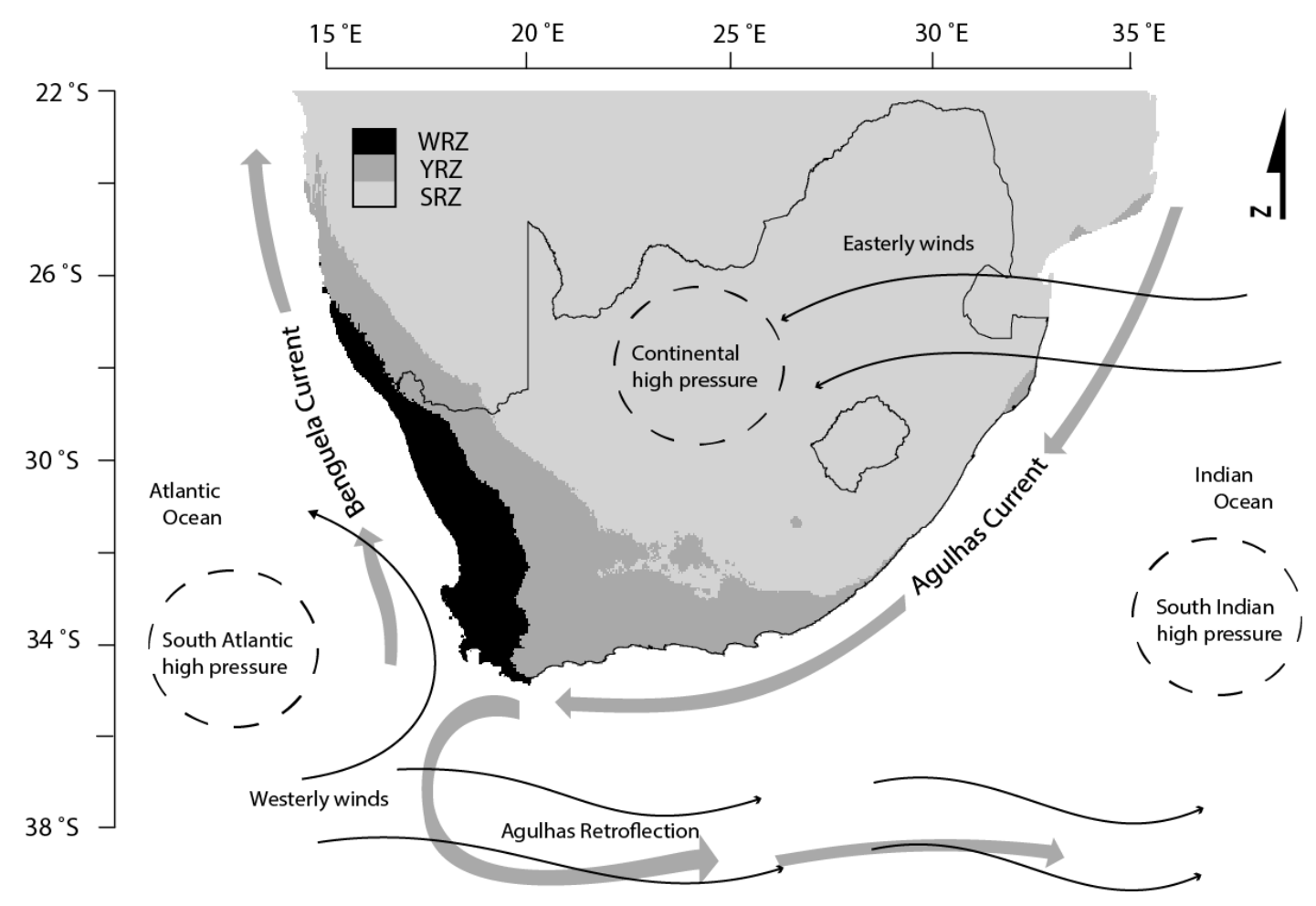

Figure 2.1.1: Map of southern Africa showing the three rainfall zones, summer (SRZ), winter (WRZ) and year-round (YRZ), and the approximate positions of the major atmospheric features, including the easterly and westerly winds, and the high pressure systems. Precipitation data downloaded from www.worldclim.org.

rainfall zones (WRZ and SRZ) receives rainfall year-round (Tyson and Preston-Whyte, 2000).

South Africa's climate is also strongly influenced by topography - a steep escarpment separates the interior of the country from the coastal lowlands, and while the high-altitude interior region experiences extreme temperature ranges, daily and annual temperature fluctuations at the coast are heavily moderated. For example, frost occurs during winter above the escarpment but it is very rare at the coast. The escarpment also affects rainfall distributions by blocking coastal precipitation systems from extending inland. Thus, much of the interior highveld is characterised by savanna grassland or semi-desert vegetation, while a more varied range of ecosystems is present around the coast (see Figure 2.1.2). The moderating temperature effects of the oceans also mean that precipitation variability is the key factor for determining the ecological patterning in coastal regions, as compared to the interior of the subcontinent where temperature variations are relatively more important than they are in coastal regions.

Variation in the marine and terrestrial ecosystems along South Africa's coastline is 


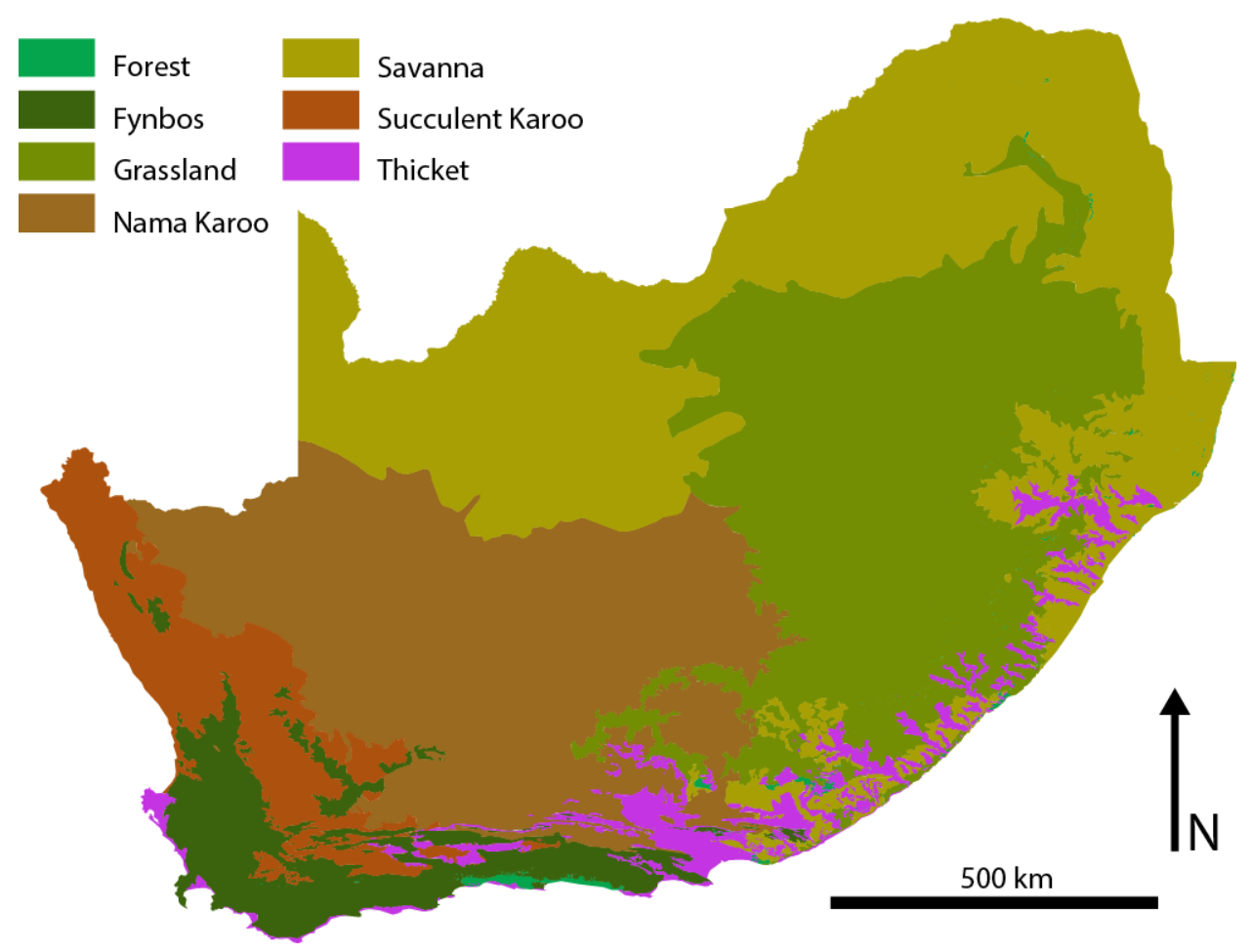

Figure 2.1.2: Map of Southern African biomes (from South African National Biodiversity Institute BGIS website www.bgis.sanbi.org).

strongly determined by two major currents, the Agulhas Current along the eastern and southern coasts, and the Benguela Current, which flows along the western coast (Tyson and Preston-Whyte, 2000). The Agulhas, which derives from warm Indian Ocean waters, is a fast-flowing western boundary current that strongly moderates air temperature variability and supplies significant amounts of moisture to local weather systems. The Benguela Current conversely, derives from cool south Atlantic Ocean waters and the southwest region is both much cooler and drier with semi-arid and arid ecosystems. However, the west coast has a highly productive marine environment, as the south-westerly winds which drive the Benguela system result in Ekman transport away from shore, causing nutrient-rich cold waters to upwell at the coast, fuelling primary and secondary productivity. By comparison, the southern coastal waters are less productive, although the coast has an abundance of rocky shore coastal habitats and species diversity is comparatively high (Branch et al., 2007). In combination, the atmospheric and oceanic circulatory systems described above determine the ecology of the southern African coastal regions. 


\subsubsection{Southern Cape environments and the Agulhas Current}

The southern Cape coast, situated at the interface of the two dominant precipitation regimes, experiences a gradient of seasonality from a summer-rainfall dominated climate in the east to a Mediterranean, winter-rainfall climate in the west. This gradation results in a mosaic of vegetation types and highly diverse local ecosystems, unlike the more ecologically homogeneous interior plateau (Low and Rebelo, 1996; Cowling et al., 1997b; Marean et al., 2014). The flora of this Cape Floristic Region (CFR), or "fynbos" (actually just the dominant vegetation component), is unusually endemic with a broad range of plant and animal resources available for humans, despite generally poor soils (e.g. Singels et al., 2015). The flora is especially rich in geophytes (Cowling et al., 1997a), plants with underground storage organs (USOs) that are thought to have been an important dietary resource for early humans (Deacon, 1984; Wrangham et al., 1999). The CFR appears to have been largely stable at the biome level in response to climate change, at least over the terminal Pleistocene and Holocene (Meadows et al., 2010; Quick et al., 2011; Valsecchi et al., 2013). Also present are stretches of evergreen forest along the southern coast between Knysna and Plettenberg Bay that were possibly much more extensive in the past. In addition to the varied terrestrial resources, the Agulhas marine province, including the abundance of rocky shore habitats along the coast, offers a wide variety of marine and estuarine resources, including fish, shellfish and marine mammals. The combination of reliable plant and marine resources has been suggested to have been an opportune combination for early humans living in this region (Deacon, 1993; Parkington, 2012; Marean, 2014).

The southern African coastline hosts three marine biogeographical "provinces" or ecosystems defined on their faunal and vegetation communities (Lombard et al., 2004): the Namaqua province on the west coast; the Natal province on the east coast, and the Agulhas province on the south coast (sometimes presented as the Algoa province - cf. Langejans et al., 2016). The warm temperate Agulhas province, stretching from Dwesa near Coffee Bay to Cape Point, is characterised by reduced biomass compared to the Namaqua province but increasing levels of species richness from west to east. Descriptions from Kilburn and Rippey (1982) show that while a quarter of the mollusc species found in the Agulhas province are warm water endemics, many species are tolerant of a range of temperatures and may be found in other regions (Langejans et al., 2016).

The Agulhas Current forms part of the wind-driven circulation of warm tropical waters in 
the south Indian Ocean (Lutjeharms, 2006) and flows from approximately the latitude of Maputo, along the South African coast, until the southern tip of Africa. Here, the current abruptly retroflects southwards and flows eastwards as the Agulhas Return Current, while large eddies and rings of warm, salty water occlude off and travel northwards into the south Atlantic Ocean. This leakage of Agulhas water into the Atlantic is an important process in the global redistribution of energy via the Atlantic Meridional Overturning Circulation (AMOC) (Beal et al., 2011). The Agulhas Current is fed mostly by water from a South West Indian Ocean sub-gyre, which circulates in the Agulhas Basin. Some water is also fed in via the Mozambique Current and the East Madagascar Current in the form of intermittent eddies and rings, which contribute to a seasonal signal in the flow of the Agulhas Current (Lutjeharms, 2006). The Current, unusually narrow and well-defined, is only about $100 \mathrm{~km}$ wide for much of its length and hugs the coastline upstream of Port Elizabeth, where the course is dictated by the topography of the continental shelf (Lutjeharms, 2006). Downstream of Port Elizabeth the coastal shelf widens considerably into the broad Agulhas Bank and from here the Agulhas Current slows, and is carried along the edge of the shelf away from the modern coast. On the shelf itself is a mass of comparatively stationary and well-stratified water, in contrast to the turbulent Agulhas Current. The intense thermal gradients between these two very different water masses has a marked effect on local weather patterns and the Cape of Good Hope is famous for its violent storms (Lutjeharms, 2006).

\subsubsection{Modern SST, air temperature and rainfall along the south coast}

The archaeological sites included in this study span some $500 \mathrm{~km}$ of coastline, from Cape St Francis in the east to Cape Agulhas near Cape Town in the west. Figure 2.1.3 below shows the annual air temperatures and precipitation at several locations along the coast (data from the online Climate Information Portal of the Climate Systems Analysis Group, University of Cape Town: www.cip.csag.uct.ac.za). Noticeable is the shift from a summer-rainfall dominated climate at East London, through a year-round rainfall region along the southern Cape, to a winter-rainfall dominated climate in the west. Also evident is the effect of distance from the coast for local climate: the inland location of Oudtshoorn experiences a markedly greater annual temperature range than locations at the coast, and markedly less rainfall. The moderating effects of the ocean on temperatures, in combination with the year round rainfall regime, is reflected in 
measures of aridity, which show that the coastal strip is markedly more humid along much of it's length (Figure 7.1.1 on page 171) Thus, the modern coastline experiences highly ameliorated climate conditions compared to the adjacent interior.

Table 2.1 shows quarterly SST statistics derived from daily morning SST measurements (requested from the South African Weather Service: see www.weathersa.co.za/climate) for five locations along the coast: Kommetjie Beach (Cape Town; 2000-2010), Mossel Bay (adjacent to Cape St Blaize; 2000-2010), Plettenberg Bay (adjacent to the Robberg Peninsula; 1990-2000), Tsitsikamma (2000-2010) and Pollock Beach (Port Elizabeth; 2000-2010). Unfortunately, SST information is not available for Cape Agulhas and Cape St Francis (near to Byneskranskop 1 and Klasies River Mouth respectively).

At all locations other than Kommetjie, closest to the Atlantic Ocean, the highest SSTs occur in January, while coolest SSTs occur in July/August. Moreover, a greater SST range is typically observed during the summer, a consequence of thermocline development during summer, and wind-induced upwellings of cold bottom waters, which cause rapid, short-lived drops in temperature for a few days at a time (Schumann et al., 1982). The low annual average temperatures for Kommetjie reflect the influence of cold Atlantic Ocean waters, while the other four sites are dominated by the warmer waters of the Agulhas Current. Thus, the coast near Byneskranskop 1, nearest to Cape Town, experiences cooler temperatures than the other locations in this study. However, the trend in declining temperatures is not linear from east to west as lower mean annual temperatures are recorded at Plettenberg Bay and Tsitsikamma, which lie between Mossel Bay and Pollock Beach. The cooler temperatures at these locations are the result of comparatively cool summer SSTs that reflect seasonal wind-driven upwellings that occur at the prominent coastal headlands of Cape St Francis (Tsitsikamma) and Cape Seal (Plettenberg Bay), but which do not occur as frequently at the Cape St Blaize headland (Mossel Bay) due to the shallow offshore topography (Schumann et al., 1982). These upwellings seemingly also influence the seasonal amplitude (measured here as the difference between the mean values for the warmest month and the coolest month, see Table 2.1), which is greater at Mossel Bay $\left(6.7^{0} \mathrm{C}\right)$ than at Plettenberg Bay $\left(3.6^{-} \mathrm{C}\right)$, Tsitsikamma $\left(3.1^{\mathrm{O}} \mathrm{C}\right)$ and Pollock Beach $\left(4.7^{\mathrm{O}} \mathrm{C}\right)$. Although there are no systematic modern observations of upwelling frequency, these results indicate that a smaller annual seasonal SST amplitude is a consequence of the increased occurrence of upwelling. 


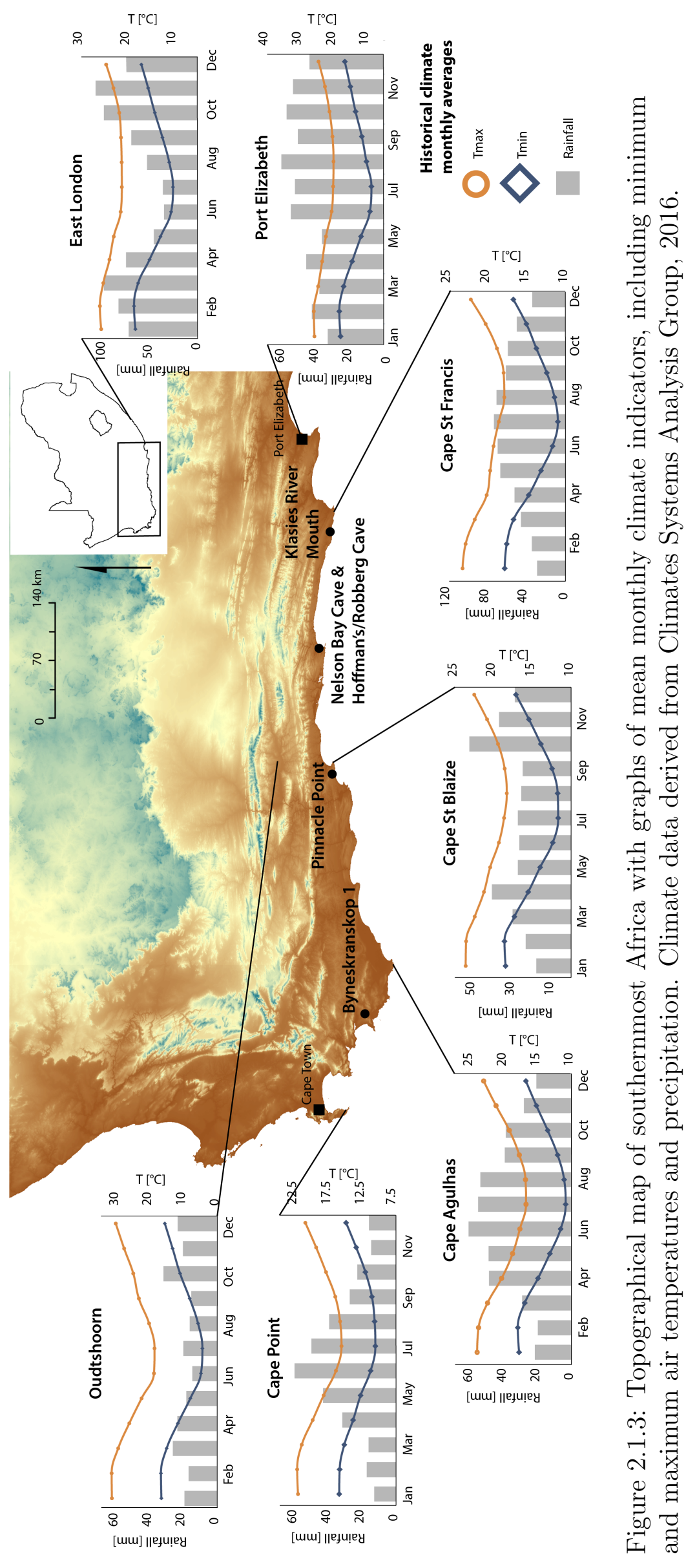


Table 2.1: Key quarterly SST statistics for five locations on the south coast, South Africa, with annual and seasonal averages. All data 2000-2010, except at Plettenberg Bay, where 1990-2000 available only. Data requested from the South African Weather Service (www.weathersa.co.za/climate).

\begin{tabular}{lrrrrr}
\hline & All & DJF & MAM & JJA & SON \\
\hline Kommetjie (Cape Town) & & & & \\
Mean & 13.3 & 12.8 & 12.9 & 14.2 & 13.4 \\
Max average & Jun (14.6) & 19.5 & 18.5 & 16.5 & 18.0 \\
Min average & Mar (12.3) & 9.3 & 9.7 & 10.7 & 9.3 \\
Max - min month & 2.3 & 10.2 & 8.8 & 5.8 & 8.7 \\
\hline Mossel Bay & & & & & \\
Mean & 18.4 & 21.7 & 19.3 & 15.9 & 17.5 \\
Max average & Feb (22.3) & 25.5 & 24.0 & 21.2 & 20.5 \\
Min average & Aug (15.5) & 18.2 & 13.8 & 11.3 & 13.8 \\
Max - min month & 6.7 & 7.3 & 10.2 & 9.8 & 6.7 \\
\hline Plettenberg Bay & & & & & \\
Mean & 16.4 & 18.3 & 15.5 & 15.5 & 16.4 \\
Max average & Jan (18.6) & 24.8 & 21.2 & 18.8 & 20.8 \\
Min average & Apr (15.0) & 8.3 & 8.5 & 12.0 & 10.7 \\
Max - min month & 3.6 & 16.5 & 12.7 & 6.8 & 10.2 \\
\hline Tsitsikamma & & & & & \\
Mean & 17.1 & 18.8 & 17.2 & 15.9 & 16.6 \\
Max average & Feb (19.0) & 26.3 & 24.0 & 20.5 & 20.4 \\
Min average & Aug (15.8) & 10.4 & 9.9 & 11.2 & 10.8 \\
Max - min month & 3.1 & 15.9 & 14.1 & 9.4 & 9.6 \\
\hline Pollock Beach (Port Elizabeth) & & & & \\
Mean & 18.2 & 20.4 & 18.5 & 16.2 & 17.8 \\
Max average & Feb (20.6) & 24.2 & 23.1 & 18.8 & 20.9 \\
Min average & Jul (15.9) & 13.3 & 13.3 & 13.3 & 14.5 \\
Max - min month & 4.7 & 10.9 & 9.8 & 5.5 & 6.4 \\
\hline \hline
\end{tabular}




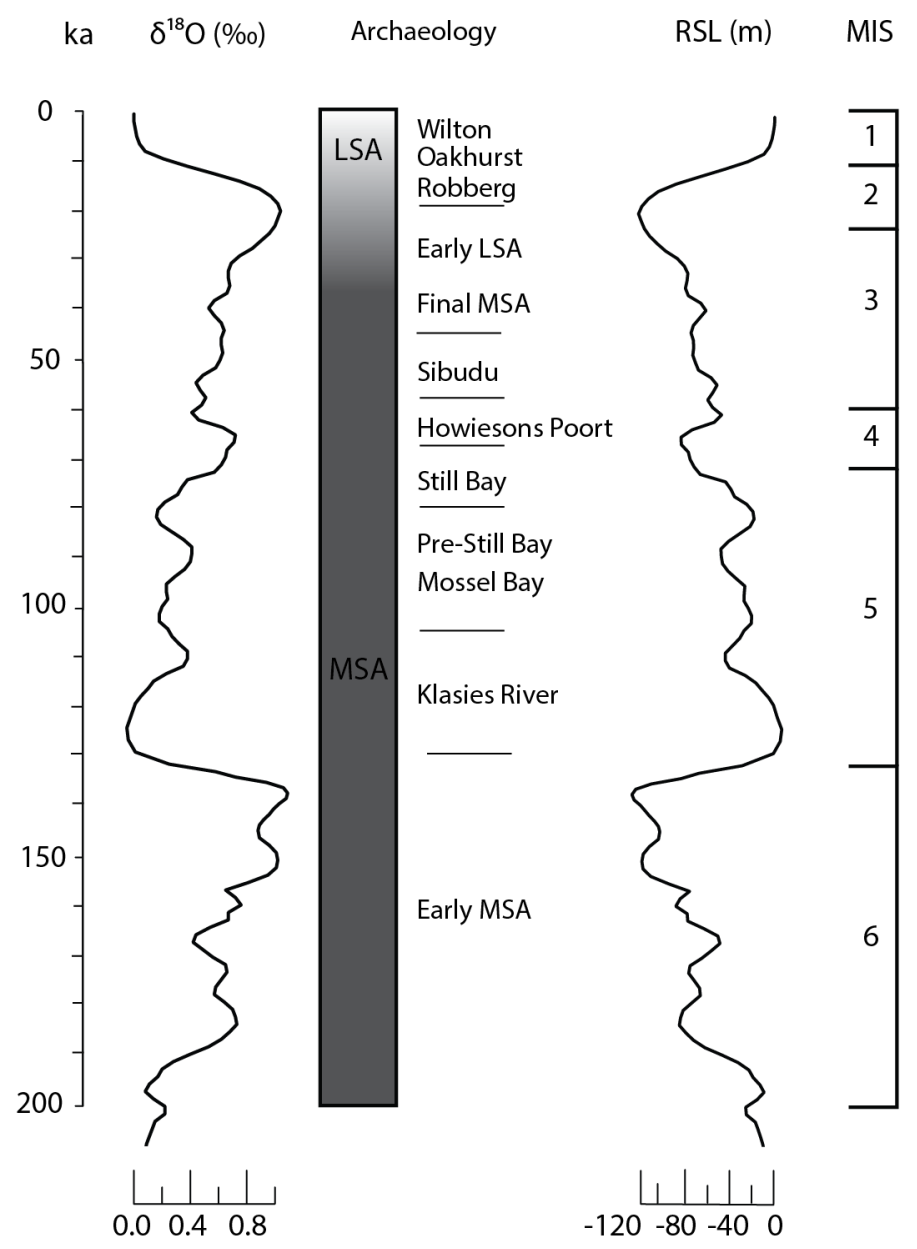

Figure 2.1.4: Schematic showing the chronological relationships between the changes in global climate, including relative sea level (RSL) and $\delta^{18} \mathrm{O}$ of the global ocean, and South African archaeology. The RSL and $\delta^{18} \mathrm{O}$ data are from Waelbroeck et al. (2002) and the lithic industries are taken from Lombard et al. (2012). 


\subsubsection{South African palaeoclimate}

Globally, the Pleistocene was a period of great climatic instability, marked by approximately hundred thousand year cycles of alternating cold glacials and warm interglacials. During glacial periods continental-sized ice sheets covered much of the Northern Hemisphere landmasses, and the Antarctic ice sheet was greatly expanded. The effect of locking up enormous amounts of the world's water in ice sheets was to substantially lower the oceans, with dramatic effects for global coastlines (Lambeck et al., 2002; Waelbroeck et al., 2002). On the south coast of South Africa, the c. 130m drop in sea levels at the Last Glacial Maximum c. 24 thousand years ago (ka) exposed a wide, gradually sloping coastal plain where the Agulhas bank is today, extending out over $100 \mathrm{~km}$ from the current shore at its greatest extent (van Andel, 1989; Fisher et al., 2010). The exposed coastal plain would have provided a rich ecological setting in comparison to the harsher environments of the interior during period of lowered sealevel, and possibly even acted as a refugium during glacials (Compton, 2011) - unfortunately, any archaeological traces have vanished with the rising seas.

The Marine Isotope Stage (MIS) chronological scheme is a convenient shorthand for contextualising glacial/interglacial climates, based upon global fluctuations in oceanic $\delta^{18} \mathrm{O}$ that occurred in lock-step with high-latitude ice-sheet formation and the resulting sea-level changes (Shackleton and Opdyke, 1973). Previous conceptualisations of southern African Pleistocene climates relied heavily on the global glacial/interglacial schema. Glacial climates were characterised as cold and dry, as in the Northern Hemisphere, whereas interglacials were warm and wet. To this end, palaeoclimate proxies that reflected wet conditions were designated as necessarily belonging to interglacial periods (e.g. Deacon and Lancaster, 1988). However, the relationship between regional southern African and global climate dynamics through time are unclear. Glaciation in southern Africa was minimal and although all of the essential features of the global glacial/interglacial oscillations are present in Southern Hemisphere marine core records (Tyson and Preston-Whyte, 2000), there are other drivers of climate variability in Africa, such as orbital obliquity and zonal moisture flux, which are not fully understood (Blome et al., 2012; Tierney et al., 2011). The simple glacial/interglacial categorisation is clearly inadequate, as it cannot account for regional asynchroneities between proxy records (Chase, 2010), nor does it account for the strong fluctuations in glacial climates.

It has long been understood that a key debate for understanding the climate history of the subcontinent concerns the interplay between the summer- vs winter-rainfall 
dominated zones. Tropical systems which bring summer rainfall to the east are affected by sea surface temperatures in the Indian Ocean (including in the Agulhas Current) and insolation dynamics in the tropics (i.e. precessional orbital forcing), while the temperate frontal systems which bring moisture to the winter rainfall zone from the west are possibly more strongly affected by global temperature gradients (i.e. obliquity) (e.g. Van Zinderen Bakker, 1967; Tyson, 1986; Cockcroft et al., 1987; Partridge et al., 1997; Chase and Meadows, 2007; Kristen et al., 2007; Chase et al., 2009; Trauth et al., 2009; Woillez et al., 2014). In addition, precipitation in south east Africa appears to have risen sharply in synchrony with abrupt Northern Hemisphere cold events, as the ITCZ, South Indian and South Atlantic anticyclonic systems all shift southwards, resulting in a pattern of millennial-scale climate variability (Ziegler et al., 2013).

Yet poorly aligned and contradictory proxy records across the region underscore the difficulty of applying simple climate models and the necessity of local palaeoclimate records (e.g. Thomas and Shaw, 2002; Chase and Meadows, 2007; Gasse et al., 2008; Chase, 2010). A coherent picture of southern African palaeoseasonality has been elusive as few palaeoenvironmental sensors attest to rainfall seasonality. The fauna and flora of the Cape are highly endemic and have been subject to considerable human intervention, such that no pristine fynbos now exists as an analogue for the past (Cowling et al., 1997a); and there is little clarity on the community of large mammals which would have occupied the area prior to habitat loss and hunting pressure (Rector and Reed, 2010). And of course, the habitats that were present over the expanded coastal plain during periods of lower sea level are largely unknown (although see Cawthra et al., 2014; 2016; Copeland et al., 2016). In addition, there are relatively few long-sequence palaeoenvironmental archives to be found in the narrow coastal strip that exists during the present-day high sea stand. Given this lack of analogue habitats and the paucity of adequately nuanced climate records, investigating the palaeoenvironmental history of this region is not straightforward.

\subsubsection{Interpretive framework for near shore SST records}

The interconnections between local, regional, and global SSTs and terrestrial rainfall across southern Africa are complex (Reason, 2001b). Of concern here are the relationships between near-shore and Agulhas Current SSTs, the Pacific El Niño-Southern Oscillation (ENSO) and southern African rainfall patterns. At the global scale, ENSO activity strongly relates to southern African rainfall, particularly summer precipitation patterns 
(Crétat et al., 2012; Hoell et al., 2014): during the warm phase (El Niño), southern Africa receives less rainfall, while during the cool phase (La Niña) the region receives more rainfall than usual. The relationships are non-linear (Fauchereau et al., 2008; Pohl et al., 2008), as ENSO activity impacts the regional-scale associations between SST and precipitation that are observed across southern Africa. Positive SST anomalies in the southwest Indian Ocean correlate with wetter conditions over the eastern and central subcontinent.

Locally, enormous heat fluxes between the Agulhas Current and the overlying air affect local atmospheric circulation (Walker, 1990; Jury et al., 1993; Mason, 1995; Reason, 2001a). Most intuitively, coastal precipitation is positively affected by the temperature of the Agulhas Current, so that warm water anomalies in the Agulhas Current induce greater amounts of rainfall immediately adjacent to the coast (Walker, 1990; Jury et al., 1993; Mason, 1995). Yet, another set of relationships is illustrated by a theoretical model of Cohen and Tyson (1995), developed to interpret a near-shore SST record derived from archaeological molluscs. This model provides a very useful framework for relating south coast SSTs, wind anomalies and regional precipitation and structures much of the climatic interpretation for the data in this thesis. Figure 2.1.5 illustrates this conceptual model: during periods of increased westerly winds (top diagram), as during the austral winter when the circumpolar vortex is displaced equator-ward, the flow of the Agulhas is weakened and warm waters are advected onshore. In addition, atmospheric circulation over the southwest Indian Ocean is weakened and less warm, moist air is advected over the subcontinent. Consequently, warm surface waters in the Agulhas system and near-shore zone are associated with dry conditions in the interior, summer rainfall zone (i.e. "dry-spell mode" or "extended winter-like conditions"). Conversely, during summer-like conditions when the zone of westerly winds is forced polewards (bottom diagram), there is an increased frequency of alongshore easterly-component winds, and the surface waters are advected away from the coast by Ekman transport processes. Consequently, cooler bottom waters are up-welled along the in-shore edge of the Agulhas Current, causing the thermocline to rise and leading to rapid drops in coastal SSTs that typically persist for several days (Schumann et al., 1982, 1995; Schumann, 1999; Walker, 1986). These easterly component winds also advect warm, moist air over the eastern half of the subcontinent, increasing rainfall to this region. Consequently, cool surface waters along the southern coast during the summer are associated with wet conditions in the summer rainfall zone (i.e. "wet-spell mode").

The Cohen and Tyson model superficially contradicts the statistical and modelling 

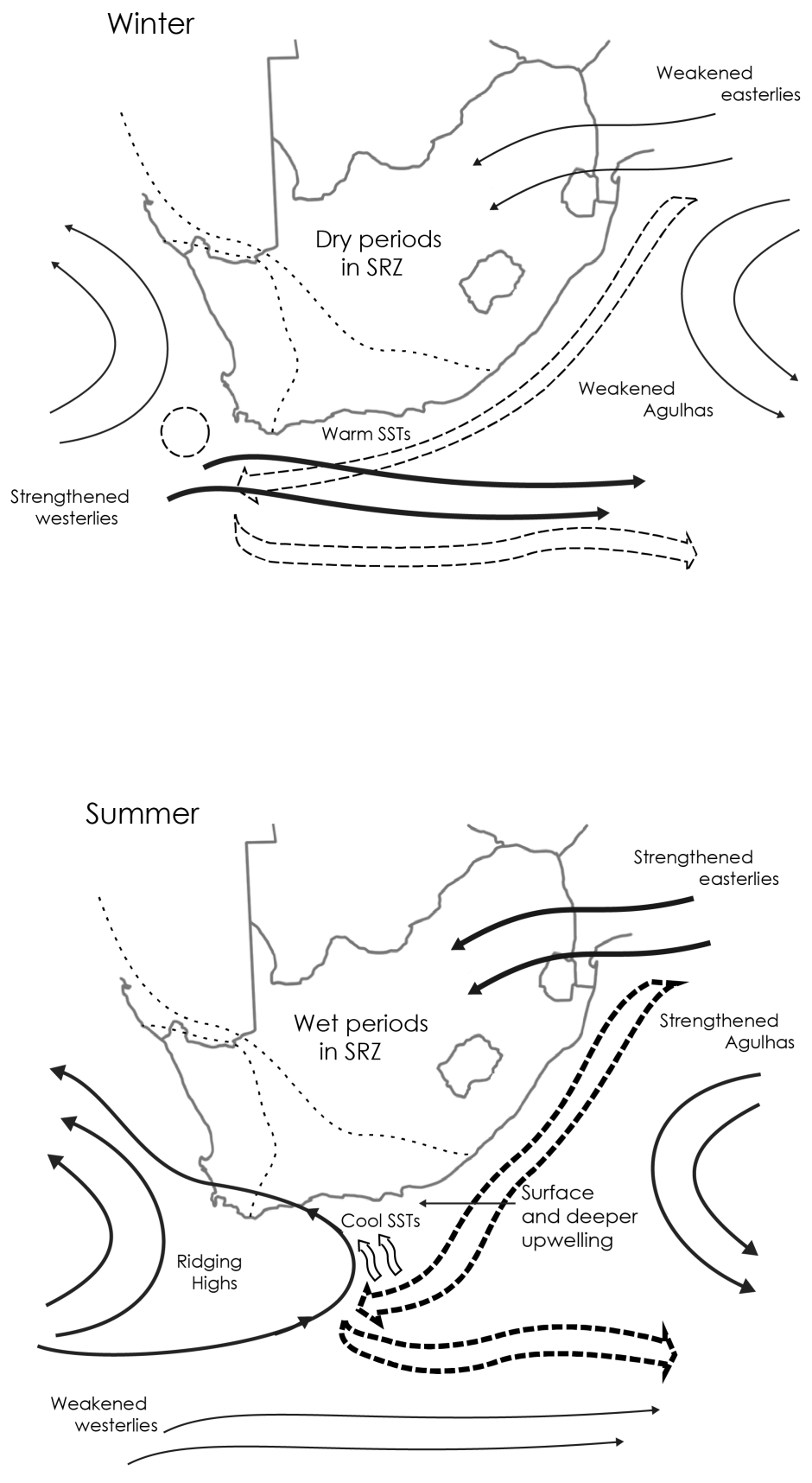

Figure 2.1.5: Diagrammatic sketches of the conceptual model that correlates surface SSTs in the Agulhas Current to regional wind anomalies and precipitation. Based on the model and diagram of Cohen and Tyson (1995). 
results showing a positive relationship between regional and Agulhas Current SSTs and terrestrial precipitation (i.e. Walker, 1990; Jury et al., 1993; Mason, 1995; Reason, 2001a), as in this model cooler SSTs actually correlate with greater amounts of precipitation. But recent assessments of the spatial extent of the influence of Agulhas Current SSTs appear to show that the precipitation effects of warmer waters in this relatively tightly constrained area are limited to the coastal region and that, in the interior region of southern Africa, Agulhas Current temperatures actually have a negative correlation with precipitation (Jury, 2015). Jury attributes this to the relationship between Agulhas Current temperatures and ENSO conditions - i.e. the correlation reflects a passive relationship, because Agulhas SSTs are positively related to an index of ENSO activity. Jury also observes how the overturning circulation induced by the movement of warm moist air over the Agulhas inhibits rainfall over the interior, as the airflow suppresses the formation of the primary cloud bands that typically dominate this region. Previous studies, which showed a positive relationship between Agulhas SSTs and interior rainfall, used larger spatial definitions of the Agulhas system, incorporating regions far offshore (e.g. Reason, 2001a). This evidence indicates that warmer Agulhas SSTs may indeed actually relate to drier conditions in the summer rainfall zone, as per the Cohen and Tyson (1995) model, while still inducing more rainfall at the coast. Thus, a record of past Agulhas SSTs should be interpreted as a record of local rainfall conditions at the site, although it may also reflect the regional precipitation patterns for the summer rainfall zone.

The annual SST range is predicted to be affected by the same relationship between SSTs, winds and upwelling. Schumann et al. (1995) showed that summer SSTs decreased as the frequency of days with easterly winds increased, due to increased upwelling of cooler bottom waters, raising the thermocline. This would reduce the difference between the warmer summer and cooler winter months. Thus, the annual SST range is expected to decrease if easterly component winds are more frequent during the summer months. As such winds are correlated with increased precipitation in the interior summer rainfall region, a reduced annual SST range may correlate with periods of increased summer rainfall at a regional level. And conversely, a high annual range of temperatures, indicative of suppressed near-shore upwelling, may correspond with drying across the wider summer rainfall region.

Stable carbon isotope values may provide a further indication of nearshore oceanographic conditions, in particular upwelling dynamics. Upwelling brings isotopically light dissolved inorganic carbon to the surface, where it can be utilised by photosynthetic organisms 
and incorporated in the carbonate skeletons of marine invertebrates. Thus, a correlation between more positive $\delta^{18} \mathrm{O}$ (i.e. cooler waters) and more negative $\delta^{13} \mathrm{C}$ (i.e. more dissolved inorganic carbon) is suggestive of increased upwelling. However, multiple factors influence $\delta^{13} \mathrm{C}$ of the various sources of carbon actually available to intertidal molluscs. Phytoplankton and algal productivity may increase with the increased availability of dissolved inorganic carbon, quickly utilising much of the isotopically light carbon, and leaving only carbon sources more enriched in ${ }^{13} \mathrm{C}$ for mollusc shell-buliding. Thus, in the absence of empirical models, interpretations of $\delta^{13} \mathrm{C}$ must be cautious.

\subsection{Archaeology}

\subsubsection{Southern African Stone Age archaeology}

The prehistoric South African archaeological record is broadly conceptualised within a tripartite scheme that divides up the whole of prehistory into the Early, Middle and Later Stone Ages (ESA, MSA and LSA; Goodwin and van Riet Lowe, 1929; Sampson, 1974). Despite some problems common among categorical systems (e.g. its relative inflexibility and poor capacity to account for transitional phases; see Mackay, 2009), the Stone Age system has "stood the test of time" (Lombard et al., 2012, 120), and is widely used to provide a chronology and organisational structure for the African archaeological record (see Table 2.2 based on Lombard et al., 2012). Importantly, the Early to Middle Stone Age transition, and the Middle to Later Stone Age transition, are still regarded as real phenomena, which record qualitative changes in the lifeways of ancient people. However, these technologically defined Ages, although originally conceived as comparable with the Palaeolithic system of Europe, cannot be mapped onto a species-level biological chronology in the same way as that system. Consequently, the nature and causes of technological change are unclear and the subject of much debate.

The dating of the transition between the ESA and MSA is poorly constrained (280-200

ka), and the role of different human species is unclear, but by c. 120 ka there is sufficient fossil and genetic evidence to indicate that H. sapiens was the dominant human species in southern Africa (Brauer et al., 1992; Rightmire and Deacon, 1991; Miller et al., 1999; Grün and Beaumont, 2001; Rightmire and Deacon, 2001; Behar et al., 2008). Technologically, the MSA, was previously characterised as largely invariant across space and time. More recently, within the debate about the origins of human behavioural 
Table 2.2: Southern African lithic cultural sequence, with key characteristics and approximate age range, as summarised in the review by Lombard et al. (2012).

\begin{tabular}{|c|c|c|c|c|}
\hline & $\begin{array}{l}\text { General } \\
\text { category }\end{array}$ & Industry & $\begin{array}{l}\text { Key typo/technological } \\
\text { characteristics }\end{array}$ & $\begin{array}{l}\text { Dated range } \\
{[\text { ka uncal }]}\end{array}$ \\
\hline \multirow[t]{6}{*}{ LSA } & $\begin{array}{l}\text { Late Holocene } \\
\text { assemblages }\end{array}$ & Ceramic LSA & Microliths, grindstones, ceramics & $<2$ \\
\hline & & Final LSA & $\begin{array}{l}\text { Considerable variability, mostly } \\
\text { informal }\end{array}$ & c. $0.1-4$ \\
\hline & $\begin{array}{l}\text { Holocene } \\
\text { microlithic }\end{array}$ & Wilton & Microlithic, highly standardised & c. $4-8$ \\
\hline & $\begin{array}{l}\text { End Pleist./early } \\
\text { Holocene } \\
\text { non-microlithic }\end{array}$ & $\begin{array}{l}\text { Albany } \\
\text { (Oakhurst) }\end{array}$ & $\begin{array}{l}\text { Flake-based, few microliths or } \\
\text { formal lithic tools }\end{array}$ & c. $7-12$ \\
\hline & $\begin{array}{l}\text { Late Pleistocene } \\
\text { microlithic }\end{array}$ & Robberg & $\begin{array}{l}\text { Systematic bladelet }(<26 \mathrm{~mm}) \\
\text { production, few formal tools }\end{array}$ & c. $12-18$ \\
\hline & Early LSA & $\begin{array}{l}\text { Early LSA } \\
\text { (informal) }\end{array}$ & $\begin{array}{l}\text { Highly variable, features of LSA } \\
\text { and MSA, possibly mixed } \\
\text { assemblages }\end{array}$ & c. $18-40$ \\
\hline \multirow[t]{8}{*}{ MSA } & $\begin{array}{l}\text { Final MSA } \\
\text { (informal) }\end{array}$ & & $\begin{array}{l}\text { High regional variability, incl. } \\
\text { microliths, bifacial tools, bipolar } \\
\text { tech., segments, etc }\end{array}$ & c. $20-40$ \\
\hline & late MSA/post & Sibudu & Sibudu point, Levallois, unifacial & c. $45-58$ \\
\hline & & $\begin{array}{l}\text { Howieson's } \\
\text { Poort }\end{array}$ & Blade tech., incl backed tools & $58-66$ \\
\hline & & Still Bay & Bifacial foliate points & $70-77$ \\
\hline & $\begin{array}{l}\text { pre-Still Bay } \\
\text { (informal) }\end{array}$ & & Under investigation & c. $72-96$ \\
\hline & MSA II, MSA 2b & Mossel Bay & $\begin{array}{l}\text { Unipolar Levallois points and } \\
\text { blades, infrequent retouch }\end{array}$ & c. $77-105$ \\
\hline & MSA I, MSA 2a & Klasies River & $\begin{array}{l}\text { Elongated blade and convergent } \\
\text { flakes, infrequent retouch }\end{array}$ & c. $105-130$ \\
\hline & early MSA & & Under investigation & c. $130-300$ \\
\hline
\end{tabular}


modernity, researchers have focussed attention on periods of technological "innovation" within the MSA (Clark, 1993), such as the distinctive Still Bay and Howiesons Poort industries, and increasingly including other less well-defined industries that were until recently considered largely homogeneous (e.g.Kuman et al., 1999; Marean et al., 2007; Lombard et al., 2012; Will et al., 2014a; Wurz, 2002).

In this view of the MSA, the apparent stasis over long periods of the MSA record is contrasted with the LSA, characterised by continent-wide patterning in lithic technologies that changes every few thousand years. The LSA is closely associated with those elements of material culture seen in the ethnographic record, including bone tools, beads, and rock art, although in fact such artefacts are rare until the Holocene. The very earliest LSA assemblages are defined more by a lack of MSA technologies and tool-kits, but "true" LSA technologies are marked by the widespread appearance of distinctive bladeletrich, microlithic toolkits across the subcontinent, commonly grouped under the label "Robberg". Crudely, then, the LSA corresponds with the onset of "modernity", although, indeed, this is now largely considered equally true for parts of the MSA, and the debate depends heavily on nuanced understandings of the term itself. The onset of the LSA broadly coincides with the Last Glacial Maximum, a period of generally cold, dry, harsh conditions across southern Africa that reached its full extent about $21 \mathrm{ka}$, but there is considerable variation in the dating of early LSA assemblages across southern Africa (e.g. Villa et al., 2012), and there is certainly no clear divide between the two periods. The southern African LSA sequence is discussed in greater detail in Chapter 4, which presents new radiocarbon dates for two LSA sequences.

\subsubsection{Cultural and environmental change}

The sites along and near the southernmost coast of Africa have provided some of the key evidence in debates about Middle Stone Age lifeways and modern human behaviour (Deacon, 1979; Deacon and Geleijnse, 1988; Marean et al., 2000; Henshilwood et al., 2001; Marean, 2010b). Essentially, these discussions have centred on what it means to be human, and how the process of becoming what we are today can be detected in the archaeological record. It is now broadly accepted that modern human behaviour is more closely aligned with the emergence of anatomically modern Homo sapiens c. $200 \mathrm{ka}$, if not even earlier (McBrearty and Brooks, 2000; Henshilwood and Marean, 2003), than with development of Upper Palaeolithic or Later Stone Age traditions (c.f. Klein, 2000, 2008). The southern African archaeological record, in particular that of the southernmost 
coast, contains some of the earliest instances of behavioural signatures that seemingly reflect advanced cognitive processes, including symbolic artifacts (Henshilwood et al., 2002), heat treatment of lithic raw materials (Brown et al., 2012), exploitation of shellfish resources (Jerardino and Marean, 2010; Marean, 2016), and the production of blades and bladelets (Marean et al., 2007). Recent ideas point to the uniquely high levels of cooperation observed among humans as the defining characteristic of our species (versus symbolic thinking, forward planning, etc.). This "hyper-prosociality", indentifiable in phenomena such as warfare, may have first emerged in an environmental setting with "dense, predictable and defendable" resources, such as the inter-tidal and coastal resources of the southernmost coast (Marean, 2015; 2016; also see Yesner, 1980 for a discussion of territoriality and population sizes among coastal hunter-gatherers).

It is increasingly apparent that there is greater variation in lithic tradition within the MSA than was previously recognised - models that attempt to fit the lithic assemblages within a chronologically-driven spectrum ranging from earlier and crude to later and innovative, are not successful. The apparent "patchiness" of technological innovation through time in the South African archaeological record has led to a paradigmatic shift in some quarters, away from the incremental progressive view, whereby each new cultural unit has "roots" in the last, to a more nuanced view that accounts for unique demographic and ecological circumstances at particular times (i.e. a "rugged fitness landscape"), and tries to understand how technological strategies function in that unique context (Lombard, 2012). Proposed drivers for technological innovation during the southern Africa MSA include environmental shifts (e.g. Ziegler et al., 2013), species-wide cognitive evolution (Klein, 2008) and demographic forcing (Powell et al., 2009), but all of these proposals face problems as general explanations. Likewise, the apparent synchroneity and ubiquity of the successive LSA lithic industries across southern Africa challenge our understandings of technological change and the function of technology. The processes driving the MSA/LSA transition are little understood, yet if coincident with the marked shifts in temperature and precipitation known to have occurred across the Last Glacial Maximum (LGM) the transition may reflect climatically mediated shifts in subsistence behaviour to accommodate changing levels of risk (Mitchell, 2000). Evidence for increased levels of inter-group contact (or "coalescence") during this period may represent another strategy for dealing with changing environmental conditions at this time (Mackay et al., 2014).

Given the marked global temperature shifts that occur throughout the MSA and LSA, and the apparent coincidences between lithic traditions such as the Still Bay and 
Howiesons Poort and global climatic transitions (the MIS 5/4 and MIS 4/3 transitions, respectively), researchers have long looked for climatic drivers of cultural change (e.g. Chase, 2010; Langejans et al., 2013; Ziegler et al., 2013; Mackay et al., 2014), but this approach has been largely confounded by the resolution of available dating methods, which are below the scale of rapid environmental change and do not allow for tight correlations between sites, and between local and regional records. Consequently, most palaeoenvironmental and cultural records cannot be easily compared, especially as they by-and-large occur in very different ecosystems. Thus, models which attempt to link the two types of record remain unsatisfyingly general and untestable. Moreover, theoretical understandings of the impact of large and small climate events for human behaviour are largely inadequate to generalise the responses of hunter-gatherers to environmental change. Is technological innovation spurred by conditions of environmental deterioration, when resource extraction needs to be maximised? Or rather, do 'hard times', when people are living close to the margins of survivability, discourage the risk-taking inherent in technological innovation (Fitzhugh, 2001)? The basic confusions within archaeological theory mean that archaeologists can be poorly equipped to generate explanations for changes observed in the record.

Chronological control is therefore crucial to determine the drivers of cultural change. Unfortunately, few sites in southern Africa are dated to sufficiently high resolution to resolve these questions. A comprehensive dating study of Howiesons Poort and Still Bay assemblages across South Africa tightly constrained the timing of these industries to c.65-59 ka and c. 72 ka respectively (Jacobs et al., 2008; this study includes the Howieson's Poort assemblage from Klasies River Main site), allowing researchers to identify correspondences with global and regional climate changes (e.g. Jacobs and Roberts, 2008; Ziegler et al., 2013). For example, Ziegler et al. (2013) noted correspondence in the timing of the Howiesons Poort and Still Bay and abrupt wet events, recorded in an offshore archive of Eastern Cape terrestrial rainfall, that are thought to link with rapid cooling events in the Northern Hemisphere (Carto et al., 2009). Yet, the error margin associated with the age estimates for the Howiesons Poort and Still Bay, although remarkably good for these type of measurements, still span some thousands of years, whereas rapid climate events can occur within a generation (e.g. Fisher et al., 2010). Moreover, the Howiesons Poort spans from MIS5-3 at Diepkloof Rock Shelter on the southwestern coast, an age range that cannot be reconciled with the tightly constrained Jacobs et al. chronology (Tribolo et al., 2009; 2013; Jacobs and Roberts, 2015), demonstrating the persistent uncertainty surrounding the chronologies of even the most intensively dated cultural traditions. Even within the range of radiocarbon dating, 
few sites have associated chronologies that can pinpoint changes in the archaeological record to these necessary levels of precision. Where reliable palaeoenvironmental evidence can be extracted from the same deposits as the material culture, correspondences between the two records are more robust.

Moreover, the observations about MSA and LSA technological variation facilitate a re-evaluation of the pressing research questions within the discipline - no longer are demonstrations of early complexity and modernity in the archaeological record of much interest on their own terms. Instead, archaeologists are now examining how the southern African archaeological record might reflect demographic processes and macro-evolutionary trends occurring on multiple scales. The role of intra- and interregional population dynamics is explored through the patterning of lithic technological change (e.g. Wurz, 2013; Villa et al., 2012) and environmental change (Mackay et al., 2014), raising questions about if and how technology shifts in response to a range of external environmental drivers. Detailed environmental data and refined chronologies are essential to answer these questions.

\subsubsection{MSA and LSA marine subsistence strategies}

Humans are known to have harvested and eaten marine intertidal resources along the coast of southern Africa from at least 164 thousand years ago (ka) (Marean et al., 2007). By $110 \mathrm{ka}$, sites along the southernmost coast contain evidence for a true coastal adaptation, with marine resources, particularly shellfish, forming a substantial portion of the diet (Marean, 2011, 2014). Yet, globally, there is considerable debate about the role of coastal habitats for demography (Yesner, 1980; Jerardino, 2010b; Parkington, 2012), migration out of Africa and around the world (Walter et al., 2000; Stringer, 2000; Erlandson, 2001; Carto et al., 2009), and evolutionary processes (Klein, 2001; Cunnane and Stewart, 2010; Parkington, 2003, 2010; Colonese et al., 2011; Klein and Steele, 2013; Will et al., 2014b; Klein and Steele, 2013; Marean, 2015; 2016) during the MSA and LSA. Given the robust evidence for early coastal resource exploitation (Voigt, 1973, 1982; Volman, 1978; Jerardino and Marean, 2010; Henshilwood et al., 2001; Langejans et al., 2012), and the long continuity of shellfish exploitation through to modern times (Jerardino, 2016), the south coast of South Africa is central to these debates.

The southern MSA African record is arguably most completely represented from coastal and near-coastal sites, including Klasies River, Pinnacle Point, Blombos Cave, Diepkloof, Ysterfontein and Die Kelders. These sites indicate a reliance on shellfish and other 
coastal resources, including the fynbos vegetation, throughout the MSA and LSA. Such habitats were then potentially important habitats for hunter-gatherer populations under the relatively harsh conditions during the last glacial, or during periods of widespread aridity across much of the interior of Africa (Scholz et al., 2007; Carto et al., 2009).

There is, however, scepticism about the feasibility of a coastal-focussed adaptation, and most especially about the importance of shellfish, the most archaeologically visible coastal resource exploited by humans. Despite the easy accessibility and high predictability of shellfish, researchers have argued that a comparatively poor nutritional value mean that shellfish were always only a small component of a larger set of food resources, supported by quantitative assessments of the shellfish remains found in the archaeological deposits (Clark and Kandel, 2013). Indeed, shellfish are commonly suggested to be "fallback foods", ranking lower than terrestrial resources such as large mammals in optimal foraging models (Clark and Kandel, 2013), and may have been harvested mostly by women and children (Waselkov, 1987). Indeed, recently Klein and Bird (2016) have reemphasised that, in the light of other coastal resources found in MSA archaeological sites (i.e. marine mammals and birds, geophytes, large mammals), shellfish should be expected to have been collected opportunistically during calm, low-tides, when the yields would justify the effort. Yet, the situation is apparently quite different during the LSA, when the abundant shellfish and other resources of the southern African coast supported healthy human populations, evident from late Holocene "megamidden" deposits of shells. These occupations are argued to be a consequence of changes in social organisation rather than environmental stress (Buchanan, 1988; Jerardino, 2010a; Parkington, 2012). However, the rarity of ethnographic studies of coastal hunter-gatherers in southern Africa, or indeed the world, contributes to an impression of such groups as peripheral or marginal (Yesner, 1980; Bailey and Milner, 2002).

Recently, experimental collection studies along the south coast have provided estimates of the calorie yields of shellfish and underground storage plant resources throughout the year and among men and women (Singels et al., 2015; De Vynck et al., 2016). These lines of evidence allow for more robust assessments of the feasibility of a coastal-based adaptations in this region. De Vynck et al. (2016) demonstrated that while calorie yields are heavily dependant upon weather and tidal conditions, and shellfishing is not possible at all on many days, under good conditions the total yields from shellfishing along the southernmost coast rival or exceed those for a diverse range of hunter-gatherer activities, including plant collection and hunting in a variety of ecological settings. Additionally, detailed nutritional studies demonstrate the value of shellfish and other coastal resources 
beyond calories. The protein yields compare favourably with terrestrial sources, and, crucially, shellfish are an easily accessed source of long chain polyunsaturated fatty acids and micro-nutrients such as iron and iodine that are rare in terrestrial foods, and yet essential for brain development (Parkington, 2003; Kyriacou et al., 2014). The requirements for these nutrients are especially onerous for lactating women, and deficiencies can inhibit cognitive development among infants, while consumption of fatty acids is necessary throughout life (Janssen and Kiliaan, 2014). Thus, while people are unlikely to have been able to sustain themselves solely from shellfish, the resource is far from being a "fallback" food, exploited only when highly ranked food items were scarce. Turbo is a particularly critical species for evaluating collection strategies through time in the De Vynck et al. (2016) study over $50 \%$ of the total calories harvested by modern shellfish foragers came from Turbo alone.

Another line of evidence for shellfish exploitation comes from measurements of absolute shell size, which decrease significantly between MSA and LSA assemblages. Klein and Steele (2013) suggest that this decrease reflects more effective harvesting strategies and overall greater numbers of people on the landscape during the LSA, which drove down the average size of molluscs (also Volman, 1978; Steele and Klein, 2008). Similar evidence comes from tortoises, another easily collected resource, albeit terrestrial (Avery et al., 2008). Klein and Steele point out that shellfish exploitation in and of itself reveals nothing about the cognitive abilities of MSA populations, given evidence for opportunistic harvesting by non-human primates. They also argue that the level of shellfish exploitation observed in MSA sites does not support interpretations of a unique importance of coastal environments for early humans (also see Jerardino, 2016; Klein and Bird, 2016). But observations of size changes are confounded by the fact that the MSA and LSA assemblages come from Late Pleistocene and Holocene deposits respectively, and so span a period of major environmental change, which may have influenced growth rates more than human predation (Sealy and Galimberti, 2011; Teske et al., 2007). A decrease in average size is also observed for a non-food species, Nassarius kraussianus, which would presumably not be subject to the same harvesting pressures (Teske et al., 2007). Yet, N. kraussianus was collected, accidentally along with estuarine sea grass, and deliberately for bead production (D'Errico et al., 2005; Henshilwood et al., 2004), and so the evidence is far from clear. As yet direct assessments of shellfish growth rates (as opposed to shellfish size) between the two periods are lacking.

Discussion about the use of marine resources relates to debates about intensification, or the "broad spectrum revolution", an interpretation of the increasing reliance on 
reproductively efficient, yet hard-to-catch prey such as hares and birds, over slow-moving and slow-growing prey, including tortoises and marine molluscs, observed between Middle and Upper Palaeolithic sites in the Mediterranean (Stiner et al., 2000; Stiner and Kuhn, 2006). This pattern of intensification is thought to be symptomatic of the far-reaching demographic and cultural changes of the Middle/Upper Palaeolithic transition, and although it now seems clear that southern Africa did not experience the same demographic turnover, a major shift in hunting and foraging behaviours is identified by Klein and colleagues between the MSA and LSA (Klein and Cruz-Uribe, 2000; Steele and Klein, 2009; also see Kyriacou et al., 2015). But other researchers have argued that there is greater variation in subsistence behaviours within the MSA than is indicated by studies of this kind (Dusseldorp, 2012; Clark and Kandel, 2013). In particular, substantial problems are encountered in trying to account for logistical transport decisions when reconstructing shellfishing behaviours, as the shell, the heaviest part of the shell, is unlikely to have been transported far from the site of collection (Dusseldorp and Langejans, 2013; Klein and Bird, 2016). Thus, the significance of differing subsistence patterns observed in archaeological sites remains heavily debated.

The seasonal timing of foraging and hunting activities reflects patterns of mobility and sedentism and the organisation of settlements and groups - it is a key dimension of how people lived their lives. Insights into seasonal resource acquisition are a means to understanding regional settlement patterns and social organisation. As regards shellfish, seasonal mobility is suggested to have been a means of limiting harvesting pressures on easily depleted shellfish species (Klein and Bird, 2016). However, it is typically difficult to reconstruct yearly resource cycles of ancient hunter-gatherer societies as few archaeological sites preserve sufficient quantities of the full range of faunal and plant resources that were exploited (Milner, 2005). Innovative approaches, grounded in observations of the developmental timing of different animal species (Parkington, 1972, 1976) and modern ecological patterning (Singels et al., 2015; De Vynck et al., 2015, 2016), were developed in southern African archaeology to better detect seasonal mobility. John Parkington, the original proponent of the seasonal mobility hypothesis in the southern African context, detected seasonal patterns of harvest/hunting in resources such as seals, corms and rock hyraxes between coastal and inland sites in the south-western Cape. Yet, the sample numbers upon which these interpretations depend are small and competing lines of evidence show conflicting patterns - stable isotope measurements of humans from the west coast differ between people buried at the coast and those buried in the interior during the late Holocene, demonstrating that these groups were not a single population (Sealy and van der Merwe, 1986). A subsequent study among later Holocene populations 


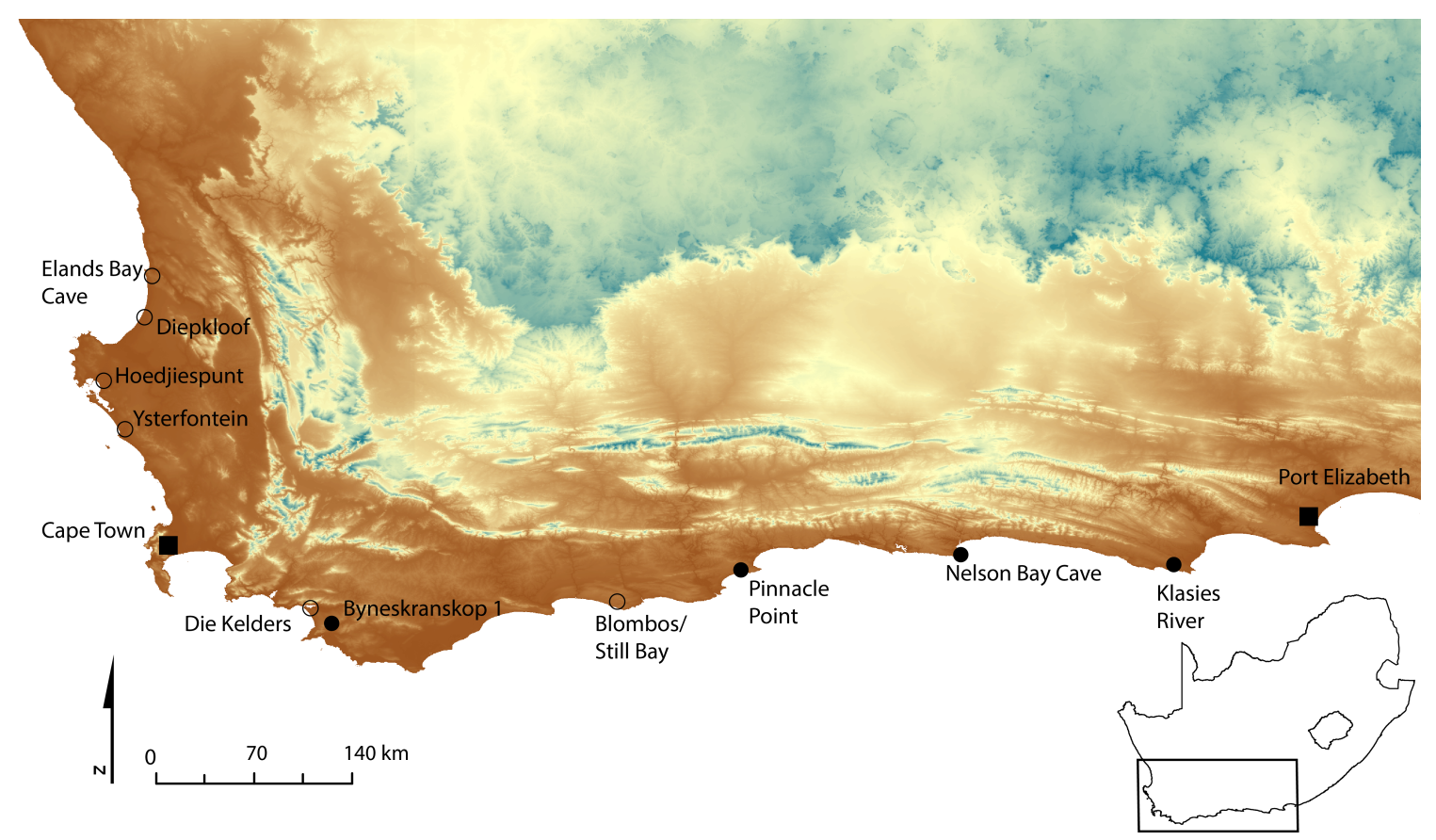

Figure 2.2.1: Map of southernmost Africa, showing the locations of the four archaeological sites in this study (filled circles). Also shown are the locations of other notable shellfish bearing sites on the coast (empty circles).

along the south coast detected dietary differences between two nearby coastal sites, suggesting that these two populations maintained territorial boundaries along the coast, inconsistent with a pattern of high seasonal mobility (Sealy, 2006). However, these data relate only to the later part of the Holocene and the seasonal mobility hypothesis still enjoys considerable intuitive and theoretical appeal.

\subsubsection{The sites}

The shell material for this project comes principally from four archaeological sites spread along the southernmost coast (see Figure 2.2.1), the LSA levels of Nelson Bay Cave (NBC) and Byneskranskop 1 (BNK1), and the MSA at Klasies River Main site (KRM) and Pinnacle Point 5-6 (PP5-6). These sites were selected to span much of the last glacial cycle, and a considerable portion of the south coast. Further, in each case a large sample of shells was available, with good stratigraphic information for the deposits. The excavations and key features of each site are discussed separately below. As part of this project, NBC and BNK1 were redated with a suite of new AMS radiocarbon dates at each site, and the chronological context and results are reported in Chapter 4. 


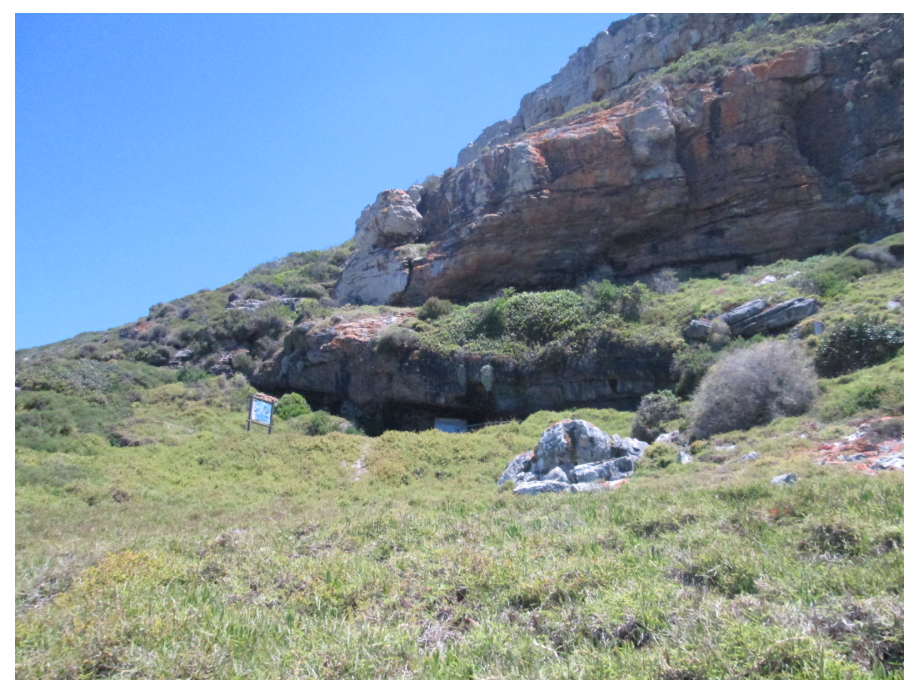

Figure 2.2.2: Photograph of the entrance to Nelson Bay Cave.

The ecosystems and precipitation patterns of the southern Cape coast are described in more detail in section 2.1.2, but it is important to note here that the distribution of these four archaeological sites means that each would have been influenced by the climatic and oceanographic gradients along this coast to differing extents. The southern coast is a mixture of rocky and sandy shores, and is subject to very high energy wave action. Extending into the sea is a large coastal plain, currently submerged, but exposed to various degrees at different times in the past depending on global sea levels (van Andel, 1989; Fisher et al., 2010). This coastal plain has been suggested to have played an important role in the occupation of this region, as it would have supported large herds of game and is found in a relatively clement climatic zone. Of course, the only remaining evidence for the people who lived on this plain has now been largely washed away.

\subsubsection{Nelson Bay Cave}

Nelson Bay Cave (Figure 2.2.2) lies on the narrow Robberg Peninsula, near the town of Plettenberg Bay. The site contains a nearly continuous LSA technological sequence spanning from the late Holocene through to an early Robberg assemblage, named for the eponymous peninsula, with MSA deposits continuing beneath a hiatus in the sequence (see Figure 2.2.3). NBC has been influential in southern African LSA archaeology through the doctoral work of Janette Deacon (1984): the sequence of lithic changes here underpins the regional technological sequence and hence, to a large degree, that of the 
southern African LSA. The site has been the focus of several foundational studies of the lifeways of LSA peoples (e.g. Inskeep, 1987; Klein, 1972; Deacon, 1978, 1984; Sealy, 2006).

The late Holocene levels were excavated by Ray Inskeep over four seasons in the 1960s and 1970s (Inskeep, 1987), while the underlying mid- to early Holocene and Pleistocene levels were excavated by Richard Klein in 1970/71, using a different naming system (Klein, 1972, excavations and finds described in detail in Deacon, 1984). Inskeep (1987) and Deacon (1984) describe a finely laminated stratigraphy, grouped into larger units on the basis of technological and faunal remains. At the base of the LSA levels is the type assemblage, and one of the earliest dated occurrences, of the Robberg bladelet industry, at c. $23 \mathrm{kcalBP}^{1}$ now widely recognised across southern Africa. Marine fauna is absent from the Robberg levels, as the shoreline was some way from the cave at this point. These levels contain a rich record of large bovids, including species no longer observed in the area, and two extinct species, Megalotragus and Pelorovis. The Albany, or Oakhurst, an industry characterised by comparatively large lithics and a paucity of formal tools, appears c. 12 kcalBP following an erosional disconformity of several thousand years. It is succeeded by Wilton cultural material with characteristic microliths, particularly segments and drills, dated to between c. 9-4 kcalBP. The Wilton is succeeded by a 'post-Wilton' or final LSA level containing large amounts of marine fauna, dated to between c. 3.3-2 kcalBP (Inskeep and Vogel, 1985). The uppermost layers contain a scanty 'ceramic LSA' assemblage, including a few bones of domesticated sheep, and are probably younger than $2 \mathrm{kcalBP}$. This sequence is essentially that recognised for the whole of southern Africa, with regional variants (Lombard et al., 2012).

Organic preservation is typically very good in the site, and several researchers have investigated changing environments at NBC. Klein's early work (1972) on the faunal assemblage provided evidence of the ecology of the large coastal plain that existed during the period of lowered sea levels before the onset of the Holocene. This region supported herds of large grazers, including buffalo (Syncerus caffer; Pelorovis sp.), wildebeest (Connochaetus cf. gnou), hartebeest (Alcelaphus cf. caama) and eland (Taurotragus $\operatorname{oryx}$ ). The onset of the Holocene, and the rise in sea-level, appears to drive substantial shifts in species composition at the site c. 9-12 ka, with increasing numbers of smaller, solitary bovids, such as steenbok (Raphicerus sp.) and reedbuck (Redunca sp.), that reflect more closed environments (Klein, 1972). Collagen stable isotope analyses from grazing herbivore remains indicate that the animals consistently consumed both $\mathrm{C}_{3}$

\footnotetext{
${ }^{1}$ calibrated radiocarbon years before AD 1950
} 


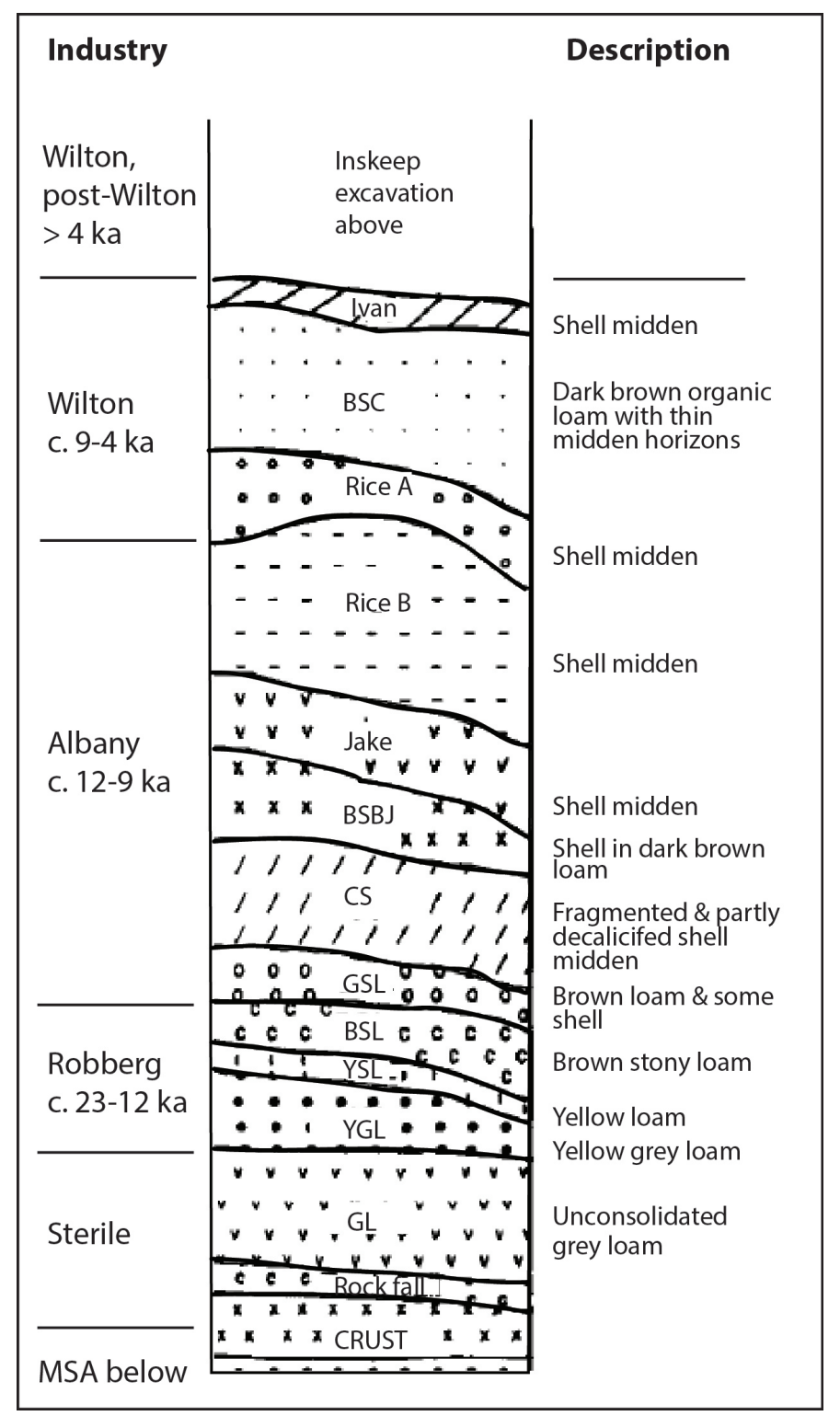

Figure 2.2.3: Generalised site stratigraphy for Nelson Bay Cave, adapted from Deacon (1978). 
and $\mathrm{C}_{4}$ grasses across the period spanning from the LGM through the Holocene (Sealy, 1996). This supports reconstructions of a year-round rainfall regime across this entire period. During the later Holocene, Inskeep (1987) suggested a dramatic shift in forager subsistence behaviour in the post-Wilton levels at c. $3.3 \mathrm{ka}$, based on marked differences in the lithic assemblage and an increased focus on marine foods. Similar changes have been observed at other sites along the coast, and are possibly indicative of rapidly increasing populations and far-reaching changes in social organisation (Sealy, 2006). Yet, stable isotope analyses of diet over this period do not provide evidence of a notable shift in diet at c. $3.3 \mathrm{ka}$, leaving the linkages between subsistence and technology over this period uncertain (Sealy, 2006).

Two further opercula analysed as part of this study come from Hoffman's/Robberg Cave (HRC), only about 500m along the peninsula from NBC, thus reflecting the same environment. In contrast to NBC and other sites in the region, HRC appears to have been only briefly occupied, for a period of about 700 years (Kyriacou, 2009). The shells analysed here come from an excavation by Judith Sealy and Katharine Kyriacou in 2007. The two levels from which the two opercula were excavated, Richard/Royden and Portia, are part of the lower shelly units, with bracketing dates on charcoal between $3760 \pm 40 \mathrm{BP}$ and $3990 \pm 90 \mathrm{BP}$. These two shells were thus assigned a calibrated age range of $4.3-4.0 \mathrm{kcal} \mathrm{BP}$.

\subsubsection{Byneskranskop 1}

Byneskranskop 1 is situated approximately $400 \mathrm{~km}$ west of the Robberg Peninsula, considerably closer to the cooler waters of the Atlantic Ocean, although the site presently lies some $7 \mathrm{~km}$ inland (Figure 2.2.4). Today, the site lies at the interface between the winter and year-round rainfall zones and so palaeoenvironmental records from the site are expected to be highly sensitive to shifts in the position of the westerly, winter rainfallbearing systems (Faith, 2013). Excavations were undertaken in the 1970's by a team led by Frank Schweitzer (Schweitzer and Wilson, 1982), and the site contains a reasonably continuous sequence spanning from terminal Pleistocene Robberg deposits through to the Late Holocene ceramic Wilton. Indeed, the site was targeted for excavation based on the length of the occupational sequence, and to serve as a counterpoint for the well-investigated coastal site at Die Kelders (Schweitzer and Wilson, 1978). The deposits were originally divided into 64 stratigraphic units and subsequently aggregated into 19 levels ( Figure 2.2.5; Schweitzer and Wilson, 1982). The basal Layers 19 and 


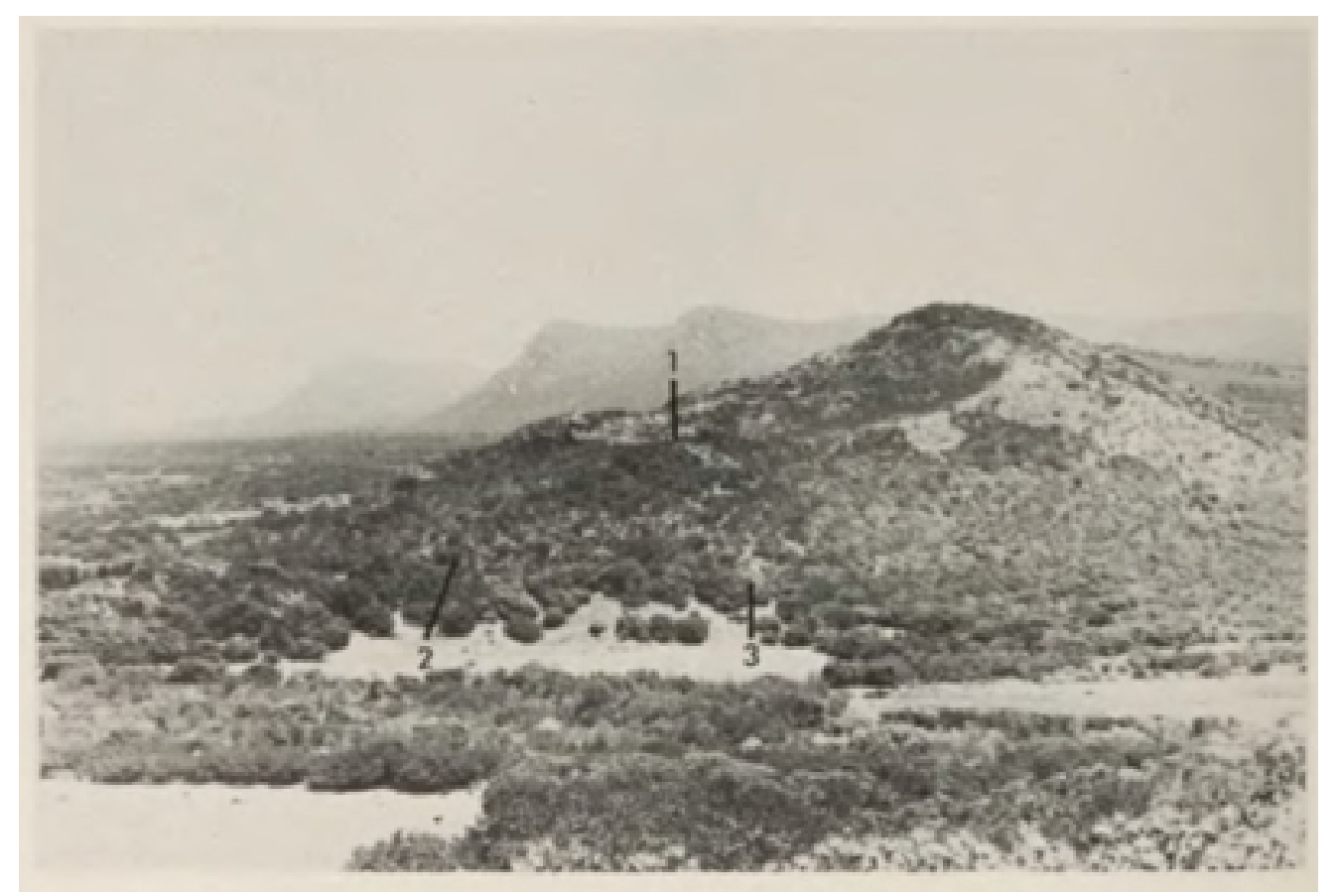

Figure 2.2.4: Photograph of Byneskranskop 1 (indicated by the arrow labelled 1) and nearby sites, taken from Schweitzer and Wilson (1982).

18 pre-date the Pleistocene/Holocene transition, and contain an assemblage described as Robberg and transitional Oakhurst. Layers 17-10 and Layers 9-5 represent an Oakhurst and an intensive Wilton occupation respectively. The uppermost Layers 1-4 contain a post-Wilton assemblage, with early evidence of domesticated livestock for the southern Cape in Layer 1. BNK1 contains well-preserved organic material back to the Pleistocene/Holocene transition, including large and small mammal remains, and charcoal, but well-preserved shells are found mostly in the Wilton and post-Wilton levels (for more details of the chronology see Chapter 4).

\subsubsection{Klasies River Main site}

Klasies River Main site (Figure 2.2.6) is one of a series of caves that lie on the Tsitsikamma coastline adjacent to Jeffrey's Bay: the section of coastline where the caves occur is now a Natural Heritage Area. The first excavations were undertaken on a large-scale in 1967-8 by Ronald Singer and John Wymer (Singer and Wymer, 1982), and a subsequent research programme was initiated by Hilary Deacon in 1984 (Deacon, 1995, seeWurz, 1999 for a history of the research at the site). The sites have produced some of the earliest evidence for anatomically modern humans in southern Africa (Rightmire and Deacon, 


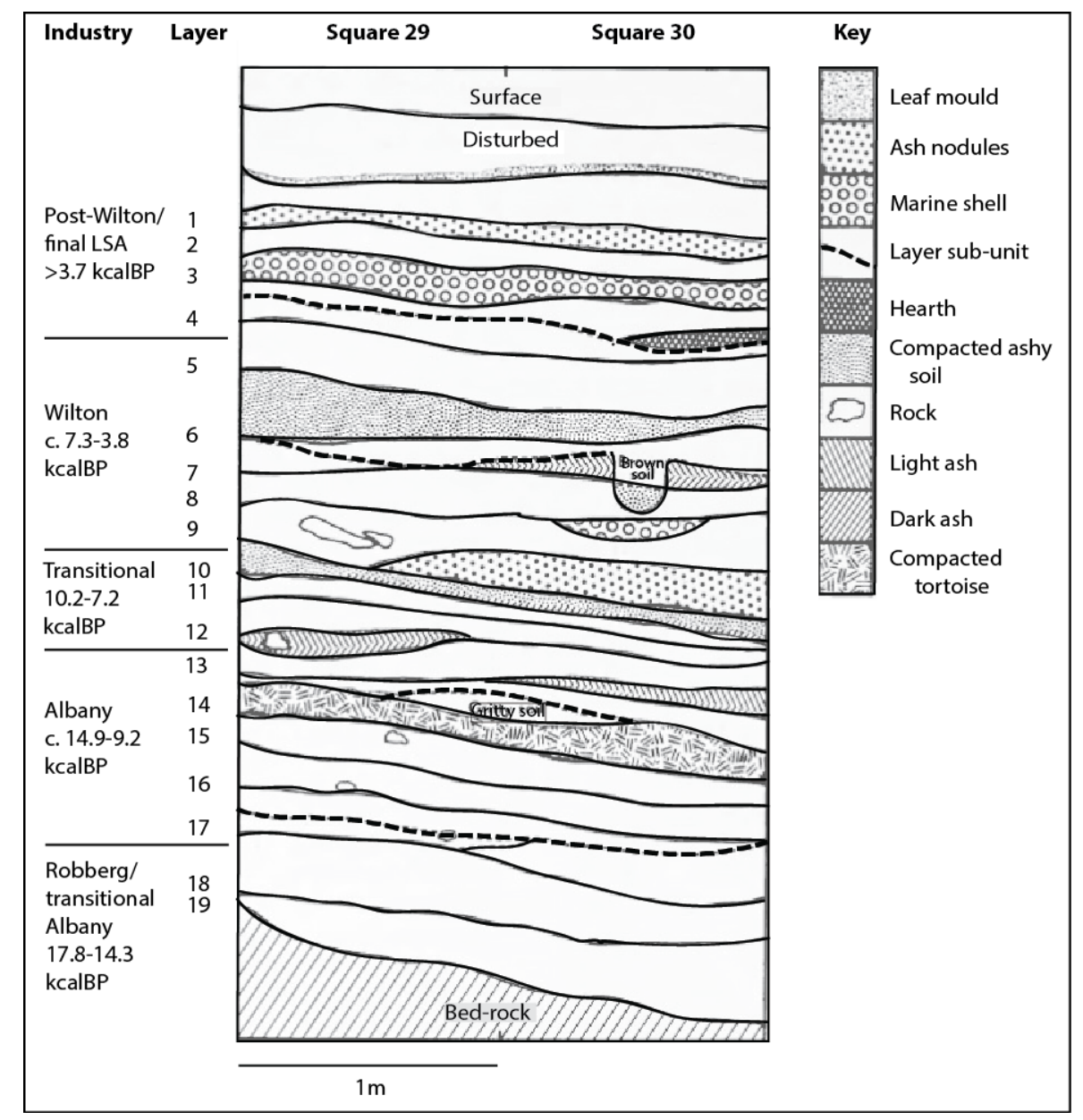

Figure 2.2.5: Stratigraphy of squares 29 and 30 at Byneskranskop 1, adapted from Schweitzer and Wilson (1982).

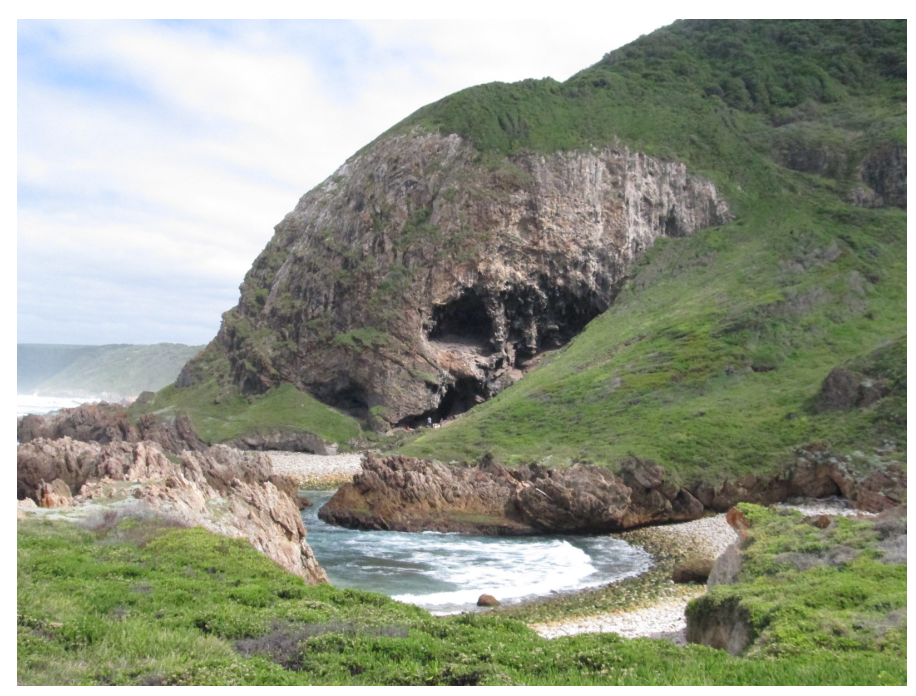

Figure 2.2.6: Photograph of Klasies River Mouth Main site. 


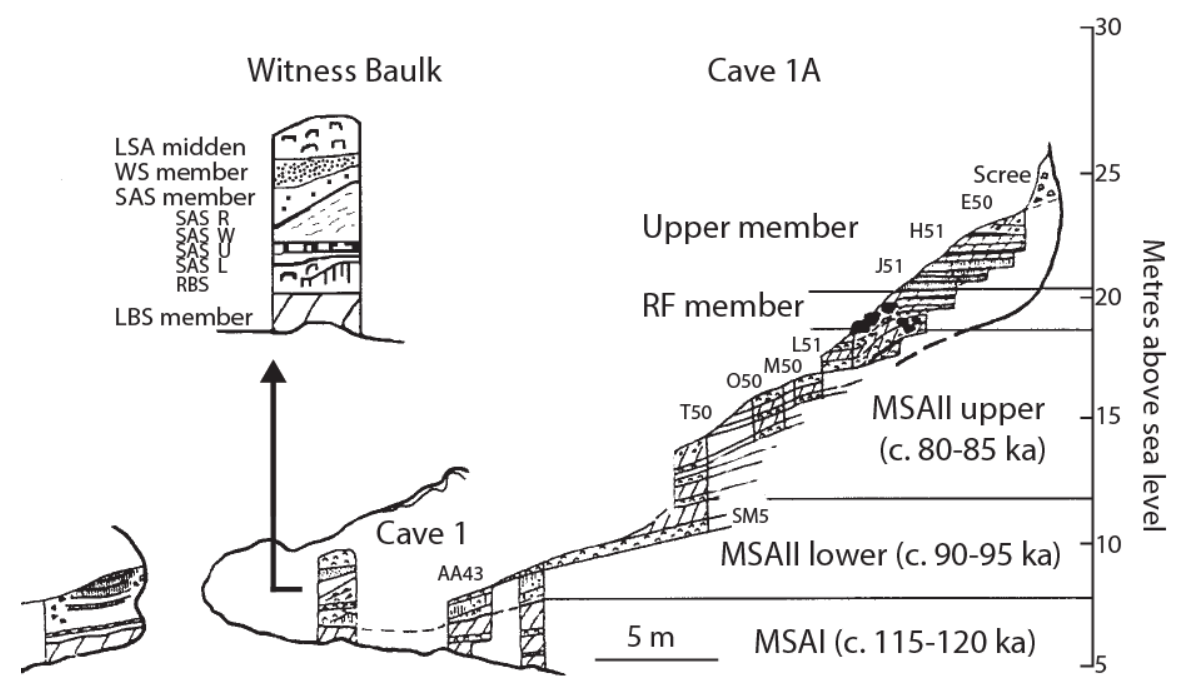

Figure 2.2.7: Stratigraphy of Klasies River Main site, adapted from Wurz, 2002.

1991; 2001; Brauer et al., 1992), and contain deposits spanning tens of thousands of years, from the time of the last interglacial (MIS5e: 130 -118 ka; Lisiecki and Raymo, 2005). The Main site is a single set of deposits, human occupation layers interbedded with levels of aeolian sands, that have accumulated against the cliff face and are preserved in several caves and rockshelters in this cliff (see Figure 2.2.7). The deposits contain abundant mammal remains and some fish bones (Avery, 1987; Klein, 1976; Milo, 1998), shells (Thackeray, 1988; Voigt, 1982), hearths and stone artefacts (Wurz, 1999; 2002; Villa et al., 2010; D'Errico et al., 2012) that have been the subject of numerous studies into the lifeways of MSA people.

The dating of the site is presently somewhat poor, and each level is constrained only broadly by OSL, uranium series, amino acid racemization, and osygen isotope ages. However, there are ongoing efforts to date the deposits reliably, and the age estimates are expected to improve (S. Wurz, pers. comm.). At the base of the sequence, c. 115-110 ka (MIS5e) (Feathers, 2002), are the MSA I layers, also assigned to the Klasies River industry, named for this site, and characterised by local raw material usage and long, thin points and blades (Wurz, 2000). The subsequent MSA II levels, or Mossel Bay substage, are divided into MSA II lower (c. 95-90 ka) and upper (c. 85-80 ka) phases, and are similarly characterised by local raw materials, but with a greater focus on the production of Levallois-like points. These levels are succeeded by the Howieson's Poort levels, but no Turbo opercula were found in the museum collections from these levels (although some are reported in the literature: Thackeray, 1988; Voigt, 1982). 


\subsubsection{Pinnacle Point 5-6}

The Pinnacle Point caves are located in a stretch of sea-facing cliffs adjacent to the seaside town of Mossel Bay (Figure 2.2.8). Initial research at this locality focussed on the cave site 13B (164 - $91 \mathrm{ka}$ ), which was the focus of intensive multi-disciplinary research detailed in a Journal of Human Evolution special issue (Marean, 2010a). However, the scope of the SACP4 (South African Coastal Paleoclimate, Paleoenvironment, Paleoecology, and Paleoanthropology) project has extended well beyond the excavation of the cave sites (e.g. Marean et al., 2015), spurring wide-ranging research into the ancient landscapes around Pinnacle Point (Fisher et al., 2010; Oestmo et al., 2014; McGrath et al., 2015; Cawthra et al., 2016), modern experimental studies (Brown et al., 2009; De Vynck et al., 2015, 2016; Singels et al., 2015) and detailed palaeoenvironmental reconstructions (Bar-Matthews et al., 2010).

The focus of current excavations at Pinnacle Point is the so-called "Long Section" of PP5-6 (see Figure 2.2.8 on the next page) spanning c. 50 - $100 \mathrm{ka}$, over 30m of vertical deposits. Excavations began in 2006, with a meticulous focus on capturing as much contextual detail as possible (e.g Karkanas et al., 2015; Fisher et al., 2015; Marean et al., 2015). A generalised stratigraphy for the site is shown in Figure 2.2.9. The ages for the different depositional layers are well-constrained due to a comprehensive suite of OSL ages, with an ongoing OSL dating project due to improve these age estimates further (C. Marean, pers. comm.). The deposits contain abundant archaeological remains, including fauna, lithics, ochre, shells, ostrich eggshell and hearths. A notable discovery at the site is an as yet unnamed microlithic industry in the Shelly Ashy Dark Brown Sand (SADBS) level (c. $71 \mathrm{ka}$ ), different from the Howieson's Poort assemblage that occurs in the overlying Dark Brown Compact Sand (DBCS) level (Brown et al., 2012). Between SADBS and DBCS lies the Orange Brown Sand 1 (OBS1), with few diagnostic tools and apparently representative of neither the Howieson's Poort nor the SADBS industry. 

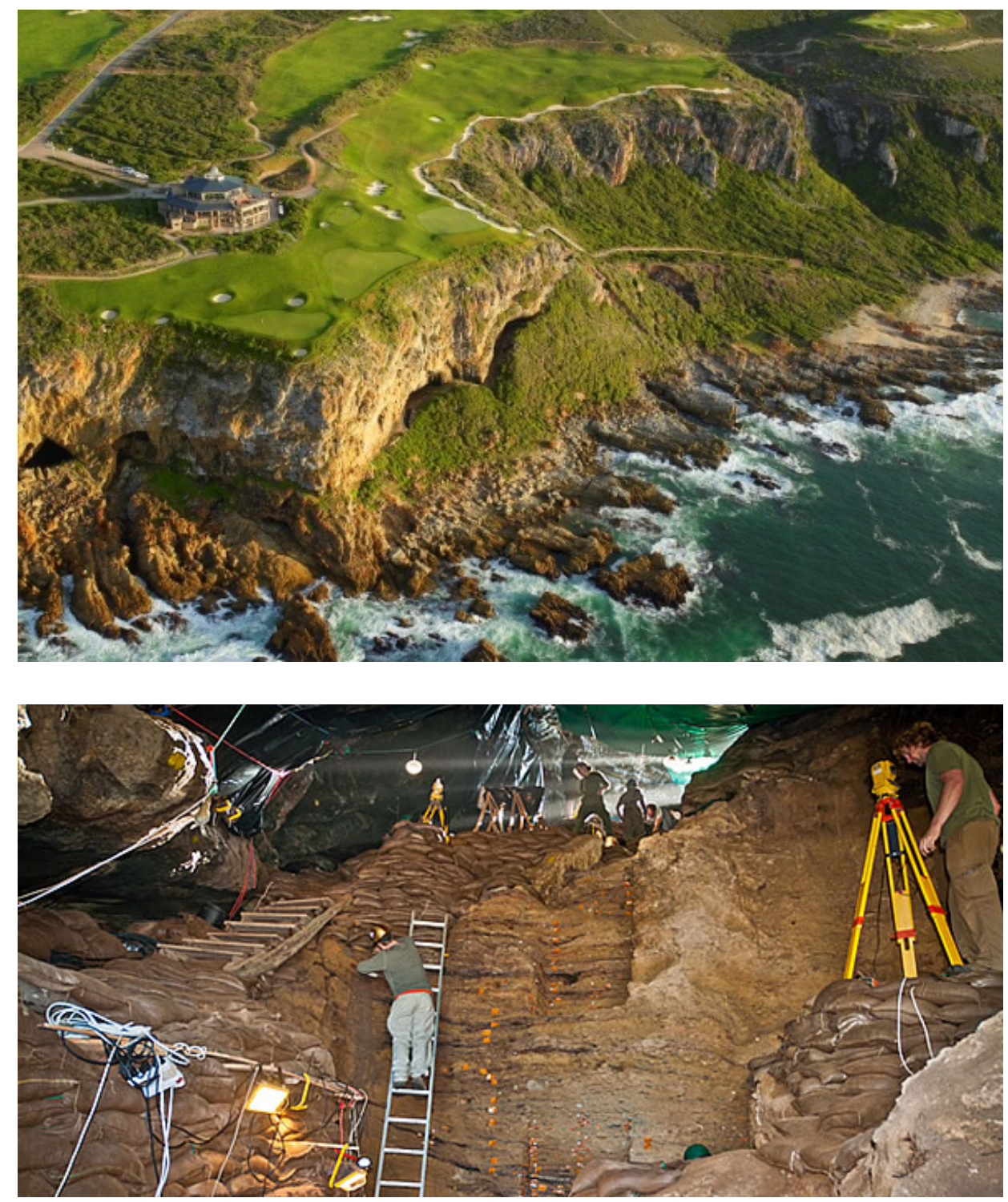

Figure 2.2.8: Top: Aerial photograph of the sea cliffs at Pinnacle Point, showing some of the caves and the overlying golf course (image from www.platinumgolf.co.za). Bottom: Photograph of Pinnacle Point 5-6 Long Section (image from www.visitmosselbay.co.za). 


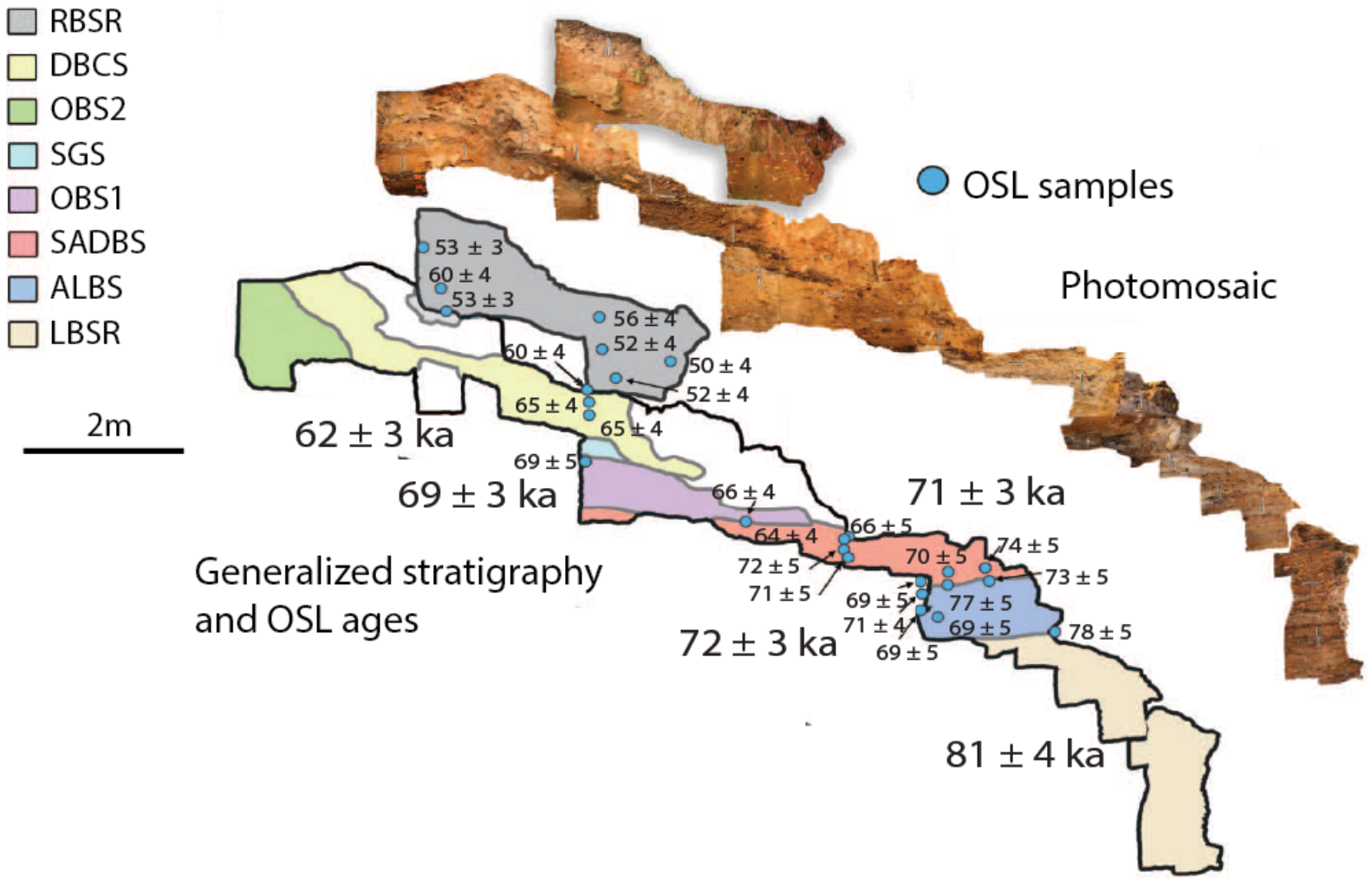

Figure 2.2.9: Stratigraphy of the Long Deposit of Pinnacle Point 5-6, with OSL age estimates and a high resolution photo mosaic of the deposits, adapted from Brown et al. (2012) 


\section{Chapter 3}

\section{Methods}

\section{Contents}

3.1 Turbo sarmaticus and modern calibration data . . . . . 44

3.1.1 Shell growth and palaeotemperature archives . . . . . . . . 45

3.1.1.1 General structure of a mollusc shell . . . . . . . . 45

3.1.1.2 Growth increments and sclerochronology . . . . . 45

3.1.2 Turbo ecology and growth . . . . . . . . . . . 47

3.1.3 Galimberti (2010) modern calibration study . . . . . . . . . . 48

3.2 Micromill sampling and $\delta^{18} \mathrm{O}$ analysis $\ldots \ldots \ldots$

3.2.1 Sampling strategies for Turbo opercula . . . . . . . . . 50

3.2.1.1 Previous sampling of opercula . . . . . . . 50

3.2.1.2 New sclerochronological insights . . . . . . . 52

3.2.2 Micromill sampling strategy . . . . . . . . . . . . . . . 53

3.2.2.1 Mineralogical and geochemical effects of drilling . . 56

$3.2 .3 \quad \delta^{18} \mathrm{O}$ analyses $\ldots \ldots \ldots \ldots \ldots \ldots$

3.3 Diagenesis ......................... 60

3.3.1 Pretreatment for organic contaminants . . . . . . . . . 61

3.3.1.1 Cleaning and pretreatment strategies used in this study ..................... 62

3.3.2 FTIR analyses for recrystallisation . . . . . . . . . 63

3.3.2.1 Experimental method . . . . . . . . . . 65 
$3.3 .2 .2 \quad$ Data analysis . . . . . . . . . . . . . 68

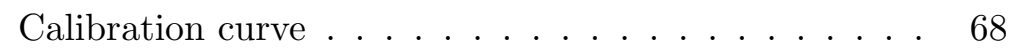

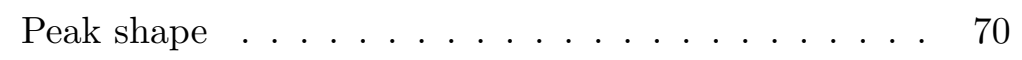

3.4 Seawater $\delta^{18} \mathrm{O}$ variability $\ldots \ldots \ldots \ldots \ldots \ldots \ldots$

This chapter discusses the methodological considerations for deriving sea surface temperature records from archaeological shells. Although molluscs are valuable as seasonally resolved palaeoclimate records, their full promise is limited by various technical and methodological constraints. In 1948 Urey noted three problems for the then nascent technique of carbonate palaeothermometry and these remain considerable obstacles for researchers today. Firstly, it must be established whether the carbonate precipitated in equilibrium with the water source; secondly, any post-depositional diagenetic recrystallisation of the carbonate must be detected and quantified; and finally, the $\delta^{18} \mathrm{O}$ value of the water in which the carbonate was precipitated must be accurately estimated. I address these three considerations here in sections 3.1, 3.3 and 3.4 respectively. In addition, I discuss the high resolution sampling strategy employed and describe the analytical systems used to measure $\delta^{18} \mathrm{O}$ in this study in section 3.2. Not discussed in this chapter are the methods of radiocarbon dating, which are described in Chapter 4.

\subsection{Turbo sarmaticus and modern calibration data}

This section briefly describes shell formation and Turbo sarmaticus ecology. Also described (section 3.1) is an earlier, unpublished oxygen isotope study of modern Turbo sarmaticus from Mossel Bay by Mariagrazia Galimberti (2010), as part of doctoral research undertaken at the University of Cape Town. Palaeotemperature reconstructions based upon individual species must demonstrate that the animal precipitates $\mathrm{CaCO}_{3}$ in isotopic equilibrium with the water in which it lives (i.e. that it records temperature reliably) and that the record is not unduly distorted by physiological factors, or "vital effects" (Urey et al., 1951; Schöne, 2008). Consequently, a so-called "calibration study" among modern animals living in well-characterised environments is a requirement for absolute palaeotemperature reconstructions. Given that the key aim of this thesis was to produce comparative palaeotemperature records for the last glacial cycle, it was decided to rely upon the findings of Galimberti's research (Galimberti, 2010). These results have 
been key to demonstrating the utility of Turbo opercula for temperature reconstructions and provided the rationale for this study.

\subsubsection{Shell growth and palaeotemperature archives}

\subsubsection{General structure of a mollusc shell}

The molluscan shell, an organic-inorganic composite of interlocking $\mathrm{CaCO}_{3}$ crystals upon a proteinaceous matrix (Lowenstam, 1981; Weiner and Dove, 2003), is secreted by the mantle, a membrane-like organ that covers the soft part of the mollusc and forms the body wall. The animal creates a supersaturated solution of bicarbonate and calcium ions, from which the biocarbonate crystals form. The ions which contribute to this solution are derived from the surrounding seawater, metabolic carbon dioxide and the animal's diet, among other sources. Despite these varied sources for the oxygen isotopes, many species precipitate their shell in isotopic equilibrium with seawater as predicted by Urey et al. (1951), and so record the temperature of the water in which the animal lives.

Molluscs may precipitate their shells in aragonite, calcite or a layered mixture of the two, depending on the species. Many species will precipitate one structure of the shell in one polymorph, and another structure in the other polymorph. Studies of the calcified opercula of other Turbo species have shown that these species have entirely aragonitic opercula (Adegoke, 1973; Sire and Bonnet, 1984). Galimberti (2010) reports that the prismatic layer of the Turbo operculum forms fan-shaped structures that resemble an irregular spherulitic prismatic morphology (Carter, 1990). This is confirmed by scanning electron microscope images (Figure 3.1.1) taken at RLAHA, University of Oxford, of the broken surface of a modern operculum collected at Cape Point, Cape Town, which show the needle-like crystals arranged in fan-shaped bundles.

\subsubsection{Growth increments and sclerochronology}

Mollusc shells do not grow at a constant rate. The growth increments evident within shells occur as a result of the regular slowdowns and pauses in the growth of the mollusc, usually when environmental conditions are not optimal for growth, such as during periods of temperature extremes. When growth does slow down and finally cease, darker, organic-rich layers are deposited that contrast with the white layers of calcium carbonate 

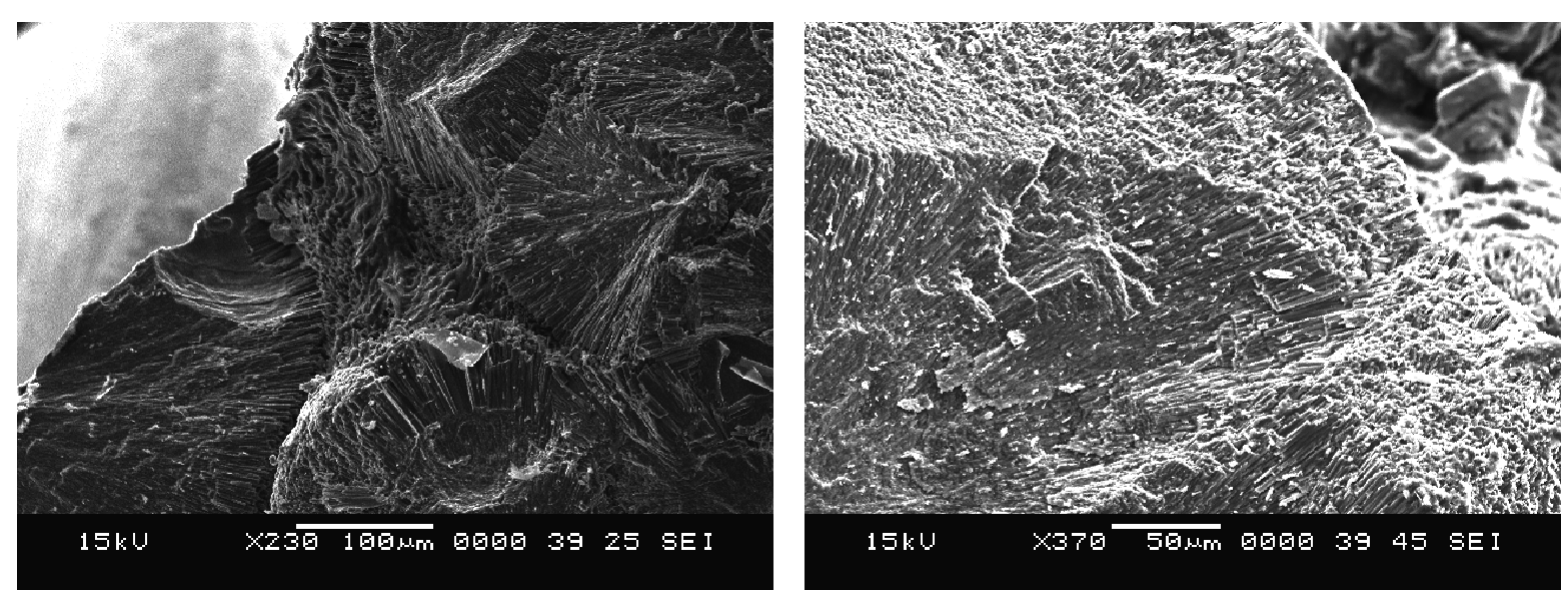

Figure 3.1.1: Scanning electron microscope image of the needle-like, fan shaped aragonite crystal structure of a modern T. sarmaticus operculum.

(Schöne, 2008). Thus a complete growth increment is composed of both a lighter, thicker band of faster growth, and an organic-rich, narrower band of slow growth. A similar phenomenon, although to a lesser degree, occurs on a tidal, or even daily scale due to exposure or lack of light. Thus, thinner increments can be grouped within larger increments, and the palaeoenvironmental record within shells can be resolved on a number of temporal scales, ranging from annual to sub-daily.

Sclerochronology is the study of these accretionary growth layers in the skeletal carbonates of marine invertebrates (such as molluscs and corals), reflecting the annual, seasonal, monthly, fortnightly, tidal, etc., increments of time. Researchers can assess both physical characteristics of the growth layers, such as width and colour; and chemical characteristics, such as stable isotope and trace element ratios, to understand the organism's life history and environmental conditions (Gröcke and Gillikin, 2008).

Gastropods, including Turbo sarmaticus, may have both a coiling top shell, formed as new material is precipitated at the outer rim of the aperture (see Figure 1.0.1), and a separate operculum affixed to the foot of the mollusc, which acts to seal the entrance of the top shell to provide protection from predators and the elements (Checa and Jiménez-Jiménez, 1998). Both the top shell and the operculum of Turbo display growth increments, although the operculum displays a tight, complex spiral that has confounded previous sampling attempts (see section 3.2.1.2). 


\subsubsection{Turbo ecology and growth}

Turbo sarmaticus (common name alikreukel or Giant Periwinkle) is a member of the globally distributed Turbinidae family (turban shells), which is characterised by a hard, calcareous operculum that protects the animal from predators (see Figure 1.0.2). T. sarmaticus, a comparatively large macroalgal grazer endemic to the southern and eastern coasts of South Africa, is a common component of rocky shore communities along this coastline (Foster, 1997). The species inhabits the lower littoral (intertidal) and sublittoral regions to depths of approximately $8 \mathrm{~m}$ (Branch et al., 2007): younger and smaller individuals live higher up the shore, sheltering in crevices and under boulders during the day, but migrate into cooler, deeper waters as they age and their tolerance to extreme shifts in temperature decreases (Foster, 1997; McLachlan and Lombard, 1980). Typically, individuals occupy well-flushed locations on this high-energy shore.

T. sarmaticus is not commercially exploited today, but it is intensively collected for food and bait by local fishing communities (Griffiths and Branch, 1997). Consequently, in many areas, particularly outside of marine reserves or in densely settled areas, populations of T. sarmaticus reflect these predation pressures (Proudfoot, 2006). There have been few studies of T. sarmaticus life-history, but Foster (1997) reports a growth rate of approximately $25 \mathrm{~mm} / \mathrm{yr}$ for the shell and $9 \mathrm{~mm} / \mathrm{yr}$ for the operculum during the first three years. The growth rate slows dramatically after this, to c. $5 \mathrm{~mm} / \mathrm{yr}$ and $2 \mathrm{~mm} / \mathrm{yr}$ for the shell and operculum respectively. Animals live to about seven years of age, with ages up to 10 years reported in the literature (Bruton et al., 1991). Turbo is the highest ranked south coast shellfish species for humans according to optimal foraging theory considerations of meat weights and handling costs (Langejans et al., 2012). The animal can also be relatively easily processed at the site of collection, discarding the heavy shell and transporting the animal attached to the operculum back to the cave site (Langejans et al., 2012). The value for human foragers is confirmed by a recent ethnographic study of shellfishing among an indigenous community on the south coast, which provides estimates for the caloric value of T. sarmaticus relative to other shellfish species (De Vynck et al., 2016). In that study, nearly $90 \%$ of the calorie yields came from only three species and over $50 \%$ of the total calories came from Turbo alone. 


\subsubsection{Galimberti (2010) modern calibration study}

Galimberti's doctoral research project was similar to this one - she intended ultimately to produce palaeotemperature reconstructions using Turbo opercula from the archaeological site Pinnacle Point 13B. To that end, she undertook a stable isotope study of modern Turbo, collected between 2004 and 2007 from Mossel Bay and it is this study that will be briefly described here. Galimberti (2010) analysed $\delta^{18} \mathrm{O}$ of sixteen modern shells, collected at various times of the year between 2004 and 2007. In addition, she collected seawater samples monthly from the same location, from which she measured an average $\delta^{18} \mathrm{O}$ value of $0.52 \pm 0.13 \%$ o $(n=19)$, consistent with the modelled range of $0.5-0.6 \%$ for this region based on a global dataset of seawater $\delta^{18} \mathrm{O}$ (LeGrande and Schmidt, 2006), and this value is used in this study. The error associated with the uncertainty of $0.13 \%$ equates to a temperature uncertainty of $0.56{ }^{\circ} \mathrm{C}$ in the aragonite palaeotemperature equation.

Galimberti's data showed that Turbo opercula do precipitate their shells in equilibrium with seawater, and that kinetic effects are minimal. This had been suspected but not closely demonstrated, and so the study established that the species is suitable for palaeotemperature studies. Galimberti also concluded that the Grossman and Ku (1986) palaeotemperature equation most closely fitted the observed temperature ranges for this species. Her results show, however, that the species does not record the full range of observed SSTs. Particularly, the opercula do not capture the cooler temperatures evident at this location, very likely due to a slowing or cessation of growth during the winter months. This is not unexpected as many mollusc species slow their growth at certain times of the year. It does, however, place some limitations on the utility of the species for palaeotemperature reconstructions as the record will be slightly compressed relative to the true temperature amplitude.

The summary statistics for the modern dataset are shown in Table 3.1, with the estimated temperatures calculated using the Grossman and Ku (1986) equation and Galimberti's estimate of seawater $\delta^{18} \mathrm{O}(0.52 \%)$. Also shown are the comparable statistics for publicly available records of SST for Mossel Bay (from the South African Weather Service), measured between 2003 and 2007 (the estimated period of growth for this entire dataset). This table makes it clear how the temperature range captured by the Turbo opercula is compressed compared to the actual observed range. And yet, the generally good match between the shell and SST data is also clear. In addition, the average range of temperatures captured by all of the individual 16 shells is $6.7^{0} \mathrm{C}$, a close match 
Table 3.1: Comparison of predicted temperatures from $\delta^{18} \mathrm{O}$ measurements of Turbo opercula collected between 2004-2007 (Galimberti, 2010) and observed SSTs at Mossel Bay (South Africa Weather Service data).

\begin{tabular}{lrrr}
\hline & $\begin{array}{r}\text { Modern shell } \\
\delta^{18} O(\%)\end{array}$ & $\begin{array}{r}\text { Converted } \\
\text { temp. }\left({ }^{\circ} \mathrm{C}\right)\end{array}$ & $\begin{array}{r}\text { Measured SST } \\
2003-2007\left({ }^{\circ} \mathrm{C}\right)\end{array}$ \\
\hline $\mathrm{N}$ & 327 & 327 & 7264 \\
Mean & 0.69 & 19.0 & 19.4 \\
Std. dev. & 0.52 & 2.3 & 2.9 \\
Minimum & 1.77 & 14.3 & 13.0 \\
Maximum & -0.35 & 23.5 & 25.0 \\
Range & 2.12. & 9.2 & 12 \\
Averaged min & 1.47 & 15.6 & $16.0($ Aug $)$ \\
Averaged max & -0.07 & 22.2 & $22.9(\mathrm{Feb})$ \\
Averaged range & 1.54 & 6.7 & $6.9($ Aug-Feb) \\
\hline \hline
\end{tabular}

to the difference of $6.9{ }^{\circ} \mathrm{C}$ between the warmest month (January, $22.9{ }^{\circ} \mathrm{C}$ ) and the coolest month (August, $16.0^{\circ} \mathrm{C}$ ) from 2003 to 2007. This indicates that the species may reliably capture the average seasonality at a site, although it does not precisely record the absolute warmest and coolest temperatures (in addition to which the scale of sampling here is not likely to capture such temperature fluctuations). Further, the average maximum and minimum temperatures for the entire modern Turbo dataset are $22.2^{\circ} \mathrm{C}\left(-0.07 \%\right.$ ) and $15.6{ }^{\circ} \mathrm{C}(1.47 \%)$ respectively, which is much closer to the averaged values for the warmest and coolest months.

These results indicate that, while the opercula of Turbo do reflect a suppressed range of the full set of actual SSTs, larger datasets based upon more than one shell can provide close estimates of key climate parameters, including the average seasonal amplitude and the averaged maximum and minimum temperatures for the warmest and coolest periods of the year. They emphasise the importance of securing relatively large datasets for robust climate reconstructions, and not interpreting SSTs based on single shell records, which may reflect microhabitats or events in the life of an individual mollusc. 


\subsection{Micromill sampling and $\delta^{18} \mathrm{O}$ analysis}

\subsubsection{Sampling strategies for Turbo opercula}

\subsubsection{Previous sampling of opercula}

To construct an accurate seasonal sea surface temperature record it is essential to follow the direction of growth of the opercula, and avoid cross cutting the growth increments. However, as discussed below, the growth trajectory of Turbo opercula is complex. Several researchers have attempted to construct seasonal SSTs from the oxygen isotope composition in Turbo sarmaticus opercula. Shackleton (1982) analysed the oxygen isotope ratios in shells from several layers within the Klasies River Mouth deposits to correlate the stratigraphy of the site with the global sea level curve and so provide approximate dates for the different levels. Figure 3.2.1a shows Shackleton's sampling strategy - the shell was sampled at approximately $2 \mathrm{~mm}$ intervals across one to two years of growth. This is sufficient to provide seasonal resolution of SST changes within a year of the animal's life, as seen in the somewhat cyclical reconstructed SST curves. However, the only photograph of a sampled shell that is provided (which is not individually identified to a level) clearly shows how the sampling trajectory did not precisely follow the actual growth trajectory of the opercula. This presumably accounts for the scatter of the seasonal reconstructions.

Henshilwood (1995, also see 2008a) sampled the final growth increments of several opercula from a series of Later Stone Age sites in the Blombosfontein Nature Reserve (Garcia State Forest) on the south coast to establish changes in the season of collection through the Holocene. Henshilwood (p. 129) notes the problems he encountered in trying to establish a seasonal signal due to insufficiently high resolution drilling. Although only a schematic diagram is provided to show the direction of sampling (see Figure 3.2.1b), it does not appear to follow the spiral direction of growth. Brune (2006) attempted to extend the work of Henshilwood at the Blombosfontein sites and similarly used a handheld drill, sampling at approximately $2 \mathrm{~mm}$ resolution. However, the sampling pattern (see Figure 3.2.1c) chosen for each shell is inexplicable and cannot be expected to yield an accurate seasonal SST signal, as it does not follow the direction of growth whatsoever.

The most extensive and careful study of Turbo as a palaeotemperature archive was undertaken by Galimberti (2010). Her sampling strategy, as seen in Figure 3.2.1d, is 

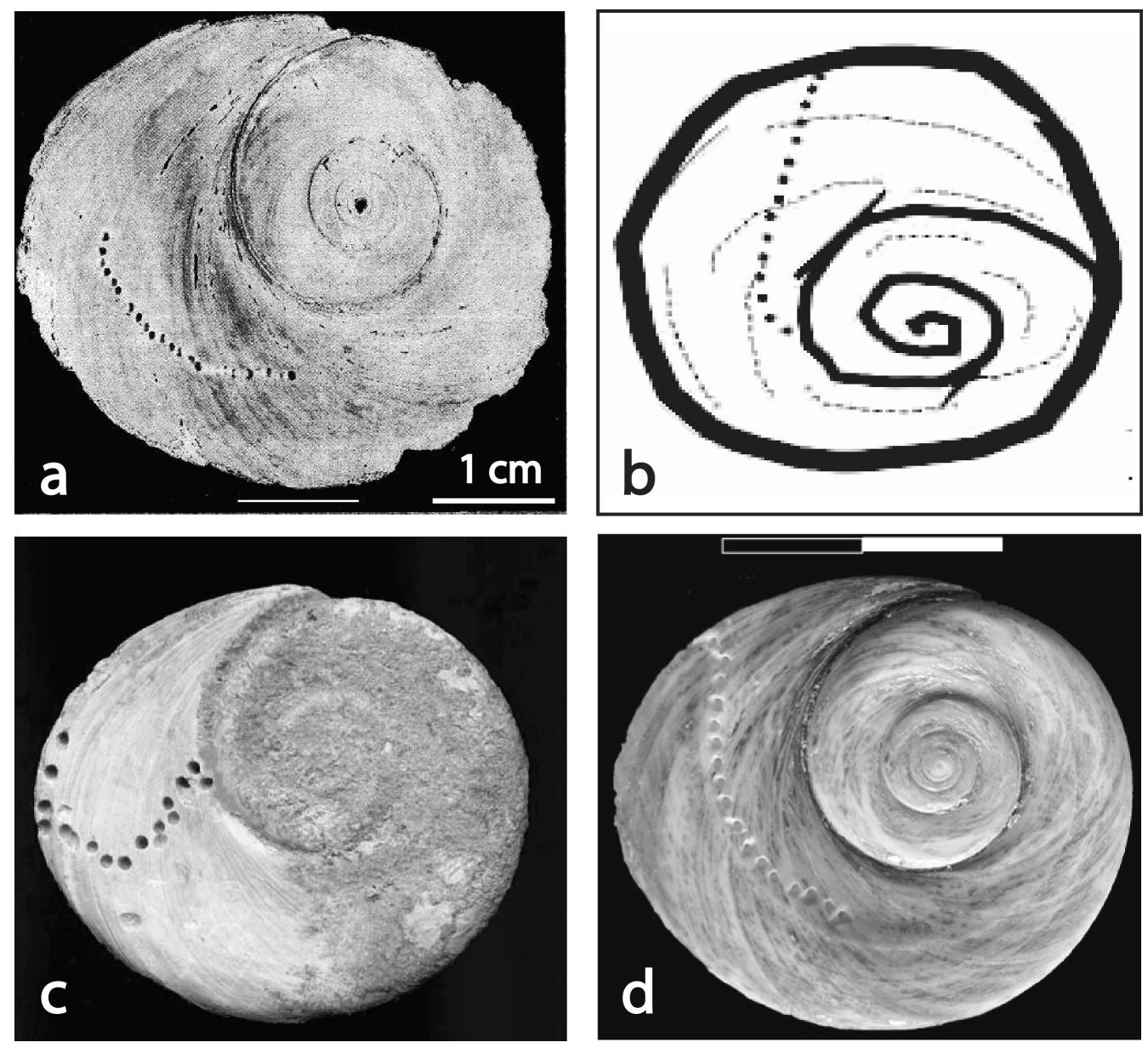

Figure 3.2.1: The drilling strategies of four researchers. a.) Shackleton, 1982; b.) Henshilwood, 1995; c.) Brune, 2006; and d.) Galimberti, 2010. All images at approximately the same scale. Compare with drilling strategy of this study (Figure 3.2.3). 
a considerable improvement over previous efforts and provides seasonal resolution for SST reconstructions. However, the drilling was performed by hand, which proved a limitation. Additionally, she did not accurately parallel the direction of growth in several cases (she provides photographs for each operculum), and it is likely that the samples cross-cut several growth increments. This trend seems exaggerated in the final few growth increments, which are often sampled almost parallel to a growth increment . This is not sufficient to entirely obscure the seasonal signal, as evidenced by the cyclical patterns observed in the data, but it may be sufficient to obscure intra- and interannual variability, as the reconstructed SST pattern will be "flattened" for these samples.

\subsubsection{New sclerochronological insights}

These previous studies have highlighted the necessity for a clear assessment of the Turbo sarmaticus operculum growth pattern prior to sampling. To this end, insights and techniques from the field of sclerochronology are useful. Techniques to improve visual assessment of the growth increments of shells include staining, acetate peels, and microscopy. All three techniques have been applied to Turbo opercula, in this study and others, with varying degrees of success. Galimberti (2010) undertook extensive sclerochronological experiments to elucidate the growth patterning of Turbo opercula and reports the results of these experiments in detail. She noted the difficulty of applying traditional sclerochronological methods to Turbo opercula. Typically, shells are sectioned and ground smooth to provide a suitably flat and uniform surface to better see the growth patterning, often using a stain or acetate peel. However, the layer of the Turbo operculum that displays the growth increments is only a few millimetres thick - below the surface is a complex protrusion of finger-like tuberculae (see Figures 3.2.2 and 1.0.2) and it cannot be further polished without removing the growth layers. Consequently, the surface does not lend itself to staining or peels. Limited sclerochronological experiments were undertaken as part of the present study to gain fresh insights into the growth patterning, leading to a different sampling strategy from those previously applied.

The Turbo sarmaticus operculum grows in a flattened (hemispherical) spiral around a central point, with a domed outer surface (i.e. that not attached to the animal) covered in small irregular spiricules. It is the inner surface that provides a surface with visible growth increments suitable for sampling. $\mathrm{CaCO}_{3}$ is laid down at the margin of the operculum, and at the centre of the outside surface, thickening the operculum towards the centre. The animal rotates the operculum as it increases in size, accounting for the 


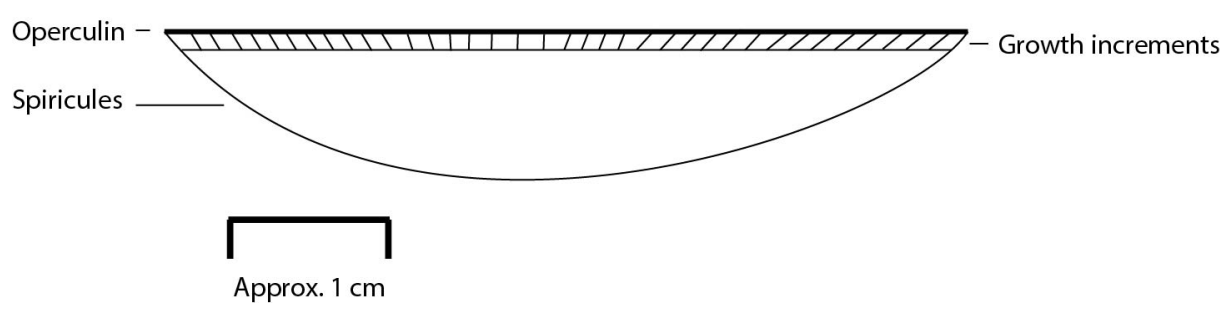

Figure 3.2.2: Schematic of cross section through a T. sarmaticus operculum, showing the relative thickness of the growth increments.

operculum's increasingly ovoid shape (Checa and Jiménez-Jiménez, 1998). Unlike the shells of other mollusc species, common in sclerochronological studies, Turbo opercula do not usually display increments that can be neatly distinguished into annual, sub-annual, and daily bands. Particularly unclear are the major growth increments representing an entire year of growth (Galimberti, 2010). This is problematic, as these are the periods of interest for reconstructing seasonal SST variations. The marked changes in the direction of growth that are evident across the surface suggest that the animal rotates the operculum to fit inside the increasing diameter of the top shell mouth in discrete shifts, rather than incrementally. Figure 3.2.3 shows a modern operculum after drilling, with the direction of growth indicated by the lines overlain perpendicular to the growth increments. These shifts in the direction of growth were relied upon to guide sampling in this study.

\subsubsection{Micromill sampling strategy}

A micromill is a high-precision drilling instrument comprising a microscope and a drill, with the sample mounted on a moveable stage with sub-micron scale motion control. The user defines the drilling path on the sample under magnification, and the drilling is executed automatically, greatly increasing the accuracy and resolution of sampling over hand operated systems. Micromills are increasingly used to extract precisely located, closely spaced samples from mollusc shell increments (e.g. Ferguson et al., 2006; Reynolds et al., 2013). With a micromill, it is possible to drill curving lines that exactly follow the curvilinear growth lines of mollusc shells. Micromill sampling along an increment reduces the number of increments which are cross-cut by the drill (by, for example, circular drill holes), and so improves temporal resolution, but still extracts sufficient material for analysis.

For this study, a New Wave Merchantek micromill was used, with tungsten carbide 


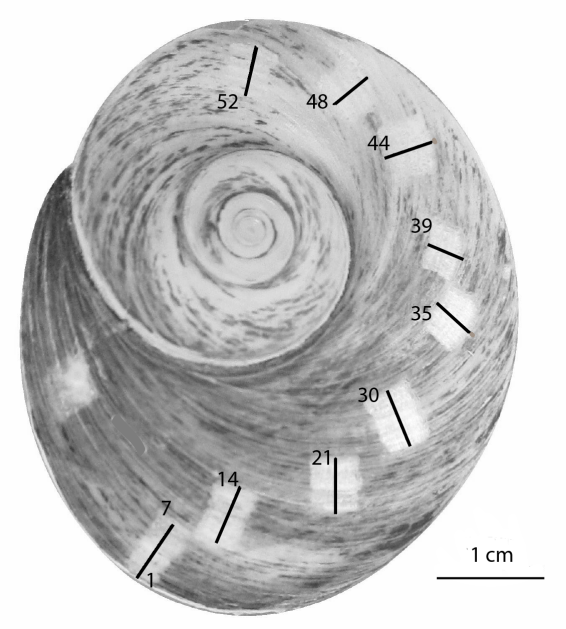

Figure 3.2.3: Modern operculum CP One (from Cape Point) showing micromill sampling. The changing growth direction is indicated by the dark lines, while the position of the serial samples from the edge is indicated by the numbers.

dental burrs $(0.8 \mathrm{~mm})$. Samples were taken in a nested series of curving lines that lie perpendicular to the direction of growth, identifiable under the microscope. The sample direction is shifted in accordance with the direction of growth changes, forming sets of discontinuous, but overlapping, samples, unlike the single continuous arc of drill holes in earlier studies (contrast Figures 3.2.1 on page 45 (earlier studies) and 3.2.3 (this study)). The micromill software allows the user to specify the depth to which the sample is drilled - all samples were drilled to c. 300um depth. Samples are overlapped, so that although the sampling path is c. $0.8 \mathrm{~mm}$ wide, the sampling resolution is c. $0.6 \mathrm{~mm}$ for most samples. Individually micromilled samples provide enough sample powder for both the FTIR-ATR (see section 3.3.2) and $\delta^{18} \mathrm{O}$ analyses (c. $0.5 \mathrm{mg}$ of powder).

Analysis of a modern shell over almost the entire area of growth shows that the drilling strategy adopted in this study does indeed capture the seasonal changes in SST experienced by the animal. Figure 3.2.4 shows $\delta^{18} \mathrm{O}$ values over 52 samples milled from a modern operculum (CP One from Cape Point, pictured in Figure 3.2.3). The grey vertical lines indicate where the direction of growth changes (and the sampling direction is shifted) - it is evident that the direction changes much more frequently when the animal is younger, and the spiral of the operculum is tighter, further complicating the sampling. However, this sampling method captures the directionality of the temperature changes across the shifts in growth direction.

When sampled at half-resolution (i.e. every second sample, c. $1 \mathrm{~mm}$ ), the sequence 

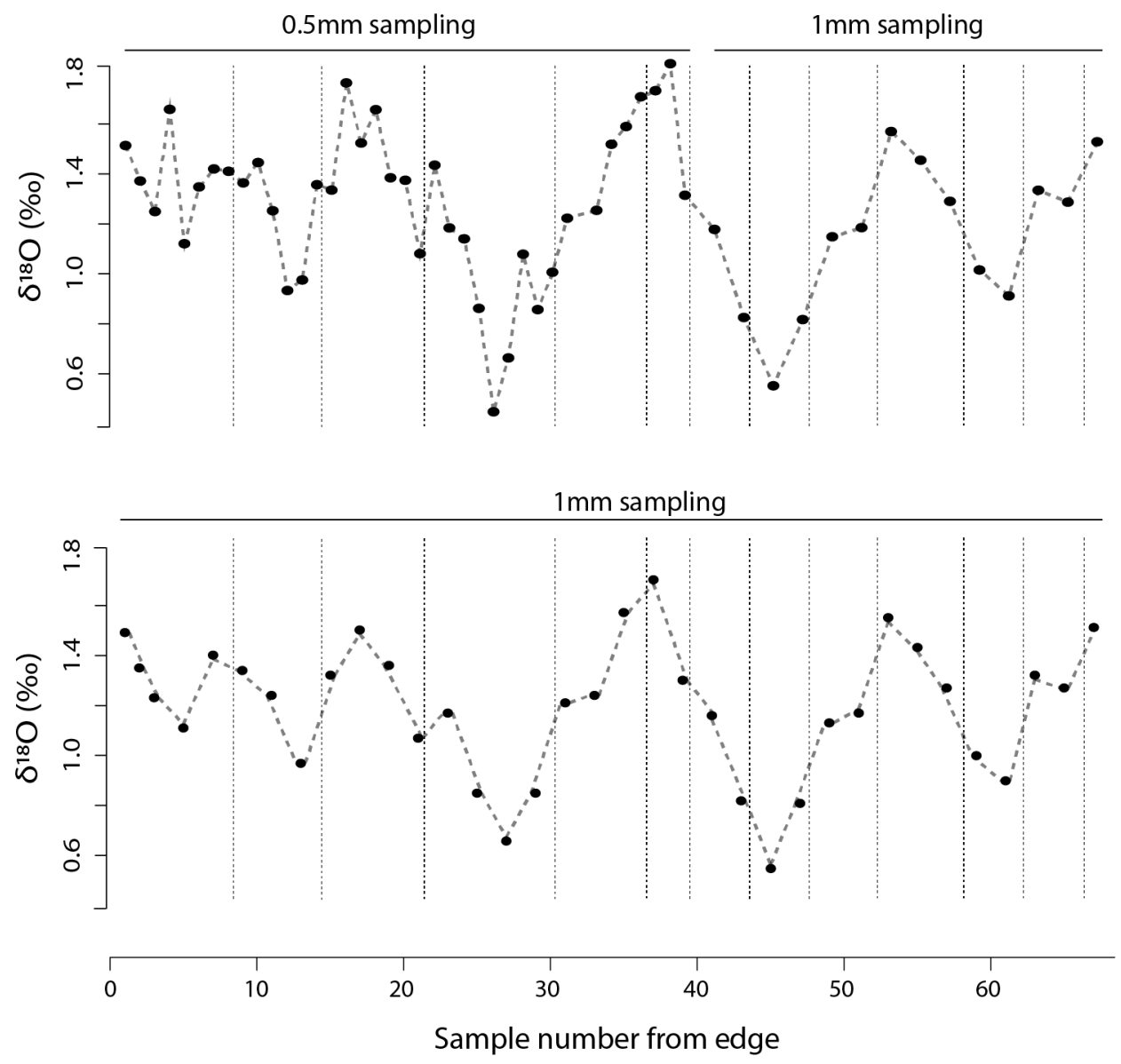

Figure 3.2.4: Series of $\delta^{18} \mathrm{O}$ measurements across one modern operculum from Cape Point, shown with differing sampling resolutions: upper plot shows every sample (c. 0.5 $\mathrm{mm}$ resolution), changing to every second sample after sample 39 (c. $1 \mathrm{~mm}$ resolution), whereas lower plot shows only every second sample throughout. The grey vertical lines indicate the positions where the direction of growth changes and the sampling position was shifted. 
displays the seasonal trends that are evident in the more highly resolved sequence more clearly, especially in the later part of the animal's life, when growth slows markedly. This is promising for processing more shells, as sampling resolution can be reduced. However, a higher resolution record (i.e. samples every c. $0.5 \mathrm{~mm}$ ) displays more detail of the temperature series and may be informative of intra-seasonal temperature variability. Moreover, the higher resolution sampling captures a larger seasonal range of temperatures, and so better reflects the true range of temperatures experienced by the animal.

\subsubsection{Mineralogical and geochemical effects of drilling}

A concern for stable isotope studies are potential mineralogical and geochemical changes induced by shear stress from high-speed rotation of the drill bit. Gill et al. (1995) claimed that samples of aragonitic $\mathrm{CaCO}_{3}$ (from corals) converted to calcite during drilling and consequently $\delta^{18} \mathrm{O}$ values were enriched (although this study was challenged by Swart et al. (1996)). Further studies have explicitly found no effect of micromilling on the $\delta^{18} \mathrm{O}$ value of aragonitic samples (Foster et al., 2008). Some researchers have detected a small effect on the $\delta^{18} \mathrm{O}$ values of micromilled samples when using a Kiel carbonate device for automated $\mathrm{CO}_{2}$ extraction (Tobin et al., 2011). However, the effect is small (-0.1\%o/day) and so can be largely avoided if the sample is not stored in the Kiel device for long periods. A better approach for extracting samples with minimal calcite conversion is almost certainly by crushing or grinding manually, but this would preclude high resolution sampling.

Changes to mineralogy are evident in the FTIR spectra of micromilled opercula samples (see section 3.3.2 for the FTIR-ATR method for detecting recrystallisation). To establish the effect of different speed and rotation settings, samples were micromilled from one modern operculum at a range of different settings (see Table 3.2). To test the consistency of the effect, repeat samples were micromilled adjacent to the first set at the same settings (samples 2, 3, 6 and 8). Possible variations include the drill tip rotation, the scan speed (the speed the drill moves laterally across the sample), the plunge speed (how fast the drill descends through the sample) and the depth to which the sample is drilled. The plunge speed and drilling depth were kept constant at $200 \mu \mathrm{m} / \mathrm{s}$ and $300 \mu \mathrm{m}$ respectively.

FTIR analyses of these samples show varying degrees of recrystallisation to calcite, from below detection levels to almost $50 \%$ conversion at high rotation speeds. This 
Table 3.2: Micromill settings and estimated conversion to calcite according to FTIR analysis.

\begin{tabular}{lccr}
\hline Sample No. & $\begin{array}{c}\text { Drill } \\
\text { speed }(\%)\end{array}$ & $\begin{array}{c}\text { Scan speed } \\
(\mu \mathrm{m} / \mathrm{s})\end{array}$ & $\begin{array}{r}\text { Calcite } \\
\text { conversion }(\mathrm{c} . \%)\end{array}$ \\
\hline 1 & 75 & 60 & $10-15$ \\
$1 \mathrm{a}$ & 75 & 60 & $10-15$ \\
2 & 45 & 60 & $5-10$ \\
$2 \mathrm{a}$ & 45 & 60 & $5-10$ \\
3 & 30 & 40 & $5-10$ \\
4 & 90 & 80 & $>50$ \\
5 & 25 & 40 & $10-15$ \\
$5 \mathrm{a}$ & 25 & 40 & $10-15$ \\
6 & 15 & 40 & $10-15$ \\
7 & 15 & 80 & $5-10$ \\
$7 \mathrm{a}$ & 15 & 80 & $5-10$ \\
8 & 20 & 80 & $10-15$ \\
9 & 40 & 80 & $>50$ \\
\hline \hline
\end{tabular}

indicates that micromilling may be problematic for extracting samples for mineralogical analysis. However, generally the amount of conversion is not extreme, and an important factor is consistency between drill samples. The repeat micromilled samples do show a high degree of replicability in three out of four samples, providing confidence that any effects will be consistent, as long as the drill settings are kept consistent. I chose to keep the rotation and scan speed at $15 \%$ and $80 \mu \mathrm{m} / \mathrm{s}$ respectively. As micromilled samples were intended for oxygen isotope analysis, it is important that micromilling does not cause unpredictable variations in $\delta^{18} \mathrm{O}$ values, although it is difficult to think of a mechanism for substantial isotopic exchange in these circumstances. A series of micromilled samples were taken from within one growth increment (and therefore likely to have very similar $\delta^{18} \mathrm{O}$ values) but at a range of micromill settings (and therefore affected by different degrees of calcite conversion). The $\delta^{18} \mathrm{O}$ values across these samples are similar with low standard deviations of $0.18 \%$ for $\delta^{13} \mathrm{C}$ and $0.22 \%$ for $\delta^{18} \mathrm{O}$, indicating that micromilling does not affect $\delta^{18} \mathrm{O}$ much, or does so predictably (Foster et al., 2008; Gillikin et al., 2005). 


\subsection{3 $\quad \delta^{18} \mathrm{O}$ analyses}

Oxygen and carbon isotope ratios are reported in $\delta$ (delta) notation, in units of parts per thousand (denoted as \%o or permil). These values represent the ratio of the relatively rare heavy isotopes $\left({ }^{18} \mathrm{O},{ }^{13} \mathrm{C}\right)$ to the more abundant light isotopes $\left({ }^{16} \mathrm{O},{ }^{12} \mathrm{C}\right) . \delta$ values are calculated relative to an international reference standard of known isotopic composition, which has been defined as $0 \%$, according to the equation:

$$
\delta_{x}=\left(\frac{R_{x}-R_{s t d}}{R_{s t d}}\right) \times 1000
$$

where $R_{x}$ is the ratio of the abundance of the heavy isotope to the light isotope (e.g. ${ }^{18} \mathrm{O}:{ }^{16} \mathrm{O}$ ) for the sample, and $\mathrm{R}_{\text {std }}$ is that ratio for the known standard. The use of such a standard makes measurements comparable between laboratories and instruments. The $\delta^{18} \mathrm{O}$ values of waters are normally reported relative to the SMOW standard (Standard Mean Ocean Water; Craig, 1961) while those of carbonates are reported relative to PDB (Pee Dee Belemnite) standard. The $\delta^{13} \mathrm{C}$ values of carbonates are also reported relative to $\mathrm{PDB}^{1}$.

$\delta^{18} \mathrm{O}$ of carbonates is inversely correlated to the temperature at which the carbonate precipitated and the potential of oxygen isotope analysis for the reconstruction of palaeotemperatures from marine carbonates was recognised by Harold Urey and students working at the University of Chicago in the 1940's and 1950's. They devised an empirically-based formula which relates to reconstruct the temperature of the growth environment to the $\delta^{18} \mathrm{O}$ value of a marine carbonate (Epstein et al., 1951, 1953; Epstein and Mayeda, 1953).

$$
T\left({ }^{\circ} \mathrm{C}\right)=16.5-4.3\left(\delta^{18} O_{\text {carbonate }}-\delta^{18} O_{\text {water }}\right)+0.14\left(\delta^{18} O_{\text {carbonate }}-\delta^{18} O_{\text {water }}\right)
$$

This equation shows how the other main control on the $\delta^{18} \mathrm{O}$ of biogenic marine carbonates, in addition to temperature, is $\delta^{18} \mathrm{O}_{\text {water }}$, the original isotopic composition of the seawater in which the organisms grew (Urey, 1948; Epstein and Lowenstam, 1953). Thus, it is essential that $\delta^{18} \mathrm{O}_{\text {water }}$ is accurately estimated.

\footnotetext{
${ }^{1}$ Note that VSMOW and VPDB are equivalent to SMOW and PDB respectively
} 
Early palaeotemperature equations like that shown above did not differentiate the fractionation effects between seawater and the different polymorphs of calcium carbonate $\left(\mathrm{CaCO}_{3}\right)$, namely calcite and aragonite. But it was quickly realised that the different forms of $\mathrm{CaCO}_{3}$, and even different taxa of marine organisms, fractionate oxygen isotopes in subtly different ways due to differing bond energies. This is why they require slightly different palaeotemperature equations and there are several empirically derived equations for the different polymorphs of $\mathrm{CaCO}_{3}$, based upon synthetic $\mathrm{CaCO}_{3}$, foraminifera, corals and molluscs. The most widely accepted equation for studies of aragonitic molluscs is that of Grossman and Ku (1986):

$$
T\left({ }^{\circ} \mathrm{C}\right)=20.6-4.34\left(\delta^{18} O_{\text {aragonite }}-\delta^{18} O_{\text {water }}\right)
$$

based on measurements of aragonitic molluscs and foraminifera, where $\delta^{18} \mathrm{O}_{\text {aragonite }}$ is expressed relative to $\mathrm{PDB}$ and $\delta^{18} \mathrm{O}_{\text {water }}$ is relative to SMOW. This equation has been slightly modified to correct for the $0.2 \%$ difference between SMOW and "average marine water" (Hudson and Anderson, 1989):

$$
T\left({ }^{\circ} C\right)=19.7-4.34\left(\delta^{18} O_{\text {aragonite }}-\delta^{18} O_{\text {water }}\right)
$$

It is important to ensure that the most appropriate equation is used: to illustrate, an identical $\delta^{18} \mathrm{O}$ carbonate value converted to temperature using the Grossman and $\mathrm{Ku}$ (1986) equation for aragonite and the "classic" palaeotemperature equation of Epstein et al. (1953) will return a difference in temperature of nearly $4^{\circ} \mathrm{C}$.

A necessary correction is made for ancient shifts in global ocean $\delta^{18} \mathrm{O}$. The isotopic composition of the ocean becomes more enriched in ${ }^{18} \mathrm{O}$ during periods of increased polar ice cover and lowered sealevels, by c. $0.011 \%$ per meter decrease (Shackleton and Opdyke, 1973). In this thesis, the Waelbroeck et al. (2002) global mean ocean $\delta^{18} \mathrm{O}$ curve is used to correct the shell isotope values based upon the archaeological estimates of each shell's age (see section 3.4 for further discussion of local and global seawater $\delta^{18} \mathrm{O}$ variation). 


\section{Measurement systems used in this study}

Well-preserved powder samples (less than 5-10\% calcite) were analysed on one of three instruments (indicated in Tables 5.3; 5.8 and 5.9 of the $\delta^{18} \mathrm{O}$ results): a Kiel Device coupled to a Delta $\mathrm{V}$ Advantage isotope mass spectrometer in the Earth Science Department, University of Oxford (reproducibility of $0.1 \%$ for both $\delta^{13} \mathrm{C}$ and $\delta^{18} \mathrm{O}$ ); an automated Thermo GasBench II device, coupled to a Thermo Delta V Advantage isotope mass spectrometer at the Division of Archaeological, Geographical and Environmental Sciences of the University of Bradford (reproducibility of $0.1 \%$ for $\delta^{13} \mathrm{C}$ and $0.3 \%$ for $\left.\delta^{18} \mathrm{O}\right)$; and a Multiprep prep device coupled to a GV Isoprime isotope mass spectrometer at the National Isotope Geoscience Laboratory (NIGL) of the British Geological Survey, Keyworth (reproducibility of $0.1 \%$ for both $\delta^{13} \mathrm{C}$ and $\delta^{18} \mathrm{O}$ ). In each case $\mathrm{CO}_{2}$ was produced by anhydrous phosphoric acid hydrolysis and the usual corrections were made

for ${ }^{17} \mathrm{O}$, gas-solid fractionation at the appropriate temperature and within-run analytical drift. ${ }^{18} \mathrm{O} /{ }^{16} \mathrm{O}\left(\delta^{18} \mathrm{O}\right)$ results are reported in permil $(\%)$ relative to VPDB. The samples were calibrated against internal standards calibrated in turn to international standards (NBS19: $\delta^{13} \mathrm{C}=1.95 \%$ o $\delta^{18} \mathrm{O}=-2.20 \%$ ) : NBS18 $\left(\delta^{13} \mathrm{C}=-5.014 \%\right.$; $\delta^{18} \mathrm{O}=-23.2 \%$ o $)$ and NBS19 in Oxford; Merck-CaCO3 $\left(\delta^{13} \mathrm{C}=-35.25 \% ; \delta^{18} \mathrm{O}=13.15 \%\right.$ ) and CO-1 $\left(\delta^{13} \mathrm{C}=\right.$ $2.492 \pm 0.030 \% 0 ; \delta^{18} \mathrm{O}=-2.4 \pm 0.1 \%$ ) in Bradford; and Carrera Marble (KCM: $\delta^{13} \mathrm{C}=$ $2.00 \% ; \delta^{18} \mathrm{O}=-1.73 \%$ ) at NIGL.

\subsection{Diagenesis}

Demonstrating the integrity of the original isotopic composition preserved in marine carbonates is critical for palaeothermometry, as carbonate is prone to dissolution and recrystallisation. This is especially true for shells in archaeological contexts with meteoric water filtering through the sediments. Aragonite, a polymorph of carbonate commonly precipitated by molluscs, is less thermodynamically stable than calcite and so aragonitic mollusc shells are prone to conversion to calcite (depending on the depositional environment). During recrystallisation, the original isotopic record may be erased, but without necessarily causing obvious changes to the appearance of the shell. Moreover, recrystallisation can occur patchily across the surface of a shell. The danger then, is that recrystallised carbonate is not distinguished and the measured isotopic values are taken to reflect the original environmental conditions. Moreover, calcite and aragonite have different fractionation factors with water, and so different equations are needed to convert 
the carbonate $\delta^{18} \mathrm{O}$ value to a palaeotemperature value (Tarutani et al., 1969; Grossman and $\mathrm{Ku}, 1986)$. Recrystallisation thus presents a problem for palaeothermometry, but also an opportunity: as calcite and aragonite can be distinguished analytically by various methods, the presence of calcite within a shell of a species known to produce an aragonitic shell is a clear indication of diagenesis. Thus, aragonitic shells, while more prone to recrystallisation than calcitic shells, provide a simple and unambiguous test of preservation. The preservation of the original aragonite thus strongly indicates that the isotopic composition of the shell reflects the original temperature signal.

Below, I discuss the two possible sources of "contamination" when measuring the isotopic values of carbonate materials: organic contamination and recrystallisation of the original carbonate. Section 3.3 describes the pretreatment strategy of this study and section 3.3.2 describes a rapid and simple method for the detection of diagenetic calcite in aragonitic shells using FTIR-ATR. This latter section has been published in a modified form as Loftus et al. (2015).

\subsubsection{Pretreatment for organic contaminants}

Skeletal carbonates naturally contain small amounts of organic material, the protein matrices around which the carbonate skeleton is deposited. Further, carbonates recovered from sedimentary contexts may have incorporated extraneous organic contaminants. The concern is that some of these compounds may form molecules with masses that match those of the $\mathrm{CO}_{2}$ isotopologues $\left(\mathrm{CO}_{2}\right.$ molecules with different combinations of $\mathrm{C}$ and $\mathrm{O}$ isotopes) released from the carbonate sample (i.e. 44 - 46). Moreover, the organic component in theory could react with the phosphoric acid used to liberate carbon dioxide from carbonate samples, and also produce carbon dioxide or other gases (Epstein et al., 1953). Concerns such as these have led researchers to employ roasting and chemical (oxidation) methods to remove organics, but there has been little consistency in approach over the years and published studies have not routinely reported pretreatment in adequate detail.

However, pretreatment can bias palaeotemperature reconstructions: various studies show that all of the commonly used pretreatment strategies, tested across a range of marine biocarbonates, affect geochemical signatures, including stable isotopes and trace element ratios, in unexpected ways (Boiseau and Juillet-Leclerc, 1997; Watanabe et al., 2001; Grottoli et al., 2005; Keatings et al., 2006; Wierzbowski, 2007; Serrano 
et al., 2008). Moreover, these commonly used methods may not even be very successful at removing organic contaminants (Sarkar et al., 1990; Grottoli et al., 2005; Dauphin et al., 2006; Keatings et al., 2006). Indeed, removal of organics may not be necessary as the small organic component of skeletal carbonate (including that of molluscs) does not appear to affect isotope measurements (Sarkar et al., 1990; Grottoli et al., 2005; Wierzbowski, 2007). Typical organic compounds such as chitins and proteins will not oxidise with the standard acid hydrolysis methods used to release $\mathrm{CO}_{2}$ from carbonates. Although it is still standard practice to clean and pretreat samples, with a number of accepted methodologies, researchers are increasingly recognising that pretreatment may be unnecessary, and that it may do more harm than good. Even minor effects may be interpreted as apparently significant temperature fluctuations, given the sensitivity of the palaeotemperature equations (i.e. $1 \% 0=$ c. $4^{0} \mathrm{C}$ ).

\subsubsection{Cleaning and pretreatment strategies used in this study}

To minimise chemically induced alteration of the original stable isotope signal, cleaning and pretreatment methods were kept as simple as possible for both modern and archaeological shells. To remove the flesh and operculin from modern shells, opercula were soaked in distilled water overnight and then the softened organics were scraped away using a plastic spatula to avoid damaging the surface growth lines. This method does not entirely remove the operculin staining but more aggressive methods (with metal implements or a slow rotary drill) obscure the growth lines. Importantly, the operculin staining does not extend deeper than the immediate surface. Soaking the opercula in water may nevertheless affect the oxygen isotope values. Grottoli et al. (2005) found that soaking powdered carbonate samples in distilled water for 24 hours lowered the $\delta^{18} \mathrm{O}$ values by on average $0.06 \%$. This would cause an error of approximately $0.25^{\circ} \mathrm{C}$ in the reconstructed temperature. However, I soaked the whole shells, not the powder, which would cause a smaller effect, as there is less surface contact between the carbonate crystals and the water and so fewer opportunities for isotopic exchange.

The archaeological samples come from a number of sites, and have been treated differently after excavation by the various archaeological and conservation teams. It is a reasonable assumption that at most sites the shells were rinsed with water to remove adhering dirt, although this is not true of all the sites (for example, at Hoffman's/Robberg Cave). Where there was sediment or staining of the shell surface, a toothbrush and distilled water were used to lightly scrub the drilling area. In some instances, I used a 
handheld drill to lightly scour encrusted dirt from the sampling area. After micromilling, the powdered samples were not pretreated further. In addition to the considerations described above, namely how chemical pretreatments a.) are often unnecessary, b.) often ineffective and c.) may alter the original geochemical values unpredictably, a formidable problem for pretreatment of high-resolution samples is the sample loss incurred by repeated rinsing of the powdered sample. An individual micromilled powder sample is typically c. $0.5 \mathrm{mg}$ and pretreatment, including multiple washes would guarantee the complete loss of many samples. However, individual micromilled samples were assessed for recrystallisation as this is likely to be the major cause of diagenesis and altered $\delta^{18} \mathrm{O}$ values.

\subsubsection{FTIR analyses for recrystallisation}

The two common carbonate polymorphs, aragonite and calcite, are easily distinguishable using standard crystallographic methods such as powder X-ray diffractometry (pXRD), cathodoluminescence microscopy, Raman spectroscopy, scanning electron microscopy (SEM) and Fourier transform infrared spectrometry (FTIR). However, most of these techniques require relatively large amounts of sample material and analysis can be expensive and complex. Consequently, assessments of recrystallisation are not performed routinely on large numbers of shells, but rather results of a few high-precision measurements from a small number of shells are extrapolated to an entire assemblage. But this approach is not appropriate where variation in preservation within a site is expected. The extent of diagenesis can vary considerably across the site and even within an individual shell. Conversely, FTIR with an attenuated reflectance attachment (ATR) is quick and simple, and requires only a relatively small powder sample, allowing for much greater spatial resolution.

FTIR utilises mid-infrared radiation (c. $4000-400 \mathrm{~cm}^{-1}$ ) to study the vibrational characteristics of molecules, which are related to the molecular structure of the material. Different molecules absorb specific frequencies of IR light, depending on the particular vibrational frequencies of atomic bonds. Consequently, FTIR can provide information on the structural differences between polymorphs of the same mineral e.g. $\mathrm{CaCO}_{3}$. The discrimination of pure calcite and aragonite is relatively straightforward using FTIR, as the two polymorphs have quite different vibrational characteristics and present clearly different spectra (see Figure 3.3.1). But despite some early studies showing the utility of FTIR for determining calcite:aragonite ratios in shells (Louisfert and Pobbequin, 1952; 
Adler and Kerr, 1962; Compere and Bates, 1973), FTIR is not a widely used method for detecting recrystallisation in archaeological shell. Until recently the most common FTIR method required time-consuming preparation of samples whereby sample powder was mixed with potassium bromide $(\mathrm{KBr})$ powder and pressed into a pellet under high pressure. Further, FTIR methods are not considered very reliable at quantitatively distinguishing polymorphs with extensive peak overlap, such as calcite and aragonite (Dickinson and McGrath, 2001). Thus, the method has generally been used to provide only qualitative estimates of composition, and may feature as an initial step in a series of more in-depth analyses. Where FTIR has been used to detect mineralogical changes in studies of archaeological shell, the results are typically not reported in any detail (e.g. Slack et al., 2004; Lange et al., 2008; Faylona et al., 2011). For qualitative estimates of calcite:aragonite, XRD and SEM analyses are typically preferred.

Advances in the field of FTIR spectroscopy, however, have improved the possibilities for using FTIR techniques in a more quantitative manner in archaeology (for nonarchaeological applications of binary mixture compound and polymorph detection see e.g. Helmy et al., 2003; Jasco; Planinsek et al., 2006; Gulley-Stahl et al., 2009). ATR attachments for FTIR spectrometers allow materials to be analysed directly in solid form, without having to produce $\mathrm{KBr}$ pellets. Sample powder is simply placed onto the ATR crystal (more properly, the internal reflection element), and a high pressure (up to 30 $000 \mathrm{psi}$ ) is evenly applied to the sample via a pressure clamp. With the single reflection method, the infrared beam is directed through the ATR crystal and bounced once off of the internal surface of the crystal. This results in an evanescent wave that penetrates a short distance $(<2 \mu)$ into the overlying sample, and the spectra is collected as the beam leaves the crystal. A sample spectrum can be collected within a few minutes, with minimal instrument set up and changeover time between samples. Because no extensive preparation is required, samples can be processed and analysed much more rapidly using FTIR-ATR than traditional FTIR techniques. Importantly, the sample material can be recovered after analysis, allowing for other types of analysis on the same powder sample. This allows researchers to analyse samples where only a very small amount of material is available, extending the technique to materials which previously would not have been analysed at all. Finally, the complex preparation methods required for traditional FTIR instruments introduce variability into the system, and so measurements using FTIR-ATR may have improved reproducibility over other types of FTIR. Because of these advantages, ATR is now the most common technique in infrared spectroscopy (Griffiths and de Haseth, 2007). 
Arguably, powder XRD (pXRD) is a more precise and accurate analytical technique for detecting calcite contamination, as detection and quantification limits for calcite can be as low as $0.2 \%$ and $1 \%$ respectively (Reimer et al., 2006). However, the instrumentation is expensive and not readily available in most archaeological science laboratories. Analysis of the results is complex, requiring specialist curve-fitting software and extensive training. The method requires substantially larger sample sizes than FTIR-ATR, of at least $8 \mathrm{mg}$ and more typically c. $300 \mathrm{mg}$, which can be a serious limitation for archaeological studies such as the present one. Additionally, to achieve such high detection and quantification limits with pXRD of biogenic samples, time-consuming pretreatment protocols must be applied, to tackle problems of preferred orientation, sample heterogeneity and crystallinity variance (e.g. Douka et al., 2010; FTIR-ATR and pXRD analyses of calcite:aragonite mixtures are compared below). For this study, where only relatively large amounts of calcite contamination need to be detected (i.e. $>5-10 \%$ ), a faster and simpler method is preferable.

\subsubsection{Experimental method}

To establish a calibration set with which to compare unknown samples, a series of artificial mixtures of with varying amounts of pure calcite and aragonite were analysed. Ideally, the calibration calcite and aragonite sources should be as similar (in terms of crystallinity, impurities, etc.) to the sample (i.e. archaeological shell) as possible. While the aragonitic portion of the mixture is straightforward (modern shell), the "recrystallised" calcite portion presents more of a problem. Two calibration sets were compared, one which used highly crystalline, very pure Iceland spar (geological calcite) for the calcite proportion, and another which used less crystalline, and potentially heavily substituted biogenic calcite derived from an oyster shell (Crassotrea gigas). The two calibration sets match each other well, although there are small differences evident in relative peak height. Birefringent Iceland spar is very pure and highly anisotrophic (it displays a strong preferred orientation of the crystalline direction), a property which can affect peak height ratios (Spragg, 2011). The biogenic calcite (oyster shell), composed of high-Mg calcite, may not be a perfect analogue for diagenetically recrystallised low-Mg calcite found in archaeological sources, but it is likely to match better than Iceland spar in terms of crystallinity and purity. For this reason, the artificial mixtures composed of modern aragonitic shell and modern oyster shell were used as the primary calibration set. 
Samples were measured on an Agilent Cary 640 with a GladiATR Single Reflection ATR accessory by PIKE Technologies. Each individual spectrum is comprised of 64 scans, measured at $4 \mathrm{~cm}^{-1}$ resolution. Each artificial mixture was measured in triplicate, with different aliquots and non-sequentially, and an average value was calculated. After every three spectra measured, a background measurement was taken, to remove the spectral effects of accumulating carbon dioxide and water vapour in the laboratory. Upon measurement, each spectrum is shifted downwards to a baseline using the Varian Resolutions Pro software. Baseline corrections are kept consistent across all samples as they may affect relative (i.e. peak ratio) and absolute absorbance values - the same four baseline correction points were selected for all measured samples and calibration standards, at c. $500 \mathrm{~cm}^{-1}, 1800 \mathrm{~cm}^{-1}, 3650 \mathrm{~cm}^{-1}$ and $4000 \mathrm{~cm}^{-1}$. For analysis, all spectra were normalised to the highest peak.

The five major peaks of aragonitic $\mathrm{CaCO}_{3}$ are a double peak at 711 and $700 \mathrm{~cm}^{-1}(\mathrm{u} 4$, C-O in-plane bending); a mid-size peak at $856 \mathrm{~cm}^{-1}$ (u2, out-of-plane bending); a weak peak at $1082 \mathrm{~cm}^{-1}(\mathrm{u} 1$, symmetrical stretching); the strongest peak centred c. 1454 $\mathrm{cm}^{-1}\left(\mathrm{u} 3\right.$, asymmetrical stretching) and another weak peak at $1785 \mathrm{~cm}^{-1}$ (a combination of $\cup 1$ and $\cup 4$ ). In calcite, similar peaks occur, with the exception of $v 1$ at $1082 \mathrm{~cm}^{-1}$, and u4 occurs only as a single peak at $711 \mathrm{~cm}^{-1}$. Others are slightly offset: $u 2$ at $875 \mathrm{~cm}^{-1}$, the combined $\cup 1$ and $\cup 4$ at $1793 \mathrm{~cm}^{-1}$, and the major $\cup 3$ peak at $1411 \mathrm{~cm}^{-1}$. However, because the two peaks are comparatively broad, there is a great deal of overlap between these two in this region (see Figure 3.3.1).

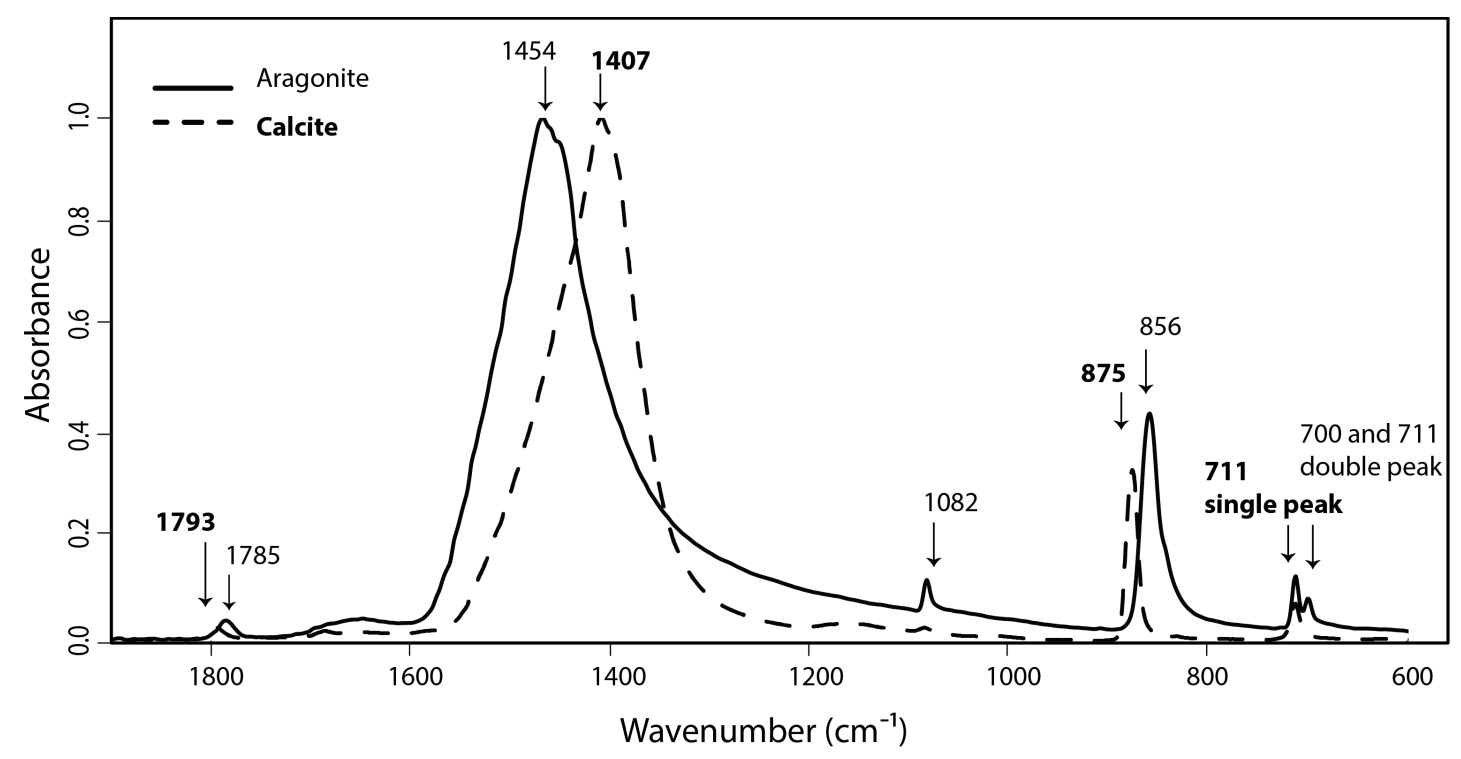

Figure 3.3.1: FTIR spectra $\left(400-2000 \mathrm{~cm}^{-1}\right)$ of aragonite (green) and calcite (brown) with peak positions labelled. 


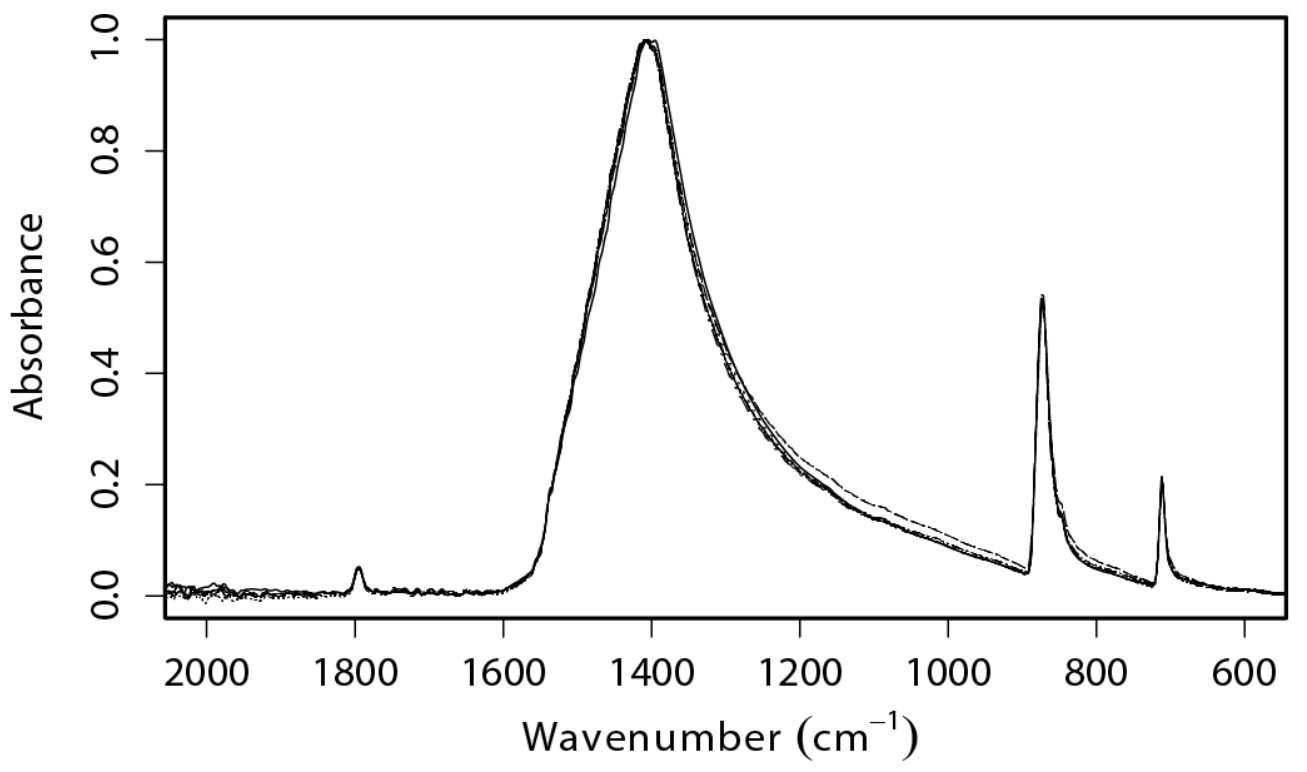

Figure 3.3.2: Eight replicate measurements of FTIR spectra of 100\% Iceland spar.

Reproducibility is difficult to quantify with spectroscopic methods, particularly with FTIR-ATR, where numerous small factors change from measurement to measurement the baseline correction points used, the background atmosphere in the laboratory, the height of the major absorbance peak (which varies according to the amount of pressure applied, and the amount of sample powder). While there are best practice guidelines for minimising this type of variability, two identical samples may be slightly vertically offset at some regions of the spectra (after normalisation). However, repeated measurements of samples in this study, both within and between measurement runs, show a high degree of reproducibility within a single measurement system. Figure 3.3.2 shows eight measurements of $100 \%$ Iceland spar, measured over three separate days. The graph shows how consistent the peak height and shape of the normalised spectra are. The most variation across samples is evident in the slope of the highest peak, between c. $1300-1000 \mathrm{~cm}^{-1}$, which may be due to the background and to structural features of the crystals unrelated to the differences between calcite and aragonite. Nevertheless differences in this region should be interpreted cautiously.

The accuracy of this method is supported by a small number of paired FTIR and pXRD measurements on calcite and aragonite samples (see also section 3.3.2.2 below). Six mixtures, of geological aragonite with varying but known amounts of calcitic "contamination" (Iceland spar), were weighed out and homogenised (geological sources of $\mathrm{CaCO}_{3}$ were necessary as $>300 \mathrm{mg}$ of powder was required for the pXRD analyses). The samples were analysed at the Cranfield Forensic Institute of Cranfield University by 
Table 3.3: FTIR-ATR and pXRD analyses of calcite:aragonite mixtures compared.

\begin{tabular}{lcc}
\hline \% calcite & $\begin{array}{c}\text { FTIR-ATR } \\
\text { estimate }(\%)\end{array}$ & $\begin{array}{c}\text { XRD } \\
\text { estimate }(\%)\end{array}$ \\
\hline 0 & 3 & - \\
5 & 5.4 & 8.4 \\
7.5 & 8.0 & 11.8 \\
10 & 9.5 & 16.1 \\
15 & 13.5 & 19.6 \\
\hline \hline
\end{tabular}

Prof. Keith Rogers and quantification was undertaken using whole pattern, standardless analysis, i.e. the values are derived entirely from a modelling approach to the data. More accurate estimates can be obtained with more time-consuming methods but these are not routinely undertaken for studies of archaeological shells. The estimates for the FTIR analyses were calculated by comparison with the calibration curves discussed below (3.3.2.2). Table 3.3 shows the estimates of calcite derived from the two methods. Both methods correctly establish the relative amounts of calcite, but the pXRD measurements systematically overestimate the amount of calcite in the sample. The FTIR-ATR measurements predict the actual proportions to within a few per cent, an accuracy sufficient for most palaeoenvironmental applications.

\subsubsection{Data analysis}

Two analytical methods for establishing the proportion of calcite in an archaeological sample were explored: i) by plotting linear least squares models to the calibration data of peak height ratios and comparing the set of peak ratios of an unknown sample, and ii) by graphically comparing the entire (i.e. $400-4000 \mathrm{~cm}^{-1}$ ) spectrum of an unknown sample to multiple spectra of different artificial calibration mixtures.

Calibration curve "Calibration curves" were constructed by plotting the ratio of absorbance values at two peaks against the percentage of calcite in the sample. Some problems arise because of the substantial overlap of the major peaks of calcite and aragonite - contributions from a major component in the calibration mixture can contribute to the peak height of the minor component, forcing that peak higher. However, the method does provide a good estimate of calcite contamination and the $\mathrm{R}^{2}$ values of 
peak height ratios (of the artificial mixes of calcite and aragonite) against the percent calcite in the mixture is generally above 0.9 . These calibration curves can be used to estimate the proportion of calcite in an archaeological shell. Figure 3.3.3 shows five of the calibration curves with the best $\mathrm{R}^{2}$ values. These peak ratios are better at consistently predicting the amount of calcite in shells than others and several of the calibration curves appear to be more sensitive than others to small fluctuations and differences. This typically leads to a very wide range of estimates for each sample. However, the five calibration curves shown in Figure 3.3.3, namely 1411:1785; 875:1785; 875:700; 875:711; and 1794:1785, consistently provide estimates that support the others, and which are in line with comparisons of peak shape (see below). Using these five peak ratios together provides more robust assessments of recrystallization. 

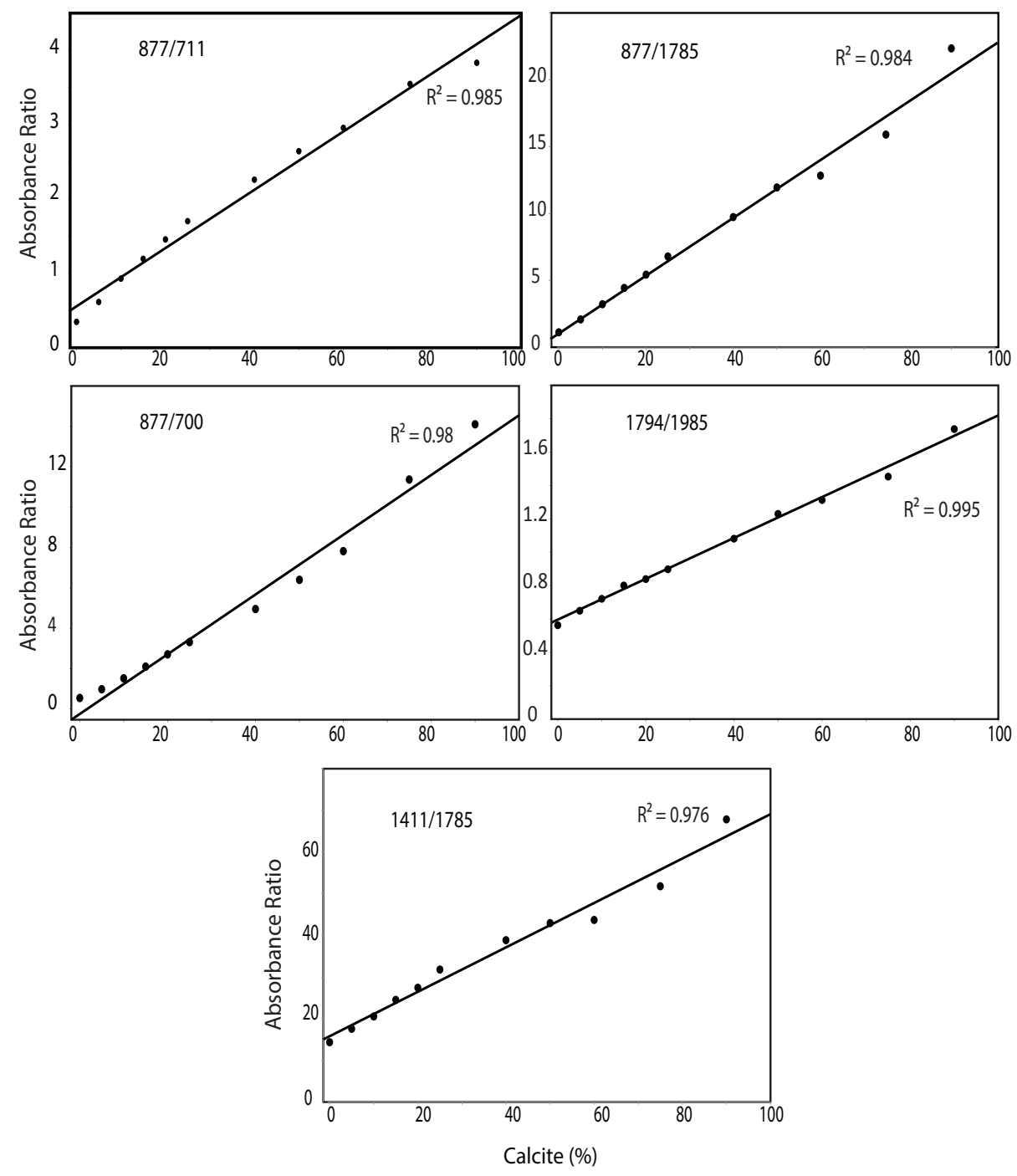

Figure 3.3.3: Ratios of five aragonite and calcite peaks against the ratio of calcite in each sample, with the $\mathrm{R}^{2}$ value for each calibration curve.

Peak shape In addition to calculating the peak height ratios, the shapes of the different peaks are diagnostic of the calcite:aragonite ratio of the sample. I established the reliability of the peak shapes by measuring the spectra of a series of artificial mixtures of calcite and aragonite, with several sources of calcite and aragonite (see Table 3.4).

Figure 3.3.4 shows five peak regions of the ground oyster and ground modern aragonite shell calibration set described above. Note that not all of the mixtures are shown for clarity. This method is not dependent on the peak height at a particular wavenumber, but rather enables the assessment of areas where there is substantial peak overlap, as is the case between calcite and aragonite. For example, observe Figure 3.3.5 which shows 
Table 3.4: Sources of calcite and aragonite used in calibration mixtures.

\begin{tabular}{lll}
\hline Mixture & Aragonite & Calcite) \\
\hline CP Two: Iceland spar & Modern shell (biological) & Geological \\
CP Two: calcite rhomb & Modern shell (biological) & Geological \\
Morocco orange: Iceland spar & Geological & Geological \\
Cuttlefish: Iceland spar & Modern cuttlefish (biological) & Geological \\
CP One: oyster & Modern shell (biological) & Modern shell (biological) \\
CP Two: oyster & Modern shell (biological) & Modern shell (biological) \\
\hline \hline
\end{tabular}

the full calibration set for the region between 800 and $900 \mathrm{~cm}^{-1}$. Here pure aragonite has a peak at $856 \mathrm{~cm}^{-1}$ and pure calcite has a peak at $875 \mathrm{~cm}^{-1}$, but there is considerable peak overlap and a visual assessment of the region is useful for determining percentage composition. Visual assessments also help assess the calcite percentage for the major peaks at $1454 \mathrm{~cm}^{-1}$ (aragonite) and $1407 \mathrm{~cm}^{-1}$ (calcite), as these peaks are used to normalise the entire spectra, and so the absorbance value is artificially set to 1 . In addition, there is substantial flattening of the spectra of the mixtures between these wave numbers, resulting in little variation in absorbance (i.e. note the spectrum for the $20 \%$ calcite mixture in the lower left plot of Figure 3.3.4), and thus little effect on calibration curves. 

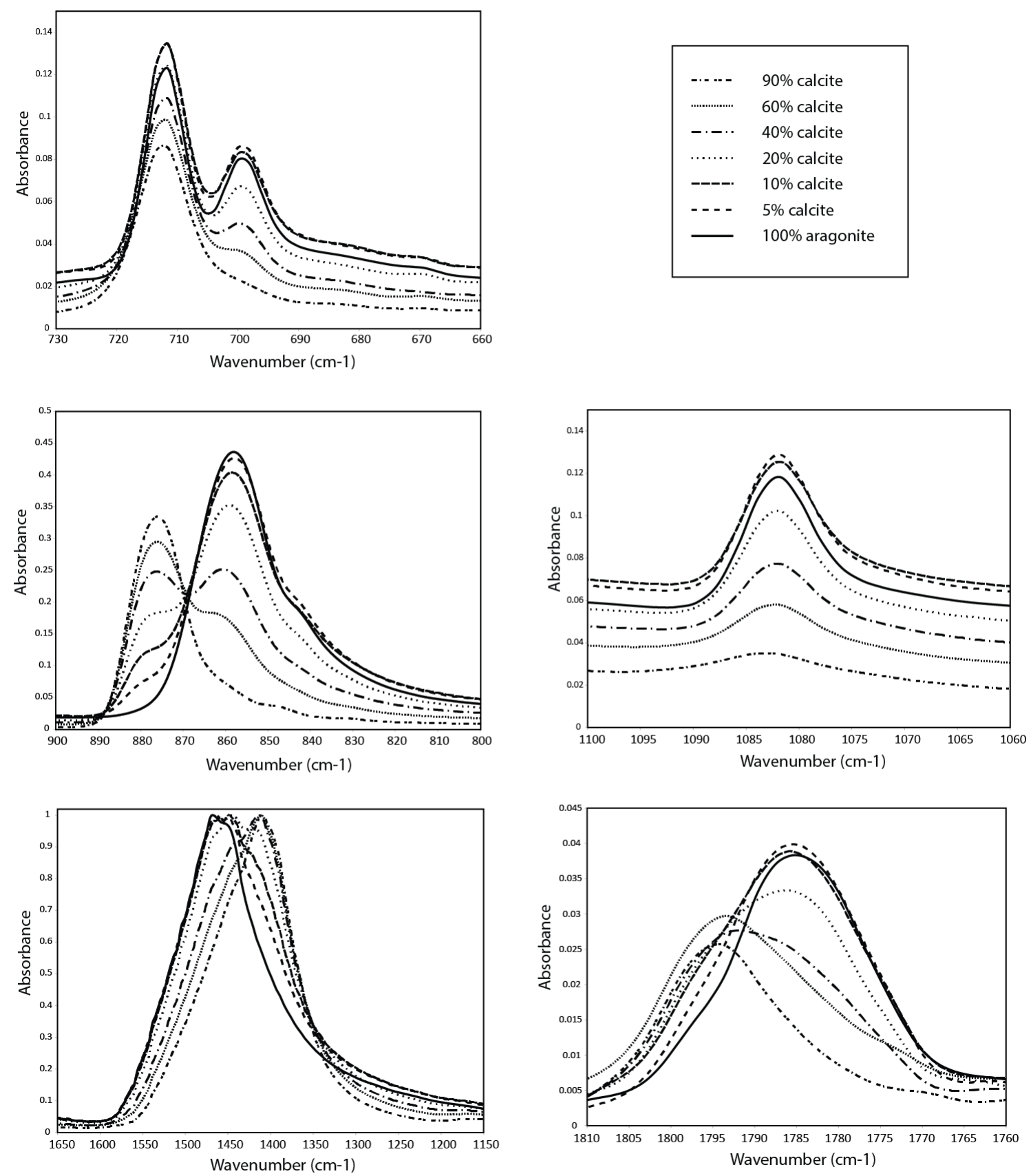

Figure 3.3.4: All peaks for the half the calibration set composed of artificial mixtures of ground oyster shell (calcite) and aragonitic Turbo sarmaticus shell. 


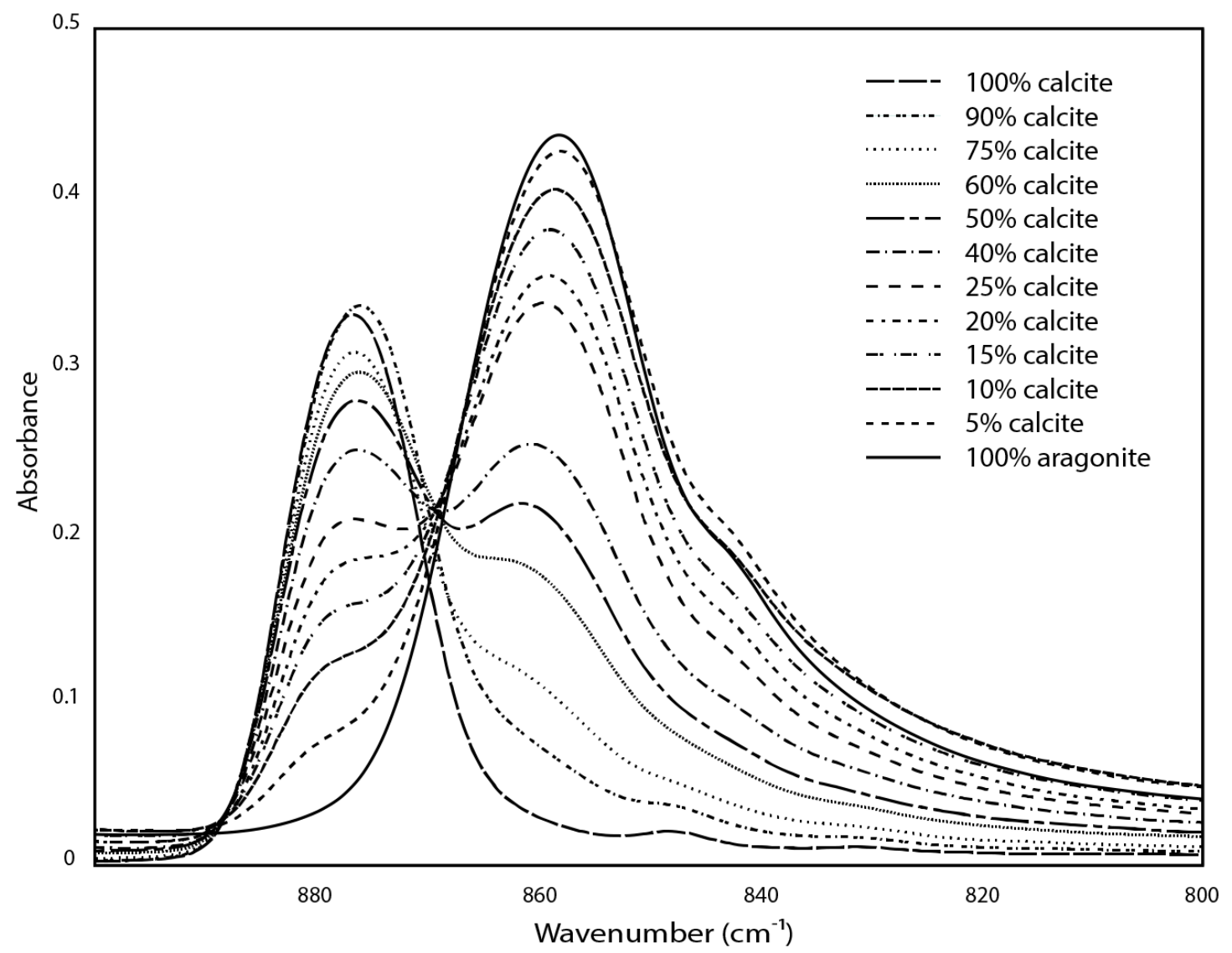

Figure 3.3.5: FTIR spectra between $800-900 \mathrm{~cm}^{-1}$ for the complete calibration set composed of artificial mixtures of ground oyster shell (calcite) and aragonitic Turbo sarmaticus shell.

FTIR is a useful method for quickly establishing the viability of a particular shell sample for stable isotope analysis without sacrificing the powdered sample. The advantages of sample size and the rapidity and ease of analysis make it preferable to more intensive and accurate methods of establishing calcite percentage in many circumstances. For the diagenetic assessment of archaeological samples, every fourth or fifth micromilled powder sample in a series was evaluated against the calibration dataset, as small scale changes in carbonate preservation, on the order of a few millimetres, were observed across the surface of opercula. Thus, this method allows for a highly spatially resolved assessment of diagenesis, rather than the common practice of taking only a single sample from a shell, or even from a depositional context, and extrapolating the results across the entire set of samples. 


\subsection{Seawater $\delta^{18} \mathrm{O}$ variability}

The palaeotemperature equation to reconstruct SSTs from carbonate $\delta^{18} \mathrm{O}$ requires two inputs - the $\delta^{18} \mathrm{O}$ value of the carbonate sample and the $\delta^{18} \mathrm{O}$ value of the water from which the carbonate precipitated. The oxygen isotope composition of the oceans varies substantially both over space and time at a number of scales and moreover this value is usually not directly measurable for palaeotemperature studies and so must be estimated. Yet, for the Grossman and $\mathrm{Ku}$ (1986) palaeotemperature equation, a change of $1 \% 0$ in seawater $\delta^{18} \mathrm{O}$ leads to an approximately $4{ }^{\circ} \mathrm{C}$ difference in temperature. It is thus vitally important to estimate the past $\delta^{18} \mathrm{O}$ of the seawater as accurately as possible, for each particular proxy record.

Reasonable estimates of $\delta^{18} \mathrm{O}$ have been derived for the global oceans back through the Holocene and Pleistocene via analyses of marine sediment deposits (Shackleton, 1967; 1987), and a 10m increase in sea level (a proxy for global ice volume) accords to a $0.11 \%$ increase in $\delta^{18} \mathrm{O}$ of the global ocean (Shackleton and Opdyke, 1973). In this study, I rely upon the comprehensive dataset of Waelbroeck et al. (2002), based on six globally-distributed deep-sea foraminifera cores, to correct for global variations in $\delta^{18} \mathrm{O}$ across glacial-interglacial timescales (see Figure 2.1.4). This study provides estimates of global seawater $\delta^{18} \mathrm{O}$ in 1500 year timesteps, a greater resolution than other similar studies (e.g. Shakun et al., 2015). For the LSA samples, the age resolution of these correction data is thus greater than the age estimates of the samples themselves, and so the errors incurred by correction are simply those of the Waelbroek data points. However, for the MSA samples, especially those from PP5-6, where deposits span rapid changes in $\delta^{18} \mathrm{O}$ at the MIS5/4 transition, the age ranges of the samples can span several estimates of global seawater $\delta^{18} \mathrm{O}$, and so the associated errors for correction are larger, equivalent to nearly $1.5{ }^{\circ} \mathrm{C}$ for some levels, although typically much less (see Tables 5.2, 5.6 and 5.7 in Chapter 5 for the corrections made to each shell).

Use of the Waelbroeck correction assumes that long-term changes in the Agulhas Current system correspond with global patterns. However, a possibly greater concern is regional and local-scale variability, which is typically not well-constrained even over modern timescales (Rohling, 2000). Outside of the polar regions, global patterning in seawater $\delta^{18} \mathrm{O}$ is driven largely by the evaporation-precipitation balance and inputs of freshwater

such as spring melt and large rivers. Previous studies of palaeotemperature from the South African coast have assumed that seasonal and geographic variation is negligible (Shackleton, 1973; Cohen and Tyson, 1995; Galimberti, 2010), but there are very few 
data describing coastal $\delta^{18} \mathrm{O}$ variation in this region. Several factors may influence coastal $\delta^{18} \mathrm{O}$ variability, including seasonal freshwater run-off from rainfall or rivers, evaporative flux and seasonal upwellings. However, the southern Cape region today does not have rivers sufficiently large to substantially affect coastal $\delta^{18} \mathrm{O}$ and past shifts in rainfall are unlikely to have dramatically altered the run-off regime. Moreover, the open coastline and generally high energy wave action along the coast ensure thorough mixing of water sources at most locations. Thus, it is not unreasonable to assume minimal spatial and seasonal variation, although there are little data exploring isotopic variability for the South African coastline. Ecological studies (e.g. Hill et al., 2006; Hill and McQuaid, 2008; Allan et al., 2010) have measured $\delta^{13} \mathrm{C}$ and $\delta^{15} \mathrm{~N}$ along the South African coastline and observed biogeographical and temporal geochemical variation, including effects of the upwelling cells, that is subsequently translated into the hard tissues of molluscs. This suggests that nutrient sources vary along the coast, but there is little information for $\delta^{18} \mathrm{O}$. As part of an exploratory study into the utility of certain mollusc species for palaeotemperature, Talma et al. (1992) measured seawater $\delta^{18} \mathrm{O}$ at fifteen locations along the entire South African coastline and observed an average value of $0.6 \pm 0.15 \%$, with no clear geographic trends. Galimberti (2010) measured seawater $\delta^{18} \mathrm{O}$ at the site of Pinnacle Point approximately once a month spanning April to August and observed a limited range of $\delta^{18} \mathrm{O}$ values $(0.42 \%$ to $0.60 \%$ ). But this range excludes one extreme outlier, which cannot be readily dismissed as attributable to instrumental error, as the deuterium isotope measurement was consistent with the others (M. Galimberti, pers. comm.). These samples were all collected in winter and so do not permit assessment of seasonal variation, potentially the timescale of greatest variability along this coast.

Specifically to explore the possible influence of wind-driven upwelling for seawater $\delta^{18} \mathrm{O}$ variability I undertook limited sampling at locations and times where upwelling was occurring. Eleven samples were taken from well-flushed, high-energy locations on eleven different beaches, spanning the coast from Jeffreys Bay to Pinnacle Point. Unfortunately, sampling was not undertaken further west due to time constraints, and so information is not available for the coast near Byneskranskop 1. The samples were kept in 50 $\mathrm{ml}$ plastic centrifuge tubes and completely filled to the top to prevent evaporation and isotopic exchange with the air in the bottle (Kendall and Caldwell, 1998). The samples were equilibrated with $\mathrm{CO}_{2}$ using disposable pre-evacuated $7 \mathrm{ml}$ glass vials and the fractionation factor between $\mathrm{CO}_{2}$ and water at $25^{\circ} \mathrm{C}$ was assumed to be 1.0412 (Coplen, 1993). Oxygen isotope ratios were measured at the University of Cape Town Archaeology Department, on a DeltaXP dual-inlet gas source mass spectrometer. The 
Table 3.5: Stable isotope values of seawater samples collected along the south coast of South Africa.

\begin{tabular}{llrrr}
\hline & Site & Date collected & $\delta D(\%)$ & $\delta^{18} O(\%)$ \\
\hline 1 & Dana Bay (Mossel Bay) & $28 / 11 / 2013$ & 7.98 & 0.64 \\
2 & Santos Bay (Mossel Bay) & $28 / 11 / 2013$ & 5.97 & 0.55 \\
3 & Myoli Beach (Sedgefield) & $28 / 11 / 2013$ & 5.17 & 0.53 \\
4 & Lookout Beach (Plettenberg Bay) & $28 / 11 / 2013$ & 8.32 & 0.49 \\
5 & Klasies River & $01 / 12 / 2013$ & 7.00 & 0.61 \\
6 & Jeffreys Bay & $02 / 12 / 2013$ & 6.13 & 0.24 \\
7 & Pinnacle Point & $17 / 12 / 2013$ & 5.29 & 0.23 \\
8 & Witsands, Robberg Peninsula & $18 / 12 / 2013$ & 8.47 & 0.49 \\
9 & Robberg Beach & $18 / 12 / 2013$ & 6.18 & 0.07 \\
10 & Tsitsikamma Nature Reserve & $19 / 12 / 2013$ & 5.39 & 0.20 \\
11 & Noetzie Beach (Knysna) & $20 / 12 / 2013$ & 6.15 & 0.26 \\
\hline \hline
\end{tabular}

long-term average difference between duplicates of internal water standards on this system is $0.10 \%$ for oxygen.

These preliminary measurements suggest that there may be sufficient intra-annual variability to affect temperature reconstructions (see Table 3.5). $\delta^{18} \mathrm{O}$ values range from $0.07 \%$ to $0.64 \%$ o (mean $=0.39 \pm 0.19 \%$ ), a range of $0.57 \%$ o which translates to an approximately $2.5^{\circ} \mathrm{C}$ difference in reconstructed temperature. Notably, samples 8 and 9 were taken on the same day, from different sides of the Robberg Peninsula headland, and they differ by c. $0.4 \%$. Interestingly, the lower values seem to correspond with upwelling events occurring at the sampling location, as seen in satellite SST imagery (provided by Jean Pierre Arabonis of Ocean Satellite Imaging Systems - www.osis.co.za). If correct, this suggests that the frequency of summer wind-driven upwellings could affect the average seasonal values of seawater $\delta^{18} \mathrm{O}$. This phenomenon would suppress the magnitude of upwelling-induced SST shifts recorded in a carbonate temperature proxy, as cooler SSTs are accompanied by lower $\delta^{18} \mathrm{O}$ values, that lead to warmer reconstructed SSTs if not corrected. Certainly, future work on deriving seasonal SST records from molluscs will benefit from more in depth assessments of seawater $\delta^{18} \mathrm{O}$ variability, both throughout the year and in more detail along the coast, and alternative measures of oceanographic conditions, including $\delta^{13} \mathrm{C}$ and trace elements, should be utilised. 


\section{Chapter 4}

\section{Chronology of Nelson Bay Cave and Byneskranskop 1}

\section{Contents}

4.1 Introduction .................... 78

4.2 Previous chronological research . . . . . . . . 79

4.2 .1 Nelson Bay Cave . . . . . . . . . . . . . . . . . 79

4.2 .2 Byneskranskop $1 \ldots \ldots$. . . . . . . . . . . 80

4.3 Materials and methods ............... 80

4.3.1 Principles of radiocarbon dating . . . . . . . . . . 80

4.3 .2 Materials .................. 86

4.3.3 Laboratory Methods . . . . . . . . . . . . . . . 86

4.4 Results ..................... 88

4.4 .1 Nelson Bay Cave . . . . . . . . . . . . . . . . 88

4.4 .2 Byneskranskop $1 \ldots \ldots$. . . . . . . . . . . . . . 92

4.5 Bayesian models and discussion . . . . . . . . . 95

4.5.1 Nelson Bay Cave . . . . . . . . . . . . . . . . . . . 95

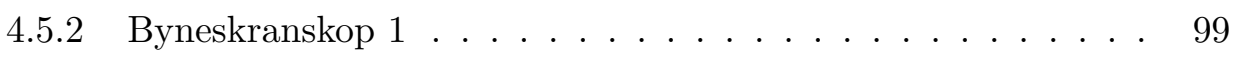

4.5.3 Correspondence with the overall southern African LSA chronology . . . . . . . . . . . . . . . 102

4.6 Conclusions ......................... 105 
This chapter revises the chronologies of two Later Stone Age sites, Nelson Bay Cave (NBC) and Byneskranskop 1 (BNK1), based on a suite of new AMS radiocarbon dates and Bayesian modelling techniques. A brief background to the radiocarbon method and previous dating efforts at the two sites is provided for context (see section 2.2.2 for a fuller description of both sites). The implications of the new chronologies for regional interpretations of technological change are briefly discussed, with potential further avenues of research.

\subsection{Introduction}

The Southern African Later Stone Age is characterised by a well-defined succession of lithic industries (Table 2.2), which appear to occur more or less simultaneously across the region. The distinct features of each industry have helped cement the LSA lithic sequence, which encompasses all of the variations of stone toolmaking that occurred during the Late Pleistocene in southern Africa (see Lombard et al., 2012). As it is currently understood, the LSA sequence is in large part underpinned by the changes in lithic technology observed in several key sites along the Southern Cape coast, including Nelson Bay Cave (J. Deacon, 1984), Boomplaas (H. Deacon, 1979), Kangkara (J. Deacon, 1984), Melkhoutboom (H. Deacon, 1976), and Byneskranskop 1 (Schweitzer and Wilson, 1982). Yet none of these sites is dated comprehensively enough or with sufficient precision to test the widely accepted southern African chronology in this region. Given the marked

environmental gradients and the enormous area over which similar LSA industries are found, their apparent synchrony across the subcontinent warrants close investigation. Moreover, the valuable palaeoenvironmental records recovered from these sites (e.g. Avery, 1982; Faith, 2013; Klein, 1976; Scholtz, 1986; Sealy, 1996, this study) can be of only limited use without detailed and precise chronologies with which to correlate them to one another and to regional climate shifts.

A recent synthesis of dated lithic assemblages from South Africa and Lesotho by Lombard et al. (2012), utilising a large dataset of published radiocarbon dates from over fifty different sites, confirmed the previously proposed chronology of LSA transitions across the sub-continent (Table 2.2). However, the authors neither calibrated the radiocarbon dates included in the dataset consistently nor controlled for the quality of individual dates. A careful examination of the dataset highlights the inadequacy of several of 
the radiocarbon chronologies across the region - many dates are three or four decades old, and so pre-date the adoption of methodological improvements now standard for radiocarbon analyses. Consequently, upon closer inspection, it is clear that the timing of even major cultural shifts is only poorly constrained at a regional level, greatly limiting our ability to detect, for example, centres of origin and potential diffusion patterns.

Beyond the major shifts in technocomplex, better chronologies at these sites will improve understandings of LSA technological change that are presently somewhat hampered by the static existing technological structure. In only a few LSA sites in southern Africa

(e.g. Sehonghong, Rose Cottage Cave, Elands Bay Cave) are the chronologies adequate to explore change below the level of the technocomplex. Yet, many researchers have emphasised the intra-assemblage variability evident at particular sites and cautioned against applying overly rigid technological frameworks (Mitchell, 1995; Wadley, 1996; Orton, 2006). Improved chronologies will enable more fruitful and nuanced assessments of technological change between key sites.

\subsection{Previous chronological research}

Both Nelson Bay Cave and Byneskranskop 1 contain near-continuous Later Stone Age technological sequences from the Robberg through to the Post-Wilton, while the deposits at Nelson Bay Cave extend into the MSA. The sites are approximately $400 \mathrm{~km}$ apart but lie within the same fynbos-dominated ecosystem: Byneskranskop 1 is located at the present border between the winter and year-round rainfall zones, while Nelson Bay Cave lies securely within the region that receives rainfall year-round. Both sites have preserved rich faunal assemblages that have been investigated for cultural significance and environmental changes across the Late Pleistocene and Holocene (Faith, 2013; Klein, 1972). Importantly for this study, both sites contain abundant shell remains spanning the Late Pleistocene and Holocene, and the seasonal SST records from these sites provide complementary datasets, with the Byneskranskop 1 material presumably reflecting a greater influence of the Atlantic Ocean waters.

\subsubsection{Nelson Bay Cave}

The NBC levels re-dated as part of this study were excavated in 1970/71 by Richard Klein and described in detail in Janette Deacon's doctoral thesis (J. Deacon, 1984: see 
Figure 2.2.3). The LSA levels span the full temporal range of the LSA in southern Africa, and the lithic succession observed by Deacon is essentially that recognised for the whole of southern Africa (see Table 2.2). The basal LSA levels contain one of the earliest dated assemblages of the microlithic Robberg industry, named for this site (which lies on the Robberg Peninsula). The chronology for the mid- to early-Holocene and Late Pleistocene levels excavated by Klein was based on 24 conventional radiocarbon dates (Table 4.1), measured largely at the University of Washington laboratory (Fairhall et al., 1976). Many of the dates have very wide errors, and the dated materials were in many cases unsuitable, as they mixed a variety of materials of marine and terrestrial origin. Despite the clear inadequacies of these individual dates, the Nelson Bay Cave sequence is generally considered secure, and has served as a reference for other undated LSA sequences in the region.

\subsubsection{Byneskranskop 1}

BNK1 was excavated by Frank Schweitzer and a team from the South African National Museum (now Iziko South African Museum) in 1974 and 1976 (see Figure 2.2.5). The chronology of the site was based on 12 conventional radiocarbon dates (Table 4.2), although the excavation report provides few details about these samples, such as what material was dated or where in the level they were collected. The age of several levels was very poorly constrained by the available set of dates, limiting further studies of the material from this site. For instance, dates for the Robberg and Oakhurst assemblages show a gap of at least $2-3 \mathrm{ka}$, but whether this reflected an occupational hiatus was unclear due to the small number of radiocarbon dates.

\subsection{Materials and methods}

\subsubsection{Principles of radiocarbon dating}

Radiocarbon, ${ }^{14} \mathrm{C}$, is a radioactive isotope formed in the upper atmosphere, and incorporated into all organic systems via the global carbon cycle. Upon death, an organism ceases exchanging carbon with the atmosphere, and the ratio of radiocarbon to the stable isotopes of carbon $\left({ }^{12} \mathrm{C}\right.$ and $\left.{ }^{13} \mathrm{C}\right)$ begins to diminish due to the radioactive decay of ${ }^{14} \mathrm{C}$. The rate of radiocarbon decay is constant and well-known (half-life $=5730 \pm$ 
Table 4.1: Previously published radiocarbon dates from Nelson Bay Cave (Deacon 1984) with sample material details (reported in Fairhall et al. (1976)). Dates are calibrated using OxCal, SHCal13, reported at 95\% CI.

\begin{tabular}{|c|c|c|c|c|c|c|c|}
\hline \multirow[t]{2}{*}{ Layer } & \multirow{2}{*}{$\begin{array}{l}\text { Cultural } \\
\text { unit }\end{array}$} & \multirow[t]{2}{*}{ ID no. } & \multirow{2}{*}{$\begin{array}{l}\text { Date } \\
{[\mathrm{BP}]}\end{array}$} & \multirow[t]{2}{*}{ \pm} & \multicolumn{2}{|c|}{ Date $[$ cal BP] } & \multirow[t]{2}{*}{ Material } \\
\hline & & & & & From & To & \\
\hline Ivan & Wilton & UW-217 & 4860 & 65 & 5710 & 5325 & Shell \\
\hline \multirow[t]{4}{*}{ BSC } & Wilton & UW-216 & 5830 & 115 & 6878 & 6318 & Charcoal \\
\hline & & UW-186 & 6050 & 80 & 7156 & 6661 & $\begin{array}{l}\text { Charcoal rich soil, bone } \\
\text { fragments removed }\end{array}$ \\
\hline & & UW-176 & 6020 & 160 & 7245 & 6467 & $\begin{array}{l}\text { Charcoal fragments separated } \\
\text { from soil }\end{array}$ \\
\hline & & UW-187 & 5825 & 150 & 6950 & 6289 & $\begin{array}{l}\text { Charcoal rich soil, no } \\
\text { fragments }\end{array}$ \\
\hline \multirow[t]{2}{*}{ Rice A } & Wilton & UW-222 & 6070 & 125 & 7246 & 6568 & Charcoal fragments \\
\hline & & UW-179 & 9080 & 185 & 10654 & 9599 & Shell, Patella sp. \\
\hline \multirow[t]{2}{*}{ Rice B } & Oakhurst & UW-181 & 8070 & 240 & 9475 & 8413 & $\begin{array}{l}\text { Small charcoal frags, shells } \\
\text { and sand mixed in }\end{array}$ \\
\hline & & UW-184 & 8570 & 170 & 10147 & 9092 & Shell, Patella sp. \\
\hline Jake & Oakhurst & Pta-391 & 8990 & 80 & 10243 & 9771 & Charcoal \\
\hline \multirow[t]{2}{*}{ BSBJ } & Oakhurst & Q-1085 & 10256 & 210 & 12552 & 11256 & Ash with charcoal \\
\hline & & UW-178 & 10540 & 110 & 12671 & 12035 & $\begin{array}{l}\text { Dense, clay-like black } \\
\text { material with no clear } \\
\text { charcoal }\end{array}$ \\
\hline \multirow[t]{3}{*}{ CS } & Oakhurst & Pta-392 & 10150 & 90 & 12015 & 11321 & Charcoal from hearth \\
\hline & & UW-164 & 10180 & 85 & 12045 & 11348 & $\begin{array}{l}\text { Charcoal frags in sediment } \\
\text { mix of shells, soil }\end{array}$ \\
\hline & & UW-162 & 11505 & 110 & 13490 & 13082 & $\begin{array}{l}\text { Charcoal frags in sediment } \\
\text { mix of shells, soil }\end{array}$ \\
\hline \multirow[t]{2}{*}{ GSL } & Oakhurst & UW-177 & 11950 & 150 & 14118 & 13445 & $\begin{array}{l}\text { Large fragments of charcoal } \\
\text { in sediment }\end{array}$ \\
\hline & & I-6515 & 11080 & 260 & 13450 & 12433 & $\begin{array}{l}\text { Large fragments of charcoal } \\
\text { in sediment }\end{array}$ \\
\hline BSL & Robberg & UW-218 & 10600 & 150 & 12728 & 12004 & Charcoal \\
\hline YSL & Robberg & I-6516 & 16700 & 240 & 20695 & 19527 & Charcoal \\
\hline \multirow[t]{2}{*}{ YGL } & Robberg & UW-175 & 18100 & 550 & 23190 & 20513 & $\begin{array}{l}\text { Finely divided charcoal in a } \\
\text { mixture of clay material }\end{array}$ \\
\hline & & GrN-5884 & 18660 & 110 & 22797 & 22258 & Ostrich eggshell fragments \\
\hline \multirow[t]{3}{*}{ MSA } & MSA & UW-224 & 17600 & 195 & 21783 & 20708 & Black earth \\
\hline & & UW-223 & 24120 & 660 & 29779 & 27125 & Black earth \\
\hline & & UW-290 & 22400 & 340 & 27348 & 25989 & Brown soil \\
\hline
\end{tabular}


Table 4.2: Previously published radiocarbon dates from Byneskranskop 1 (materials unreported; Schweitzer and Wilson, 1982) with calibrated ages presented at 95\% confidence intervals (Faith 2013). *Unpublished dates from Horsburgh, 2008 (not included in OxCal models, as neither the uncalibrated dates nor detailed provienience information is reported).

\begin{tabular}{lllrrrr}
\hline Stratum & Lab no. & Date & \pm & \multicolumn{2}{c}{ Date $[$ calBP $]$} & Cultural \\
& & {$[\mathrm{BP}]$} & & From & To & Unit \\
\hline Layer 1 & Pta-1864 & 255 & 50 & 265 & 466 & Post-Wilton \\
& Pta-1866 & 535 & 50 & 504 & 568 & Post-Wilton \\
& Pta-1865 & 1880 & 50 & 1705 & 1930 & Post-Wilton \\
& Pta-1631 & 3220 & 45 & 3365 & 3513 & Post-Wilton \\
& Beta-232588* & & & 1840 & \pm 40 & Post-Wilton \\
& Beta-232589* & & & 2100 & \pm 40 & Post-Wilton \\
& Beta-232590* & & & 1740 & \pm 40 & Post-Wilton \\
& Beta-232591* & & & 1880 & \pm 40 & Post-Wilton \\
Layer 2 & Pta-1569 & 3400 & 55 & 3552 & 3735 & Post-Wilton \\
Layer 5 & Pta-1571 & 3900 & 60 & 4152 & 4445 & Wilton \\
Layer 9 & Pta-1772 & 6100 & 140 & 6653 & 7306 & Wilton \\
& UW-409 & 6370 & 90 & 7155 & 7442 & Wilton \\
Layer 10 & Pta-1905 & 6540 & 55 & 7411 & 7522 & Oakhurst \\
Layer 12 & Pta-2347 & 7750 & 90 & 8376 & 8777 & Oakhurst \\
Layer 14 & Pta1587 & 9760 & 55 & 11061 & 11353 & Oakhurst \\
Layer 19 & I-7948 & 12730 & 185 & 14162 & 16115 & Robberg \\
\hline \hline
\end{tabular}




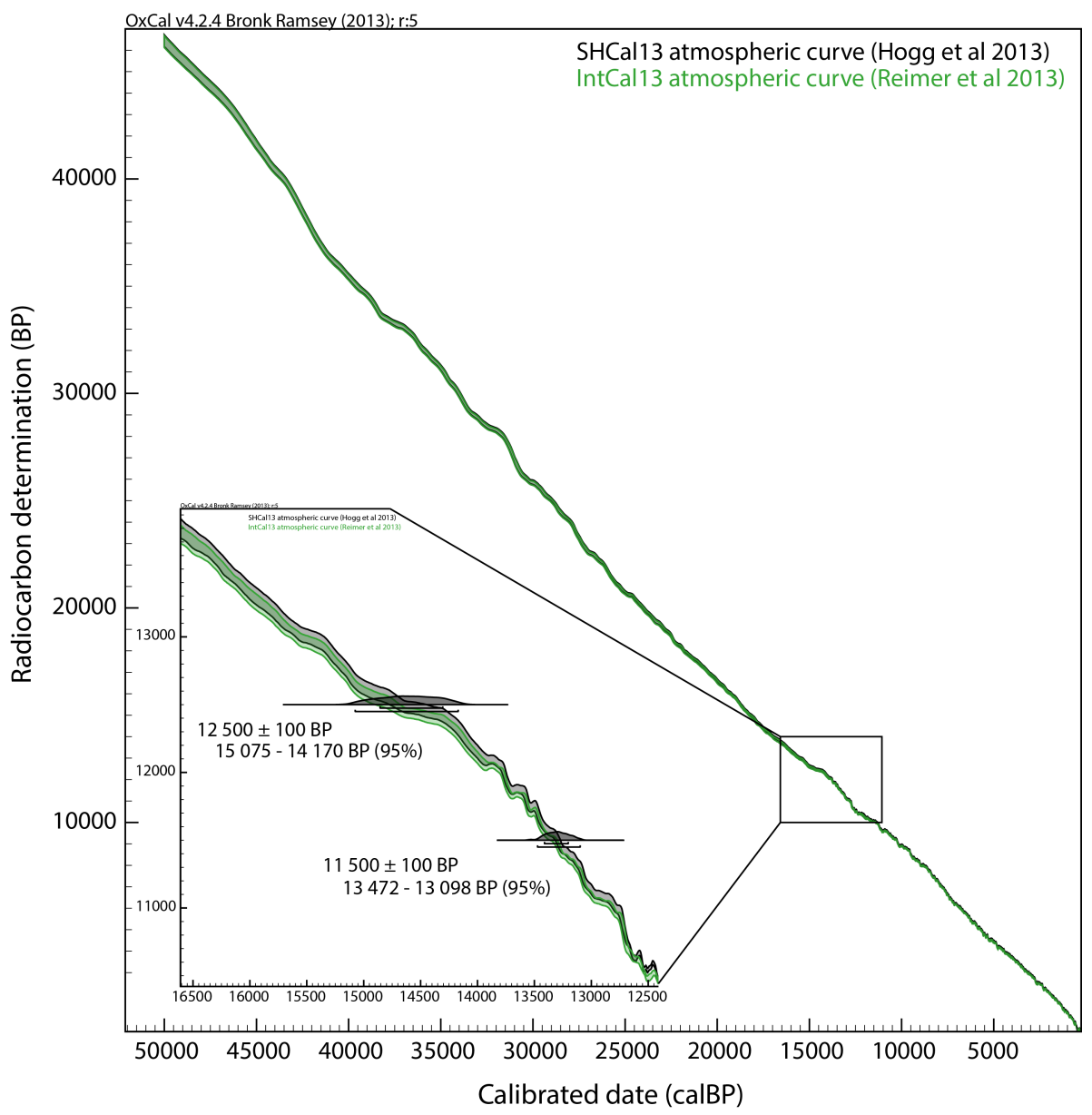

Figure 4.3.1: OxCal 4.2 plot of IntCal09 and SHCal13 calibration curves. The inset shows the effect of the calibration curve on the age ranges of two dates with identical errors.

40 years), and thus precise measurements of the ratio of the remaining radiocarbon in organic material can be used as age estimates from the time of death. The relatively rapid half-life and instrumental sensitivity together constrain the period over which this method is useful to within the last 60000 years. Several factors need to be considered to convert the ${ }^{14} \mathrm{C}$ measurement, a "radiocarbon age", into a true "calendar age", but these are largely well-understood and uncontroversial (Taylor and Bar-Yosef, 2014).

Various aspects of the radiocarbon methodology should be considered when evaluating the reliability of an individual date. When selecting samples from coastal sites, a key consideration is the contribution of carbon derived from marine ecosystems. Radiocarbon in the atmosphere is mixed very rapidly, and so carbon derived from these sources (i.e. terrestrial photosynthesis) is globally homogeneous in age. However, the oceans can have significant "reservoir" effects, where carbon is stored in water masses for long periods 
(Taylor and Bar-Yosef, 2014). Consequently, at a global level, organisms that derive all their carbon from oceanic waters are on average 400 years "older" than a terrestrial organism of the same age. Crucially, this marine reservoir can vary considerably globally, according to the influence of different water masses through upwelling of old carbon and other processes. The reservoir for the south coast of South Africa is presently not well-constrained (although see Dewar et al. (2012) for a marine reservoir estimate for the west coast) and dates on shell, or organisms that consumed marine foods, may be considerably "too old". Thus, terrestrial samples with no marine input are preferred for dating.

A different problem concerns the effect of "old wood", long-lived trees that were burnt as firewood and subsequently dated as charcoal. As some trees can live many hundreds of years, charcoal derived from the inner portion of the trunk may be substantially offset in age from the wood that formed later in the tree's life, and that more closely represents the time when the tree was burnt by humans. In southern Africa, few trees are long-lived enough for this to be a major concern over the timescales considered here, except possibly some species in the forested areas of the southern Cape such as the yellowwood (Podocarpus latifolius and Afrocarpus falcatus). Given this complication, potential radiocarbon charcoal samples should ideally be identified to species, an analysis that requires a considerable degree of regional specialist knowledge.

Given that the amount of ${ }^{14} \mathrm{C}$ in a sample decays exponentially, even very small amounts of modern carbon contamination can dramatically affect the apparent age of older samples. It is therefore critical that rigorous pre-treatment strategies are employed to remove as much exogenous carbon as possible (e.g. Bird et al., 1999). For bone samples, ultra-filtration of the extracted collagen removes more contaminants than other methods and produces more reliable dates (Higham et al., 2006). There are two main methods of radiocarbon mass spectrometry: the older conventional beta-counting technique and accelerator mass spectrometry (AMS), developed in the 1970s and 1980s. The AMS method is markedly more sensitive and so requires dramatically smaller sample sizes than the conventional method. This typically produces more accurate dates, as the larger samples required for conventional techniques are more likely to be a mix of materials (Taylor and Bar-Yosef, 2014).

A critical step for the production of a calendar age estimate involves transforming the radiocarbon age via a statistical process known as calibration. This transformation accounts for non-linear and unpredictable changes in the global amount of ${ }^{14} \mathrm{C}$ through time (principally due to variable solar activity), which cause a misalignment of the 
radiocarbon and calendar timescales. Calibration curves are based upon large numbers of radiocarbon measurements of materials that are also dated independently by alternative methods (including tree-rings, lake varves, corals and deep-sea sediments). Presently, there are several reliable calibration curves available that extend over nearly the entire period considered in this study, including one for the Southern Hemisphere, SHCal13, which takes into account the small discrepancy between the two hemispheres (Hogg et al., 2013). Because the amount of global ${ }^{14} \mathrm{C}$ varies randomly through time, there is no simple relationship between a normally distributed radiocarbon measurement (mean $(\mu) \pm$ standard deviation $(\sigma))$ and a calibrated date, which is simply a probability range and should always be presented as such. Figure 4.3.1 shows two calibration curves IntCal09 (Reimer et al., 2009) and SHCal13 (Hogg et al., 2013) over their entire range: only relatively minor differences exist between the two. Also shown in this figure is the effect that the shape of the curve at any particular point can have on a radiocarbon age estimate. The two dates both have standard deviations of 100 years but the resulting calibrated range differs markedly in length between the two as a result of the shape of the calibration curve. Fortunately, several free software packages exist to calibrate radiocarbon measurements, ensuring the reliable presentation of radiocarbon results in the literature. The software used in this study is OxCal, version 4.2 (Bronk Ramsey, 1995; Bronk Ramsey, 2009a). Calibrated ages are reported here as "calBP", where BP means "before 1950", and uncalibrated ages are presented simply as "BP" or "ka".

OxCal also enables the modelling of ages according to Bayesian principles, in order to produce more statistically robust age models (Bronk Ramsey, 2009a). Bayesian techniques allow one to incorporate prior knowledge and assumptions to better constrain the range of probable values. For example, within a stratified and undisturbed depositional sequence we can assume that more recent material overlies older material. Bayesian models, when used with due consideration of the potential biases and pitfalls, can produce more precise and accurate age estimates than unmodelled series of dates. In OxCal models, the modelled ages are shown with a darker fill than the unconstrained calibrated ages, which are illustrated with a light grey fill (e.g. Figure 4.5.1). In addition to constraining the ages of individual dates, OxCal can also model the ages of entire phases based on groups of dates (for example, from single depositional units or grouped depositional units thought to reflect a single cultural unit), and the ages of boundaries between these phases. Clearly, such modelled age estimates are heavily dependant on the structure of the model as determined by the user. 


\subsubsection{Materials}

Fourteen fragments of bovid long bone and fifteen fragments of tortoise bone carapace from NBC and BNK1 respectively were selected from the excavation collections housed at the Iziko National Museum, Cape Town. These materials were chosen for their unambiguous identification as either bovids or tortoise and the improbability of any reservoir effects among these taxa (bones were not identified to species level). No charcoal was available for dating. None of the selected specimens displayed any clear modifications by humans or animals, but, given the abundance of archaeological material, including shell, large and small fauna, stone tools and burnt materials, the association with human occupation is not in question.

The bones were stored in brown paper bags labelled to level and to square in the case of NBC, and sub-unit in the case of BNK1 (see Table 4.3). None of the bones was preserved or consolidated with any chemical contaminants, except some of the tortoise carapace fragments from BNK1, which were labelled with India ink. The necessary permissions for export and sampling were obtained from the curator of the archaeological collections at Iziko Museum (Dr Wendy Black) and Heritage Western Cape (case number 15021902AS0219E).

\subsubsection{Laboratory Methods}

The exterior surface of the bone was abraded with aluminium oxide powder (shotblasting) and a fragment of c. $1 \mathrm{~g}$ was removed with a tungsten carbide drill at low speed, before mechanical crushing. The pretreatment strategy employed an acid-base-acid treatment, followed by gelatinization and ultrafiltration (Brock et al., 2010). The bone powder was placed inside glass tubes and treated four times with $0.5 \mathrm{M} \mathrm{HCl}$, including one rinse overnight. The sample was then rinsed three times with ultrapure Milli-Q water, centrifuging between rinses, before a $0.1 \mathrm{M} \mathrm{NaOH}$ base wash for $30 \mathrm{mins}$. The sample was again washed three times with ultrapure water before a final treatment with $0.5 \mathrm{M} \mathrm{HCl}$ for 15 mins. After another three ultrapure water rinses, the collagen was gelatinised in a small amount of $\mathrm{pH} 3$ solution inside a $75^{\circ} \mathrm{C}$ oven for 20 hours. This gelatin solution was filtered with an Ezee-filter before being passed into a cleaned ultrafilter and centrifuged until only $0.5-1.0 \mathrm{~mL}$ of the gelatin remained (10 mins - 1 hour). The gelatin was extracted from the filter with a glass pipette and ultrapure water, frozen and freeze-dried for at least 36 hours. 
Table 4.3: Samples selected for radiocarbon dating from Nelson Bay Cave and Byneskranskop 1.

\begin{tabular}{|c|c|c|c|c|}
\hline Site & Layer & Square or Sub-unit & Cultural unit & Mass [g] \\
\hline \multirow[t]{14}{*}{$\mathrm{NBC}$} & Ivan & $\Delta 4$ & Wilton & 6.4 \\
\hline & Ivan & $\gamma 5$ & Wilton & 5.8 \\
\hline & Rice A & $\Delta 9$ & Wilton & 20.6 \\
\hline & Rice B & $\beta 1$ & Oakhurst & 22.1 \\
\hline & Rice B & $\gamma 7$ & Oakhurst & 6.8 \\
\hline & Jake & $\gamma 4$ & Oakhurst & 34.0 \\
\hline & BSBJ & $\beta 4$ & Oakhurst & 10.8 \\
\hline & CS & $\beta 5$ & Oakhurst & 10.8 \\
\hline & GSL & $\Delta 9$ & Oakhurst & 24.4 \\
\hline & BSL & $\gamma 4$ & Robberg & 20.1 \\
\hline & $\mathrm{BSL}$ & $\Delta 3$ & Robberg & 9.1 \\
\hline & YSL & $\beta 7$ & Robberg & 37.4 \\
\hline & YGL & $\beta 8$ & Robberg & 16.2 \\
\hline & YGL & $\Delta 5$ & Robberg & 15.6 \\
\hline \multirow[t]{15}{*}{ BNK1 1} & 1 & Eva & Wilton & 9.5 \\
\hline & 4 & Dud & Wilton & 4.2 \\
\hline & 5 & Frank & Wilton & 2.5 \\
\hline & 6 & Hilary & Wilton & 5.0 \\
\hline & 7 & Klein & Wilton & 4.0 \\
\hline & 8 & Lalle & Wilton & 2.6 \\
\hline & 9 & Mort & Wilton & 2.9 \\
\hline & 10 & Twit & Oakhurst & 2.6 \\
\hline & 11 & Ulk & Oakhurst & 9.1 \\
\hline & 13 & Wet B & Oakhurst & 3.5 \\
\hline & 14 & Level 14 & Oakhurst & 3.5 \\
\hline & 15 & Level 15 & Oakhurst & 3.5 \\
\hline & 17 & Gunge & Oakhurst & 5.6 \\
\hline & 19 (top) & Jol & Robberg & 2.9 \\
\hline & 19 (bottom) & Rock Bottom (19) & Robberg & 3.9 \\
\hline
\end{tabular}


If the collagen yield was $>1 \%$ of the starting weight of bone powder, the collagen was considered suitable for dating. 4.25 - 4.75mg of collagen was weighed into clean tin capsules and loaded into a elemental analyzer (Carlo-Erba NA 2000) coupled to a gas source isotope ratio mass spectrometer (Sercon 20/20). While a small amount of the $\mathrm{CO}_{2}$ gas produced upon sample combustion is introduced to the mass spectrometer for measurement of $\delta^{13} \mathrm{C}, \delta^{15} \mathrm{~N}$ and the carbon and nitrogen content (for the C:N ratio), $98 \%$ of the $\mathrm{CO}_{2}$ gas is collected cryogenically in an outgassed quartz tube containing iron powder as a catalyst. The sample gas is graphitised by heating at $560^{\circ} \mathrm{C}$ for hours. The graphite powder is then transferred to a specially designed target and pressed in preparation for dating on the ORAU HVEE AMS system (Bronk Ramsey et al., 2004). Successful measurements, with satisfactory collagen yields, C:N ratios and other quality assessments, are assigned a unique OxA number.

\subsection{Results}

\subsubsection{Nelson Bay Cave}

The radiocarbon measurements, with the calibrated range (at $2 \sigma$ ) and $\delta^{13} \mathrm{C}$ values, are presented in Table 4.4. In general, the new AMS dates are consistent with the previously published conventional dates (Table 4.1). Below I briefly describe the effect of individual dates on the chronology. A discussion of the overall chronology is provided in the discussion section.

Layer Ivan - was previously only poorly constrained by one date (4 $860 \pm 65$ BP) that indicated the level was c. 1000 years younger than the preceding level (Brown Soil Complex, BSC), which is well-dated to c. 6 ka by four consistent ages (no new dates were acquired for this level). Two new AMS dates for Ivan (4 $968 \pm 31 \mathrm{BP}$ and $4860 \pm$ $45 \mathrm{BP}$ ) are consistent with the old date and indicate that the level dates to c. 5500 calBP. They also suggest that the observed hiatus between Ivan and BSC is real, as the age of both levels is now tightly constrained.

Layer Rice A - two conventional dates, on charcoal and a marine shell, were c. 3000 years apart (6 $070 \pm 125 \mathrm{BP}$ and $9080 \pm 185 \mathrm{BP}$ respectively), providing a very uncertain range for this level. Deacon (1984) suggested that the bottom of this level (and thus the transition between the Wilton and Oakhurst levels at NBC) dated to only 
c. $7 \mathrm{ka}$, disregarding the date on shell. The new AMS date, at $8281 \pm 38 \mathrm{BP}$, is not consistent with either of the previous two dates. Given the lack of stratigraphic control for these dates within Rice A, the three dates take together could indicate that the level spans a considerable period of time. The new date contradicts Deacon's suggestion that the transition between Rice A and Rice B dates to c. 7 ka, but instead indicates that it occurred between 9400 - 9032 calBP at least.

Layer Rice B - is the most recent Oakhurst level and was dated to c. $8 \mathrm{ka}$, although the errors on the two conventional dates for this level (8 $070 \pm 240 \mathrm{BP}$ and $8570 \pm$ $170 \mathrm{BP}$ ) were both very broad, giving a very uncertain estimate of the age of this level. Further, both dates were based on unreliable materials. The two new AMS dates (8 550 $\pm 37 \mathrm{BP}$ and $8447 \pm 39 \mathrm{BP}$ ) are consistent with one another and one of the previous dates. Given the new AMS age for Rice A (above), the youngest date for Rice B can be confidently excluded. The calibrated range on these two new dates indicates the uppermost Oakhurst levels date to c. 9500 calBP.

Layer Jake - the interface of Jake and Rice B was dated to $8990 \pm 80 \mathrm{BP}$. The new AMS age at $9325 \pm 45 \mathrm{BP}$ is slightly older but not inconsistent when considered in the overall chronology.

Layer Brown Soil Below Jake (BSBJ) - a new date (10 $155 \pm 45 \mathrm{BP})$ is slightly younger than the two conventional dates (10 256 $\pm 210 \mathrm{BP}$ and $10540 \pm 110 \mathrm{BP}$ ), but is not inconsistent with the overall chronology.

Layer Crushed Shell (CS) - three conventional dates for this level indicated an age between 10 and $11.5 \mathrm{ka}$, although one of the dates (11 $505 \pm 110 \mathrm{BP})$ is older than a date from the underlying layer GSL. The new AMS age (10 $340 \pm 50 \mathrm{BP})$ is more consistent with the two other conventional dates from this level (10 150 $190 \mathrm{BP}$ and 10 $180 \pm 85 \mathrm{BP}$ ). Given that the sample material for the conventional dates is reported to have included marine shells, the oldest date may well be unreliable and can be excluded.

Layers Grey-brown Shelly Loam (GSL) and Brown Stony Loam (BSL) - two previous dates for GSL indicated it was between 11 and $12 \mathrm{ka}(11950 \pm 150 \mathrm{BP}$ and $11080 \pm 260 \mathrm{BP})$. However, these conflicted with a date from the underlying BSL of $10600 \pm 150 \mathrm{BP}$, although, given the wide error margins, the date ranges could still be consistent (Deacon, 1984). New AMS dates from these levels, however, confirm the inversion, and indeed lengthen it. A sample from GSL (OxA-32456) dates to $12425 \pm$ $55 \mathrm{BP}$, while two samples from BSL below it, and which come from adjacent squares, 
date to $10450 \pm 50 \mathrm{BP}$ and $12155 \pm 55 \mathrm{BP}$ respectively. These dates indicate problems with the interpretation of the stratigraphy in these levels (discussed below).

Layer Yellow Stony Loam (YSL) - the new age for this level (14 $715 \pm 65$ BP) is c. 2000 years younger than the previous date for this level (16 $700 \pm 240 \mathrm{BP})$. If the conventional date is taken to be reliable, it suggests that this level may span a considerable period of occupation. YSL and the overlying BSL are separated by an erosional disconformity, but the new age suggests that the disconformity reflects only a couple of thousand years, and that occupation of the site was more continuous than previously thought.

Layer Yellow-Grey Loam (YGL) - the new dates for this level (19 $110 \pm 110$ BP and $18450 \pm 100 \mathrm{BP}$ ) extend the age range of the basal LSA deposits at NBC by c. 500 years, although they are consistent with the original ages for this level (18 $100 \pm$ $550 \mathrm{BP}$ and $18660 \pm 110 \mathrm{BP})$. 
Table 4.4: AMS dates on bone collagen (bovid long bone shaft fragments) from Klein's excavation at Nelson Bay Cave, with $\% \mathrm{C}$ and $\delta^{13} C$. Dates are calibrated using the SHCal13 curve (Hogg et al., 2013).

\begin{tabular}{|c|c|c|c|c|c|c|c|c|c|c|c|c|}
\hline Layer & $\begin{array}{l}\text { Cultural } \\
\text { Unit }\end{array}$ & $\begin{array}{l}\mathrm{P}- \\
\text { number }\end{array}$ & OxA-number & $\begin{array}{l}\text { Date } \\
{[\mathrm{BP}]}\end{array}$ & \pm & $\begin{array}{l}\text { Date }[\mathrm{c} \\
\text { from }\end{array}$ & $\begin{array}{c}\text { al } \mathrm{BP}] \\
\text { to }\end{array}$ & $\% \mathrm{C}$ & $\begin{array}{c}\delta^{13} \mathrm{C} \\
{[\% 0 \mathrm{PDB}]}\end{array}$ & $\mathrm{F}^{14} \mathrm{C}$ & \pm & $\mathrm{C}: \mathrm{N}$ \\
\hline Ivan & Wilton & 38886 & OxA-32448 & 4968 & 31 & 5727 & 5594 & 42.6 & -11.17 & 0.539 & 0.0021 & 3.36 \\
\hline Ivan & Wilton & 38887 & OxA-32449 & 4860 & 45 & 5652 & 5333 & 42.2 & -22.10 & 0.546 & 0.0030 & 3.36 \\
\hline Rice A & Wilton & 38888 & OxA-32450 & 8281 & 38 & 9400 & 9032 & 42.3 & -11.59 & 0.357 & 0.0017 & 3.37 \\
\hline Rice B & Oakhurst & 38889 & OxA-32451 & 8550 & 37 & 9545 & 9461 & 41.6 & -10.20 & 0.345 & 0.0016 & 3.34 \\
\hline Rice B & Oakhurst & 38890 & OxA-32452 & 8447 & 39 & 9520 & 9305 & 41.9 & -11.72 & 0.349 & 0.0017 & 3.36 \\
\hline Jake & Oakhurst & 38891 & OxA-32453 & 9325 & 45 & 10588 & 10276 & 42.1 & -19.00 & 0.313 & 0.0017 & 3.37 \\
\hline BSBJ & Oakhurst & 38892 & OxA-32454 & 10155 & 45.0 & 11971 & 11405 & 42.2 & -12.20 & 0.283 & 0.0016 & 3.42 \\
\hline $\mathrm{CS}$ & Oakhurst & 38893 & OxA-32455 & 10340 & 50 & 12397 & 11829 & 41.0 & -19.71 & 0.276 & 0.0017 & 3.38 \\
\hline GBSL & Oakhurst & 38894 & OxA-32456 & 12425 & 55 & 14807 & 14125 & 41.6 & -8.70 & 0.213 & 0.0014 & 3.37 \\
\hline BSL & Robberg & 38895 & OxA-32606 & 12155 & 55 & 14132 & 13780 & 46.0 & -10.29 & 0.220 & 0.0015 & 3.42 \\
\hline BSL & Robberg & 38896 & OxA-32457 & 10450 & 50 & 12513 & 12025 & 40.9 & -19.72 & 0.272 & 0.0017 & 3.40 \\
\hline YSL & Robberg & 38897 & OxA-32458 & 14715 & 65 & 18049 & 17645 & 41.9 & -13.80 & 0.160 & 0.0013 & 3.35 \\
\hline YGL & Robberg & 38898 & OxA-32607 & 18450 & 100 & 22485 & 21963 & 43.8 & -21.93 & 0.101 & 0.0013 & 3.42 \\
\hline YGL & Robberg & 38899 & OxA-32608 & 19110 & 110 & 23353 & 22616 & 42.6 & -14.30 & 0.093 & 0.0012 & 3.40 \\
\hline
\end{tabular}




\subsubsection{Byneskranskop 1}

The radiocarbon measurements, with the calibrated range (at $2 \sigma$ ) and $\delta^{13} \mathrm{C}$ values, are presented in Table 4.5. Dates OxA-32675 and OxA-32676 are repeats of the same sample, undertaken for quality assurance purposes. Several samples originally selected for dating (Table 4.3) did not yield sufficient collagen and there are no measurements for those samples (from levels 10, 13 and 14).

Layer 1 - the new date for this level $(1891 \pm 27 \mathrm{BP})$ relates to the basal unit of layer 1 (Eva) and supports the excavator's suggestion that the old date of $3220 \pm 45 \mathrm{BP}$ probably related instead to the underlying level 2 . The new date is very consistent with the date of $1880 \pm 50 \mathrm{BP}$ that dates the overlying sub-unit Clara in layer 1.

Layer 2 - was previously dated to $3400 \pm 55 \mathrm{BP}$.

Layer 4 - this layer, relating to the start of the post-Wilton assemblage, was previously undated and is here dated to $3599 \pm 28 \mathrm{BP}$, which is consistent with the date for layer 2 above.

Layer 5 - this layer relates to the end of the Wilton and was previously dated to 3900 $\pm 60 \mathrm{BP}$ : the new date for this level is $5428 \pm 33 \mathrm{BP}$. The old date may be unreliable, suggesting a possible hiatus between the end of the Wilton and start of the post-Wilton or alternatively the deposits from this level may span over 1500 years as the new date is consistent with the age for the underlying level.

Layer 6 - was previously undated and is here dated to $5684 \pm 32 \mathrm{BP}$.

Layer 7 - was previously undated and is here dated to $5263 \pm 33 \mathrm{BP}$. The inversion with the layer above is possibly explained by this comment in the site report: "In places it was difficult to determine the base of layer 6 , but on the whole layer 7 was less compacted and less ashy than layer $6[. .]$.$" . Thus, this may reflect stratigraphic$ uncertainties in the sequence.

Layer 8 - was previously undated and is here dated to $5589 \pm 34 \mathrm{BP}$. The inversion with layer 6 may be explained by this comment in the site report: "This layer was not recognized in squares $\mathrm{P} 27-28$, and in the other squares its base was determined by the presence of a fine, grey ash band."

The sample from layer 8 is from the same square as that from layer 7 and is in stratigraphic order. Unfortunately, the square is not recorded for the sample from layer 6 . Thus, 
the dates from layers 6, 7 and 8 may possibly come from essentially the same level, mistakenly sub-divided by the excavator, or a mixed level.

Layer 9 - was previously dated to c. 6 ka by two dates (6 $370 \pm 90$ BP from sub-unit Mort and $6100 \pm 140 \mathrm{BP}$ from sub-unit Nellie). A new date, $6048 \pm 33 \mathrm{BP}$, is not inconsistent with these ages, and fits with the ages of the adjacent levels. The new date comes from sub-unit Mort, which is the upper sub-unit, and was originally dated as older than sub-unit Nellie below it, although the errors on these dates make this difficult to state with certainty. The new date suggests that the original date from Mort may have been in error, as it is now more coherent with the underlying age from Nellie.

Layer 10 - was previously dated to $6540 \pm 55$ BP. A new date was sought for this level but the collagen preservation was not adequate.

Layer 11 - was previously undated and is here dated to $5872 \pm 33 \mathrm{BP}$. The inversion with the above layer may be explained by the description of the layer as "the in-fill" between the layers above and below. Alternatively, either the old date for the level above or new date may be erroneous.

Layer 12 - was previously dated to $7750 \pm 90 \mathrm{BP}$.

Layer 13 - a date was sought for this level but the collagen preservation was not adequate.

Layer 14 - was previously dated to $9760 \pm 85 \mathrm{BP}$. A new date was sought for this level but the collagen preservation was not adequate.

Layer 15 - was previously undated and is here dated to $10015 \pm 45 \mathrm{BP}$, which is consistent with the adjacent levels.

Layer 17 - was previously undated and is here dated to $12250 \pm 55 \mathrm{BP}$, which is consistent with the adjacent levels. This provides an age for the start of the Oakhurst levels.

Layer 19 - was previously dated to $12730 \pm 185 \mathrm{BP}$. Two new dates extend the age range of the site by c. 1000 years: the basal sub-unit Rock Bottom is dated to $13945 \pm$ $65 \mathrm{BP}$, while sub-unit Jol above was dated to $13565 \pm 60 \mathrm{BP}$. The correspondence of these two ages suggests that the original date is possibly erroneous, although it is not inconsistent with the overall chronology. 
Table 4.5: AMS dates on bone collagen (tortoise carapace fragments) from Byneskranskop 1, with $\% \mathrm{C}$ and $\delta^{13} C$. Dates are calibrated using the SHCal13 curve (Hogg et al., 2013).

\begin{tabular}{|c|c|c|c|c|c|c|c|c|c|c|c|c|}
\hline Layer & $\begin{array}{l}\text { Cultural } \\
\text { Unit }\end{array}$ & $\begin{array}{l}\text { P- } \\
\text { number }\end{array}$ & OxA-number & $\begin{array}{l}\text { Date } \\
{[\mathrm{BP}]}\end{array}$ & \pm & $\begin{array}{l}\text { Date [ca } \\
\text { from }\end{array}$ & $\begin{array}{l}\mathrm{BP}] \\
\text { to }\end{array}$ & $\% \mathrm{C}$ & $\begin{array}{c}\delta^{13} \mathrm{C} \\
{\left[\begin{array}{ll}\% & \mathrm{PDB}\end{array}\right]}\end{array}$ & $\mathrm{F}^{14} \mathrm{C}$ & \pm & $\mathrm{C}: \mathrm{N}$ \\
\hline Level 1 & Post-Wilton & 38900.0 & OxA-32675 & 1891 & 27 & 1867 & 1715 & 42.0 & -22.44 & 0.790 & 0.0026 & 3.35 \\
\hline Level 1 & Post-Wilton & 38900.1 & OxA-32676 & 1891 & 28 & & & 44.8 & -22.25 & 0.790 & 0.0027 & 3.37 \\
\hline Level 4 & Wilton & 38901 & OxA-32677 & 3599 & 28 & 3966 & 3720 & 42.8 & -22.41 & 0.639 & 0.0022 & 3.33 \\
\hline Level 5 & Wilton & 38902 & OxA-32678 & 5428 & 33 & 6286 & 6016 & 44.2 & -21.83 & 0.509 & 0.0021 & 3.35 \\
\hline Level 6 & Wilton & 38903 & OxA-32679 & 5684 & 32 & 6495 & 6315 & 44.3 & -22.74 & 0.493 & 0.0020 & 3.32 \\
\hline Level 7 & Wilton & 38904 & OxA-32680 & 5263 & 33 & 6176 & 5908 & 43.5 & -22.28 & 0.519 & 0.0021 & 3.32 \\
\hline Level 8 & Wilton & 38905 & OxA-32681 & 5589 & 34 & 6406 & 6286 & 43.7 & -23.39 & 0.499 & 0.0021 & 3.34 \\
\hline Level 9 & Wilton & 38906 & OxA-32682 & 6048 & 33 & 6945 & 6745 & 44.0 & -22.16 & 0.471 & 0.0020 & 3.34 \\
\hline Level 11 & Transitional & 38908 & OxA-32683 & 5872 & 33 & 6738 & 6508 & 41.2 & -21.52 & 0.481 & 0.0020 & 3.34 \\
\hline Level 15 & Oakhurst & 38911 & OxA-32684 & 10015 & 45 & 11695 & 11249 & 40.6 & -24.10 & 0.287 & 0.0017 & 3.29 \\
\hline Level 17 & Oakhurst & 38912 & OxA-32685 & 12250 & 55 & 14320 & 13860 & 38.9 & -24.02 & 0.218 & 0.0015 & 3.39 \\
\hline Level 19 & Robberg & 38913 & OxA-32686 & 13565 & 60 & 16535 & 16063 & 40.7 & -23.25 & 0.185 & 0.0014 & 3.33 \\
\hline Level 19 & Robberg & 38914 & OxA-32687 & 13945 & 65 & 17105 & 16555 & 43.1 & -23.61 & 0.176 & 0.0014 & 3.35 \\
\hline
\end{tabular}




\subsection{Bayesian models and discussion}

\subsubsection{Nelson Bay Cave}

The new dates from NBC, while generally in agreement with the existing chronology, conflict with it in several instances. Below (Figure 4.5.2) are date estimates for each level derived from two Bayesian Sequence models produced in OxCal: the upper model includes only the old dates, while the lower model incorporates the new AMS dates. In both instances, the model would not run initially due to the dating inversion in layers BSL and GSL so these two levels have been combined based on the assumption that the stratigraphy in these levels was misunderstood (see below). Further, not all the dates reported in Table 4.1 are included in these models as several were highlighted as statistical outliers according to the indice method in OxCal (Bronk Ramsey, 2009b): UW-162 from CS, UW-178 from BSBJ, UW-181 from Rice B and UW-179 from Rice A. The priors in Sequence models are based on stratigraphic information, namely relative position and the grouping of dates into phases (i.e. the archaeological levels), with Boundaries between the Phases. The changes in the model illustrate how the new dates have affected the age of the boundaries between levels. The modelled age ranges for each Phase (level) and Boundary between levels are provided in Table 4.6, while the individual dates are shown in Figure 4.5.1.

In general the age estimates for layers as a whole and the boundaries between layers have been constrained by the incorporation of the new dates, by up to half of the non-AMS age estimates. The smaller errors of the AMS dates as compared to the conventional dates improve the age ranges of the levels, even in some cases where the new dates are quite different from the conventional dates. This greatly increases the utility and credibility of comparisons between the technological and palaeoenvironmental datasets at NBC and other archaeological sites or climate records.

The start of the Wilton deposits at NBC is confirmed to have begun relatively early based on a date from Rice A (c. 9400 - 9032 calBP), contra Deacon's (1984) suggestion that the transition between the two industries was at c. $7 \mathrm{ka}$. In addition, the probable range of values of Rice $B$ has been markedly narrowed in the model that incorporates the new dates, from spanning nearly 1400 years (9 990 - 8628 calBP; $2 \sigma$ ) in the model with only old dates to spanning less than 500 years in the model that incorporates the new AMS dates (9 784 - 9299 calBP; $2 \sigma$ ). This suggests a model of fairly rapid technological changeover between the Oakhurst and Wilton at NBC. This early date also challenges 


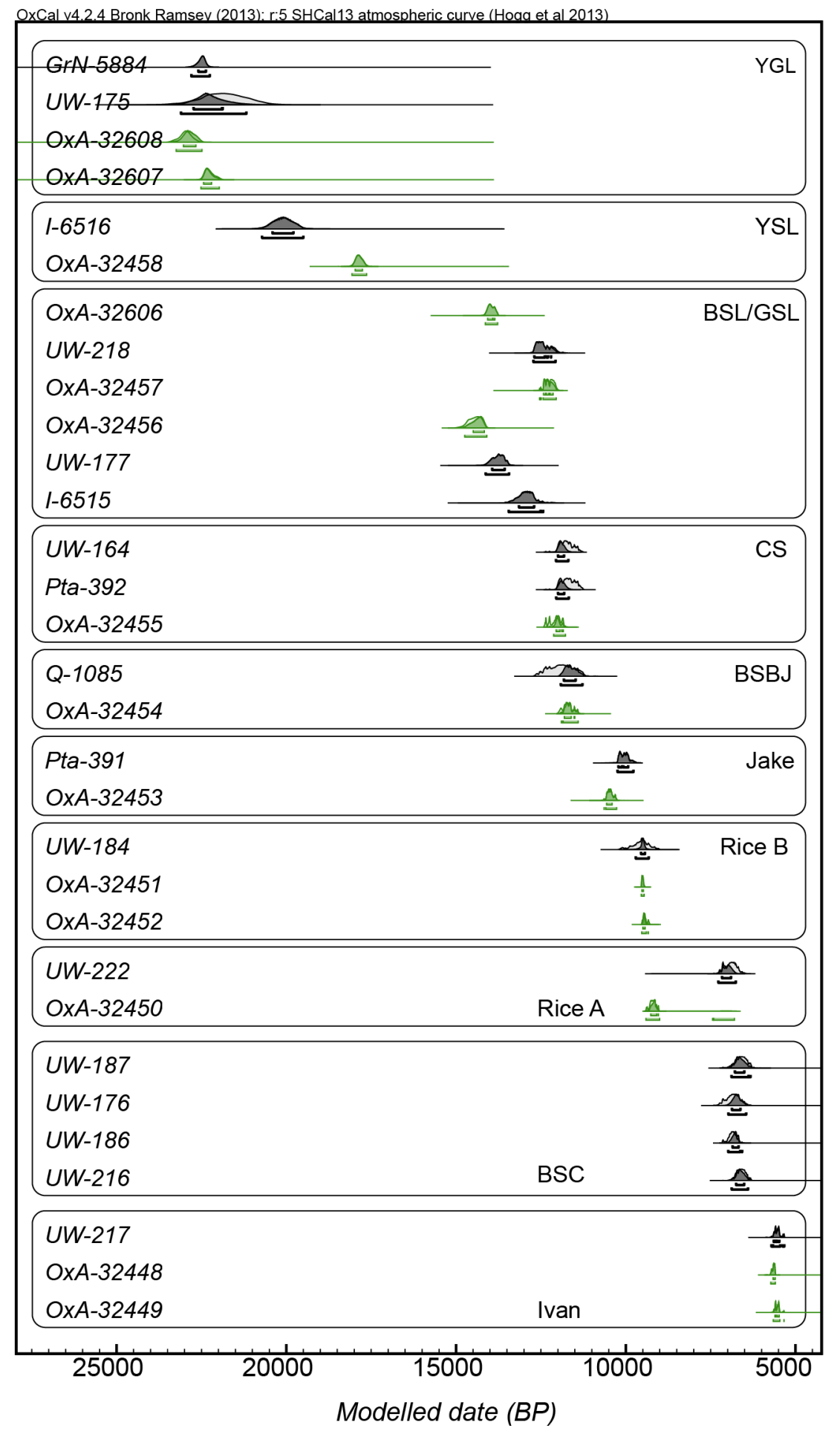

Figure 4.5.1: Bayesian model of radiocarbon dates from Nelson Bay Cave, indicating the unmodelled age distributions in light shading and the modelled ranges in dark shading. The dates coloured green are the new AMS dates reported in this study. 

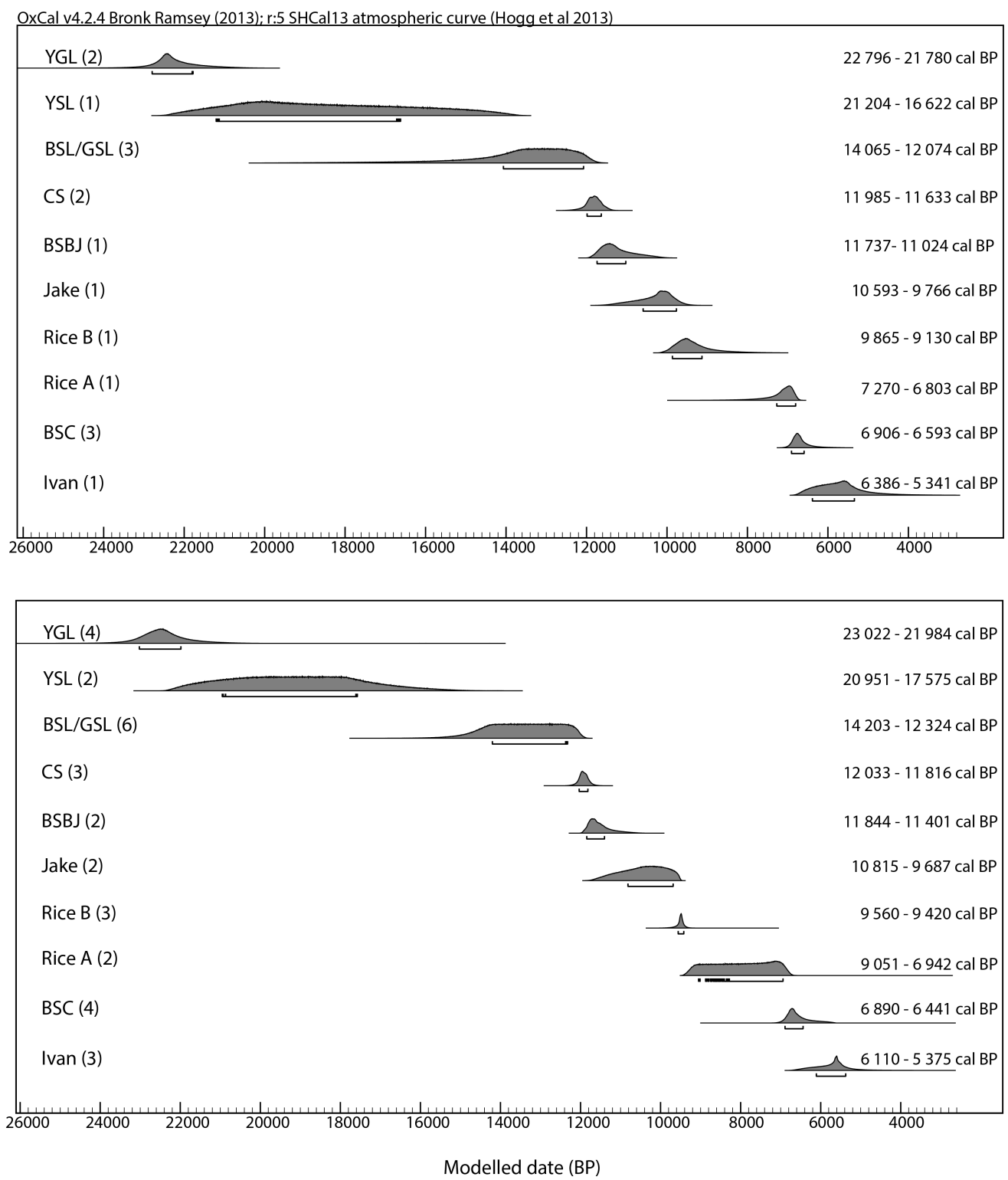

Figure 4.5.2: Modelled age ranges of the stratigraphic levels at Nelson Bay Cave, (top) based on the dates published in Deacon (1984) and (bottom) incorporating fourteen AMS dates from this study. The number of dates for each level is indicated in brackets. 
Table 4.6: Two sets of modelled age results in calibrated years BP for levels and boundaries at NBC, based on the previously published dates only and with the new AMS ages incorporated. Results are shown at one and two standard deviations, and the range for each is also provided in each case. Produced in OxCal 4.2, using SHCal13

\begin{tabular}{|c|c|c|c|c|c|c|c|c|}
\hline \multirow{3}{*}{ YGL } & \multirow{6}{*}{$\begin{array}{l}\text { Old only } \\
\text { with AMS }\end{array}$} & & \multirow{2}{*}{\multicolumn{2}{|c|}{ Modelled $1 \sigma$}} & \multirow[t]{2}{*}{ Range } & \multicolumn{2}{|c|}{ Modelled $2 \sigma$} & \multirow[t]{2}{*}{ Range } \\
\hline & & & & & & from & to & \\
\hline & & Span & 22796 & 21780 & 1016 & 23509 & 20630 & 2879 \\
\hline & & Boundary & 22496 & 21124 & 1372 & 22582 & 20180 & 2402 \\
\hline & & Span & 23022 & 21984 & 1038 & 23678 & 20921 & 2757 \\
\hline & & Boundary & 22384 & 21378 & 1006 & 22456 & 20328 & 2128 \\
\hline \multirow[t]{4}{*}{ YSL } & Old only & Span & 21204 & 16622 & 4582 & 21926 & 14492 & 7434 \\
\hline & & Boundary & 15589 & 13549 & 2040 & 19761 & 13471 & 6290 \\
\hline & with & Span & 20951 & 17575 & 3376 & 22062 & 16260 & 5802 \\
\hline & & Boundary & 17874 & 16150 & 1724 & 17951 & 14894 & 3057 \\
\hline \multirow{4}{*}{$\begin{array}{l}\text { GSL/ } \\
\text { BSL }\end{array}$} & Old only & Spal & 14065 & 12074 & 1991 & 16729 & 11735 & 4994 \\
\hline & & Boundary & 12152 & 11737 & 415 & 12513 & 11612 & 901 \\
\hline & with AMS & Span & 14203 & 12324 & 1879 & 14939 & 11979 & 2960 \\
\hline & & Boundary & 12152 & 11927 & 225 & 12310 & 11835 & 475 \\
\hline \multirow[t]{4}{*}{$\mathrm{CS}$} & Old only & Spar & 11985 & 11633 & 352 & 12218 & 11422 & 796 \\
\hline & & Boundary & 11826 & 11484 & 342 & 11946 & 328 & 618 \\
\hline & wit & Span & 12033 & 11816 & 217 & 12174 & 11669 & 505 \\
\hline & & Boundary & 11935 & 11708 & 227 & 12002 & 11546 & 456 \\
\hline \multirow[t]{4}{*}{ BSBJ } & $\overline{\text { Old }}$ & $\overline{\mathrm{Spa}}$ & 11737 & 11024 & 713 & 11866 & 10389 & 1477 \\
\hline & & Boundary & 11510 & 10082 & 1428 & 11675 & 9959 & 1716 \\
\hline & witl & Spr & 11844 & 11401 & 443 & 11947 & 10897 & 1050 \\
\hline & & Bou & 11770 & 11042 & 728 & 11810 & 10489 & 1321 \\
\hline \multirow[t]{4}{*}{ Jake } & Old only & $\mathrm{Sp}$ & 10593 & 9766 & 827 & 11271 & 9562 & 1709 \\
\hline & & Bor & 10027 & 9565 & 462 & 10187 & 9340 & 847 \\
\hline & with AMS & Span & 10815 & 9687 & 1128 & 11412 & 9538 & 1874 \\
\hline & & Boundary & 9647 & 9476 & 171 & 9949 & 9452 & 497 \\
\hline \multirow{6}{*}{ Rice B } & Old only & Spa & 9865 & 9130 & 735 & 10096 & 8294 & 1802 \\
\hline & & $\mathrm{Bo}$ & 670 & & 1111 & 9873 & 7492 & 2381 \\
\hline & & Bounds & 7690 & 6847 & 843 & 8826 & 6770 & 2056 \\
\hline & with AMS & Span & 9560 & 9420 & 140 & 9784 & 9299 & 485 \\
\hline & & Boun & 9492 & & 122 & 9522 & 9231 & 291 \\
\hline & & Boundary & 9405 & 9180 & 225 & 9510 & 6903 & 2607 \\
\hline \multirow[t]{4}{*}{ Rice A } & Old only & $\mathrm{Spa}$ & 7270 & 6803 & 467 & 8078 & 6708 & 1370 \\
\hline & & & 6980 & 6761 & 219 & 7121 & 6688 & 433 \\
\hline & with AMS & Span & 9051 & 6942 & 2109 & 9236 & 6870 & 2366 \\
\hline & & Boun & 6990 & 6753 & 237 & 7145 & 6671 & 474 \\
\hline \multirow[t]{4}{*}{$\mathrm{BSC}$} & Old only & Spa & 6906 & 6593 & 313 & 7047 & 6155 & 892 \\
\hline & & & 6830 & & 465 & 6892 & & 1252 \\
\hline & with AMS & Span & 6890 & 6441 & 449 & 7004 & 5861 & 1143 \\
\hline & & Boundary & 6732 & 5612 & 1120 & 6764 & 5604 & 1160 \\
\hline \multirow[t]{4}{*}{ Ivan } & Old only & Spar & 6386 & 5341 & 1045 & 6753 & 4509 & 2244 \\
\hline & & Boundary & 5607 & 4815 & 792 & 5692 & 3447 & 2245 \\
\hline & with AMS & Span & 6110 & 5375 & 735 & 6632 & 4929 & 1703 \\
\hline & & Boundary & 5598 & 5144 & 454 & 5647 & 4223 & 1424 \\
\hline
\end{tabular}


the observations that the Wilton may have dispersed from north to south, appearing first in Zimbabwe and Namibia, although the dates upon which that observation is based may well require upward revision themselves (Mitchell, 2002). Alternative interpretations of the technological changes within these levels may nullify these models, however, as some researchers have noted that the transition between the Oakhurst and Wilton might be better delineated after Rice A (e.g. Inskeep, 1987), in which case Wilton characteristics dominate much later, c. 7 kcalBP. The matter is confounded by the stratigraphic resolution of Klein's excavation, however, and cannot be resolved here.

The rationale for redating levels BSL and GSL was to clarify the date inversion which existed for this level. However, three new dates for these two levels instead confirmed the inversion. While the description of the stratigraphy in Deacon (1984) does not note that there was difficulty in distinguishing these two levels, the excavation was stepped in at this level over the back two rows (9 and 10) and the AMS sample from GSL comes from square $\Delta 9$. However, a new AMS date from the underlying BSL still conflicts with the two conventional dates from BSL. A possible answer to this confusion is found in Mitchell's (1988) analysis of the Robberg lithic material from NBC. He reports that the level GSL should not be considered as a true Robberg assemblage, but rather a transitional stage with the Oakhurst, along with level BSL, as these two levels reflect a mix of Robberg and Oakhurst features. Taken together with the confusing set of dates form this level, this may in fact demonstrate that these two levels may be mixed, and this was not recognised by the excavator. This new information indicates that this assemblage may not be suitable for evaluating the transition between the two technocomplexes.

\subsubsection{Byneskranskop 1}

The individual modelled ages are shown in Figure 4.5.3 and Figure 4.5.4 shows the modelled date ranges for each level (also provided in Table 4.7 at one and two standard deviations, with the range of each age estimate). A model based upon only the old set

of dates is not included here, as that dataset was small and many levels were completely undated. The general coherence of the stratigraphy is confirmed by the new set of AMS dates, although several inversions indicate that the stratigraphy is insecure in places. In general, the stratigraphy was described by Schweitzer and Wilson (1982: 21) as "poor", which "allows the possibility that material from adjacent layers may have been incorrectly assigned in some of the squares. The presence of seed cases of probably 


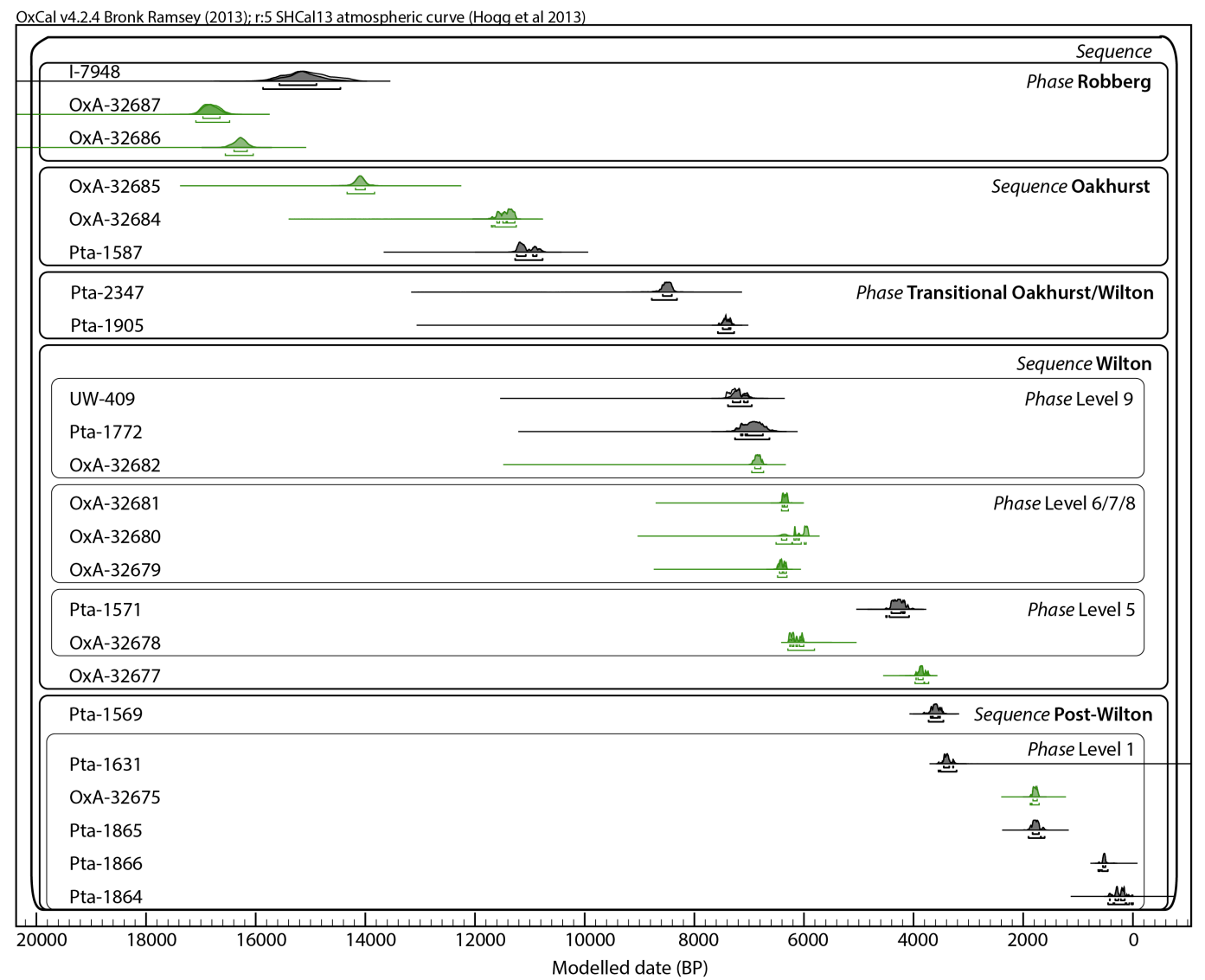

Figure 4.5.3: Bayesian model of radiocarbon dates from Byneskranskop 1, indicating the unmodelled age distributions in light shading and the modelled ranges in dark shading. The dates coloured green are the new AMS dates reported in this study.

recent date, as far down as layer 15 and ascribable to rodent activity (see section on plant remains), represents another factor that cannot be ignored. However, since there was no clear evidence of major disturbance of the deposits in the excavated area apart from the surface deposits and the human burial in the test pit, the amount of mixing of material is not likely to have been great." OxCal Bayesian models are useful for identifying incongruities in the sequence of ages: in particular, the new ages for Layer 6 and Layer 11 are not accepted in the model and are highlighted as outliers.

In the model, levels 6,7 and 8 are modelled as a single phase, to accommodate the inversion in level 6 , and given the uncertainty in the stratigraphy in this part of the sequence. The reasonably tight clustering of ages from these three levels indicates rapid deposition rates over these levels. Given the descriptions of the stratigraphy of level 11 as an "in-fill", this date is discarded from the model. However, the inversion may also explain the archaeological sequence in this part of the sequence. Schweitzer and Wilson 


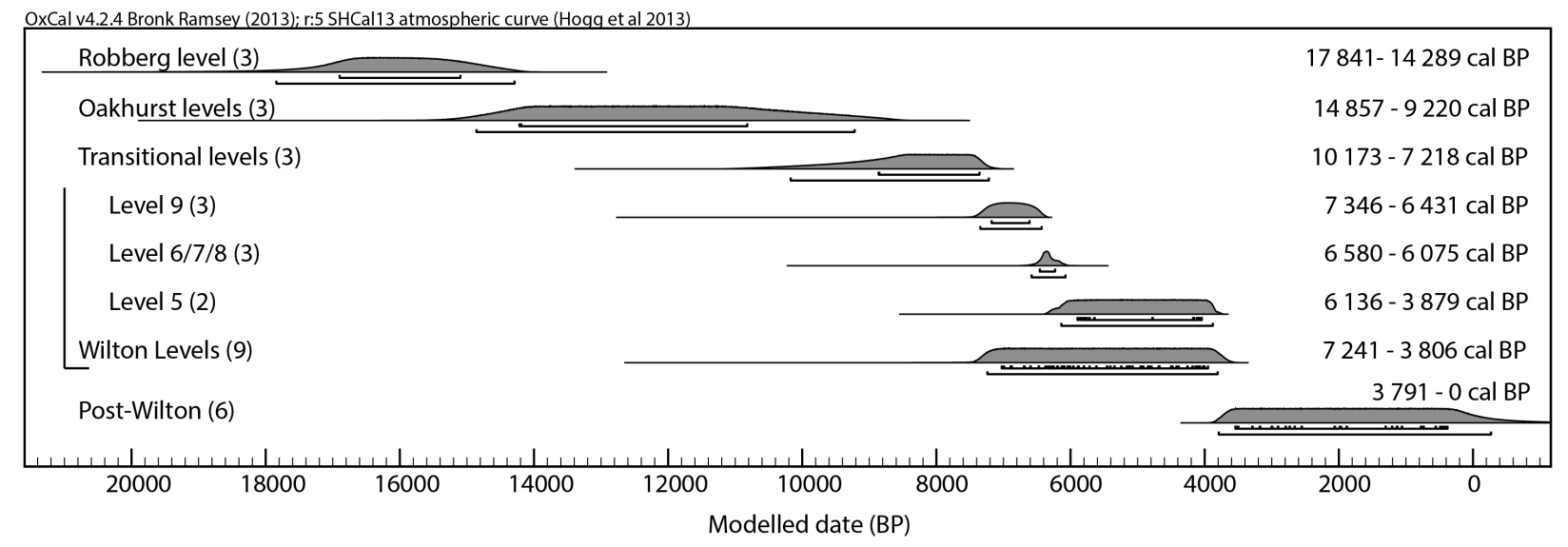

Figure 4.5.4: Modelled age ranges of the stratigraphic levels at Byneskranskop 1. The number of radiocarbon dates for each level is indicated in brackets.

Table 4.7: Modelled age results in calibrated years BP for levels and boundaries at BNK1, based on the previously published and new AMS dates. Results are shown at one and two standard deviations, and the range for each is also provided in each case. Produced in OxCal 4.2, using SHCal13

\begin{tabular}{lrrr|rrr}
\hline & \multicolumn{2}{c}{ Modelled age $1 \sigma$} & Range & \multicolumn{2}{c}{ Modelled age 2 $\sigma$} & Range \\
& from & to & & from & to & \\
\hline Level 19 & 16898 & 15097 & 1801 & 17841 & 14289 & 3552 \\
Robberg/Oakhurst boundary & 15010 & 14170 & 840 & 15545 & 14025 & 1520 \\
Oakhurst levels & 14216 & 10820 & 3396 & 14857 & 9220 & 5637 \\
Trans./Oakhurst boundary & 10785 & 8489 & 2296 & 11028 & 8451 & 2577 \\
Trans. levels & 8861 & 7358 & 1503 & 10173 & 7218 & 2955 \\
Wilton/Trans. boundary & 7422 & 7218 & 204 & 7504 & 7040 & 464 \\
Wilton Levels & 7027 & 3951 & 3076 & 7241 & 3806 & 3435 \\
Level 9 & 7177 & 6611 & 566 & 7346 & 6431 & 915 \\
9/678 boundary & 6533 & 6355 & 178 & 6707 & 6320 & 387 \\
Level 6/7/8 & 6459 & 6232 & 227 & 6580 & 6075 & 505 \\
678/5 boundary & 6356 & 6055 & 301 & 6412 & 6005 & 407 \\
Level 5 & 5897 & 4043 & 1854 & 6136 & 3879 & 2257 \\
Wilton/Post-Wilton boundary & 3847 & 3656 & 191 & 3914 & 3549 & 365 \\
Post-Wilton & 3543 & 379 & 3164 & 3791 & -270 & 4061 \\
Level 1 & 3247 & 380 & 2867 & 3540 & -301 & 3841 \\
\hline \hline
\end{tabular}


(1982) assign the tool assemblage in levels 10-12 to a separate phase $2 / 3$, transitional between the Oakhurst (phase 2) and Wilton (phase 3) assemblages, in terms of tool types and raw material patterning. Thus, the actual dates for these levels may reflect mixing in this part of the sequence. Unfortunately, given that these levels span the change from an Oakhurst to Wilton technology, these uncertainties about the stratigraphy undermine the possibility of studying this transition in detail.

The age of the oldest occupation levels at the site are extended back in time by approximately 1000 years from 14236 - 15669 calBP to 17105 - 16555 calBP. In the site report, levels 19 and 18 were assigned to phase 1, suggested tentatively to be the Robberg. However, the authors note that the assemblage has affinities with the Oakhurst and may be transitional between the two. This may be the case, as there are dates for Oakhurst assemblages in the southern Cape, from Nelson Bay Cave and Kangkara, that fall on the more recent end of the modelled range for level 19 (17 963 14273 calBP based on the three available dates). However, updated understandings of the technological variation in Robberg assemblages, in conjunction with the new early dates, rather suggest that the assemblage is better interpreted as a regional variant of the Late Pleistocene microlithic assemblages that are found across southern Africa (Pargeter, in press), than as a transitional phase.

The new date for level 1 clarifies a small uncertainty about the age of this layer, the base of which was previously dated to c. $3.5 \mathrm{kcalBP}$. However, this level contains bones of domesticated animals, and such an early date would dramatically pre-date other evidence for domesticates in this region. Thus, the date was assumed to relate to the underlying level 2 (Schweitzer and Wilson, 1982). The new date for the lowest sub-unit of level 1 (Eva) now confirms that this date was likely erroneous and indicates that the age of the domesticated animal bones is c. $1.8 \mathrm{kcalBP}$, which accords well with other dates for early herding sites in the southern Cape (Henshilwood, 1996).

\subsubsection{Correspondence with the overall southern African LSA chronology}

Despite the relative lack of stratigraphic control for the samples dated here, several conclusions about the site chronologies are possible. Firstly, the age of the Robberg in the southern Cape is older by several hundred years than previously known, with implications for the origin and diffusion of the Late Pleistocene microlithic technologies. 
The AMS date at NBC of $19110 \pm 110$ BP matches closely with a date for the microlithic assemblage from Sehonghong in the Lesotho highlands (19 $400 \pm 200$ BP for level BAS: Mitchell and Vogel, 1994), which is a possible expression of Robberg-like technologies (i.e. those directed towards bladelet production, Mitchell, 1995). These new results challenge somewhat an impression that microlithic, bladelet technologies might have first emerged in highland settings in response to deteriorating environmental conditions around the LGM. It is possible that the early dates for microlithic technologies from the Lesotho highlands represent a sampling bias that will be redressed as more early Robberg assemblages in other regions are dated. Alternatively, if microlithic bladelet technologies did indeed first manifest in the Lesotho highlands, then they spread very rapidly outwards to the southern coast, implying a considerable degree of interconnectedness between groups in southern Africa.

The stratigraphic uncertainties noted in levels GSL and BSL at NBC make it difficult to assess the age of the transition between the Robberg and the Oakhurst at this site. The first secure Oakhurst level is thus CS, which is now modelled to between 12174 11669 calBP ( $2 \sigma$ range; see table 4.6 ), which is well within the known age range for this industry in the southern Cape. The Robberg/Oakhurst transition is dated earlier at Byneskranskop 1, however, where the earliest Oakhurst assemblage, in level 17, has

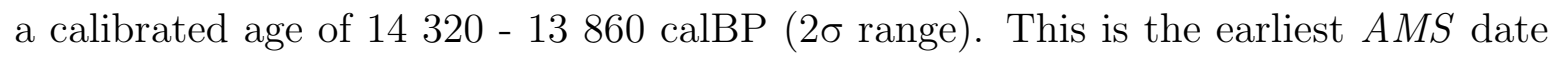
for an Oakhurst assemblage and is the fourth earliest radiocarbon date for Oakhurst material, after the sites of Heuningneskrans and Bushman Rock Shelter in Limpopo, and Kangkara in the southern Cape. The calibrated range for level 17 at BNK1 falls a couple of thousand years before the age usually given for the start of the Oakhurst at c. $12 \mathrm{ka}$. In part, this simply highlights the importance of considering the calibrated age range, a surprisingly frequently overlooked consideration in discussions of technological change in southern Africa. Interestingly, Inskeep (1987), in his monograph on the Nelson Bay Cave excavations, suggested that the Oakhurst industry might have originated in the southern Cape, based on ???

NBC now provides the earliest AMS date yet obtained for a Wilton assemblage in South Africa, calibrated to between 9400 and 9032 calBP (2 $\sigma$ range). There is one earlier date for a Wilton assemblage in South Africa of $8670 \pm 140$ BP, from Maqonqo Shelter in the Thukela Basin, KwaZulu-Natal, reported in Mazel (1996), and still earlier dates from sites in Zimbabwe and Namibia (Wendt, 1976; Cooke, 1979). However, Mazel notes that the date for the underlying level is over 1000 years more recent $(7460 \pm 140$ $\mathrm{BP}$ ), indicating stratigraphic problems in this part of the site. Mazel himself thought 
that the more recent date was the more secure, and noted the need for additional dates to confirm the ages of these levels. And the early dates from the north were obtained in the 1970's from large aggregated samples - a reassessment of the MSA chronology at Apollo 11 has already substantially revised the age estimates for the site, although not during the Holocene levels (Vogelsang et al., 2010). Thus, the new AMS date from NBC is the oldest secure date for a Wilton assemblage. This and other early dates from Dikbosch (8010 \pm 60 BP: $9005-8635$ calBP, $2 \sigma)$ and Oakhurst itself $(7910 \pm 70$ BP; 8990 - 8521 calBP, $2 \sigma$ ) provide support for an earlier transition between the Oakhurst and Wilton in some regions than the rather imprecise c. 8 ka that is widely accepted (Lombard et al., 2012).

Before concluding, it is briefly noted that modelling approaches also hold promise for understanding the processes of technological change. Figure 4.5.5 below shows the modelled boundary ages across southern Africa for the major technocomplexes as based on several hundred radiocarbon dates from fifty-four sites across the subcontinent (taken from Lombard et al. (2012), with corrections for incorrect calibration), divided according to location in the fynbos and forest biome of the southern coast, and the savanna and grasslands of the interior. Note that the model for the fynbos/forest biome does not include the new AMS radiocarbon dates for NBC and BNK1 reported in this study, to allow their comparison with the existing chronology for this region. Further, as this demonstration is intended to be only illustrative of the potential for refined regional chronologies, the suitability of each date included has not been closely evaluated. Each set of dates associated with the different industries is in an independent Sequence model, with Boundaries at the start and end of each, and thus the modelled ages of each industry are independent from one another. The age ranges for the boundaries are provided in the figure at the $1 \sigma$ range. In all instances, the industry starts earlier in the savanna/grassland biome and ends later there. Also evident in the figure is the extent of overlap between the technocomplexes, which may speak to the processes of transition from one industry to another (the differences are provided in Table 4.8). The difference between the modelled boundary ages for the Robberg and Oakhurst across all sites indicates that these two technologies co-existed for between approximately four and five thousand years. This is a relatively long period of overlap as compared to between the Oakhurst and Wilton, approximately one and a half thousand years, and suggests that the drivers, mechanisms and/or processes of technological change may have differed between the two transitions. However, although this analysis indicates some future directions for chronological reesarch in southern Africa, any firm conclusions about the sequence and transitional processes are currently impossible, given the need 


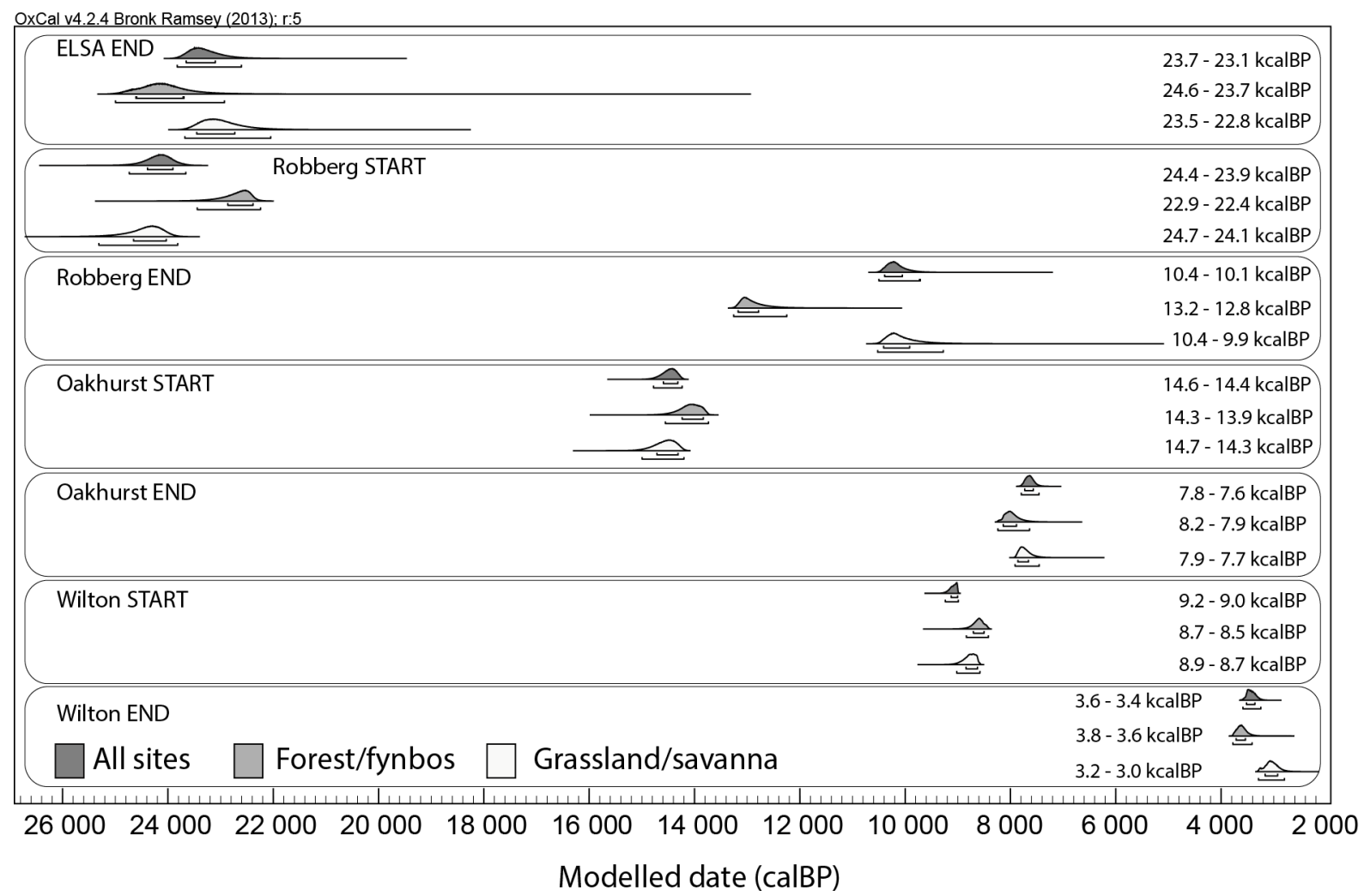

Figure 4.5.5: Modelled start and end boundaries for the major Later Stone Age technocomplexes, separated according to region.

for comprehensive assessments of both the actual dates that are included in the models and of the lithic assemblage categorisations at the industry level.

\subsection{Conclusions}

Principally, the results presented in this chapter demonstrate how improved radiocarbon dating methods and more dates per site can improve site and regional chronologies, usually by constraining age ranges and improving the associated errors of modelled ages. In addition, the modelling and mapping approaches included here allow more nuanced observations on the appearance and spread of technologies, and hence on the processes of technological change. Future work with the southern African dataset will assess the quality of individual radiocarbon dates, and their archaeological associations. Alternative, less arbitrary spatial and temporal boundaries should be explored, as more coherent patterning may emerge at smaller scales. There is also scope to employ more sophisticated modelling and mapping approaches in coordination, using advanced GIS 
Table 4.8: Differences in years between the modelled boundaries of lithic industries in three regions, based on several hundred radiocarbon dates from across 54 sites (at the $1 \sigma$ and $2 \sigma$ range). These differences provide a measure of the length that the different lithic industries overlapped in time in the three regions.

\begin{tabular}{lrrrr}
\hline & $1 \sigma$ range & \multicolumn{2}{r}{$2 \sigma$ range } \\
\hline Robberg-Oakhurst Difference & & & & \\
All sites & 4047 & 4498 & 3880 & 4853 \\
Fynbos-forest & 814 & 1435 & 625 & 1979 \\
Savanna-grassland & 4070 & 4760 & 3851 & 5406 \\
\hline Oakhurst-Wilton Difference & & & & \\
All sites & 1336 & 1550 & 1253 & 1684 \\
Fynbos-forest & 437 & 781 & 310 & 1057 \\
Savanna-grassland & 1479 & 2000 & 1238 & 2230 \\
\hline \hline
\end{tabular}

capabilities (e.g. Higham et al., 2014; Green, 2011).

The new dates for Nelson Bay Cave and Byneskranskop 1 have greatly improved the chronologies for these two sites, increasing the utility of the sea surface temperature reconstructions that are the aim of this thesis. In addition, these dates have helped clarify aspects of the stratigraphy of the two sites, mostly obviously the inversion in layers GSL and BSL at NBC and in levels 6, 7 and 8 at BNK1. Other notable findings that have emerged from the new dates are the extension of the Robberg further back at both sites, particularly at NBC where this is now the earliest dated Robberg assemblage in the southern Cape, and the early start for the Wilton at NBC. 


\section{Chapter 5}

\section{Shell isotope data: climate trends and seasonality}

\section{Contents}

5.1 Assessing physiological effects on seasonal amplitude . . . 108

5.2 Alternative correction for changes in seawater $\delta^{18} \mathrm{O} \ldots . .109$

5.3 Holocene study . . . . . . . . . . . . . . 110

5.3 .1 Results ....................... 113

$5.3 .1 .1 \quad \delta^{18} \mathrm{O}$ results $\ldots \ldots \ldots \ldots \ldots$

$5.3 .1 .2 \quad \delta^{13} \mathrm{C}$ results . . . . . . . . . . . 117

5.3.2 Discussion of LSA $\delta^{18} \mathrm{O}$ and $\delta^{13} \mathrm{C}$ sample results . . . . . . 119

5.4 MIS4 and MIS5 study . . . . . . . . . . . 122

5.4 .1 Results . . . . . . . . . . . . . . . 123

$5.4 .1 .1 \quad \delta^{18} \mathrm{O}$ results $\ldots \ldots \ldots \ldots \ldots$

$5.4 .1 .2 \quad \delta^{13} \mathrm{C}$ results . . . . . . . . . . . . 135

5.4 .2 Discussion of MSA sample results . . . . . . . . . 137

5.5 Comparison with other estimates of seasonality . . . . 140

5.5.1 Comparison with shell records of SST seasonality . . . . . 140

5.5.2 Comparison with an offshore core record of SST seasonality · 142

5.5.3 Comparison with modelled estimates of SST seasonality . . . 144

5.6 Conclusions . . . . . . . . . . . . . . . 147 
The core results of this thesis, namely the serial $\delta^{18} \mathrm{O}$ measurements of twenty-seven Holocene and terminal Pleistocene aged Turbo opercula and forty-five MIS4 and MIS5 aged opercula, collectively spanning about 115000 years, are presented here. I first assess whether the physiological tolerances of Turbo sarmaticus bias the temperature records captured in their shells across glacial and interglacial periods (section 5.1) and assess the validity of using the global Waelbroeck et al. (2002) $\delta^{18} \mathrm{O}$ curve for data correction by comparison with an Agulhas record of $\delta^{18} \mathrm{O}$. I describe the results of the Holocene and MIS4 and 5 datasets separately (sections 5.3 and 5.4 respectively), and then subsequently compare the Holocene and Pleistocene results. For comparison, this analysis will refer to the dataset of modern Turbo analyses collected by Mariagrazia Galimberti (2010), introduced briefly in section 3.1 of the Methods chapter. Finally, I briefly discuss the results in the light of previous studies of SST seasonality from the Agulhas region (section 5.5).

\subsection{Assessing physiological effects on seasonal amp- litude}

As outlined in section 3.1.1, Turbo do not grow all the time, and the SST record captured in modern opercula is compressed as compared to the true range of SSTs (see section 3.1.3). The results from Galimberti (2010) show that individual Turbo opercula appeared to not capture approximately the $1.5{ }^{\circ} \mathrm{C}$ warmest and coolest SSTs measured directly at the coast, indicating that the molluscs slow or cease growth during temperature extremes, below temperatures of c. $14{ }^{\circ} \mathrm{C}$ and above c. $24{ }^{\circ} \mathrm{C}$. If these data reflect firm environmental limits for T. sarmaticus, there is the strong likelihood that the seasonal amplitude recorded in archaeological shells may be more compressed during periods when average temperatures are either considerably cooler or warmer, as temperatures will be outside this physiological range for more of the year, and the mollusc will cease growth for longer. This would invalidate comparisons of the seasonal range between glacial and interglacial periods, as the bias against cool temperatures would lead to a greatly compressed seasonal signal under glacial conditions, regardless of the actual seasonal range. However, Galimberti also suspected that T. sarmaticus does continue to grow at least in temperatures below the minimum $14.3^{\circ} \mathrm{C}$ recorded in the modern shells from Mossel Bay as the archaeological Pleistocene-aged shells that she analysed recorded 

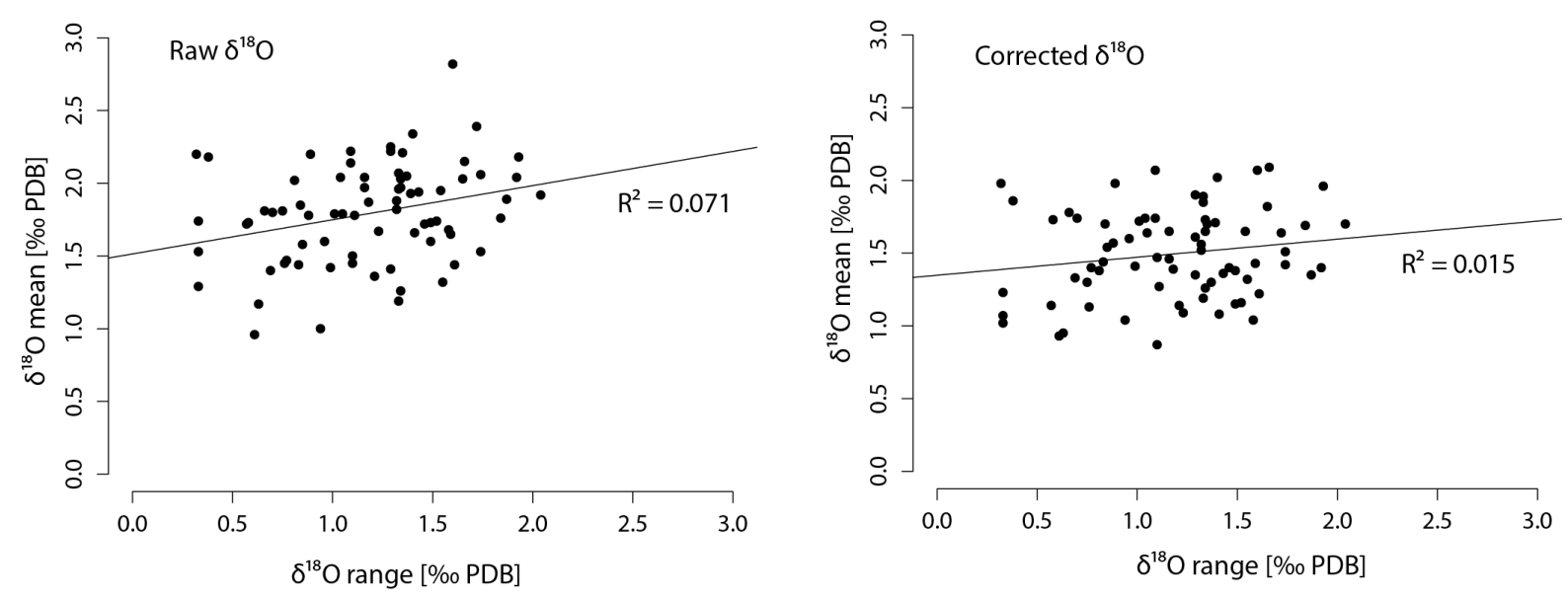

Figure 5.1.1: Scatterplots with linear regression models of average $\delta^{18} \mathrm{O}$ for each shell against the range of $\delta^{18} \mathrm{O}$ values per shell for both the raw $\delta^{18} \mathrm{O}$ values (left) and $\delta^{18} \mathrm{O}$ values corrected for changes in global seawater $\delta^{18} \mathrm{O}$ (right) (Waelbroeck et al., 2002).

cooler temperatures, and the modern ecological range of Turbo sarmaticus extends all the way to the markedly cooler Atlantic waters around the Cape Point peninsula. These observations hint rather that the reduced SST amplitude recorded in the modern shells might reflect a physiological limit on time spent growing, and that the animals can shift their temperature tolerances to some degree.

To evaluate if there is a bias on growth during cooler periods, the average $\delta^{18} \mathrm{O}$ values for each shell (presented in greater detail in sections 5.3 and 5.4 below), which reflect the mean temperature experienced during growth, are compared to the total range for that shell (Figure 5.1.1), for both the raw $\delta^{18} \mathrm{O}$ values and the $\delta^{18} \mathrm{O}$ values corrected for changes in global seawater $\delta^{18} \mathrm{O}$ using the Waelbroeck et al. (2002) dataset. These regressions show little sign of a relationship between cooler average SSTs and reduced SST ranges. This lack of a relationship indicates that the range of reconstructed temperatures recorded by the shells reflect real shifts in seasonal amplitude.

\subsection{Alternative correction for changes in seawater $\delta^{18} \mathrm{O}$}

To evaluate the validity of applying the Waelbroeck et al. (2002) global $\delta^{18} \mathrm{O}$ seawater correction (see section 3.4 for a discussion of the necessity for corrections), the shells were alternatively corrected using a comparatively high-resolution planktic foraminiferal 
Table 5.1: Alternative $\delta^{18} \mathrm{O}[\mathrm{PDB}]$ corrections and temperature calculations for Holocene shells using the Simon et al. (2015) Agulhas planktic foraminiferal record $\delta^{18} \mathrm{O}$ ( G. ruber $\left.\delta^{18} \mathrm{O}\right)$, shown against the averaged temperatures calculated using the Waelbroeck et al. (2002) correction (full shell data to follow, see Table 5.4). Shell temperatures calculated using Grossman and $\mathrm{Ku}$ (1986) temperature equation with the Hudson and Anderson (1989) correction.

\begin{tabular}{lccccc}
\hline Period & $\begin{array}{c}\text { G. ruber } \delta^{18} \mathrm{O} \\
\text { average }\end{array}$ & $\begin{array}{c}\delta^{18} \mathrm{O} \\
\text { correction }\end{array}$ & $\begin{array}{c}\text { Shell } \delta^{18} \mathrm{O} \\
\text { average }\end{array}$ & $\begin{array}{c}\mathrm{T}^{\circ} \\
\text { average }\end{array}$ & $\begin{array}{c}\text { Waelbroeck T} \\
\text { average }\end{array}$ \\
\hline Late Holo & -1.47 & 0 & 1.44 & 15.7 & 15.7 \\
Mid Holo & -1.37 & -0.10 & 1.71 & 14.5 & 14.7 \\
Early Holo & -1.10 & -0.37 & 2.00 & 13.3 & 13.4 \\
Late Pleisto & -0.48 & -0.99 & 2.62 & 10.6 & 11.6 \\
\hline \hline
\end{tabular}

$\delta^{18} \mathrm{O}$ record, from an offshore core located adjacent to the East London coast, c. $500 \mathrm{~km}$ east of NBC (Simon et al., 2015). This record does not extend to the recent past (i.e. there is no "modern" set of values) and so the late Holocene $\delta^{18} \mathrm{O}$ values are used as a baseline to compare the changes in $\delta^{18} \mathrm{O}$ for the other periods, assuming that changes in $\delta^{18} \mathrm{O}$ between the late Holocene and the recent past were minimal. The uncorrected $\delta^{18} \mathrm{O}$ values for Globigerinoides ruber were averaged according to the same time definitions as the shells, and the averaged value for each period was applied to the uncorrected $\delta^{18} \mathrm{O}$ values of each shell from that period. Table 5.1 shows the averaged $\delta^{18} \mathrm{O}$ values per period, the resulting $\delta^{18} \mathrm{O}$ corrections, the averaged $\delta^{18} \mathrm{O}$ shell values after correction and the converted temperature value for each period. The values are very similar to those using the Waelbroeck et al. (2002) curve, and suggest that the Waelbroeck corrections account for most of the seawater $\delta^{18} \mathrm{O}$ variability in this region, although the temperature reconstruction for the Late Pleistocene differs by c. $1{ }^{\circ} \mathrm{C}$. However, it is preferable to use the Waelbroeck correction, which is continuous at high-resolution over the entire period of this study, unlike the Simon et al. 2015 dataset, for which $\delta^{18} \mathrm{O}$ data are only available through to the LGM.

\subsection{Holocene study}

When viewed alongside the major climate fluctuations experienced during the preceding 120000 years, the Holocene is a period of comparatively stable climate. However, rapid, 
global-scale climate changes are still observed in climate archives and, given the lack of substantial greenhouse gas or ice sheet variations over the Holocene, the drivers of rapid climate change are still obscure (Mayewski et al., 2004; Wanner et al., 2011). A possible forcing is solar variability, overlain on the long-term orbitally-induced (Milankovitch) insolation changes (Mayewski et al., 2004), which principally affect seasonality at these timescales. However, the effect of solar variation for Southern Hemisphere (SH) climate has been disputed (Wanner et al., 2008), with apparent muting of climate reactions due to oceanic heat transport effects. The dearth of seasonally resolved SH climate proxies is still a shortcoming for large synthetic studies that have attempted to understand Holocene climate at the regional and global levels (e.g. Wanner et al., 2008; 2011). In addition, of significance for this thesis, at least four major technological transitions across Southern Africa (Lombard et al., 2012) occurred over this period, from the terminal Pleistocene c. 14000 years ago through to the late Holocene, c. 2000 years ago, as outlined in section 2.2. The intersection between climate and technology is one of the long-standing questions in southern African Later Stone Age archaeology (Deacon and Thackeray, 1984).

The Holocene is subdivided in this study into early (c. 12-8 ka; EH); middle (c. 8-4 ka; $\mathrm{MH}$ ) and late phases (c. $<4 \mathrm{ka} ; \mathrm{LH}$ ) according to convention (the Holocene is formally subdivided to $11.7 \mathrm{ka}$ b2k (before AD 2000) - $8.2 \mathrm{kcal} \mathrm{BP} ; 8.2$ - $4.2 \mathrm{kcal} \mathrm{BP}$ and $<4.2$ kcal BP (Walker et al., 2012)). Also included are three shells from terminal Pleistocene deposits at Nelson Bay Cave, dated to between c. 12-14.9 kcal BP. This dataset thus provides coverage for the Pleistocene/Holocene transition, and throughout much of the Holocene.

The three Holocene-aged sites from which samples were obtained are described in section 2.2.2 of Chapter 2. The age estimates for each shell are established by association with the radiocarbon dated stratigraphic sequences of each site (those for Byneskranskop 1 and Nelson Bay Cave were redated as part of this thesis - the results are reported in Chapter 4). The shells are individually named according to site, level and sample number, according to the accession information available for them from the Iziko South African Museum. Thus sample names beginning with an N, H and B are from Nelson Bay Cave, Hoffman's/Robberg Cave and Byneskranskop 1 respectively. The individual shells are listed in Table 5.2, with stratigraphic information, age estimates and seawater $\delta^{18} \mathrm{O}$ correction. Several powder samples from each shell (typically every fourth or fifth sample) were evaluated for recrystallisation, using the FTIR-ATR method described in section 3.3.2. Note, that the summary statistics provided in the results section have 
Table 5.2: Holocene and terminal Pleistocene opercula samples in chronological order, with associated stratigraphic information, age estimates, dimensions and ocean $\delta^{18} \mathrm{O}$ correction (from Waelbroeck et al., 2002).

\begin{tabular}{|c|c|c|c|c|c|c|c|c|c|}
\hline No. & Sample Name & Site & Strat Level & Square & $\begin{array}{r}\text { Length } \\
(\mathrm{mm})\end{array}$ & $\begin{array}{r}\text { Width } \\
(\mathrm{mm})\end{array}$ & $\begin{array}{l}\text { Age } \\
\text { (ka) }\end{array}$ & Period & $\begin{array}{c}\text { Correction } \\
\delta^{18} O[\% 0]\end{array}$ \\
\hline 1 & BEI_34 & BNK1 & Eva 1 & & 38.8 & 33.0 & $1.9-1.7$ & $\mathrm{LH}$ & 0 \\
\hline 2 & NIEIII_A5_10 & $\mathrm{NBC}$ & EIII (Inskeep) & A5 & 41.8 & 35.2 & c. 2.5 & $\mathrm{LH}$ & 0 \\
\hline 3 & NIEIII_A5_7 & $\mathrm{NBC}$ & EIII (Inskeep) & A5 & 37.5 & 31.4 & & & 0 \\
\hline 4 & BDud4_26 & BNK1 & 4 (Dud) & & 35.9 & 30.6 & $4.0-3.7$ & $\mathrm{LH}$ & 0 \\
\hline 5 & BDud4_27 & BNK1 & 4 (Dud) & & 38.2 & 32.2 & & & 0 \\
\hline 6 & HRCD6a-P-1 & $\mathrm{HRC}$ & Portia & D6a & 43.1 & 36.2 & $4.3-4.0$ & LH & 0 \\
\hline 7 & HRCD6c_RR1 & $\mathrm{HRC}$ & Rich./Royden & D6c & 33.5 & 29.1 & & $\mathrm{LH}$ & 0 \\
\hline 8 & BI5_29 & BNK1 & 5 (Inge) & & 45.7 & 37.9 & $6.1-3.9$ & $\mathrm{MH}$ & 0.03 \\
\hline 9 & NIA5_12 & $\mathrm{NBC}$ & Ivan & A5 & 36.6 & 30.9 & $6.6-4.9$ & $\mathrm{MH}$ & 0.03 \\
\hline 10 & NIA5_15 & $\mathrm{NBC}$ & Ivan & A5 & 42.3 & 36.8 & & & 0.03 \\
\hline 11 & BH6_34 & BNK1 & 6 (Hilary) & & - & 41.0 & $6.6-6.1$ & $\mathrm{MH}$ & 0.04 \\
\hline 12 & NGB4_6 & $\mathrm{NBC}$ & Glen & B4 & - & 32.6 & $7.0-5.9$ & $\mathrm{MH}$ & 0.06 \\
\hline 13 & BMort9_30 & BNK1 & 9 (Mort) & & 41.5 & 35.3 & $7.4-6.4$ & $\mathrm{MH}$ & 0.06 \\
\hline 14 & BMort9_35 & BNK1 & 9 (Mort) & & 46.9 & 39.4 & & & 0.06 \\
\hline 15 & NRAB4_20 & $\mathrm{NBC}$ & Rice A & B4 & 37.3 & - & $9.2-6.8$ & $\mathrm{MH}$ & 0.15 \\
\hline 16 & NRAB4_21 & $\mathrm{NBC}$ & Rice A & B4 & 37.5 & - & & $\mathrm{MH}$ & 0.15 \\
\hline 17 & NRB_B3_17 & $\mathrm{NBC}$ & Rice B & B3 & - & 30.2 & $9.7-9.2$ & $\mathrm{LH}$ & 0.21 \\
\hline 18 & NRB_B3_18 & $\mathrm{NBC}$ & Rice B & B3 & 37.9 & 32.3 & & & 0.21 \\
\hline 19 & NJB4_7 & $\mathrm{NBC}$ & Jake & A4 & 43.5 & 37.1 & $11.4-9.5$ & $\mathrm{LH}$ & 0.3 \\
\hline 20 & NJB4_9 & $\mathrm{NBC}$ & Jake & $\mathrm{A} 4$ & 38.4 & 33.3 & & & 0.3 \\
\hline 21 & NJB_A4_9 & $\mathrm{NBC}$ & Jake B & B4 & 38.9 & 32.0 & & LH & 0.3 \\
\hline 22 & NJB_A4_13 & $\mathrm{NBC}$ & Jake B & B4 & 43.0 & 36.1 & & & 0.3 \\
\hline 23 & NBSBJB4_2 & $\mathrm{NBC}$ & BSBJ & B4 & 33.2 & 28.5 & 11.9-10.9 & $\mathrm{LH}$ & 0.48 \\
\hline 24 & NBSBJB4_3 & $\mathrm{NBC}$ & BSBJ & B4 & - & 29.4 & & & 0.48 \\
\hline 25 & NGB_B8B_17 & $\mathrm{NBC}$ & GSL & $\mathrm{B} 8 \mathrm{~B}$ & 38.3 & 32.9 & $14.9-12$ & $\mathrm{LH}$ & 0.75 \\
\hline 26 & NGB_B8B_18 & $\mathrm{NBC}$ & GSL & $\mathrm{B} 8 \mathrm{~B}$ & - & - & & & 0.75 \\
\hline 27 & NGB_B8B_15 & $\mathrm{NBC}$ & GSL & $\mathrm{B} 8 \mathrm{~B}$ & - & 31.4 & & & 0.75 \\
\hline
\end{tabular}


already been corrected for global changes in seawater $\delta^{18} \mathrm{O}$ as per Waelbroeck et al. (2002). Statistical evaluations for the raw $\delta^{18} \mathrm{O}$ shell values are also provided, however, to demonstrate that the differences between levels are not driven entirely by the corrections to the Waelbroeck curve. However, these values are not representative of absolute or relative temperatures and cannot be interpreted without the seawater $\delta^{18} \mathrm{O}$ correction.

\subsubsection{Results}

The raw $\delta^{18} \mathrm{O}$ and $\delta^{13} \mathrm{C}$ serial sampling results for each shell, including a photo of each shell showing the drilling path, are provided in Appendices A and B. The coefficients of determination $\left(\mathrm{R}^{2}\right)$ for the regression between $\delta^{18} \mathrm{O}$ and $\delta^{13} \mathrm{C}$ for each shell are provided in Table 5.3. A strong relationship between $\delta^{18} \mathrm{O}$ and $\delta^{13} \mathrm{C}$ may indicate alteration of the carbonate, as $\delta^{18} \mathrm{O}$, which reflects temperature and water $\delta^{18} \mathrm{O}$, and $\delta^{13} \mathrm{C}$, which reflects the nutrient source and availability, should be independent of, or at least offset from, one another during formation of the carbonate. However, $\delta^{13} \mathrm{C}$ is also likely to be subject to seasonal variation, and so the two values may co-vary. Generally, the $\mathrm{R}^{2}$ values for each shell are low, but $\delta^{18} \mathrm{O}$ and $\delta^{13} \mathrm{C}$ are positively correlated for a few shells (i.e. $>0.30$ ). In none of these cases, however, do the $\delta^{18} \mathrm{O}$ averaged statistics for each time period substantially change if the shell is removed from that group, and the inclusion of these values does not substantially change the climatic interpretation and therefore they have been retained.

\subsubsection{1 $\delta^{18} \mathrm{O}$ results}

The $\delta^{18} \mathrm{O}$ values not corrected for changes in global seawater $\delta^{18} \mathrm{O}$ are significantly different when aggregated according to time period (i.e. EH, MH, LH and LP; one way ANOVA $(\mathrm{F}=5.055, \mathrm{p}=0.00186)$ : results of a post-hoc Tukey multiple comparison test reported in Table C1 of Appendix 3). In greater detail, Figure B1 of Appendix B shows the individual sets of serial samples recovered from each shell, corrected for changes in seawater $\delta^{18} \mathrm{O}$, displayed against the sample number from edge. Seasonal temperature cycles are clearly evident in some shells, although in many instances the sampling path or resolution seems to have been inadequate to capture these patterns.

Summary statistics (based on the corrected values for the changes in seawater $\delta^{18} \mathrm{O}$ ) for each of the twenty-seven opercula are provided in Table 5.3 below, while Figure 
5.3.1 displays the boxplots for each shell, coloured according to site. Also included for comparison are the modern Turbo opercula data of Galimberti (2010). It is immediately evident from this plot that the nearshore SST records correspond well with global temperature trends over this period, with coolest temperatures during the terminal Pleistocene and warming temperatures through the Holocene. No clear trends in temperature are evident over the $\mathrm{MH}$ and $\mathrm{LH}$, although the mean temperatures for each shell are either below the lowest measured value in the modern Galimberti dataset or at the lower end of the measured range.

Table 5.4 shows the aggregated results for each period, with equivalent temperature conversion statistics and the difference from Galimberti's modern dataset - the $\delta^{18} \mathrm{O}$ results are presented graphically in Figure 5.3.2. An ANOVA with post-hoc Tukey multiple comparison test at $95 \%$ confidence intervals reveals that all of the periods differ from one another significantly $(\mathrm{p}<<0.001$; the full results of the ANOVA and post-hoc tests are provided in Tables $\mathrm{C} 2$ and C3 of Appendix C). The general trend reflects warming near-shore SSTs from the Late Pleistocene through to the late Holocene and into the present.

A high degree of variation is sometimes evident between shells from the same level. Ten pairs of shells from the same level (in one instance, three shells from the same level) were measured and significant differences are observed between three of these sets (between NIA5_12 and 15 [p < 0.001]; BMort_9_30 and $35[\mathrm{p}<0.001]$ and NGB_B8B_17 and 18, and 17 and $15[\mathrm{p}<0.05$ and $<0.001$, respectively $]$ ). The differences may reflect time averaging across these stratigraphic units: all three of these paired sets come from stratigraphic contexts with age estimates that span over a millennium and so the shells could span periods of substantial environmental change. Alternatively, the differences between samples may reflect the micro-habitats of individual animals, suggesting that robust temperature estimates require sampling of multiple shells per unit of time. However, in most cases, the paired sets of samples are not significantly different, providing confidence that the molluscs generally record the local SST conditions adequately, and are not simply representative of micro-scale conditions. This was expected, given that the high energy wave dynamics of this coastline ensure thorough water mixing.

A possible confounding factor for the general trends observed here is site location, as BNK1 is likely to reflect much cooler temperatures, given its closer proximity to the cool waters of the Atlantic. As well-preserved shells are only available from the late and mid-Holocene levels at BNK1, this effect has the potential to bias the results of these two periods versus the early Holocene and terminal Pleistocene. Thus, the summary 
Table 5.3: Summary statistics of $\delta^{18} \mathrm{O}$ values for each Holocene and terminal Pleistocene operculum. Values are converted to temperature values using Grossman and $\mathrm{Ku}$ (1986) equation. The coefficient of determination $\left(R^{2}\right)$ is given for the regression between $\delta^{18} \mathrm{O}$ and $\delta^{13} \mathrm{C}$ for each shell. Sample names are provided in Table 5.2. Samples 1-7 date to the late Holocene, 8-16 to the middle Holocene, 17-24 to the early Holocene and 25-27 to the terminal Pleistocene. Facilities: a - Oxford Earth Sciences Kiel device; b - Bradford Archaeological Sciences Gasbench; c - NIGL Multiprep.

\begin{tabular}{|c|c|c|c|c|c|c|c|c|c|c|c|c|c|}
\hline \multirow{4}{*}{$\begin{array}{l}\text { Facility } \\
R^{2}\end{array}$} & \multicolumn{8}{|c|}{ Late Holocene } & \multicolumn{5}{|c|}{ Middle Holocene } \\
\hline & 1 & 2 & 3 & 4 & 5 & 6 & 7 & 8 & 9 & 10 & 11 & 12 & 13 \\
\hline & $\mathrm{c}$ & $\mathrm{b}$ & $\mathrm{a}$ & $\mathrm{b}$ & $\mathrm{c}$ & $\mathrm{c}$ & b & $\mathrm{b}$ & $\mathrm{a}$ & $\mathrm{b}$ & $\mathrm{a}$ & $\mathrm{a}$ & $\mathrm{a}$ \\
\hline & .18 & 0.08 & 0.09 & 0.00 & 0.12 & 0.44 & 0.08 & 0.00 & 0.15 & 0.35 & 0.51 & 0.02 & 0.05 \\
\hline \multicolumn{14}{|l|}{$\delta^{18} O[\%]$} \\
\hline Mean & 1.73 & .42 & .19 & 1.60 & 1.44 & 1.26 & 1.53 & 1.81 & 0.96 & 1.50 & 1.58 & 1.41 & 1.80 \\
\hline & & 9 & 33 & 0.96 & 0.83 & 1.34 & 1.74 & 0.66 & 0.61 & 1.10 & 0.85 & 1.29 & 0.70 \\
\hline Std. dev. & & 0.30 & 0.36 & 0.28 & 0.24 & 0.48 & 0.49 & & 19 & 0.27 & 0.24 & 0.39 & 0.23 \\
\hline Min & 1.40 & 0.94 & 0.50 & 1.04 & 0.96 & 0.47 & .64 & 1.50 & 58 & 0.81 & 1.14 & 0.66 & 1.44 \\
\hline $1 \mathrm{~s}$ & & 1.23 & 0.96 & 1.44 & 1.27 & 0.81 & 1.15 & 71 & 81 & 1.34 & .40 & 1.18 & 1.64 \\
\hline & & 1.44 & .17 & 1.66 & 1.41 & & .59 & 32 & 02 & 1.47 & .61 & 1.57 & 1.76 \\
\hline & & 34 & 42 & 1.79 & 1.65 & & .82 & 95 & & 1.74 & 75 & 1.67 & 1.99 \\
\hline & & .93 & 1.82 & 2.00 & 1.79 & 1.81 & 2.38 & 2.16 & .19 & 1.91 & 1.99 & 1.95 & 2.14 \\
\hline $\mathrm{N}$ & 0 & 18 & 13 & 13 & 16 & 15 & 19 & 24 & 13 & 20 & 17 & 20 & 16 \\
\hline \multicolumn{14}{|l|}{ Temp C } \\
\hline & 4 & 2 & 3.8 & 3.5 & 5.7 & 16.5 & 4.0 & 4.1 & 8 & .8 & 1 & 15.9 & 4.1 \\
\hline & & & & & & .8 & 7.7 & 8 & 2.7 & 4.9 & 3.7 & 5.6 & 3.0 \\
\hline & 0.8 & 1 & 1.6 & 2 & 1.0 & 2.1 & 2.1 & 0.8 & 0.8 & 1.2 & 1.1 & 1.7 & 1.0 \\
\hline & 15.9 & 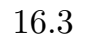 & 8 & 16.0 & 17.8 & 19.9 & 17.8 & 6.5 & .4 & 6.9 & .0 & 19.1 & 15.7 \\
\hline \multirow[t]{3}{*}{ Min. $\mathrm{T}$} & 13.4 & 11.9 & 14.0 & 11.8 & 14.2 & 14.1 & 10.1 & 12.6 & 16.8 & 12.0 & 13.3 & 13.5 & 12.7 \\
\hline & & & \multicolumn{8}{|c|}{ Early Holocene } & \multicolumn{3}{|c|}{ Late Pleistocene } \\
\hline & 15 & 16 & 17 & 18 & 19 & 20 & 21 & 22 & 23 & 24 & 25 & 26 & 27 \\
\hline Facility & a & & b & a & a & a & b & c & a & b & a & b & \\
\hline$R^{2}$ & 0.04 & 0.34 & 0.00 & 0.05 & 0.21 & 0.03 & 0.04 & 0.04 & 0.05 & 0.01 & 0.02 & 0.00 & 0.14 \\
\hline \multicolumn{14}{|l|}{$\delta^{18} \mathrm{O}[\% 0]$} \\
\hline Mean & & & 3 & 1.78 & 5 & 2.03 & & 4 & & .22 & 15 & 2.39 & 2.82 \\
\hline & & & 65 & 0.88 & 1.54 & 1.34 & 1.32 & 1.04 & .18 & 1.09 & .37 & 1.72 & 1.60 \\
\hline Std. dev. & 0.31 & 0.3 & 45 & 0.28 & 0.43 & 0.38 & 0.36 & 0.33 & 0.36 & 0.34 & 11 & 0.42 & 0.56 \\
\hline Min & 1.47 & 1.29 & 1.02 & 1.30 & 1.16 & 1.32 & 1.10 & 1.50 & 1.23 & 1.72 & .36 & 1.26 & 2.20 \\
\hline & 1.55 & 1.55 & 1.75 & 1.52 & 1.66 & 1.81 & 1.51 & 1.82 & 1.56 & 1.93 & .73 & 2.10 & 2.36 \\
\hline 2nd & 1.79 & 1.80 & 2.11 & 1.86 & 2.02 & 2.05 & 1.84 & 2.13 & 1.86 & 2.23 & 2.02 & 2.53 & 2.56 \\
\hline 3rd qu & 2.16 & 2.09 & 2.34 & 1.98 & 2.21 & 2.30 & 2.09 & 2.26 & 2.20 & 2.46 & 2.43 & 2.67 & 3.31 \\
\hline Max & 2.32 & 2.34 & 2.67 & 2.18 & 2.70 & 2.65 & 2.43 & 2.54 & 2.41 & 2.81 & 2.73 & 2.97 & 3.80 \\
\hline $\mathrm{N}$ & 16 & 13 & 20 & 20 & 21 & 20 & 25 & 13 & 24 & 22 & 26 & 20 & 19 \\
\hline \multicolumn{14}{|l|}{ Temp. C } \\
\hline Mea & 13.9 & 14 & 13.1 & 14.2 & 13.5 & 13.2 & 14.1 & 13.1 & 13.8 & 12.3 & 13.1 & 11.6 & 9.7 \\
\hline & 3 & 4 & 7.1 & 3.8 & 6.7 & 5.8 & 5.7 & 4.5 & 5.1 & 4.7 & 6.0 & 7.4 & 7.0 \\
\hline Std. dev. & 1.3 & 1.6 & 1.9 & 1.2 & 1.9 & 1.6 & 1.6 & 1.5 & 1.6 & 1.5 & 1.8 & 1.8 & 2.4 \\
\hline & 15.6 & 16.3 & 17.5 & 16.3 & 16.9 & 16.2 & 17.2 & 15.4 & 16.6 & 14.5 & 16.1 & 16.5 & 12.4 \\
\hline Min. $\mathrm{T}$ & 11.9 & 11.8 & 10.4 & 12.5 & 10.2 & 10.4 & 11.4 & 10.9 & 11.5 & 9.8 & 10.1 & 9.1 & 5.5 \\
\hline
\end{tabular}




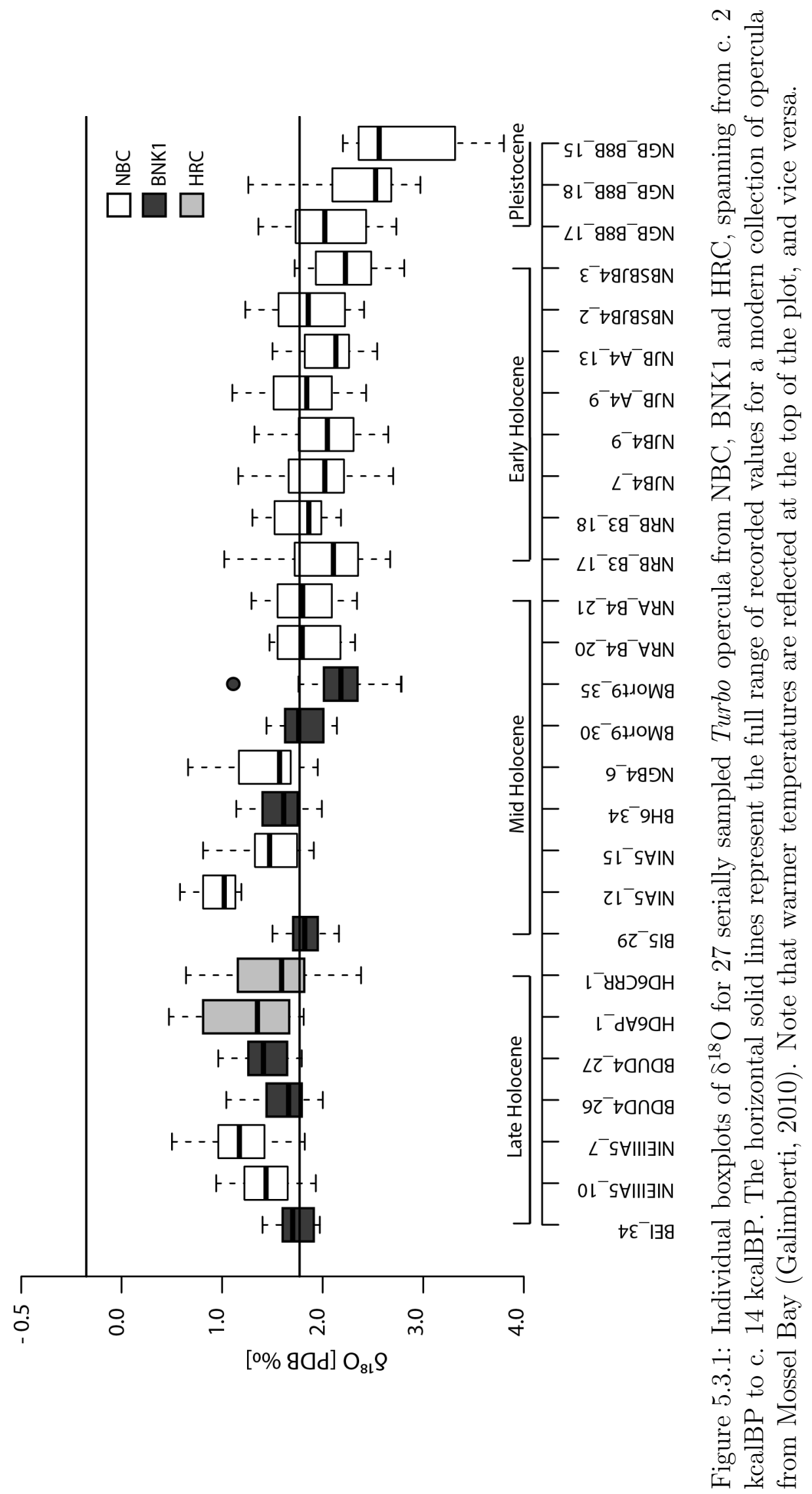




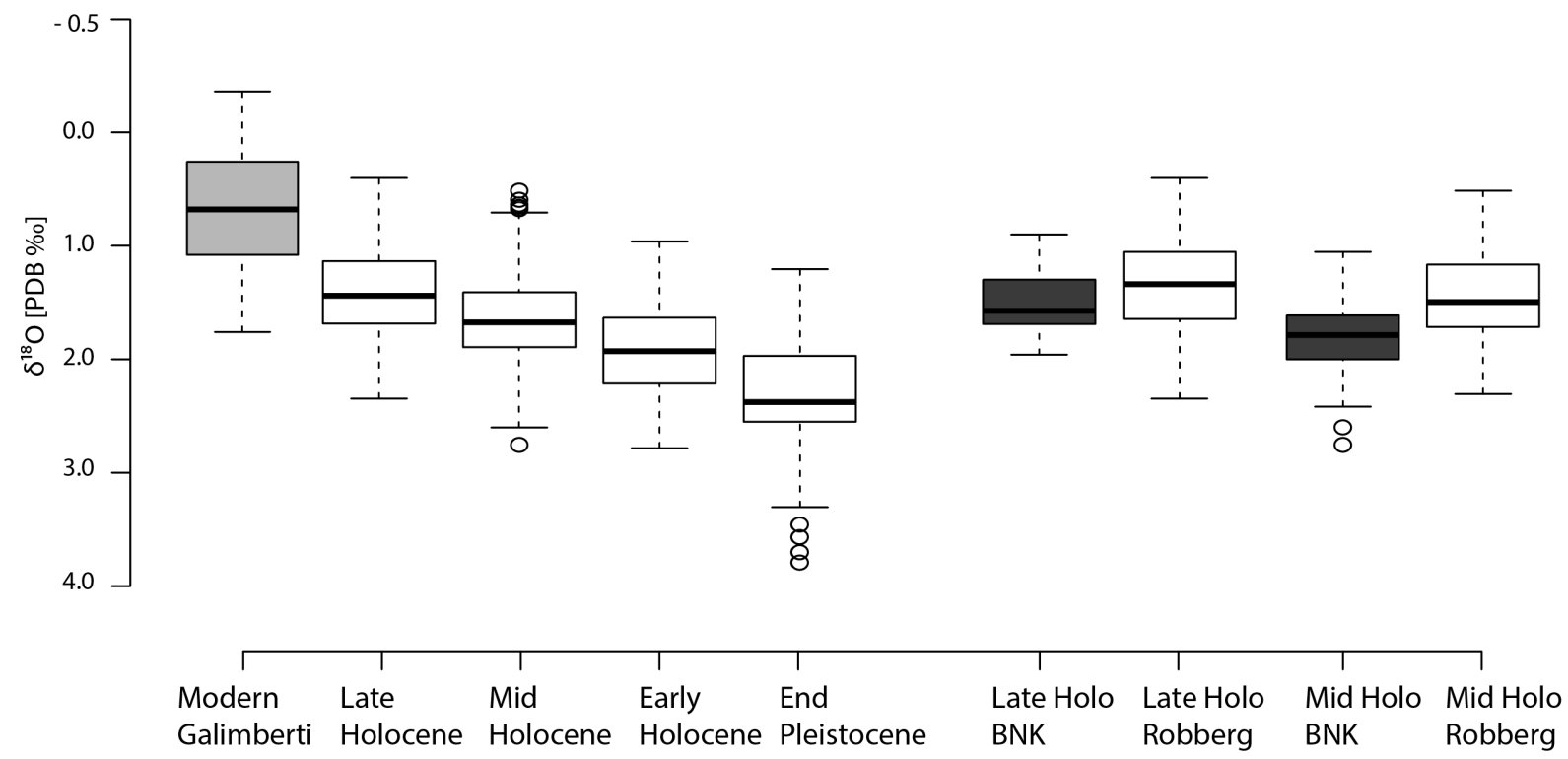

Figure 5.3.2: Boxplots of $\delta^{18} \mathrm{O}$ for the Holocene dataset, aggregated according to broad time period. The late and middle Holocene results are also displayed separated according to site (BNK1 vs NBC and HRC, both on the Robberg Peninsula). Note that warmer temperatures are reflected at the top of the plot, and vice versa.

statistics for the late and mid Holocene datasets are also provided by location, with the BNK1 data separated from the Robberg Peninsula data (NBC and HRC) in Table 5.4. However, the post-hoc Tukey comparisons of the late and mid Holocene records from these two sites (Table C4 of Appendix C) show that they only differ significantly during the mid Holocene, but not the late Holocene. Further, when the trend is examined for the Robberg dataset alone, the difference between the mid and early Holocene remains, suggesting that the temperature trend is real, and not driven by the conflation of the two regional datasets.

\subsubsection{2 $\quad \delta^{13} \mathrm{C}$ results}

Table 5.5 and Figure 5.3.3 provide the summary statistics for the $\delta^{13} \mathrm{C}$ results for each shell (full data in Appendix A). Notably, the archaeological values are markedly higher than the modern shell values from Mossel Bay (Galimberti, 2010). Further, the average values for the mid Holocene, especially those of the NBC shells, are significantly higher than for the other levels (one way ANOVA $\mathrm{p}<<0.001$ : full results of the Tukey multiple comparison test aggregated by each of the time periods are presented in Table C5 of Appendix C). 
Table 5.4: Statistics for aggregated by broad time period (the terminal Pleistocene and early, middle and later Holocene). Also provided for both the late and middle Holocene are the values from BNK1 and the Robberg Peninsula sites separately.

\begin{tabular}{|c|c|c|c|c|c|c|c|c|c|}
\hline & Modern & $\begin{array}{l}\text { Late } \\
\text { Holo }\end{array}$ & $\begin{array}{c}\text { BNK1 } \\
\text { only }\end{array}$ & $\begin{array}{c}\text { Robb. } \\
\text { only }\end{array}$ & $\begin{array}{c}\text { Mid } \\
\text { Holo }\end{array}$ & $\begin{array}{c}\text { BNK1 } \\
\text { only }\end{array}$ & $\begin{array}{c}\text { Robb. } \\
\text { only }\end{array}$ & $\begin{array}{c}\text { Early } \\
\text { Holo }\end{array}$ & $\begin{array}{l}\text { Late } \\
\text { Pleis }\end{array}$ \\
\hline$\delta^{18} O$ adjust. & 0.00 & & $\begin{array}{c}2-4 \mathrm{ka} \\
0.00\end{array}$ & & & $\begin{array}{c}5-9 \mathrm{ka} \\
0.03-0.15\end{array}$ & & $\begin{array}{c}9-12 \mathrm{ka} \\
0.21-0.48\end{array}$ & $\begin{array}{c}12-14 \mathrm{ka} \\
0.75\end{array}$ \\
\hline $\mathrm{N} \delta^{18} O$ & 327 & 104 & 39 & 65 & 159 & 77 & 82 & 165 & 65 \\
\hline $\mathrm{N}$ shells & 16 & 7 & 3 & 3 & 9 & 4 & 5 & 8 & 3 \\
\hline Mean & 0.69 & 1.44 & 1.57 & 1.37 & 1.67 & 1.85 & 1.51 & 1.96 & 2.38 \\
\hline Stdev & 0.52 & 0.39 & 0.26 & 0.43 & 0.42 & 0.32 & 0.42 & 0.39 & 0.56 \\
\hline Max & 1.77 & 2.38 & 2.00 & 2.38 & 2.78 & 2.78 & 2.34 & 2.81 & 3.80 \\
\hline Min & -0.35 & 0.47 & 0.96 & 0.47 & 0.58 & 1.11 & 0.58 & 1.02 & 1.26 \\
\hline Range & 2.12 & 1.91 & 1.04 & 1.91 & 2.20 & 1.66 & 1.76 & 1.79 & 2.54 \\
\hline Ave. max & 1.47 & 1.96 & 1.92 & 1.98 & 2.09 & 2.27 & 1.94 & 2.55 & 3.17 \\
\hline Ave. min & -0.07 & 0.85 & 1.13 & 0.64 & 1.11 & 1.30 & 0.96 & 1.29 & 1.60 \\
\hline \multicolumn{10}{|c|}{ Temperature conversion } \\
\hline Mean $\mathrm{T}^{\circ}$ & 19.0 & 15.7 & 15.1 & 16.0 & 14.7 & 13.9 & 15.4 & 13.4 & 11.6 \\
\hline Stdev & 2.2 & 1.7 & 1.2 & 1.9 & 1.8 & 1.4 & 1.8 & 1.7 & 2.4 \\
\hline $\operatorname{Min} T^{\circ}$ & 14.3 & 11.6 & 13.3 & 11.6 & 9.9 & 9.9 & 11.8 & 9.8 & 5.5 \\
\hline $\operatorname{Max} \mathrm{T}^{\circ}$ & 23.5 & 19.9 & 17.8 & 19.9 & 19.4 & 17.1 & 19.4 & 17.5 & 16.5 \\
\hline Range & 9.2 & 8.3 & 4.5 & 8.3 & 9.5 & 7.2 & 7.7 & 7.8 & 11.0 \\
\hline Ave. $\min \mathrm{T}^{\circ}$ & 15.6 & 13.5 & 13.6 & 13.3 & 12.9 & 12.1 & 13.5 & 10.9 & 8.2 \\
\hline Ave. $\max \mathrm{T}^{\circ}$ & 22.3 & 18.3 & 17.0 & 19.2 & 17.1 & 16.3 & 17.8 & 16.3 & 15.0 \\
\hline Ave. range & 6.7 & 4.8 & 3.4 & 5.9 & 4.2 & 4.2 & 4.2 & 5.4 & 6.8 \\
\hline \multicolumn{10}{|c|}{ Departure from modern } \\
\hline Mean $\mathrm{T}^{\circ}$ & - & -3.3 & -3.8 & -2.9 & -4.3 & -5.0 & -3.5 & -5.5 & -7.3 \\
\hline $\operatorname{Min} T^{\circ}$ & - & -2.6 & -1.0 & -2.6 & -4.4 & -4.4 & -2.5 & -4.5 & -8.8 \\
\hline $\operatorname{Max} \mathrm{T}^{\circ}$ & - & -3.5 & -5.7 & -3.5 & -4.0 & -6.4 & -4.0 & -6.0 & -7.0 \\
\hline Range & - & -0.9 & -4.7 & -0.9 & 0.3 & -2.0 & -1.5 & -1.4 & 1.8 \\
\hline Ave. $\min \mathrm{T}^{\circ}$ & - & -2.1 & -2.0 & -2.2 & -2.7 & -3.5 & -2.1 & -4.7 & -7.4 \\
\hline Ave. $\max \mathrm{T}^{\circ}$ & - & -4.0 & -5.2 & -3.1 & -5.1 & -5.9 & -4.5 & -5.9 & -7.3 \\
\hline Ave. range & - & -1.9 & -3.3 & -0.8 & -2.5 & -2.5 & -2.4 & -1.2 & 0.1 \\
\hline
\end{tabular}


Table 5.5: Statistics for $\delta^{13} \mathrm{C}$ values aggregated by broad time period (the terminal Pleistocene and early, middle and later Holocene). Also provided for both the late and middle Holocene are the values from BNK1 and the Robberg Peninsula sites separately.

\begin{tabular}{|c|c|c|c|c|c|c|c|c|c|}
\hline & Modern & $\begin{array}{l}\text { Late } \\
\text { Holo }\end{array}$ & $\begin{array}{l}\text { BNK1 } \\
\text { only }\end{array}$ & $\begin{array}{c}\text { Robb. } \\
\text { only }\end{array}$ & $\begin{array}{l}\text { Mid } \\
\text { Holo }\end{array}$ & $\begin{array}{c}\text { BNK1 } \\
\text { only }\end{array}$ & $\begin{array}{c}\text { Robb. } \\
\text { only }\end{array}$ & $\begin{array}{c}\text { Early } \\
\text { Holo }\end{array}$ & $\begin{array}{l}\text { Late } \\
\text { Pleis }\end{array}$ \\
\hline & & & 2-4ka & & & 5-9ka & & 9-12ka & $12-14 \mathrm{ka}$ \\
\hline $\mathrm{N} \delta^{13} C$ & 327 & 104 & 39 & 65 & 159 & 77 & 82 & 165 & 65 \\
\hline $\mathrm{N}$ shells & 16 & 7 & 3 & 3 & 9 & 4 & 5 & 8 & 3 \\
\hline Mean & 1.90 & 2.68 & 2.76 & 2.64 & 2.88 & 2.78 & 2.97 & 2.54 & 2.45 \\
\hline Stdev & 0.44 & 0.53 & 0.43 & 0.59 & 0.44 & 0.51 & 0.32 & 0.66 & 0.54 \\
\hline Max & 2.98 & 4.00 & 4.00 & 3.93 & 3.84 & 3.84 & 3.67 & 4.62 & 3.25 \\
\hline Min & 0.31 & 1.32 & 3.12 & 1.32 & 1.12 & 3.59 & 2.17 & 1.00 & 1.45 \\
\hline Ave. mean & 1.90 & 2.67 & 2.77 & 2.59 & 2.91 & 2.82 & 2.98 & 2.55 & 2.36 \\
\hline Ave. $\max$ & 2.46 & 3.36 & 3.69 & 3.10 & 3.59 & 3.70 & 3.51 & 3.12 & 2.68 \\
\hline Ave. min & 1.10 & 2.04 & 2.20 & 1.92 & 2.19 & 1.89 & 2.43 & 1.96 & 1.98 \\
\hline
\end{tabular}

\subsubsection{Discussion of LSA $\delta^{18} \mathrm{O}$ and $\delta^{13} \mathrm{C}$ sample results}

The lack of a statistically significant difference between the late Holocene BNK1 and Robberg $\delta^{18} \mathrm{O}$ datasets is surprising, given the temperature gradient that exists along this coast today, and may point towards an extended influence of the warmer waters of the Agulhas Current at this time. However, the total number of shells represented is small, and so this result should be interpreted cautiously. In general though, the BNK1 shells record cooler average temperatures than those from the Robberg peninsula, with a statistically significant difference of $1.5{ }^{\circ} \mathrm{C}$ during the mid Holocene.

The aggregated $\delta^{18} \mathrm{O}$ results (Table 5.4) show a $4^{0} \mathrm{C}$ increase in average SSTs on the south coast across the Holocene. The minimum and maximum values averaged across each period provide information about shifts in seasonality across this period: in the modern dataset of Turbo values from Mossel Bay (Galimberti, 2010), the range between the maximum and minimum values averaged across the full set of shells $\left(6 .{ }^{\circ} \mathrm{C}\right)$ corresponds well with the magnitude of the difference between observed mean winter and summer SSTs, i.e. the full seasonal range $\left(6.9^{\circ} \mathrm{C}\right.$ : see discussion of the Galimberti (2010) modern study in section 3.1). During all three periods of the Holocene, the mean minimum temperatures differ less from the modern dataset than do the mean maximum temperatures. For example, during the late Holocene, the averaged minimum recorded SSTs are $2.1^{\circ} \mathrm{C}$ cooler than recorded by the modern dataset, but the averaged maximum recorded SSTs are $4.0^{\circ} \mathrm{C}$ cooler. This suggests that during this period cooler summer 


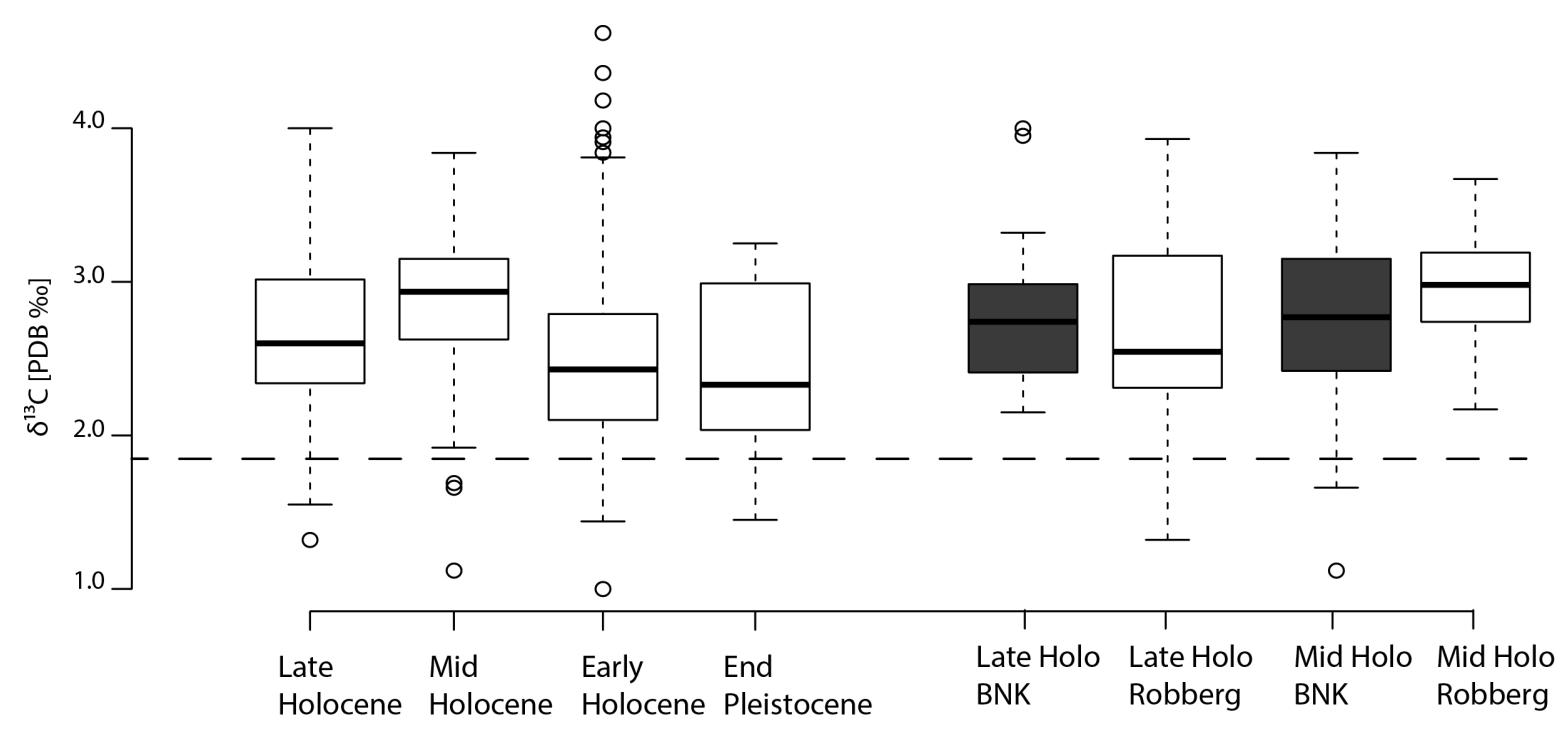

Figure 5.3.3: Boxplots of $\delta^{13} \mathrm{C}$ for the Holocene dataset, aggregated according to broad time period. The late and middle Holocene results are also displayed separated according to site (BNK1 vs NBC and HRC, both on the Robberg Peninsula). The dotted horizontal line represents the average of the modern collection of Turbo opercula from Mossel Bay (Galimberti, 2010).

SSTs had more of an effect on the overall temperature shifts than did the cooler winter SSTs. Arguably, this pattern of cooler maximum SSTs could be attributable to the growth of Turbo, which slows under cool conditions (Galimberti, 2010). But during the late Pleistocene, the departure from modern was approximately equal between the averaged maximum and minimum SSTs, indicating the overall cooling of about $7.3{ }^{\circ} \mathrm{C}$ was more or less equal throughout the year. This supports suggestions that Turbo do continue to grow under cooler conditions and that this proxy can capture markedly cooler minimum/winter temperatures.

The cooler summer temperatures in the late Holocene dataset result in a smaller annual temperature range $\left(4.8^{\circ} \mathrm{C}\right)$ during the late Holocene compared to modern $\left(6.7^{\circ} \mathrm{C}\right)$, by nearly $2{ }^{\circ} \mathrm{C}$ (see Figure 5.4.6 on page 138). When the results from BNK1 and Robberg are examined separately, it is evident that much of this pattern of reduced seasonality is driven by the temperature record from BNK1 alone, which reflects dramatically cooler maximum (i.e. summer) SSTs. During the mid Holocene, seasonality is approximately the same between the two locations $\left(4.2{ }^{\circ} \mathrm{C}\right), 2.5{ }^{\circ} \mathrm{C}$ less than the modern seasonal amplitude measured at Mossel Bay. During the early Holocene the seasonal amplitude of $5.4{ }^{\circ} \mathrm{C}$ is only c. $1{ }^{0} \mathrm{C}$ different from the modern amplitude, and during the Late Pleistocene the seasonal amplitude $\left(6.8^{\circ} \mathrm{C}\right)$ is approximately the same as the modern dataset, although in both periods the entire SST range is shifted towards substantially 
cooler temperatures.

By reference to the model of Cohen and Tyson (1995) (see section on page 19), the $\delta^{18} \mathrm{O}$ results indicate a period of increased upwelling and easterly winds during the mid Holocene. Although temperatures continue to warm in line with global trends, the annual temperature range drops to its lowest throughout the Late Pleistocene and Holocene, largely due to the summer temperatures, which are more than twice as cool as the winter departures from modern. This pattern is consistent with increased summer upwellings lowering the average summer temperatures (Schumann et al., 1995). The more positive $\delta^{13} \mathrm{C}$ values at the Robberg peninsula at this time present a conflicting line of evidence however, as they are predicted to reflect a reduced incidence of upwelling, with less ${ }^{12} \mathrm{C}$-rich dissolved inorganic carbon available for shell carbonate formation. However, given the lack of clear understanding of the $\delta^{13} \mathrm{C}$ dynamics along this coast, this line of evidence is far from certain.

Another line of support for increased upwelling during the mid Holocene comes from what is known of terrestrial climates during the mid-late Holocene. The mid Holocene, known as the Holocene altithermal, was a time of high temperatures and apparently moister conditions across much of the summer rainfall region (Scott and Lee-Thorp, 2004; Scott et al., 2012). According to the Cohen and Tyson (1995) model, increased upwelling and easterly wind incidence corresponds with increased precipitation in the summer rainfall zone. Yet, the southern Cape witnessed arid conditions from c. 8-4 ka (Chase and Meadows, 2007), with evidence for long dry, hot summers in the southern Cape at this time (Scholtz, 1986). Understandings of the role of Agulhas and near-shore SSTs in driving local rainfall may help explain this discrepancy: cool near-shore SSTs brought about by increased summer upwelling may have suppressed moisture availability and summer rainfall in the coastal strip. In conjunction with the warmer air temperatures (Chevalier and Chase, 2016), and drying in the winter rainfall zone (Chase and Meadows, 2007), this may well have created conflicting trends in the two regions.

By comparison, the Late Pleistocene datase present the opposite pattern to the mid Holocene: the annual SST range is high at $6.8^{\circ} \mathrm{C}$ and cooling is observed equally throughout the year. $\delta^{13} \mathrm{C}$ values are the lowest for this period. The Cohen and Tyson (1995) model suggests that the $\delta^{18} \mathrm{O}$ range indicates a period of relatively suppressed upwelling, and reduced frequency of those easterly component winds that bring moisture to the summer rainfall region. Given the very different temperature trends for this period, other drivers of summer rainfall trends may well be expected to be operating. Yet, during the Younger Dryas period from c. 13-11.5 ka, pollen evidence from several 
sites in the summer rainfall zone shows a drying trend, although the pattern is spatially and temporally complex (Scott et al., 2012). Regardless, this general drying trend is consistent with the Cohen and Tyson model and the evidence presented here.

$\delta^{13} \mathrm{C}$ among the entire set of archaeological shells is much more positive than is recorded in the modern dataset from Mossel Bay (Galimberti, 2010). However, the cause of the generally higher values is not clear, and could reflect numerous factors, including changes in water source, algal and phytoplankton productivity or upwelling intensity. Comparison with the modern values is possibly confounded by geographic variation in $\delta^{13} \mathrm{C}$ along the southern coast (Hill et al., 2006; Hill and McQuaid, 2008), as the modern and archaeological datasets come from different locations along the coast. However, the $\delta^{13} \mathrm{C}$ values of the shells do not seem to capture this patterning directly, as, in measurements of intertidal mollusc flesh, Hill et al. (2006) and Hill and McQuaid (2008) noted an admittedly small enrichment in ${ }^{13} \mathrm{C}$ from east to west. Yet the shells of BNK1 and the Robberg peninsula reflect quite similar $\delta^{13} \mathrm{C}$ averages during both the mid and late Holocene. It may be then, that any spatial variation in $\delta^{13} \mathrm{C}$ is too small to affect the shell record. Notably, $\delta^{13} \mathrm{C}$ values are highest during the mid Holocene, and lowest during the Late Pleistocene (mirroring the pattern observed for the annual SST ranges).

A possible line of evidence for comparison with the $\delta^{13} \mathrm{C}$ record comes from sediment cores in the Agulhas region - unfortunately, given the difficulty of interpreting marine $\delta^{13} \mathrm{C}$ values, few studies report these data and the resolution over the Holocene is frequently poor. Moreover, the sediment core data come from offshore locations and their relationship to the coastal environmental record is highly uncertain. Three $\delta^{13} \mathrm{C}$ records of planktic foraminifera from marine cores MD02-2594 (Dyez et al., 2014), MD02-2588 (Ziegler et al., 2013) and CD154 10-06P (Simon et al., 2015; unpublished data) all show increasing values through the terminal Pleistocene and Holocene, on the order of $0.5-1.0 \%$. Given the disparate locations of these three cores, this then seems likely to reflect a regional trend in the Agulhas system. Yet, none of the three core records show a $\delta^{13} \mathrm{C}$ increase in the mid Holocene especially, although admittedly the records are low-resolution.

\subsection{MIS4 and MIS5 study}

The following section presents the results of analyses from Pinnacle Point 5-6 (PP5-6) and Klasies River Main site (KRM). Background information for the two sites, including 
chronologies, is presented in section 2.2.2 of Chapter 2. Together, the samples from these sites span from c. 115 ka to c. 62 ka, and so capture both glacial MIS4 (57 -71 ka) and interglacial MIS5 (71 - $130 \mathrm{ka}$ ) climatic conditions (Lisiecki and Raymo, 2005). Globally, MIS5 witnessed a series of increasingly cooler fluctuations between warm and cold conditions from the last interglacial high-stand at c. 130 ka through to the onset of glacial conditions at MIS4 (see global sea level curve in Figure 2.1.4). These rapid shifts in global temperature had significant implications for changing sea levels along this stretch of coastline. Fisher et al. (2010) note that the speed of these changes means that people living at the coast would have witnessed dramatic advances and retreats of the shorelines within a single lifetime. During MIS4, climatic and environmental shifts are highly uncertain for southern Africa, but appear to have varied markedly across the subcontinent (Chase, 2010).

The $\delta^{18} \mathrm{O}$ values presented here have been corrected for global changes in ocean $\delta^{18} \mathrm{O}$ using the Waelbroeck et al. (2002) curve, similarly to the Holocene dataset. However, the dating uncertainties are typically greater for the Pleistocene deposits than for the Holocene sites, with consequent uncertainty about the magnitude of the correction. The approach taken here uses a mean correction value for the entire date range, and the errors associated with the range of ocean $\delta^{18} \mathrm{O}$ values are provided in Tables 5.6 and 5.7. For some periods that range may be small, but where the age estimates span marked changes in global temperature, the $\delta^{18} \mathrm{O}$ range may be quite large, and results in a correspondingly large error for the temperature conversion (up to $1.35{ }^{\circ} \mathrm{C}$ ).

Tables 5.6 and 5.7 below list the operculum samples from PP5-6 and KRM, respectively. At KRM the samples are identified according to the square and stratigraphic unit from which they were recovered, but at PP5-6 each operculum was individually piece plotted and assigned a unique find number, which serves as the sample number here. Several powder samples from each shell (typically every fourth or fifth sample) were evaluated for recrystallisation, using the FTIR-ATR method described in section 3.3.2.

\subsubsection{Results}

The uncorrected serial sampling results for each shell (i.e. with no correction for seawater $\delta^{18} \mathrm{O}$ ), including a photo of each shell showing the drilling path, are provided in Appendices $\mathrm{A}$ and $\mathrm{B}$. The coefficients of determination $\left(\mathrm{R}^{2}\right)$ for the regression between $\delta^{18} \mathrm{O}$ and $\delta^{13} \mathrm{C}$ for each shell are provided in Table 5.8 and Table 5.9, for PP5-6 and KRM 


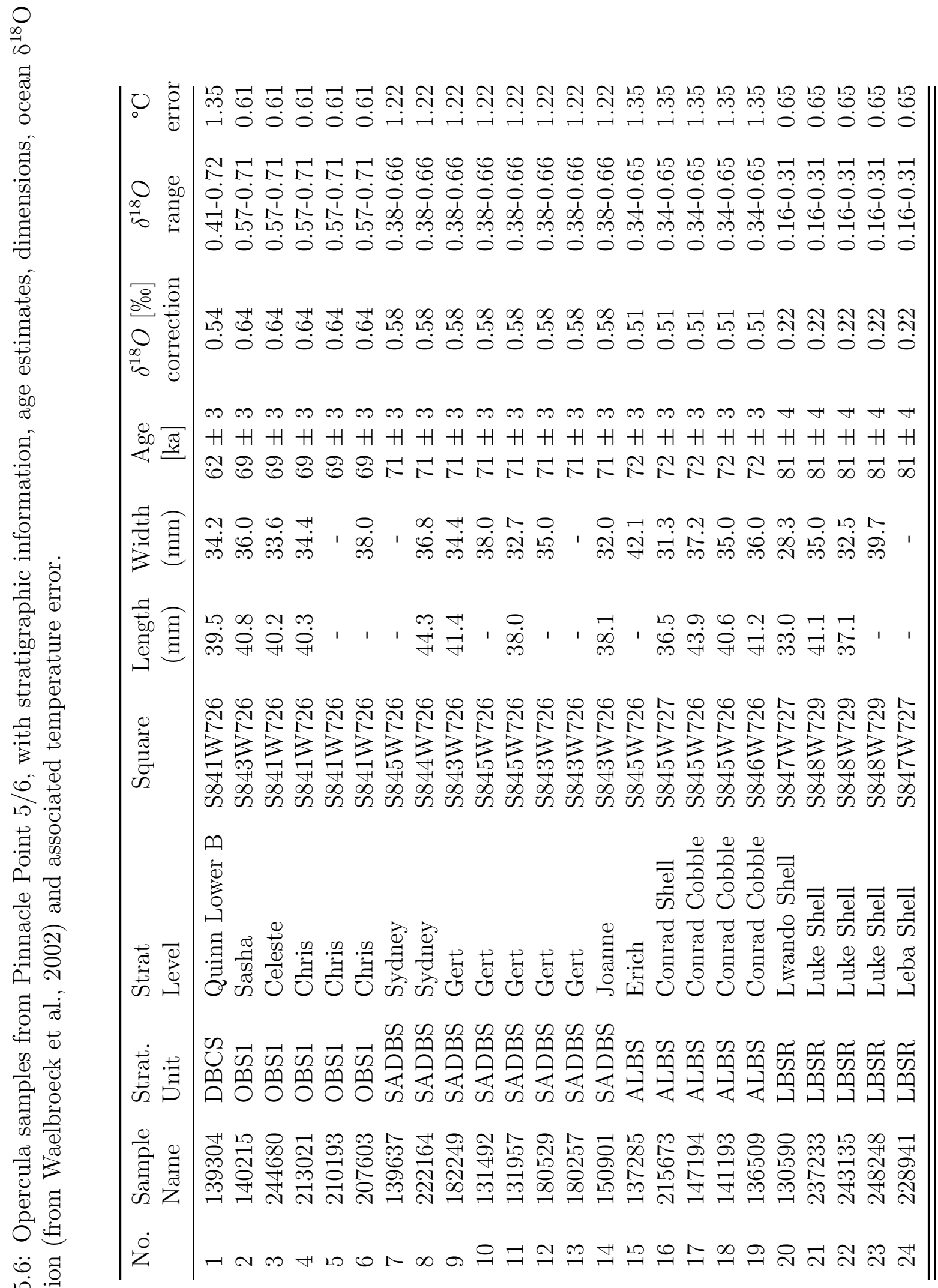




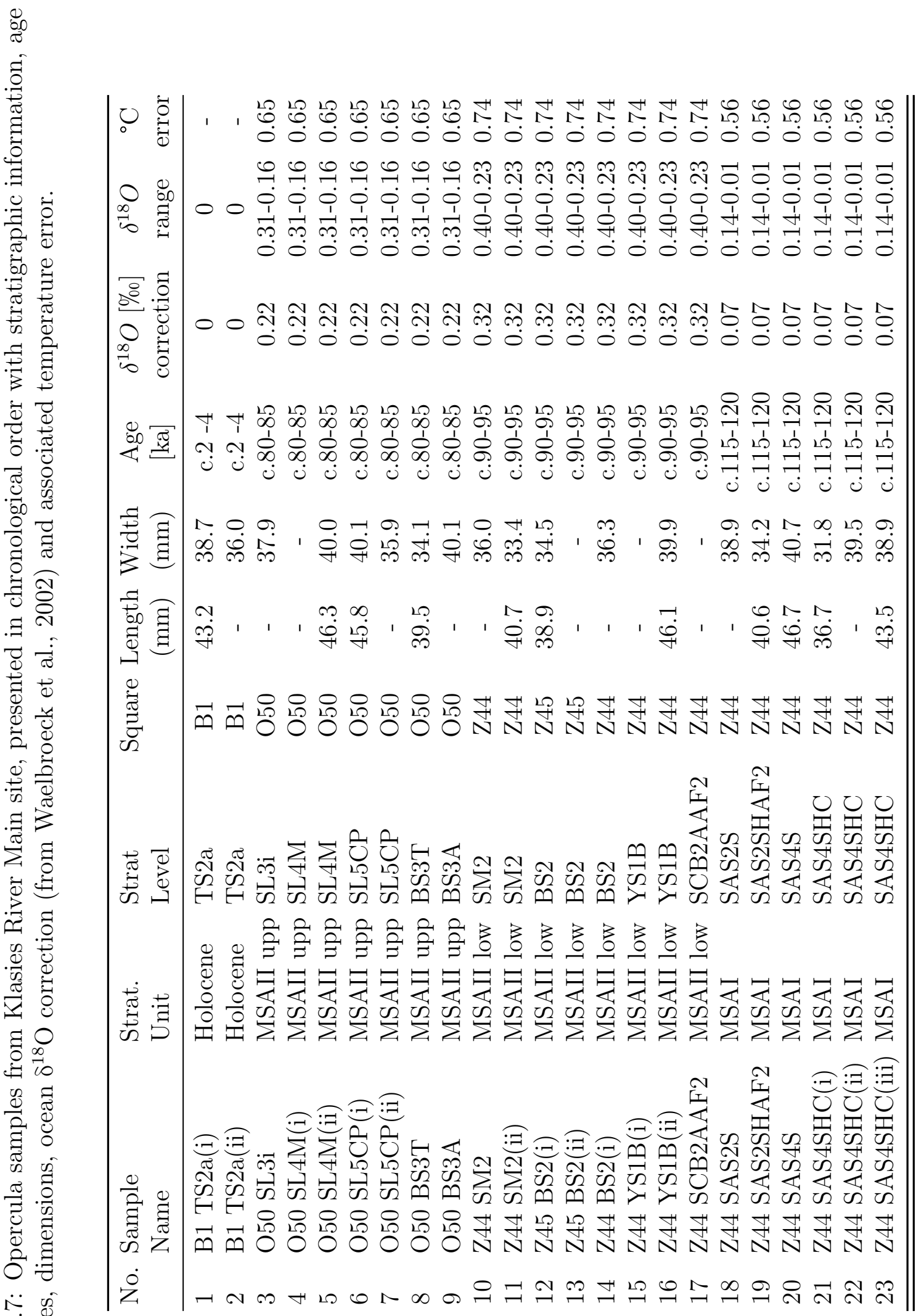


respectively. Five shells from PP5-6 have an $\mathrm{R}^{2}$ between $\delta^{18} \mathrm{O}$ and $\delta^{13} \mathrm{C}$ that is greater than 0.3 , but the inclusion of these shells does not significantly affect the statistics for each level. Seven shells from KRM have positive correlations between $\delta^{18} \mathrm{O}$ and $\delta^{13} \mathrm{C}$ with $\mathrm{R}^{2}$ greater than 0.3 , but the total number of micromilled samples from each of these shells is less than eight. Other shells from the same level with more samples do not show the same positive correlation, suggesting that the correlations seen in these shells are simply a result of the small sample sizes, and not indicative of diagenetic alteration.

\subsubsection{1 $\quad \delta^{18} \mathrm{O}$ results}

The uncorrected $\delta^{18} \mathrm{O}$ values from PP5-6 are significantly different according to depositional unit (ANOVA, F=7.395; $\mathrm{p}<<0.001$; results of Tukey multiple comparison test reported in Table C6 of Appendix C), but those from KRM are not significantly different when aggregated according to technological unit (ANOVA, $\mathrm{F}=0.993 ; \mathrm{p}=0.372$; results of Tukey multiple comparison test reported in Table C9 of Appendix C). Figures B2 and B3 of Appendix B show the serial samples for each shell from PP5-6 and KRM respectively.

The summary statistics (based on the corrected values for the changes in seawater $\delta^{18} \mathrm{O}$ (Waelbroeck et al., 2002)) for each of the twenty-four opercula from PP5-6 and the twenty-three opercula from KRM are provided in Table 5.8 and Table 5.9, respectively. Figures 5.4.1 and 5.4.2 display the boxplots for each shell from PP5-6 and KRM, respectively.

The shells have been grouped according to the stratigraphic schemes used by the excavators of the two sites. At PP5-6 these groups are largely based upon features of the sediments (see site description in section 2.2.2.4), whereas at KRM the relatively coarse scale of the dating requires that the shells are grouped into broader cultural phases largely defined by the nature of the lithic technology (see site description in section 2.2.2.3; Wurz, 2002). Tables 5.10 and 5.11 present the aggregated results for each phase at PP5-6 and KRM respectively, with equivalent temperature conversion statistics and the temperature difference from the modern Galimberti dataset. The temperature error associated with the uncertainty for the seawater $\delta^{18} \mathrm{O}$ correction is also provided. The aggregated results for PP5-6 and KRM are presented graphically in Figure 5.4.3.

An ANOVA with post-hoc Tukey multiple comparison test at 95\% confidence intervals was carried out for both sites (the full results of ANOVA and Tukey multiple comparison 
Table 5.8: Summary statistics of $\delta^{18} \mathrm{O}$ values for each operculum from Pinnacle Point $5 / 6$, separated according to dated stratigraphic unit. The number of measured samples per shell was not always sufficient to calculate all summary statistics. The coefficient of determination $\left(\mathrm{R}^{2}\right)$ is given for the regression between $\delta^{18} \mathrm{O}$ and $\delta^{13} \mathrm{C}$ for each shell. Values are converted to temperature values below using the Grossman and $\mathrm{Ku}$ (1986) equation. Sample names are provided in Table 5.6 and all samples were analysed on the NIGL Isoprime system.

\begin{tabular}{|c|c|c|c|c|c|c|c|c|c|c|c|c|}
\hline \multirow[b]{3}{*}{$R^{2}$} & \multicolumn{3}{|c|}{ DBCS } & \multicolumn{3}{|c|}{ OBS1 } & \multicolumn{6}{|c|}{ SADBS } \\
\hline & \multirow{2}{*}{$\begin{array}{r}1 \\
0.00\end{array}$} & \multirow{2}{*}{$\begin{array}{r}2 \\
0.00\end{array}$} & \multirow{2}{*}{$\begin{array}{r}3 \\
0.08\end{array}$} & \multirow{2}{*}{$\begin{array}{r}4 \\
0.31\end{array}$} & \multirow{2}{*}{$\begin{array}{r}5 \\
0.00\end{array}$} & \multirow{2}{*}{$\begin{array}{r}6 \\
0.01\end{array}$} & \multirow{2}{*}{$\begin{array}{r}7 \\
0.00 \\
\end{array}$} & \multirow{2}{*}{$\begin{array}{r}8 \\
0.33 \\
\end{array}$} & \multirow{2}{*}{$\begin{array}{r}9 \\
0.12 \\
\end{array}$} & \multirow{2}{*}{$\begin{array}{r}10 \\
0.65\end{array}$} & \multirow{2}{*}{$\begin{array}{r}11 \\
0.17\end{array}$} & \multirow{2}{*}{$\begin{array}{r}12 \\
0.01 \\
\end{array}$} \\
\hline & & & & & & & & & & & & \\
\hline \multicolumn{13}{|l|}{$\delta^{18} O[\%]$} \\
\hline Mean & 1.89 & $\begin{array}{l}9.06 \\
9\end{array}$ & $\begin{array}{ll}6 & 2.25\end{array}$ & $\begin{array}{ll}5 & 2.04\end{array}$ & $1 \quad 2.02$ & $2 \quad 1.68$ & 1.67 & $7 \quad 1.72$ & 1.66 & $\begin{array}{ll}6 & 2.04\end{array}$ & $\begin{array}{ll}4 & 1.94\end{array}$ & $4 \quad 1.74$ \\
\hline Range & 1.87 & $7 \quad 1.74$ & $\begin{array}{ll}4 & 1.29\end{array}$ & $\begin{array}{ll}9 & 1.92\end{array}$ & 0.81 & $1 \quad 1.58$ & 1.23 & $3 \quad 0.57$ & 1.41 & 1.16 & $\begin{array}{ll}6 & 1.43\end{array}$ & $3 \quad 1.52$ \\
\hline Std. dev. & 0.49 & 0.50 & $\begin{array}{ll}0 & 0.41\end{array}$ & $\begin{array}{ll}1 & 0.48\end{array}$ & $3 \quad 0.23$ & $3 \quad 0.59$ & 0.34 & $\begin{array}{ll}3 & 0.24\end{array}$ & 0.38 & 0.39 & $\begin{array}{ll}9 & 0.43\end{array}$ & 0.40 \\
\hline Min. & 1.12 & $2 \quad 1.10$ & $\begin{array}{ll}0 & 1.68\end{array}$ & 1.00 & 1.62 & $2 \quad 1.19$ & 1.09 & 1.46 & 0.97 & 1.47 & $\begin{array}{ll}7 & 1.31\end{array}$ & $1 \quad 0.95$ \\
\hline 1st quar. & 1.59 & 1.75 & 1.97 & 1.80 & 1.85 & 5 & 1.31 & & 1.42 & 1.65 & $\begin{array}{ll}5 & 1.60\end{array}$ & J 1.53 \\
\hline 2nd quar. & 1.76 & \begin{tabular}{|l|l}
5 & 2.12
\end{tabular} & 2.18 & $\begin{array}{ll}8 & 2.02\end{array}$ & 2.03 & 3 & 1.59 & & 1.70 & 2.06 & $\begin{array}{ll}6 & 1.85\end{array}$ & $5 \quad 1.73$ \\
\hline 3rd quar. & 2.25 & $5 \quad 2.36$ & 2.52 & $2 \quad 2.35$ & 2.18 & 8 & 1.98 & & 1.87 & 2.38 & $\begin{array}{ll}8 & 2.29\end{array}$ & $9 \quad 2.00$ \\
\hline Max. & 2.99 & 2.85 & 2.97 & $\begin{array}{ll}7 & 2.92\end{array}$ & 2.43 & 2.77 & 2.32 & 2.03 & 2.38 & 2.63 & $\begin{array}{ll}3 & 2.74\end{array}$ & 2.47 \\
\hline $\mathrm{N}$ & 20 & 21 & 23 & 14 & 16 & 6 & 29 & 99 & 22 & 23 & 19 & 9 \\
\hline \multicolumn{13}{|l|}{ Temp. $\mathrm{C}^{\circ}$} \\
\hline Mean & 13.8 & 13.0 & $\begin{array}{ll}0 & 12.2\end{array}$ & $\begin{array}{ll}2 & 13.1\end{array}$ & 13.2 & 14.7 & 14.7 & 14.5 & 14.8 & 13.1 & 13.5 & 14.4 \\
\hline Range & 8.1 & 7.6 & 5.6 & 8.3 & 3.5 & 6.9 & 5.4 & 2.5 & 6.1 & 5.0 & 6.2 & 6.6 \\
\hline Std. dev. & 2.1 & 2.2 & 1.8 & 2.1 & 1.0 & 2.6 & 1.5 & 1.0 & 1.7 & 1.7 & 1.9 & 1.7 \\
\hline $\operatorname{Max} . \mathrm{T}^{\circ}$ & 17.1 & 17.2 & 14.7 & $\begin{array}{ll}7 & 17.6\end{array}$ & 14.9 & 16.8 & \begin{tabular}{l|l}
3 & 17.2
\end{tabular} & $2 \quad 15.6$ & 17.7 & 15.6 & 16.3 & 317.8 \\
\hline \multirow[t]{3}{*}{$\operatorname{Min} . \mathrm{T}^{\circ}$} & 9.0 & 9.6 & 9.1 & 9.3 & 311.4 & 9.9 & \begin{tabular}{l|l}
9 & 11.9
\end{tabular} & $.9 \quad 13.2$ & 11.6 & 10.5 & $\begin{array}{ll}5 & 10.1\end{array}$ & $1 \quad 11.2$ \\
\hline & \multicolumn{2}{|c|}{ SADBS } & \multicolumn{5}{|c|}{ ALBS } & \multicolumn{5}{|c|}{ LBSR } \\
\hline & 13 & 14 & 15 & 16 & 17 & 18 & 19 & 20 & 21 & 22 & 23 & 24 \\
\hline$R^{2}$ & 0.01 & 0.12 & 0.02 & 0.00 & 0.00 & 0. & 0.03 & 0.03 & 0.00 & 0.03 & 0.36 & 0.09 \\
\hline \multicolumn{13}{|l|}{$\delta^{18} \mathrm{O}[\% 0]$} \\
\hline Mean & 1.73 & 1.45 & 2.21 & 1.78 & 1.81 & 1.74 & 1.53 & 1.44 & 1.36 & 1.60 & 1.29 & 1.17 \\
\hline Range & 1.49 & 1.10 & 1.35 & 1.11 & 0.75 & 0.33 & 0.33 & 1.61 & 1.21 & 1.49 & 0.33 & 0.63 \\
\hline Std. dev. & 0.41 & 0.28 & 0.36 & 0.32 & 0.24 & 0.13 & 0.15 & 0.38 & 0.35 & 0.40 & 0.14 & 0.25 \\
\hline Min. & 1.13 & 0.89 & 1.51 & 1.31 & 1.46 & 1.60 & 1.35 & 0.70 & 0.91 & 0.88 & 1.09 & 0.86 \\
\hline 1st quar. & 1.45 & 1.25 & 1.96 & 1.51 & 1.62 & - & - & 1.17 & 1.13 & 1.40 & - & - \\
\hline 2nd quar. & 1.63 & 1.46 & 2.29 & 1.72 & 1.74 & - & - & 1.45 & 1.29 & 1.51 & - & - \\
\hline 3rd quar. & 1.94 & 1.61 & 2.47 & 2.02 & 1.92 & - & - & 1.64 & 1.56 & 1.87 & - & - \\
\hline Max. & 2.62 & 1.99 & 2.86 & 2.42 & 2.22 & 1.93 & 1.68 & 2.32 & 2.12 & 2.37 & 1.42 & 1.49 \\
\hline $\mathrm{N}$ & 20 & 14 & 23 & 23 & 17 & 6 & 5 & 22 & 21 & 20 & 5 & 6 \\
\hline Temp. $\mathrm{C}^{\circ}$ & & & & & & & & & & & & \\
\hline Mean & 14.5 & 15.7 & 12.4 & 14.2 & 14.1 & 14.4 & 15.3 & 15.7 & 16.0 & 15.0 & 16.4 & 16.9 \\
\hline Range & 6.5 & 4.8 & 5.8 & 4.8 & 3.3 & 1.4 & 1.4 & 7.0 & 5.3 & 6.5 & 1.4 & 2.7 \\
\hline Std. dev. & 1.8 & 1.2 & 1.5 & 1.4 & 1.0 & 0.6 & 0.6 & 1.6 & 1.5 & 1.7 & 0.6 & 1.1 \\
\hline $\operatorname{Max} . \mathrm{T}^{\circ}$ & 17.0 & 18.1 & 15.4 & 16.3 & 15.6 & 15.0 & 16.1 & 18.9 & 18.0 & 18.1 & 17.2 & 18.2 \\
\hline $\operatorname{Min} . \mathrm{T}^{\circ}$ & 10.6 & 13.3 & 9.6 & 11.5 & 12.3 & 13.6 & 14.7 & 11.9 & 12.7 & 11.7 & 15.8 & 15.5 \\
\hline
\end{tabular}


Table 5.9: Summary statistics of $\delta^{18} \mathrm{O}$ values for each operculum from Klasies River Mouth, separated according to dated stratigraphic unit. The number of measured samples per shell was not always sufficient to calculate all summary statistics. The coefficient of determination $\left(\mathrm{R}^{2}\right)$ is given for the regression between $\delta^{18} \mathrm{O}$ and $\delta^{13} \mathrm{C}$ for each shell. Values are converted to temperature values below using the Grossman and $\mathrm{Ku}$ (1986) equation. Sample names are provided in Table 5.7 and all samples were analysed on the NIGL Isoprime system.

\begin{tabular}{|c|c|c|c|c|c|c|c|c|c|c|c|}
\hline \multirow[b]{3}{*}{$R^{2}$} & \multicolumn{2}{|c|}{ Holo } & \multicolumn{7}{|c|}{ MSA II upper } & \multicolumn{2}{|c|}{ MSA II lo } \\
\hline & 1 & 2 & 3 & 4 & 5 & 6 & 7 & 8 & 9 & 10 & 11 \\
\hline & 0.38 & 0.68 & 0.00 & 0.73 & 0.16 & 0.00 & 0.26 & 0.19 & 0.00 & 0.01 & 0.09 \\
\hline \multicolumn{12}{|l|}{$\delta^{18} \mathrm{O}[\%]$} \\
\hline Mean & 1.00 & 1.32 & 1.65 & 2.20 & 1.92 & 2.18 & 2.20 & 2.07 & 1.93 & 2.22 & 2.18 \\
\hline Range & 0.94 & 1.55 & 1.59 & 0.32 & 2.04 & 1.93 & 0.89 & 1.33 & 1.39 & 1.29 & 0.38 \\
\hline Std. dev. & 0.38 & 0.53 & 0.42 & 0.14 & 0.47 & 0.48 & 0.28 & 0.38 & 0.41 & 0.36 & 0.14 \\
\hline Min. & 0.63 & 0.53 & 0.64 & 1.97 & 0.90 & 1.46 & 1.73 & 1.37 & 1.20 & 1.53 & 2.00 \\
\hline 1st quar. & - & - & 1.47 & - & 1.67 & 1.80 & - & 1.88 & 1.63 & 2.01 & - \\
\hline 2nd quar. & - & - & 1.65 & - & 2.04 & 2.16 & - & 2.11 & 1.88 & 2.24 & - \\
\hline 3rd quar. & - & - & 1.99 & - & 2.14 & 2.58 & - & 2.35 & 2.22 & 2.49 & - \\
\hline Max. & 1.57 & 2.08 & 2.23 & 2.29 & 2.93 & 3.39 & 2.62 & 2.70 & 2.58 & 2.82 & 2.37 \\
\hline $\mathrm{N}$ & 7 & 8 & 19 & 5 & 15 & 21 & 9 & 15 & 20 & 21 & 6 \\
\hline \multicolumn{12}{|l|}{ Temp. $\mathrm{C}^{\circ}$} \\
\hline Mean & 17.6 & 16.2 & 14.8 & 12.4 & 13.6 & 12.5 & 12.4 & 13.0 & 13.6 & 12.3 & 12.5 \\
\hline Range & 4.1 & 6.7 & 6.9 & 1.4 & 8.8 & 8.4 & 3.9 & 5.8 & 6.0 & 5.6 & 1.6 \\
\hline Std. dev. & 1.7 & 2.3 & 1.8 & 0.6 & 2.0 & 2.1 & 1.2 & 1.6 & 1.8 & 1.6 & 0.6 \\
\hline Max. $T^{\circ}$ & 19.2 & 19.6 & 19.2 & 13.4 & 18.1 & 15.6 & 14.5 & 16.0 & 16.8 & 15.3 & 13.3 \\
\hline \multirow[t]{3}{*}{ Min. $\mathrm{T}^{\circ}$} & 15.1 & 12.9 & 12.3 & 12.0 & 9.2 & 7.3 & 10.6 & 10.2 & 10.7 & 9.7 & 11.7 \\
\hline & \multicolumn{5}{|c|}{ MSA II lower } & \multicolumn{6}{|c|}{ MSA I } \\
\hline & 13 & 14 & 15 & 16 & 17 & 18 & 19 & 20 & 21 & 22 & 23 \\
\hline$R^{2}$ & 0.10 & 0.62 & 0.51 & 0.00 & 0.01 & 0.03 & 0.00 & 0.07 & 0.02 & 0.36 & 0.80 \\
\hline \multicolumn{12}{|l|}{$\delta^{18} O[\%]$} \\
\hline Mean & 1.88 & 1.97 & 1.45 & 2.34 & 1.97 & 1.96 & 1.76 & 2.14 & 1.40 & 1.79 & 1.47 \\
\hline Range & 1.32 & 1.34 & 0.76 & 1.40 & 1.16 & 1.33 & 1.84 & 1.09 & 0.69 & 1.01 & 0.77 \\
\hline Std. dev. & 0.39 & 0.60 & 0.32 & 0.39 & 0.36 & 0.38 & 0.45 & 0.33 & 0.29 & 0.37 & 0.32 \\
\hline Min. & 1.22 & 1.26 & 1.08 & 1.42 & 1.44 & 1.35 & 0.70 & 1.46 & 1.18 & 1.22 & 1.11 \\
\hline 1st quar. & 1.70 & - & - & 2.04 & 1.67 & 1.62 & 1.51 & 2.02 & - & - & - \\
\hline 2nd quar. & 1.78 & - & - & 2.43 & 1.97 & 2.00 & 1.81 & 2.17 & - & - & - \\
\hline 3rd quar. & 2.06 & - & - & 2.68 & 2.19 & 2.16 & 2.07 & 2.34 & - & - & - \\
\hline Max. & 2.54 & 2.61 & 1.84 & 2.82 & 2.60 & 2.69 & 2.54 & 2.54 & 1.87 & 2.23 & 1.89 \\
\hline $\mathrm{N}$ & 15 & 5 & 5 & 19 & 20 & 20 & 21 & 11 & 5 & 5 & 5 \\
\hline \multicolumn{12}{|l|}{ Temp. $\mathrm{C}^{\circ}$} \\
\hline Mean & 13.8 & 13.4 & 15.7 & 11.8 & 13.4 & 13.5 & 14.3 & 12.7 & 15.9 & 14.2 & 15.6 \\
\hline Range & 5.7 & 5.8 & 3.3 & 6.1 & 5.0 & 5.8 & 8.0 & 4.7 & 3.0 & 4.4 & 3.3 \\
\hline Std. dev. & 1.7 & 2.6 & 1.4 & 1.7 & 1.6 & 1.7 & 1.9 & 1.4 & 1.2 & 1.6 & 1.4 \\
\hline $\operatorname{Max} . \mathrm{T}^{\circ}$ & 16.7 & 16.5 & 17.3 & 15.8 & 15.7 & 16.1 & 18.9 & 15.6 & 16.8 & 16.7 & 17.1 \\
\hline $\operatorname{Min} . \mathrm{T}^{\circ}$ & 10.9 & 10.6 & 14.0 & 9.7 & 10.7 & 10.3 & 11.0 & 10.9 & 13.8 & 12.3 & 13.8 \\
\hline
\end{tabular}




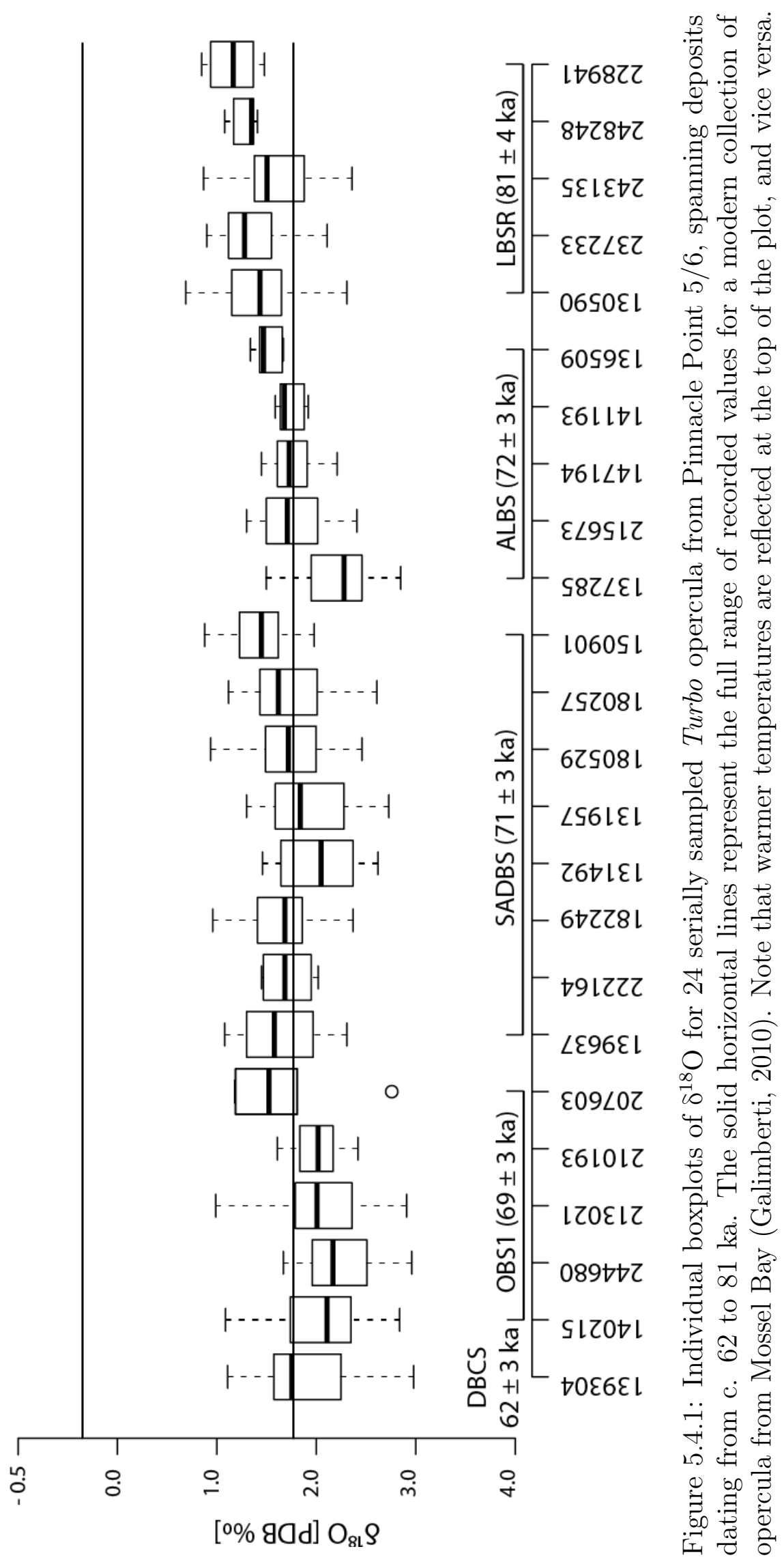




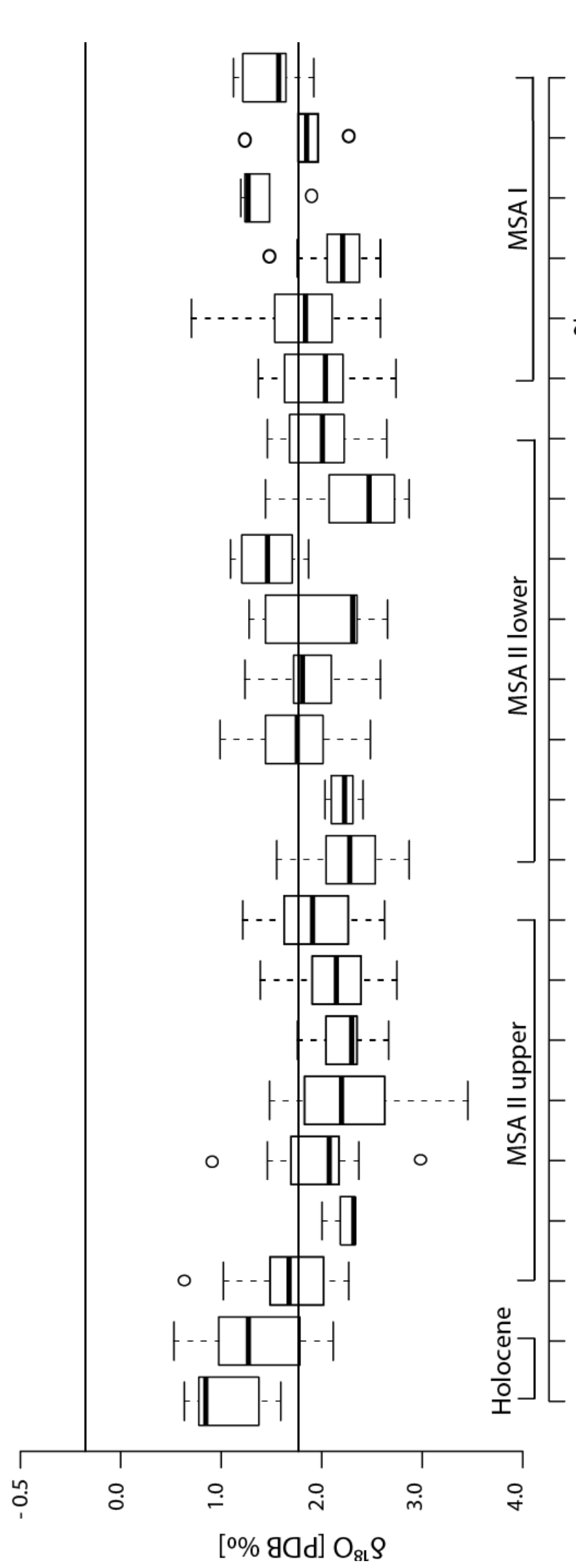

击

की

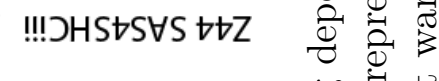

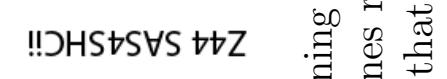

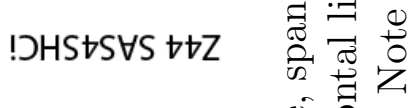

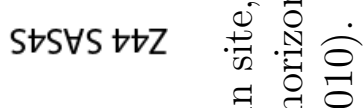

乙JVHSZSHS tZ

SZSHS tTZ छे के

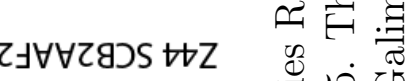

!l $\operatorname{ls} \mathrm{t} t \mathrm{tZ}$

¿ 0

!GISᄉ ttZ

zsg toz $\quad \frac{\pi}{\overrightarrow{0}} \tilde{y}^{0}$

!!ZSg StZ वैं :

ITSg StZ 贯

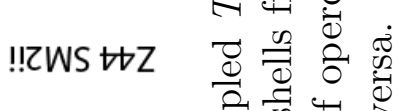

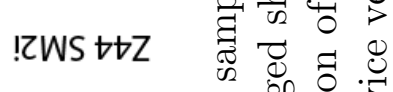

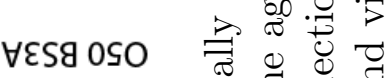

चे चे

LESg OSO की

!!dSรS OSO :

!dJSרS OSO

पै

!"WtרS OSO

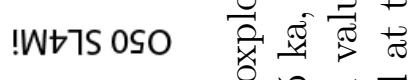

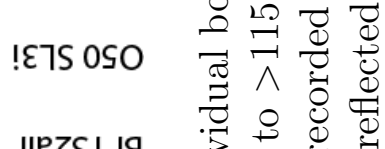

!nezs」 la

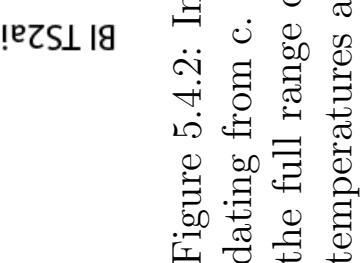


Table 5.10: Statistics for serially sampled opercula $\delta^{18} \mathrm{O}$ values from Pinnacle Point 5-6, aggregated by depositional unit. Also shown are the converted temperature values (according to the Grossman and Ku, 1986 equation) and the departures from the modern Galimberti (2010) dataset.

\begin{tabular}{lcccccc}
\hline & Modern & DBCS & OBS1 & SADBS & ALBS & LBSR \\
\hline$\delta^{18} \mathrm{O}$ adjust. & & 0.54 & 0.64 & 0.58 & 0.51 & 0.22 \\
$\delta^{18} \mathrm{O}$ range & & $0.41-0.72$ & $0.57-0.71$ & $0.38-0.66$ & $0.35-0.65$ & $0.16-0.31$ \\
$\delta^{18} \mathrm{O} \mathrm{T}^{\circ} \mathrm{C}$ error & & 1.35 & 0.61 & 1.22 & 1.35 & 0.65 \\
\hline $\mathrm{N} \delta^{18} \mathrm{O}$ & 327 & 20 & 80 & 151 & 74 & 74 \\
$\mathrm{~N}$ shells & 16 & 1 & 5 & 8 & 5 & 5 \\
Mean & 0.69 & 1.89 & 2.07 & 1.75 & 1.90 & 1.43 \\
Stdev & 0.52 & 0.49 & 0.45 & 0.40 & 0.36 & 0.37 \\
Max & 1.77 & 2.99 & 2.97 & 2.74 & 2.86 & 2.37 \\
Min & -0.35 & 1.12 & 1.00 & 0.89 & 1.31 & 0.70 \\
Range & 2.12 & 1.87 & 1.97 & 1.85 & 1.55 & 1.67 \\
Ave. max & 1.47 & - & 2.79 & 2.40 & 2.22 & 1.94 \\
Ave. min & -0.07 & - & 1.32 & 1.16 & 1.45 & 0.89
\end{tabular}

Temperature conversion

\begin{tabular}{|c|c|c|c|c|c|c|}
\hline Mean $\mathrm{T}^{\circ}$ & 19.0 & 13.8 & 13.0 & 14.3 & 13.7 & 15.7 \\
\hline Stdev & 2.2 & 2.1 & 1.9 & 1.8 & 1.6 & 1.6 \\
\hline $\operatorname{Min} \mathrm{T}^{\circ}$ & 14.3 & 9.0 & 9.1 & 10.1 & 9.6 & 11.7 \\
\hline $\operatorname{Max} \mathrm{T}^{\circ}$ & 23.5 & 17.1 & 17.6 & 18.1 & 16.3 & 18.9 \\
\hline Range & 9.2 & 8.1 & 8.5 & 8.0 & 6.7 & 7.2 \\
\hline Ave. $\min \mathrm{T}^{\circ}$ & 15.6 & - & 9.9 & 11.5 & 12.3 & 13.5 \\
\hline Ave. $\max \mathrm{T}^{\circ}$ & 22.3 & - & 16.2 & 16.9 & 15.7 & 18.1 \\
\hline Ave. range & 6.7 & - & 6.4 & 5.4 & 3.4 & 4.6 \\
\hline
\end{tabular}

Departure from modern Mossel Bay shells

\begin{tabular}{lcccccc}
\hline Mean T & - & -5.2 & -6.0 & -4.6 & -5.2 & -3.2 \\
Min T $^{\circ}$ & - & -5.3 & -5.2 & -4.2 & -4.7 & -2.6 \\
Max T & - & -6.4 & -5.9 & -5.4 & -7.2 & -4.6 \\
Range & - & -1.1 & -0.7 & -1.2 & -2.5 & -2.0 \\
Ave. min T & - & - & -5.7 & -4.0 & -3.3 & -2.1 \\
Ave. max T & - & - & -6.0 & -5.3 & -6.6 & -4.2 \\
Ave. range & - & - & -0.3 & -1.3 & -3.3 & -2.1 \\
\hline \hline
\end{tabular}


Table 5.11: Statistics for the serially sampled opercula $\delta^{18} \mathrm{O}$ values from Klasies River Main site and Cave 5, aggregated by technological unit. Also shown are the converted temperature values (according to the Grossman and $\mathrm{Ku}, 1986$ equation) and the departures from the modern Galimberti (2010) dataset.

\begin{tabular}{lccccc}
\hline & Modern & KRM5 & $\begin{array}{c}\text { MSAII } \\
\text { upper }\end{array}$ & $\begin{array}{c}\text { MSAII } \\
\text { lower }\end{array}$ & MSAI \\
\hline$\delta^{18} \mathrm{O}$ adjust. & & 0 & 0.51 & 0.32 & 0.07 \\
$\delta^{18} \mathrm{O}$ range & & 0 & $0.34-0.65$ & $0.23-0.40$ & $0.01-0.14$ \\
$\delta^{18} \mathrm{O}{ }^{\circ} \mathrm{C}$ error & & - & 1.3 & 0.7 & 0.6 \\
\hline $\mathrm{N} \delta^{18} \mathrm{~N}$ & 327 & 15 & 104 & 112 & 67 \\
$\mathrm{~N}$ shells & 16 & 2 & 7 & 8 & 6 \\
Mean & 0.69 & 1.19 & 1.98 & 2.01 & 1.84 \\
Stdev & 0.52 & 0.48 & 0.45 & 0.45 & 0.43 \\
Max & 1.77 & 2.08 & 3.39 & 2.82 & 2.69 \\
Min & -0.35 & 0.53 & 0.64 & 0.98 & 0.70 \\
Range & 2.12 & 1.55 & 2.75 & 1.84 & 1.99 \\
Ave. max & 1.47 & - & 2.68 & 2.50 & 2.29 \\
Ave. min & -0.07 & - & 1.32 & 1.37 & 1.17
\end{tabular}

Temperature conversion

\begin{tabular}{|c|c|c|c|c|c|}
\hline Mean $\mathrm{T}^{\circ}$ & 19.0 & 16.8 & 13.3 & 13.2 & 14.0 \\
\hline Stdev & 2.2 & 2.1 & 1.9 & 2.0 & 1.9 \\
\hline $\operatorname{Min} \mathrm{T}^{\circ}$ & 14.3 & 12.9 & 7.3 & 9.7 & 10.3 \\
\hline $\operatorname{Max} \mathrm{T}^{\circ}$ & 23.5 & 19.2 & 17.9 & 17.7 & 18.9 \\
\hline Range & 9.2 & 6.7 & 11.9 & 8.0 & 8.6 \\
\hline Ave. $\min \mathrm{T}^{\circ}$ & 15.6 & - & 10.3 & 11.1 & 12.0 \\
\hline Ave. $\max \mathrm{T}^{\circ}$ & 22.3 & - & 16.2 & 16.0 & 16.9 \\
\hline Ave. range & 6.7 & - & 5.9 & 4.9 & 4.9 \\
\hline
\end{tabular}

Departure from modern Mossel Bay shells

\begin{tabular}{lccccc}
\hline Mean $\mathrm{T}^{\circ}$ & - & -2.2 & -5.6 & -5.7 & -5.0 \\
Min T $^{\circ}$ & - & -1.4 & -7.0 & -4.6 & -4.0 \\
Max T & - & -3.8 & -4.3 & -5.8 & -4.6 \\
Range & - & -2.5 & 2.7 & -1.2 & -0.6 \\
Ave. min T & - & - & -5.3 & -4.5 & -3.6 \\
Ave. max T & - & - & -6.0 & -6.2 & -5.4 \\
Ave. range & - & - & -0.8 & -1.7 & -1.8 \\
\hline \hline
\end{tabular}



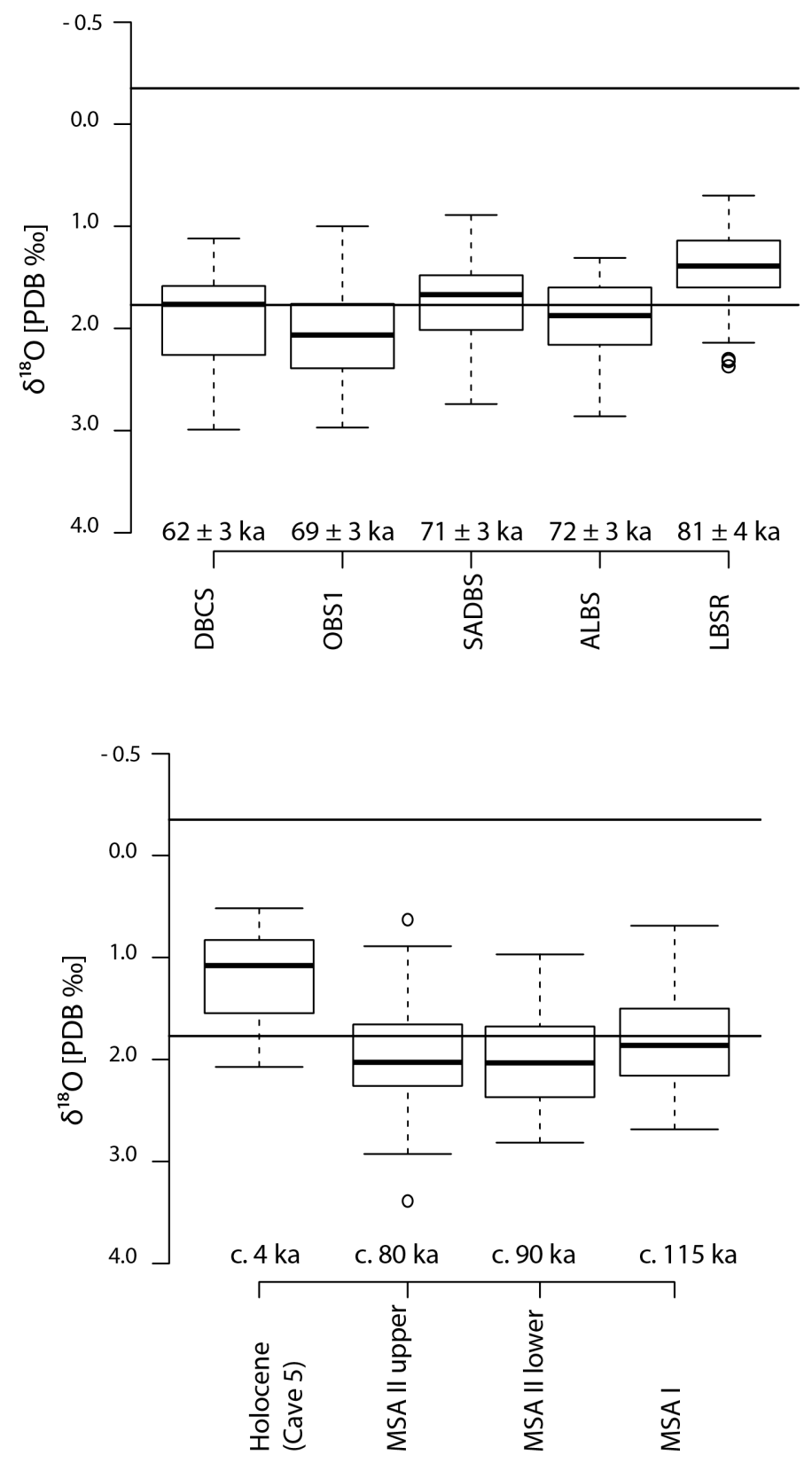

Figure 5.4.3: Boxplots of serially sampled opercula $\delta^{18} \mathrm{O}$ from Pinnacle Point 5-6, aggregated according to depositional unit (top), and Klasies River Main and Cave 5, aggregated according to technological unit (bottom). The solid horizontal lines represent the full range of recorded values for a modern collection of opercula from Mossel Bay (Galimberti, 2010). Note that warmer temperatures are reflected at the top of the plot, and vice versa. 
tests are reported in Appendix C in Tables $\mathrm{C} 7$ and $\mathrm{C} 8$ for PP5-6 and Tables $\mathrm{C} 10$ and C11). At PP5-6, the shells record a statistically significant decline in temperature of $\mathrm{c}$. $2{ }^{\circ} \mathrm{C}$ between the MIS5 sample from level LBSR $(81 \pm 4 \mathrm{ka})$ and the MIS4 samples in the overlying levels $(\mathrm{p}<<0.0001)$. The $\delta^{18} \mathrm{O}$ datasets from the succeeding two levels, ALBS (72 $\pm 3 \mathrm{ka})$ and SADBS (71 $\pm 3 \mathrm{ka})$, do not differ significantly from one another, but that from the next level, OBS1 (69 $\pm 3 \mathrm{ka}$ ), is significantly different from SADBS $(\mathrm{p}<<0.001)$, and reflects a temperature decrease of c. $1{ }^{\circ} \mathrm{C}$ between these two periods. There is only one shell suitable for sampling from the youngest level DBCS (62 $\pm 3 \mathrm{ka})$, which limits the strength of possible conclusions, but it appears to reflect a return to slightly warmer temperatures again.

At KRM, the corrected $\delta^{18} \mathrm{O}$ values capture a trend of generally declining temperatures across the three MIS5 periods, although the trend is weak, with a change in temperature of only c. $0.7^{\circ} \mathrm{C}$ from the MIS5e/d sample of MSA I (c. $115 \mathrm{ka}$ ) through to the MIS5a sample in MSA II upper (c. $80 \mathrm{ka}$ ). Only the earliest MSA I level (c. $115 \mathrm{ka})$ and the intermediate MSAII upper level (c. $90 \mathrm{ka}$ ) differ significantly from one another, and the strength of that significance is low and reflects a change in mean temperature of $<1{ }^{\circ} \mathrm{C}$ $(\mathrm{p}=0.03)$. Given that the deposits sampled here do not span the MIS5/4 transition, the apparent lack of large shifts in average temperature is perhaps not surprising, especially as occupation at the site may occur during warmer periods, when the site was closer to the shoreline. Two shells dating to the late Holocene were included and show mean temperatures $\left(16.8^{\circ} \mathrm{C}\right)$ comparable to those reconstructed from the late Holocene shells from the Robberg peninsula $\left(16.0{ }^{\circ} \mathrm{C}\right)$. However, the number of analytical samples is small $(n=15)$, and these results are not interpreted further.

The excellent stratigraphic information available for the PP5-6 samples enables the comparison of shells between sub-aggregates within the larger stratigraphic units shown above. Figure 5.4.4 shows the results from PP5-6 separated according to sub-aggregates (listed for each shell in Table 5.6). Note that the samples are still corrected for changes in ocean $\delta^{18} \mathrm{O}$ by aggregate, according to the chronology published in Karkanas et al. (2015), but ongoing dating efforts at this site mean that the sub-aggregate units themselves will soon have refined age estimates available, at which point more accurate and precise corrections can be made. Figure 5.4.4 shows some temperature variability within stratigraphic units, which might simply reflect microhabitat conditions and the generally small sample sizes per sub-aggregate, but may also reflect real environmental shifts within the stratigraphic units. This is likely considering the length of time some of the units represent. Yet generally the individual shell $\delta^{18} \mathrm{O}$ series within a sub-aggregate do not 


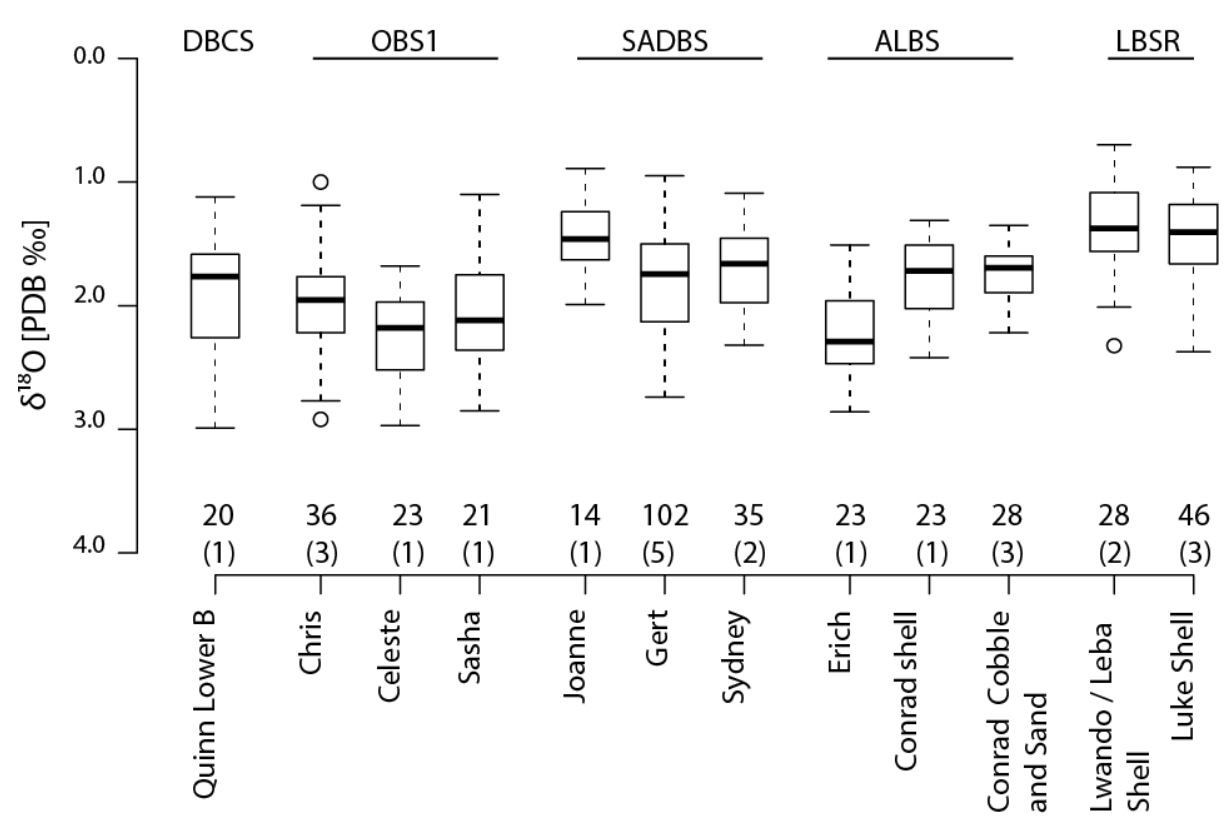

Figure 5.4.4: Boxplot of $\delta^{18} \mathrm{O}$ values from Pinnacle Point 5-6 in chronological order, analysed by sub-aggregate unit, with number of analytical samples and number of shells per unit (in brackets) shown below each box. Note that the two shells from Lwando Shell and Leba Shell were combined as the Leba Shell opercula has only 6 analytical samples.

differ significantly from one another (see also the discussion of intra-level shell differences for the Holocene dataset in section 5.3.1.1 above). For sub-aggregate Gert in level SADBS, for which 5 shells were sampled, only two shell $\delta^{18} \mathrm{O}$ series differ significantly from one another (opercula PP182249 and PP131492: Tukey multiple comparison test, $\mathrm{p}=0.0159)$. In no other sub-aggregate level where more than one shell is sampled do the individual shell $\delta^{18} \mathrm{O}$ series differ significantly from one another. This is promising for more nuanced and highly resolved climate records from Pinnacle Point, although presently caution is warranted, given the small sample sizes and available chronological resolution.

\subsubsection{2 $\quad \delta^{13} \mathrm{C}$ results}

Also provided in Appendix A are the $\delta^{13} \mathrm{C}$ results for each shell. Table 5.12 and Figure 5.4.5 below provide the summary statistics for these data. There are significant changes in $\delta^{13} \mathrm{C}$ through time between the levels at each site (one way ANOVA $\mathrm{p}<<0.001$ : full results of the Tukey multiple comparison test aggregated by site and each of the time periods are presented in Table C12 of Appendix C). 
Table 5.12: Statistics for the aggregated $\delta^{13} \mathrm{C}$ values from Pinnacle Point 5-6, according to depositional unit and from Klasies River Main site and Cave 5, according to technological unit.

\begin{tabular}{lccccccccc}
\hline & Modern & DBCS & OBS1 & SADBS & ALBS & LBSR & $\begin{array}{c}\text { MSAII } \\
\text { upper }\end{array}$ & $\begin{array}{c}\text { MSAII } \\
\text { lower }\end{array}$ & MSAI \\
\hline $\mathrm{N} \delta^{13} C$ & 20 & 80 & 151 & 74 & 74 & 77 & 104 & 112 & 67 \\
$\mathrm{~N}$ shells & 16 & 1 & 5 & 8 & 5 & 5 & 5 & 8 & 7 \\
Mean & 1.90 & 2.25 & 3.00 & 2.54 & 2.46 & 2.40 & 2.63 & 2.45 & 2.38 \\
Stdev & 0.44 & 0.23 & 0.42 & 0.49 & 0.47 & 0.32 & 0.41 & 0.43 & 0.36 \\
Max & 2.98 & 2.80 & 4.14 & 3.47 & 3.41 & 3.14 & 3.63 & 3.63 & 3.12 \\
Min & 0.31 & 1.87 & 2.36 & 0.57 & 1.54 & 1.76 & 1.89 & 1.42 & 1.42 \\
Ave. mean & 1.90 & & 3.01 & 2.53 & 2.41 & 2.44 & 2.68 & 2.48 & 2.32 \\
Ave. max & 2.46 & & 3.60 & 3.10 & 2.75 & 2.87 & 3.24 & 3.07 & 2.81 \\
Ave. min & 1.10 & & 2.50 & 1.91 & 1.98 & 1.98 & 2.20 & 1.94 & 1.90 \\
\hline \hline
\end{tabular}

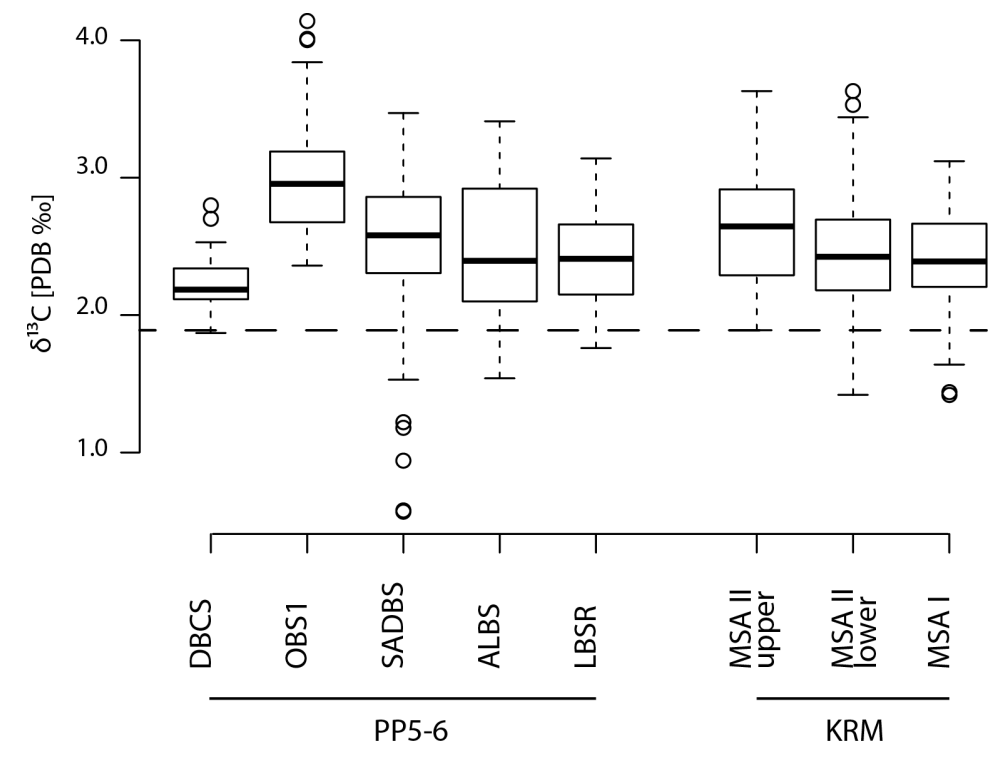

Figure 5.4.5: Boxplots of $\delta^{13} \mathrm{C}$ for the Pleistocene aged samples, aggregated by site and depositional or technological units. The dotted horizontal line represents the average of the modern collection of Turbo opercula from Mossel Bay (Galimberti, 2010). 


\subsubsection{Discussion of MSA sample results}

In combination with the terminal Pleistocene and Holocene data provided above, these results show a good relationship between near-shore SSTs and global climate shifts (see Figure 5.5.1), as do the continuous records of SSTs in the Agulhas Current (Ziegler et al., 2013). SSTs are apparently stable between the MIS5 levels at KRM, while at PP5-6, where the samples span the MIS5/4 transition, SSTs were warmest during MIS5 (unit LBSR, mean $=15.7^{\circ} \mathrm{C}$ ), decline across the MIS5/4 transitional levels (ALBS, mean $=13.7^{\circ} \mathrm{C}$ and $\mathrm{SADBS}$, mean $=14.3^{\circ} \mathrm{C}$ ), and are coolest during the glacial MIS4 stage $\left(\mathrm{OBS} 1\right.$, mean $\left.=13.0^{\circ} \mathrm{C}\right)$. This indicates that regional SST dynamics in the Agulhas system accord well with global glacial/interglacial climate trends.

The results are also consistent with modern SST patterning along the coast: where they overlap in time, the shell records from KRM record cooler average temperatures than those from PP 5-6. Shells from MSA II Upper level (c. $80 \mathrm{ka}$ ) record an average temperature of c. $13.3^{\circ} \mathrm{C}$, while the broadly equivalent dataset from LBSR (c. $82 \mathrm{ka}$ ) record average temperatures of c. $15.7^{\circ} \mathrm{C}$. Today warmer SSTs are witnessed near Mossel Bay than near Tsitsikamma (see Table 2.1).

At PP5-6, the amplitude of the seasonal SST difference (derived from the averaged maximum and minimum $\delta^{18} \mathrm{O}$ values across all shells, per level) is lower during MIS5 (LBSR $-4.6{ }^{\circ} \mathrm{C}$ ) and the MIS5/4 transitional levels (ALBS $-3.4{ }^{\circ} \mathrm{C}$ and SADBS $-5.4{ }^{\circ} \mathrm{C}$ ), than during MIS4 level OBS1 $\left(6.4^{\circ} \mathrm{C}\right)$, suggesting an increase in the seasonal amplitude between MIS5 and MIS4 (see Figure 5.4.6). An assessment of the departures from the modern dataset of Galimberti, indicates that during MIS5 and the MIS5/4 transition, the overall cooler temperatures from today are driven more by cooler summer temperatures (i.e. a greater magnitude departure from the modern maximum), whereas during MIS4 maximum and minimum averaged temperatures are equivalently depressed. During the two oldest levels at P5-6, LBSR and ALBS, the departure between the modern and ancient averaged maximum (summer) temperatures is twice that for the averaged minimum (winter) temperatures. However, during SADBS the summer and winter SSTs are more uniformly cool and by OBS1 the departure from the modern dataset is approximately the same for both the minimum and maximum averaged temperatures.

With reference to the Cohen and Tyson (1995) model, the shifts in annual SST range and in summer and winter temperatures at PP5-6 mirror the patterns seen in the LSA assemblage. During levels LBSR and ALBS the SST conditions are similar to 


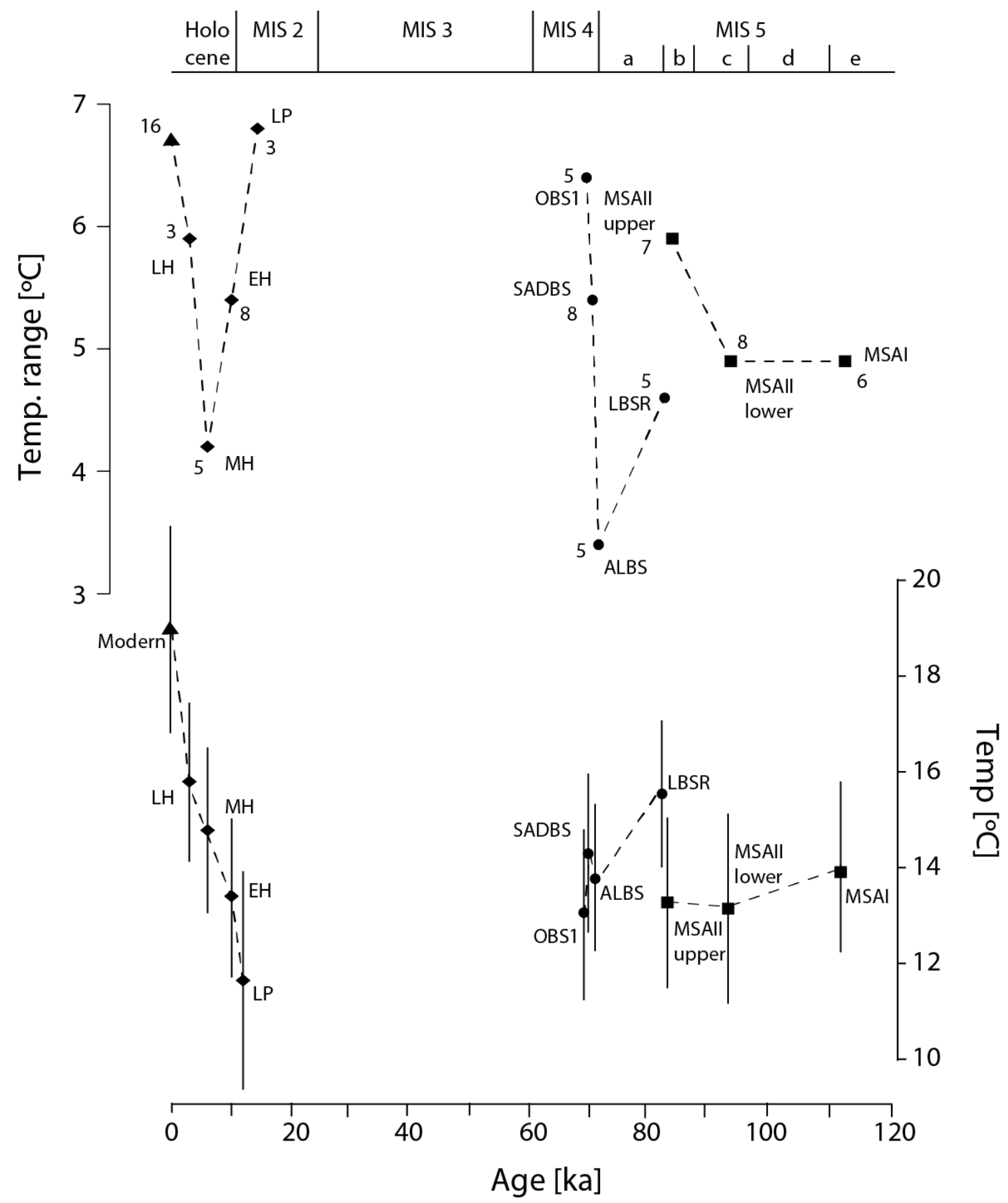

Figure 5.4.6: Top: Annual range of temperatures across the entire period of study (mean maximum - mean minimum). Bottom: Average temperatures by stratigraphic unit with the standard deviation indicated. Data in Tables 5.4 (Robberg sites (NBC and HRC only): diamonds; modern: triangle), 5.10 (PP5-6: circles) and 5.11 (KRM: squares). Note that the results from PP5-6 unit DBCS are not shown as that is only a single shell. Numbers alongside show the number of shell samples per unit. 
those seen during the mid Holocene, which apparently reflected increased upwelling and easterly winds, and was accompanied by increased rainfall in the summer rainfall region, although drier conditions at the coast due to winter rainfall dynamics and the warmer temperatures. The annual SST range is low during LBSR and especially ALBS. However, during LBSR average SSTs were also comparatively high, suggestive of increased moisture availability at the coast as well as in the interior. By contrast, average temperatures during level ALBS were $2{ }^{\circ} \mathrm{C}$ cooler, potentially driving drier conditions at the coast, although the low annual range suggests frequent easterly component winds contiinued to bring precipitation to the interior. From SADBS conditions began drying both in the interior and the coast, reaching their driest in level OBS1, when both the annual range and average temperatures are comparable to those seen in the terminal Pleistocene assemblage. This patterning is consistent with the Agulhas offshore SST record of Simon et al. (2013) which shows warmer temperatures at c. $82 \mathrm{ka}$, and cool SSTs at c. $71 \mathrm{ka}$ (see Figure 5.5.1). However, the inclusion of data for the seasonal range in the near-shore zone allows an assessment beyond the global climate trends.

Terrestrial evidence for MIS4 climates apparently reveals a high degree of variability in summer precipitation (Ziegler et al., 2013). The Ziegler et al. (2013) record of summer rainfall zone precipitation shows no clear evidence for an arid event at c. 69 ka but this may well be due to the nature of that record, which is dependant on run-off and so will better capture wet episodes when run-off from the land increases. By contrast the proposed moister conditions in levels LBSR and ALBS should be reflected in the Ziegler et al. record, and yet, if anything, their record shows drier than average conditions at this time. The age model for the Ziegler et al record is tuned to the EPICA Dome C and NGRIP ice core models and examination of the $>75$ ka portion of the record shows a poor match with either of these records, presumably confounding the tuning efforts. Interestingly, the Crevice Cave speleothem record of Bar-Matthews et al. (2010) (located adjacent to Pinnacle Point) is partially consistent with the shell $\delta^{18} \mathrm{O}$ findings. At c. 80 ka the speleothem records a shift to greater amounts of summer rainfall and increased proportions of $\mathrm{C} 4$ grass (a consequence of greater summer rainfall). Yet, the speleothem records an even stronger summer rainfall, C4 signal at the MIS 5/4 transition after 70 ka, inconsistent with the evidence from level OBS1 of reduced upwelling. However, given the very different nature of these two records and their responses to climatic conditions, any correspondences or differences may be irrelevant.

At KRM, the annual SST range is lower during the older depositional units, MSA I (4.9 $\left.{ }^{\circ} \mathrm{C}\right)$ and MSA II Lower $\left(4.9^{\circ} \mathrm{C}\right)$, than MSA II Upper $\left(5.9{ }^{\circ} \mathrm{C}\right)$. And similar to PP $5-6$, 
cooler summer temperatures alone appear to be driving the overall trends in the two oldest levels compared to MSA II Upper, when departures from the modern dataset are more equivalent for both the minimum and maximum recorded SSTs, as well as greater in magnitude. However, where the two records overlap c. $80 \mathrm{ka}$, the seasonal amplitude recorded at KRM (MSA II Upper) is greater than at PP5-6 (LBSR). This is unlike modern SST patterning, as Mossel Bay presently experiences a markedly greater seasonal amplitude $\left(5.9^{\circ} \mathrm{C}\right)$ than either Port Elizabeth $\left(4^{\circ} \mathrm{C}\right)$ or Tsitsikamma $\left(2.7^{\circ} \mathrm{C}\right)$, the two SST recording stations nearest to KRM. The discrepancy between the KRM and PP5-6 assemblage may then reflect the imprecise dating of the KRM deposits.

Further evidence for the marked oceanographic shifts that would have occurred between MIS5 and 4 is the notable increase in $\delta^{13} \mathrm{C}$ in MIS4 level OBS1 (69 $\pm 3 \mathrm{ka}$ ), where average $\delta^{13} \mathrm{C}$ values of c. $3 \%$ are comparable to those measured in the mid Holocene assemblage from the Robberg peninsula (see section 5.3.1.2 above). Although oceanographic conditions are likely to have been quite different during the glacial, and this result cannot be interpreted too strongly, the increased $\delta^{13} \mathrm{C}$ values suggest marked changes in oceanic dynamics or primary productivity. Although temperatures are apparently at their coolest at this time, the marked decrease in global temperatures during MIS4 is likely to counter any expected warming due to reduced upwelling.

\subsection{Comparison with other estimates of seasonality}

This section assesses alternative measures of SST seasonality along the south coast, including shell $\delta^{18} \mathrm{O}$ data, estimates from an offshore foraminiferal assemblage and modelled estimates of Earth Systems Models. The SST estimates derived from nearshore palaeotemperature archives, such as intertidal molluscs, are expected to differ from offshore records, such as marine cores, that will reflect a more regional signal, as SSTs can vary considerably in the near-coastal zone (e.g. Blanchette et al., 2006).

\subsubsection{Comparison with shell records of SST seasonality}

Three prior studies have assessed SST palaeoseasonality for this region using the same methodology as this study - Nick Shackleton undertook two very small studies of LSA Patella tabularis (now Scutellastra) from NBC (Shackleton, 1973) and of MSA Turbo 
sarmaticus opercula from KRM (Shackleton, 1982); Anne Cohen's doctoral research developed a Holocene SST record based upon Scutellastra tabularis limpet shells from Nelson Bay Cave (Cohen, 1993; Cohen and Tyson, 1995), and the doctoral research of Mariagrazia Galimberti developed a MIS5 SST record based on Turbo sarmaticus opercula from Pinnacle Point 13B (Galimberti, 2010). The 1982 Shackleton isotope data from KRM are commonly cited as chronological evidence for the KRM deposits, based upon correlations with the global $\delta^{18} \mathrm{O}$ sea-level curve, and Shackleton did not attempt to derive SST estimates from the data (as he assumed that the largest effect on $\delta^{18} \mathrm{O}$ was global sea-level). Given this, and that Shackleton did not evaluate diagenesis of the shells, and what is now known about the high likelihood of recrystallisation within these deposits (seven out of 22 "well-preserved" Pleistocene shells from KRM showed extensive recrystallisation across the micromill drilling path), these results cannot be considered secure.

The original dataset from Cohen and Tyson (1995) was re-analysed here to include the updated chronological information for NBC and to correct for changes in global ocean $\delta^{18} \mathrm{O}$ (Waelbroeck et al., 2002). Cohen's dataset is not exactly comparable to the present study as $S$. tabularis precipitates calcite, not aragonite - thus, temperatures are calculated using the Shackleton (1974) quadratic equation for calcite temperature conversion, with an offset of $1 \%$ (which includes the estimate of seawater $\delta^{18} \mathrm{O}$ ) as established empirically by Shackleton (1973) and Cohen and Tyson (1995):

$$
T\left({ }^{\circ} \mathrm{C}\right)=16.9-4.38\left(\delta^{18} O_{\text {carbonate }}-1+0.2\right)+0.1\left(\delta^{18} O_{\text {carbonate }}-1+0.2\right)^{2}
$$

The averaged maximum and minimum values for the early, middle and late Holocene (see Table 5.13) are remarkably similar to those recorded by the Turbo opercula for the same time periods (see "Departure from Turbo" rows in table), especially for the minimum recorded temperatures. The $S$. tabularis shells apparently record higher maximum (i.e. summer) temperatures, which may reflect habitat differences between the two species. Limpets live higher in the tidal zone, at the low-tide level of the inter-and infratidal zones only down to about $4 \mathrm{~m}$ depth compared to $8 \mathrm{~m}$ depth of Turbo (Cohen and Tyson, 1995). Thus, limpets are exposed to warmer temperatures than Turbo. Interestingly, the greatest departures from the Turbo dataset occur during the mid Holocene levels, where the limpets record warmer summer temperatures. This accords well with the evidence for increased summer upwelling of cold waters during the mid Holocene from the Turbo $\delta^{18} \mathrm{O}$ measurements: possibly the effects of upwelling were diminshed in the higher inter 
tidal zone by summer heating of the shallower waters. Unfortunately Cohen's $\delta^{13} \mathrm{C}$ data are not available for comparison.

The original data of Galimberti (2010) from Pinnacle Point sites 13B, 9B and 5-6 were re-analysed and key statistics for each aggregated period are presented in Table 5.13. The results are aggregated according to broad time period, and are compared to the similarly aged datasets from Klasies River (namely MSA II lower (c. 95 ka) and MSA I (c. 115 ka)). The Galimberti Pinnacle Point shells record mean temperatures more than $2^{\mathrm{O}} \mathrm{C}$ warmer than those recorded in the Klasies River shells, which accords well with the modern SST patterning along the south coast (see Table 2.1 on page 16), although it might indicate that, if anything, the temperature gradient along the coast was even more pronounced during the last interglacial. Further, the interpretation of similar oceanographic conditions during the last interglacial is supported by the greater difference in maximum temperatures between the two locations $\left(3.3^{\circ} \mathrm{C}\right.$ at both $98-92 \mathrm{ka}$ and 119-106 ka) than in the minimum temperatures $\left(0.8^{\mathrm{O}} \mathrm{C}\right.$ and $1.1^{\mathrm{O}} \mathrm{C}$, respectively). A similar pattern is seen today between Mossel Bay and sites adjacent to Klasies River including Tsitsikamma and Port Elizabeth (see Table 2.1). The two periods also show similar averaged SST ranges $\left(7.4^{\underline{O}} \mathrm{C}\right.$ and $\left.7.0^{\circ} \mathrm{C}\right)$ to that observed in modern SST measurements at Mossel Bay. The comparison of the results from these two locations provides further support for the reliability of Turbo as a recorder of mean near-shore SSTs.

\subsubsection{Comparison with an offshore core record of SST season- ality}

Figure 5.5.1E shows the averaged SST reconstructions (mean, maximum and minimum) derived from the shell $\delta^{18} \mathrm{O}$ values discussed above (Tables 5.4, 5.10 and 5.11) alongside (A) insolation seasonality (the difference between June and December insolation) at $30^{\circ} \mathrm{S}$

for the last $120 \mathrm{ka}$ (Berger and Loutre, 1991), (B) the relative sea level curve (Waelbroeck et al., 2002), (C) a stacked record of Agulhas Current SSTs for the last 115 ka derived from $\mathrm{Mg} / \mathrm{Ca}$ ratios, and alkenone and tetraether indices, from marine sediment core MD96-2048 located in the formation region of the Agulhas Current, adjacent to the Delagoa Bight (26 $\left.6^{\underline{0}} 10.0^{\prime} \mathrm{S}, 34^{\underline{0}} 1.0^{\prime} \mathrm{E}\right)$ (Caley et al., 2011), and (D) a record of Agulhas Current SSTs for the last 100 ka derived from a planktic foraminiferal assemblage from marine sediment core CD154 17-17K located in the main trajectory of the Agulhas

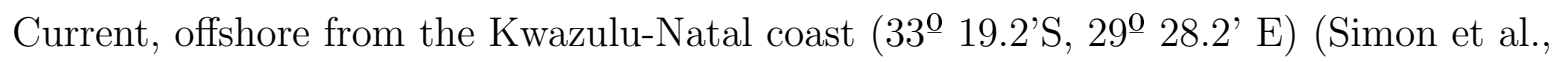


Table 5.13: Statistics for $\delta^{18} \mathrm{O}$ values from Cohen and Tyson (1995) (early, middle and later Holocene all from Nelson Bay Cave) and Galimberti (2010) (Pinnacle Point sites), aggregated by time period. The lowest set of values shows the temperature difference with equivalent-aged Turbo values from this study (note there are no similarly aged samples to Galimberti's PP5-6 shell from this study).

\begin{tabular}{lc|c|c|c|c|c}
\hline & \multicolumn{2}{c}{ Cohen's Scutellastra data } & \multicolumn{3}{|c}{ Galimberti's Turbo data } \\
\hline & $\begin{array}{c}\text { Late } \\
\text { Holo }\end{array}$ & $\begin{array}{c}\text { Mid } \\
\text { Holo }\end{array}$ & $\begin{array}{c}\text { Early } \\
\text { Holo }\end{array}$ & PP5-6 & $\begin{array}{c}\text { PP13B } \\
\text { URS/SBS }\end{array}$ & $\begin{array}{c}\text { PP13B LRS } \\
\text { and PP9B }\end{array}$ \\
\hline Age (ka) & $2-4$ & $5-9$ & $9-12$ & $48.3 \pm 2.7$ & $98-92$ & $119-106$ \\
$\delta^{18}$ O adjust. & $0.0-0.02$ & $0.02-0.15$ & $0.21-0.30$ & 0.61 & 0.27 & $0.15-0.30$ \\
\hline $\mathrm{N} \delta^{18} \mathrm{O}$ & 63 & 110 & 24 & 19 & 238 & 123 \\
$\mathrm{~N}$ shells & 5 & 8 & 2 & 1 & 9 & 5 \\
Mean & 0.93 & 0.74 & 1.49 & 1.70 & 1.41 & 1.24 \\
Stdev & 0.37 & 0.54 & 0.60 & 0.47 & 0.53 & 0.49 \\
Max & 1.89 & 2.22 & 2.60 & 2.75 & 2.30 & 2.33 \\
Min & 0.13 & -0.46 & 0.57 & 1.02 & -0.09 & 0.13 \\
Range & 1.76 & 2.68 & 2.03 & 1.73 & 2.39 & 2.20 \\
Ave. max & 1.58 & 1.56 & 2.22 & & 2.31 & 2.04 \\
Ave. min & 0.30 & 0.02 & 0.72 & & 0.60 & 0.42
\end{tabular}

Temperature conversion

\begin{tabular}{lc|c|c|c|c|c}
\hline Mean T & 16.3 & 17.1 & 13.9 & 14.6 & 15.8 & 16.6 \\
Min T $^{\circ}$ & 12.2 & 10.9 & 9.3 & 10.0 & 12.0 & 11.8 \\
Max T $^{\circ}$ & 19.9 & 22.6 & 17.9 & 17.5 & 22.3 & 21.4 \\
Range To & 7.6 & 11.7 & 8.6 & 7.5 & 10.4 & 9.5 \\
Ave. min T & 13.5 & 13.6 & 10.9 & - & 11.9 & 13.1 \\
Ave. max T & 19.1 & 20.4 & 17.3 & - & 19.4 & 20.1 \\
Range $\mathrm{T}^{\circ}$ & 5.6 & 6.8 & 6.4 & - & 7.4 & 7.0
\end{tabular}

Departure from Turbo in this study

\begin{tabular}{lc|c|c|c|c|c}
\hline Mean T & 0.3 & 1.7 & 0.5 & - & 2.6 & 2.6 \\
Min T $^{\circ}$ & -0.6 & -0.9 & -0.5 & - & 2.3 & 1.6 \\
Max T $^{\circ}$ & 0.0 & 3.2 & 0.5 & - & 4.6 & 2.5 \\
Range T & -0.7 & 4.0 & 0.8 & - & 2.4 & 0.9 \\
Ave. min T & 0.2 & 0.1 & 0.0 & - & 0.8 & 1.1 \\
Ave. max T & -0.1 & 2.6 & 1.0 & - & 3.3 & 3.3 \\
Ave. range $\mathrm{T}^{\circ}$ & -0.3 & 2.6 & 1.0 & - & 2.5 & 2.2 \\
\hline \hline
\end{tabular}


2013). The SST estimates for the Simon et al. record are derived via a similarity index transfer function based on modern analogue foraminiferal assemblages, which allows for the estimation of summer and winter SSTs in addition to a year-round average. The SST estimates for the periods coincident with the Pleistocene results from this thesis are presented in Table 5.14. Note that both the Caley et al. and Simon et al. temperature estimates are for offshore locations, closer to the Indian Ocean, and so are not directly comparable with the near-shore record from the shells. The temperatures reconstructed by these methods are considerably warmer than recorded for any of the coastal locations in the shell records, and the overall change across this period appears to be muted (temperature records are displayed at the same scale). While the estimates of seasonal amplitude shown in the Simon et al. record are broadly similar to those reconstructed from the shells, at times the seasonal amplitude recorded in the Agulhas Current is greater than is captured in the near-shore shell record, and vice versa. Overall, across this entire period, the seasonal temperature amplitudes reported by Simon et al. (2013) are muted (between $4.0-5.6^{\mathrm{o}} \mathrm{C}$ ) compared to those from shell records $\left(3.4-6.8^{\mathrm{o}} \mathrm{C}\right)$, suggesting that the seasonal amplitude in the main Agulhas Current may be buffered from the processes that influence seasonal amplitude in the near-shore SST record, such as upwelling. In addition, the marine core records are likely to be heavily time averaged due to processes of mixing and bioturbation at the sea-floor.

\subsubsection{Comparison with modelled estimates of SST seasonality}

The Paleoclimate Modelling Intercomparison Project 3 (PMIP3) was a large collaborative project to evaluate and compare the ability of numerous climate models to simulate global climate conditions at the Last Glacial Maximum (LGM) and the mid Holocene $(\mathrm{MH})$, as typifying the extremes of glacial and interglacial climate conditions, respectively (Braconnot et al., 2012). Each modelling team also produced a simulation of modern, pre-industrial (PI) conditions. Below are anomaly plots of the modelled seasonal SSTs from the LGM and MH experiments, each minus the PI control model from three of the best performing and highest resolution Earth Systems Models (ESMs) included in the project (MIROC-ESM, MPI-ESM-3 and CCSM4) - they indicate the modelled differences in seasonal SSTs from the modern, pre-industrial conditions. During the mid Holocene (Figure 5.5.2), all three models apparently show greater departures during the winter months than during the summer months. This conflicts with the temperature records from the shells, which capture much cooler maximum temperatures than minimum temperatures during this period. For the LGM experiment (Figure 5.5.3), the three 


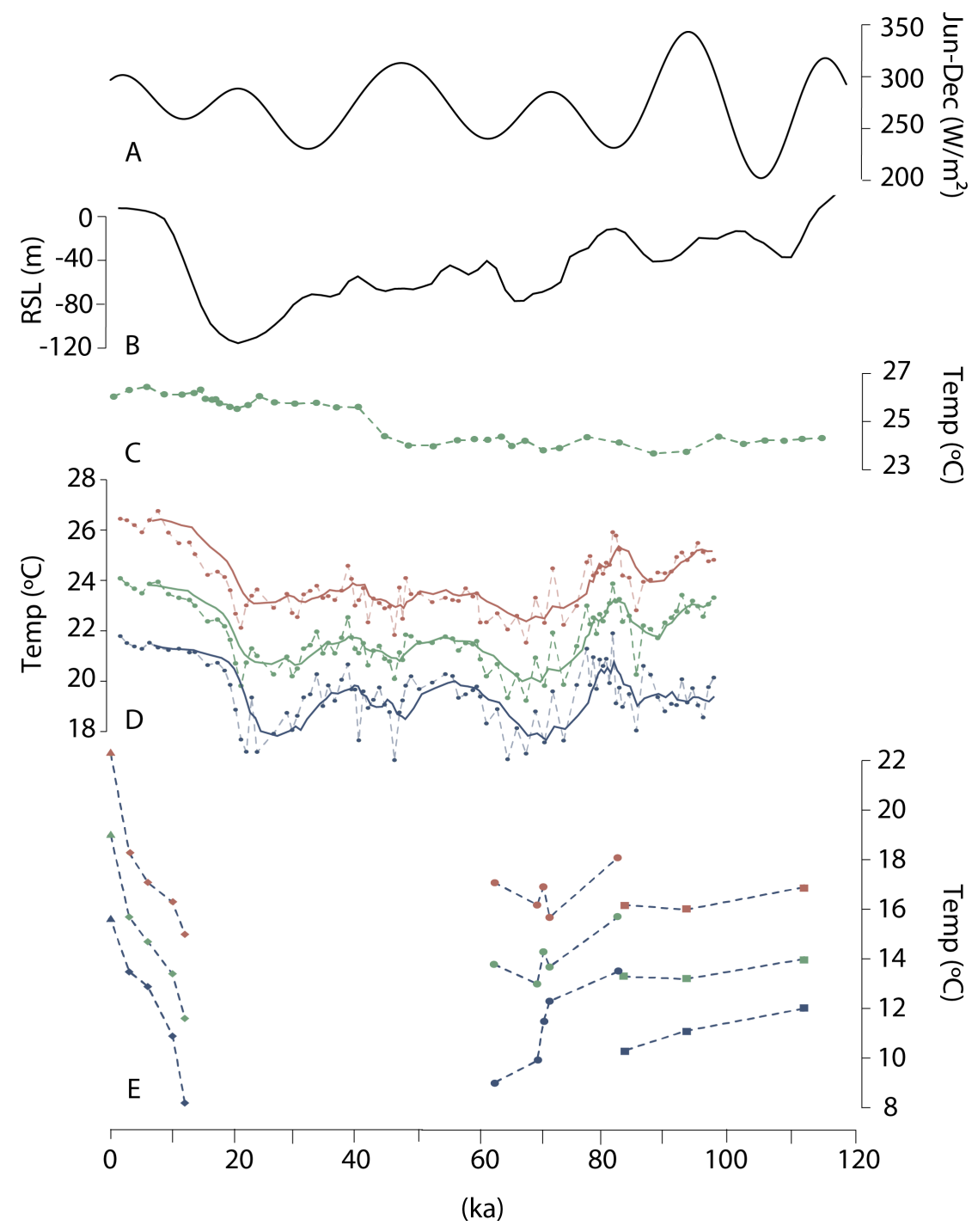

Figure 5.5.1: Climate parameters for the last 120 ka. A: Insolation seasonality (June-December insolation) at $30^{\circ} \mathrm{S}$ (Berger and Loutre, 1991). B: Relative sea level changes from modern (Waelbroeck et al., 2002). C: Reconstructed Agulhas Current SSTs from marine core MD96-2048 (Caley et al., 2011). D: Reconstructed Agulhas Current seasonal SSTs from marine sediment core CD154 17-17K with five point running averages overlaid (Simon et al., 2013). E: Averaged maximum, mean and minimum reconstructed temperatures from this study (data in Tables 5.4 (LSA sites: diamonds; modern: triangle), 5.10 (PP5-6: circles) and 5.11 (KRM: squares)). For both D and E, the green line represents the annual average SST reconstruction, while the red and blue lines reflect the summer and winter SST reconstructions, respectively. 
Table 5.14: Comparison of seasonality estimates for key periods during the Holocene and Pleistocene that are covered in the present study. Reconstruction of the Agulhas Current annual and seasonal SSTs $\left(\right.$ in ${ }^{0} \mathrm{C}$ ) from a marine sediment core record (Simon et al., 2013) and the difference between June and December insolation at $30^{\circ} \mathrm{S}$ (calculated from Berger and Loutre (1991)).

\begin{tabular}{l|cccc|c|c}
\hline $\begin{array}{l}\text { Age } \\
(\mathrm{ka})\end{array}$ & Mean & $\begin{array}{c}\text { Simon et al., 2013 } \\
\text { Summer } \begin{array}{c}\text { Winter } \\
\left(\text { temp } \mathrm{C}^{\circ}\right)\end{array}\end{array}$ & Range & $\begin{array}{c}\text { Berger and Loutre, 1991 } \\
\text { Jun-Dec insolation } \\
\left(\mathrm{W} / \mathrm{m}^{2}\right)\end{array}$ & $\begin{array}{c}\text { This study } \\
\text { Range } \\
\text { temp C }^{\circ}\end{array}$ \\
\hline Modern & & & & & 297 & 6.7 \\
$2-4$ & 23.9 & 26.3 & 21.6 & 4.8 & 300 & 4.8 \\
$5-9$ & 23.7 & 26.2 & 21.3 & 4.9 & 283 & 4.2 \\
$9-12$ & 23.4 & 25.7 & 21.3 & 4.4 & 264 & 5.4 \\
$12-14$ & 23.1 & 25.3 & 21.1 & 4.1 & 261 & 6.8 \\
$66-72$ & 20.4 & 22.8 & 18.2 & 4.6 & 275 & 6.4 \\
$69-75$ & 20.8 & 23.1 & 18.7 & 4.4 & 281 & $5.4 / 3.4$ \\
$77-85$ & 22.6 & 24.6 & 20.1 & 4.5 & 241 & $4.6 / 5.9$ \\
$90-95$ & 22.9 & 25.0 & 19.4 & 5.6 & 331 & 4.9 \\
$110-115$ & & & & 278 & 4.9 \\
\hline \hline
\end{tabular}


models shown here provide diverging seasonal responses, namely equal decreases in both summer and winter (MPI-ESM-3), a greater decrease in winter (CCSM4) and a greater decrease in summer (MIROC-ESM). Under the glacial conditions during both the Late Pleistocene (from NBC) and at c. 69 ka (level OBS1 from PP5-6) the shells record approximately equal declines in temperature between winter and summer, consistent with the MPI-ESM-3 simulation. Ideally, the quantitative seasonal SST estimates from the shell results can be used to inform and evaluate the ongoing PMIP evaluations.

\subsection{Conclusions}

A total of 74 archaeological shells were sampled from five sites, with a total of 1191 individual $\delta^{18} \mathrm{O}$ analyses, spanning from the late Holocene through to the last interglacial. The temperature trends reflected in the shell $\delta^{18} \mathrm{O}$ values generally accord well with global temperature trends, indicating that a major influence on near-shore temperatures in this region is the global temperature dynamics. The reliability of Turbo as recorders of SST seasonality is confirmed by comparison with other measures of SST, although the results do not generally match well with simulated seasonal SSTs produced by Earth System Models. The Holocene dataset is consistent with a model that relates near-shore SST seasonality and terrestrial precipitation (Cohen and Tyson, 1995), as a period of apparent increased upwelling during the mid Holocene, indicated by a reduced SST range, coincides with increased moisture availability in the summer rainfall zone. Conversely, the terminal Pleistocene results from NBC indicate reduced upwelling at this time, with drier conditions in the interior summer rainfall region. If the same relationships between the annual SST range and upwelling can be extended to the Late Pleistocene assemblage, this indicates drying during level OBS1 at $69 \pm 3$ ka when the annual SST range is comparable to that seen during the terminal Pleistocene, and wetter conditions in levels LBSR and ALBS, c. 82ka and $72 \mathrm{ka}$, when the annual SST ranges are similar to that observed during the mid Holocene. 
Winter

\section{Summer}

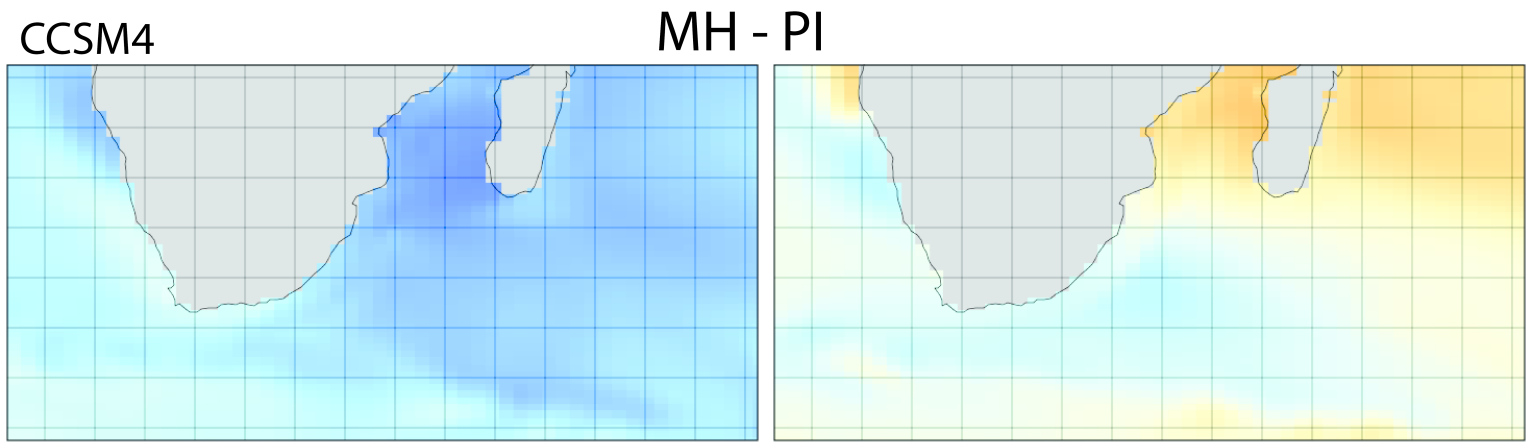

\section{MPI-ESM-3}
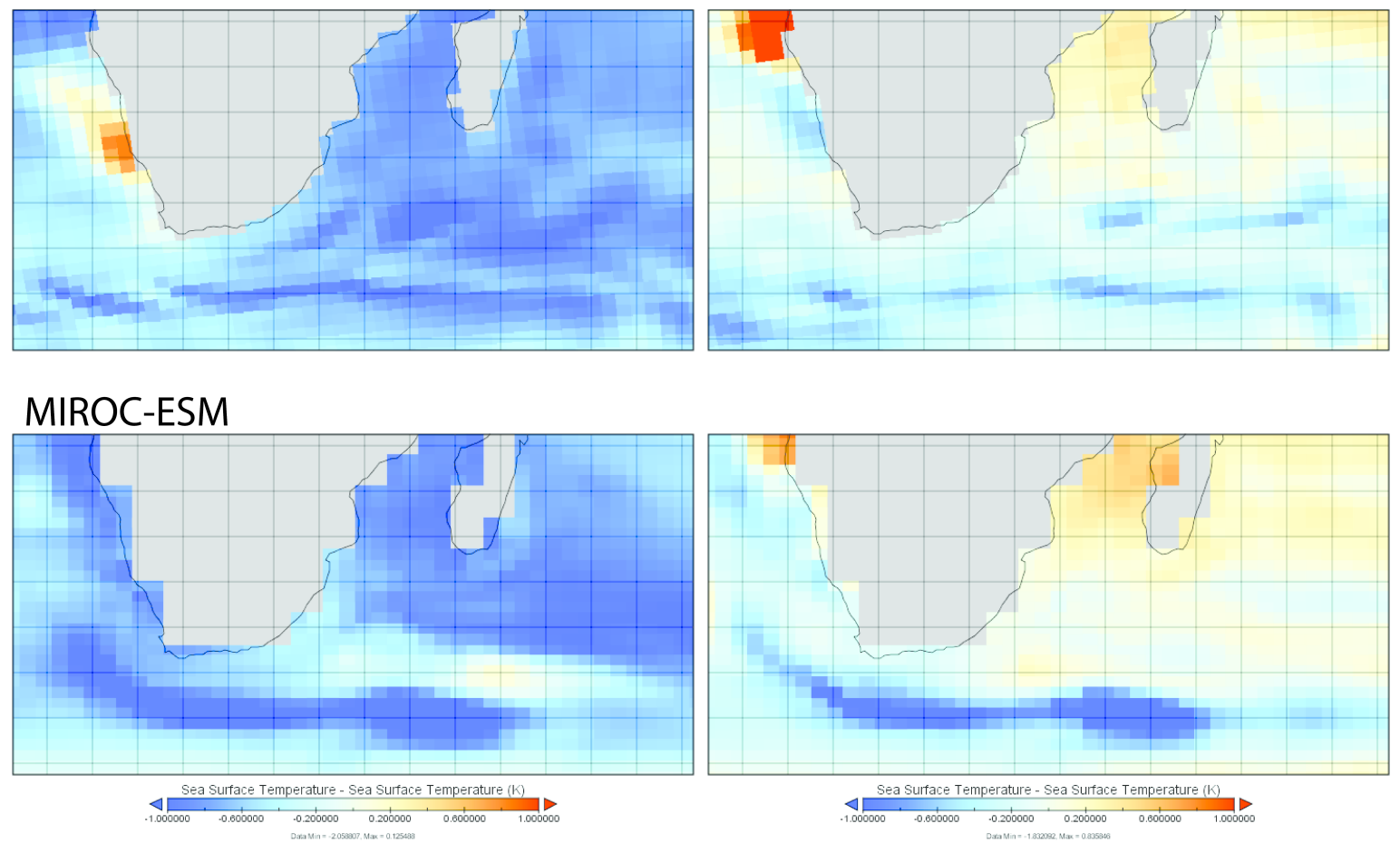

Figure 5.5.2: Anomaly plots of sea surface temperatures for mid Holocene conditions simulated by three Earth Systems Models, CCSM4, MPI-ESM-3 and MIROCESM. Data downloaded from the Earth System Grid Federation (available via https://esgf-index1.ceda.ac.uk) and plots produced in Panoply data viewer (available at www.giss.nasa.gov/tools/panoply/). 


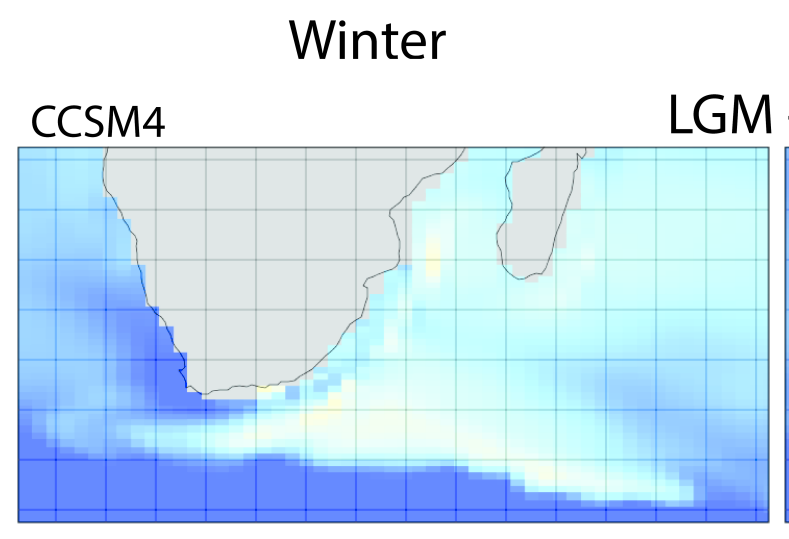

\section{Summer}

\section{MPI-ESM-3}
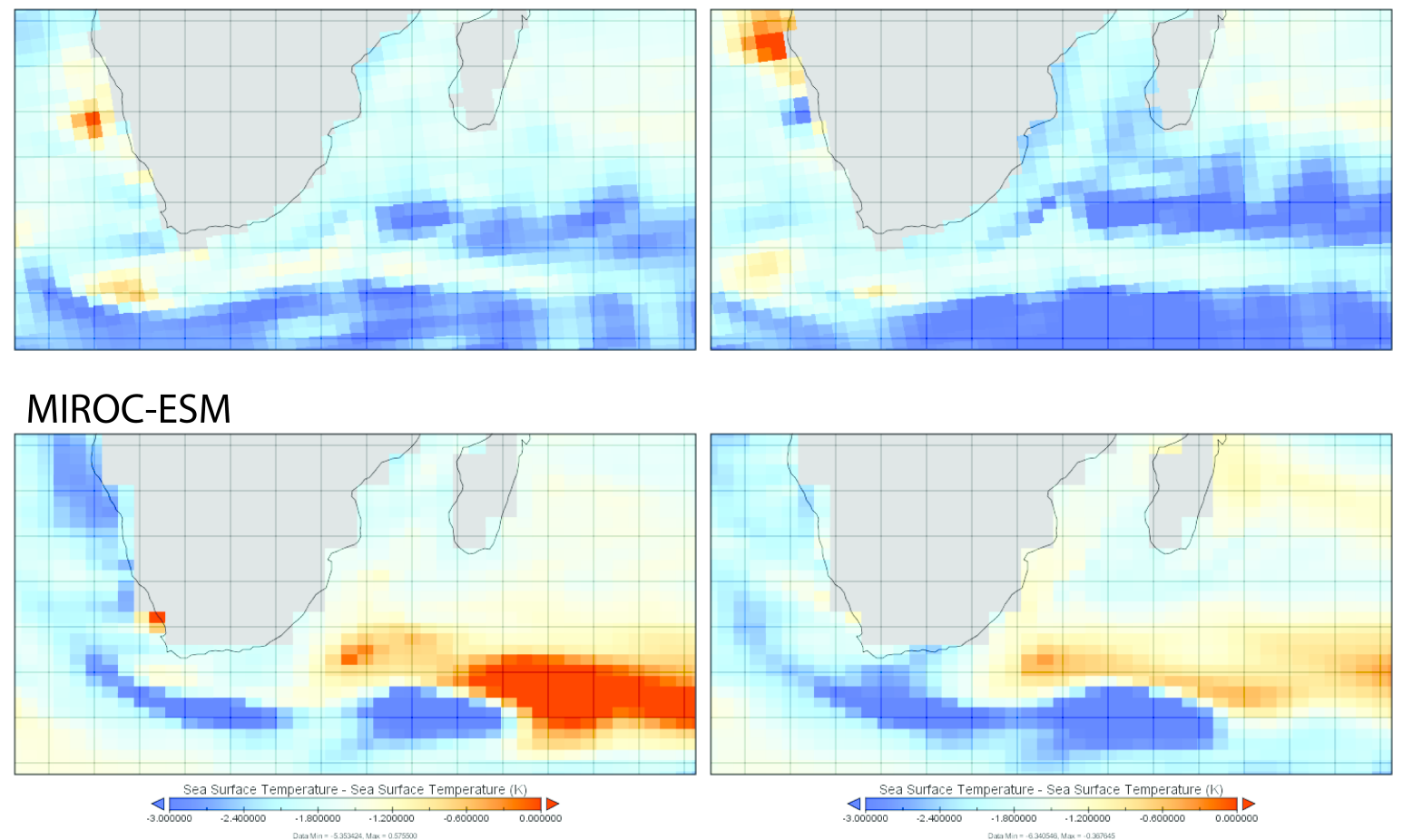

Figure 5.5.3: Anomaly plots of sea surface temperatures for Last Glacial Maximum conditions simulated by three Earth Systems Models, CCSM4, MPI-ESM-3 and MIROC-ESM. Data downloaded from the Earth System Grid Federation (available via https://esgf-index1.ceda.ac.uk) and plots produced in Panoply data viewer (available at www.giss.nasa.gov/tools/panoply/). 


\section{Chapter 6}

\section{Harvesting strategies through the MSA and LSA}

\section{Contents}

6.1 Shellfish and seasonality ................... 151

6.2 Season of harvest results . . . . . . . . . . . 152

6.2.1 Method for evaluating season of collection . . . . . . . . 152

6.2 .2 Results . . . . . . . . . . . . . . . 153

6.3 Turbo growth rates during the MSA and LSA . . . . 158

6.4 Discussion .......................... 163

It may be proposed that, wherever man came from, the discovery of the tidal sea was a major event. The seashores must have had the strongest attraction for primitive and artless folk. Here was abundant and diverse food, waiting to be picked up or dug twice daily, and less subject to seasonal fluctuation than were land supplies. . . Primitive man could hardly find a better prospect than beachcombing, which was also conducive to social grouping and reduced mobility. [Sauer, 1961: 262-264]. 
In the winter when the digging of roots is impossible and the stormy sea prevents hunting and supplies are wanting, they are threatened by famine. Then they go with their wives and children to the shore, gather seaweed and every kind of shells, and are glad when they find a stranded whale or some other sea-mammal. And under such poor conditions their lives are passed. [Jochelson, 1933: 11, on the Aleuts of the Aleutian Islands].

This chapter assesses the evidence for season of harvest and harvesting intensity, and by extension the season of site occupation, recorded in the shell isotope data (presented in Chapter 5 above). The chapter begins with a discussion of current archaeological debates on the role of coastal habitats and shellfish during the MSA and LSA, and outlines how this study can contribute to such debates. Next, the stable isotope evidence for season of harvest is presented in section 6.2, and then evidence for growth rates between the MSA and LSA in section 6.3. The chapter concludes with a brief discussion of previous assessments of the acquisition of shellfish and other coastal resources throughout this period.

\subsection{Shellfish and seasonality}

An examination of the apparent differences in marine resource usage between the MSA and LSA is key to understanding the role of marine habitats throughout this period (see section 2.2.1.2: Jerardino, 2016; Kyriacou et al., 2015). Whereas LSA coastal sites contain dense accumulations of shell that represent relatively short occupations, mollusc remains are typically found only in low densities in MSA sites, especially considering the long periods represented (Jerardino, 2015). Yet, the problems of diagenesis and preservation that affect shell-rich deposits (Karkanas et al., 2015) and the marked changes in shoreline that have doubtless erased most of the earlier deposits (Fisher et al., 2010), mean that it is difficult to directly compare resource usage between the two periods.

The seasonality of resource acquisition and site occupation is a key dimension of subsistence behaviour and social organisation among hunter-gatherers (Kelly, 1995). Within southern African archaeology, the seasonal mobility hypothesis has been an influential framework for describing how hunter-gatherers might have best exploited seasonally fluctuating resources found in different ecozones between the coastal and 
inland environments (Parkington, 1972, 1976; Sealy, 2006). Seasonal versus year-round occupation of coastal locations implies different systems of social organisation, from highly mobile bands at one end of the spectrum to permanently settled groups with defended territories at the other (Sealy, 2006). Further, the seasonal dimension of resource acquisition impacts understanding of MSA versus LSA behaviours in southern Africa, the intensification of subsistence strategies throughout this period, and the development of behaviours characteristic of modern humans (Jerardino and Marean, 2010; Marean, 2014; Will et al., 2015; Kyriacou et al., 2015; Jerardino, 2016; De Vynck et al., 2016). However, interpreting the season of site occupation from the fragmentary refuse found in archaeological sites is not straightforward, and multiple lines of evidence are necessary to confidently establish how systematically (or opportunistically) people exploited their environment. Here, I compare the seasonal patterns of harvest of Turbo sarmaticus between MSA and LSA assemblages directly, by evaluating the full temperature record captured in their shells against the temperature in the final growth increment, representing the season in which the animal died.

\subsection{Season of harvest results}

\subsubsection{Method for evaluating season of collection}

At least three shells per period were sampled over a full annual cycle or more, and the total set of $\delta^{18} \mathrm{O}$ values is used to define the temperature range for that period, in order to limit the effects of variability between shells from the same levels due to microhabitat sampling or time averaging of the deposits. To increase the number of seasonal determinations for this study, additional shells from each level were sampled in the final period of growth only (i.e. 5-6 micromilled powder samples) - thus, at least 5 shells (i.e. seasonal determinations) are available from each period (bar DBCS from PP5-6, where only one suitable shell was available). These data are presented in Chapter 5, for palaeoclimatic interpretation, and the raw $\delta^{18} \mathrm{O}$ values are provided in Appendix A. To evaluate the season of collection (shown in Figure 6.2.1), the $\delta^{18} \mathrm{O}$ value of the final growth increment was compared both to i.) the full series of $\delta^{18} \mathrm{O}$ values spanning at least one annual cycle from the same individual shell, where this was measured, and ii.) the total set of $\delta^{18} \mathrm{O}$ values for all shells per time aggregate or depositional level. Sample numbers per period therefore differ, as some shells have only a few micromilled samples, insufficient to define an annual temperature range: these 


\section{$\delta^{18} \mathrm{O} \quad$ Interpretation}

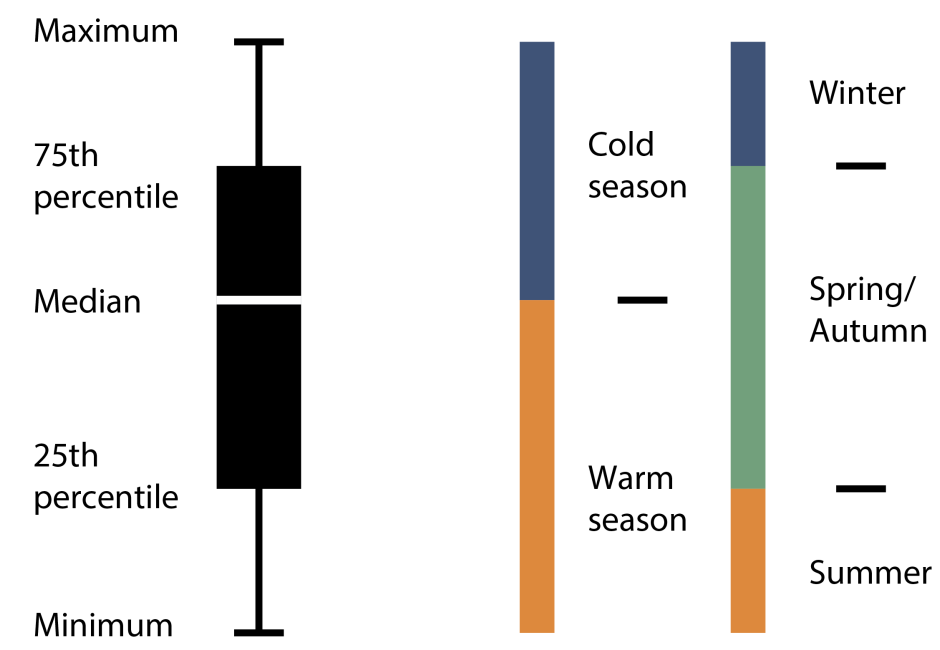

Figure 6.2.1: Schematic showing the method for evaluating the season of harvest: the $\delta^{18} \mathrm{O}$ value of the final increment is compared to the entire set of serially sampled $\delta^{18} \mathrm{O}$ values for each shell or per period, which defines the annual range of temperatures.

shells were only evaluated against the total set of $\delta^{18} \mathrm{O}$ values per period. The seasons are defined in two ways: the measured $\delta^{18} \mathrm{O}$ values, for either the entire period, or the individual shell, are divided into a.) the lowest $50 \%$ (i.e. warmer temperatures) and the highest $50 \%$ (i.e. cooler temperatures) of values, providing a conservative estimate of seasonality and b.) into interquartile ranges representing the seasonal quarters of the year, providing a less confident measure of seasonality for this species (Galimberti, 2010). For the latter method, developed by Mannino et al. (2008), the transitional seasons, spring and autumn, are distinguished by the trajectory of the final few measurements (i.e. warming (spring) vs cooling (autumn)).

\subsubsection{Results}

The seasonal determinations for each shell are provided in Tables 6.2 on page 155, 6.3 on page 156 and 6.4 on page 157, for the Holocene sites, PP-5-6 and KRM, respectively. Table 6.1 on the next page provides the interquartile $\delta^{18} \mathrm{O}$ ranges used to define the seasonal ranges for each period. Note that overall interpretations are largely unaffected whether final values are compared to i.) only those values from the shell itself, or ii.) the total set of $\delta^{18} \mathrm{O}$ from the time aggregate/depositional unit, and thus to increase the number of determinations per period, the latter method is used here. Figure 6.2.2 
Table 6.1: Interquartile ranges for $\delta^{18} \mathrm{O}$ values aggregated according to period, used to evaluate the season of harvest. Robb. is Robberg Peninsula.

\begin{tabular}{lccccccccccccccc}
\hline & LH & LH & MH & MH & EH & LP & \multicolumn{3}{c}{ DBCS OBS1 SADBS ALBS LBSR MSAII MSAII MSAI } \\
\multicolumn{1}{c}{ BNK1 Robb BNK1 Robb Robb Robb } \\
\hline Min & 0.96 & 0.47 & 1.11 & 0.58 & 1.02 & 1.26 & 1.12 & 1.00 & 0.89 & 1.31 & 0.70 & 0.64 & 0.98 & 0.70 \\
1st quar. & 1.35 & 1.11 & 1.66 & 1.23 & 1.68 & 2.01 & 1.59 & 1.76 & 1.48 & 1.60 & 1.14 & 1.67 & 1.68 & 1.51 \\
Median & 1.62 & 1.39 & 1.83 & 1.55 & 1.97 & 2.41 & 1.76 & 2.07 & 1.67 & 1.87 & 1.39 & 2.03 & 2.04 & 1.87 \\
2nd quar. & 1.74 & 1.69 & 2.04 & 1.75 & 2.25 & 2.58 & 2.25 & 2.38 & 2.02 & 2.16 & 1.59 & 2.26 & 2.38 & 2.16 \\
Maximum & 2.00 & 2.38 & 2.78 & 2.34 & 2.81 & 3.80 & 2.99 & 2.97 & 2.74 & 2.86 & 2.37 & 3.39 & 2.82 & 2.69 \\
\hline \hline
\end{tabular}

illustrates the seasonal counts for the 72 shells by period.

Given the goal of this study to evaluate differences between MSA and LSA collection strategies, the periods have been aggregated into broader temporal periods that correspond with the cultural periods of interest. Figure 6.2.3A shows the LSA material, divided according to Oakhurst, Wilton and post-Wilton deposits. All three periods are dominated by a cool season signal, with little evidence for harvesting during summer, and all three periods present similar patterns, except possibly the most recent post-Wilton period, in which only autumn and winter are represented. However, the sample size for this period is too small to state this with much confidence.

A possible confounding factor for evaluating differences across the entire period is site location (see site locations in Figure 2.2.1 on page 32): to examine possible differences in harvesting behaviour between the Robberg sites, NBC and HRC and BNK1, further to the west (for late and mid Holocene only), Figure 6.2.3B shows the shells from these two sites separated out for the late and mid Holocene. Although the sample sizes are small, the winter season is apparently better represented at BNK1, while harvesting occurred more in the transitional seasons during both the late and mid Holocene at NBC.

Figure 6.2.4 on page 161 shows the seasonal counts of the LSA versus the MSA material as percentages, with the MSA separated according to the older, MIS5 deposits, including all the KRM shells and those from level LBSR at PP-6, and the MIS4 deposits from PP5-6, from levels ALBS to DBCS. This figure illustrates a clear difference between the season of collection of the two MSA assemblages, which are not dominated by any one season (MIS5: $\chi^{2}(2), \mathrm{n}=25, \mathrm{p}=0.8$; MIS4: $\chi^{2}(2), \mathrm{n}=19, \mathrm{p}=0.8$ ) versus the LSA assemblage, which is significantly dominated by a cool season signal $\left(\chi^{2}(2), n=27\right.$, $\mathrm{p}<0.001)$. 
Table 6.2: Warm vs cool season and interquartile seasonal determinations for the Holocene shells from BNK1 and NBC, both evaluated using against the $\delta^{18} \mathrm{O}$ values from each shell and using averaged $\delta^{18} \mathrm{O}$ values for the period. Note that the $\mathrm{NBC}$ set incorporates two shells from Hoffman's/Robberg Cave, an adjacent cave on the Robberg Peninsula (Kyriacou, 2009). Where the final determinations are evaluated against the $\delta^{18} \mathrm{O}$ averages per level, the shells from BNK1 and NBC are calculated using distinct datasets.

\begin{tabular}{|c|c|c|c|c|c|c|c|}
\hline Site & Period & $\begin{array}{l}\text { Sample } \\
\text { ID }\end{array}$ & $\begin{array}{l}\text { Final } \\
\text { value }\end{array}$ & $\begin{array}{l}50: 50 \\
\text { (shell) }\end{array}$ & $\begin{array}{c}50: 50 \\
\text { (period) }\end{array}$ & $\begin{array}{c}\text { Season } \\
\text { (shell) }\end{array}$ & $\begin{array}{c}\text { Season } \\
\text { (period) }\end{array}$ \\
\hline \multirow[t]{7}{*}{ BNK1 } & \multirow[t]{3}{*}{ LH } & BEI34 & 1.97 & cool & cool & winter & winter \\
\hline & & BDud426 & 1.91 & cool & cool & winter & winter \\
\hline & & BDud427 & 1.79 & cool & cool & winter & winter \\
\hline & \multirow[t]{4}{*}{$\mathrm{MH}$} & BI529 & 2.01 & cool & cool & winter & winter \\
\hline & & BH634 & 1.76 & cool & warm & winter & spring \\
\hline & & BMort930 & 1.90 & cool & cool & winter & autumn \\
\hline & & BMort935 & 2.05 & warm & cool & spring & winter \\
\hline \multirow[t]{20}{*}{$\mathrm{NBC}$} & \multirow[t]{4}{*}{$\mathrm{LH}$} & NIEIIIA510 & 1.60 & cool & cool & autumn & autumn \\
\hline & & NIEIIIA57 & 1.61 & cool & cool & winter & autumn \\
\hline & & HRCD6a-P-1 & 1.81 & cool & cool & winter & winter \\
\hline & & HRCD6cRR1 & 1.05 & warm & warm & summer & autumn \\
\hline & \multirow[t]{5}{*}{$\mathrm{MH}$} & NIA512 & 1.07 & cool & cool & autumn & summer \\
\hline & & NIA515 & 1.64 & cool & cool & autumn & autumn \\
\hline & & NGB46 & 1.74 & cool & cool & winter & autumn \\
\hline & & NRAB420 & 1.74 & warm & warm & autumn & autumn \\
\hline & & NRAB421 & 1.85 & cool & cool & autumn & winter \\
\hline & \multirow[t]{8}{*}{$\mathrm{EH}$} & NRBB317 & 2.05 & cool & cool & spring & spring \\
\hline & & NRBB318 & 1.51 & warm & warm & summer & summer \\
\hline & & NJBA49 & 2.02 & cool & cool & spring & spring \\
\hline & & NJBA413 & 2.59 & cool & cool & winter & winter \\
\hline & & NJB47 & 2.43 & cool & cool & winter & winter \\
\hline & & NJB49 & 2.41 & cool & cool & winter & winter \\
\hline & & NBSBJB42 & 2.36 & cool & cool & winter & winter \\
\hline & & NBSBJB43 & 2.81 & cool & cool & winter & winter \\
\hline & \multirow[t]{3}{*}{ LP } & NGBB8B17 & 2.43 & cool & cool & winter & autumn \\
\hline & & NGBB8B18 & 2.58 & cool & cool & spring & spring \\
\hline & & NGBB8B15 & 3.32 & cool & cool & winter & winter \\
\hline
\end{tabular}


Table 6.3: Warm vs cool and interquartile seasonal determinations for the shells from Pinnacle Point 5-6, calculated using the $\delta^{18} \mathrm{O}$ values from each shell (when sufficient to define an annual temperature range) and using averaged $\delta^{18} \mathrm{O}$ values for the period.

\begin{tabular}{|c|c|c|c|c|c|c|}
\hline Period & $\begin{array}{l}\text { Sample } \\
\text { ID }\end{array}$ & $\begin{array}{l}\text { Final } \\
\text { value }\end{array}$ & $\begin{array}{c}50: 50 \\
\text { (shell) }\end{array}$ & $\begin{array}{c}50: 50 \\
\text { (period) }\end{array}$ & $\begin{array}{c}\text { Season } \\
\text { (shell) }\end{array}$ & $\begin{array}{l}\text { Season } \\
\text { (period) }\end{array}$ \\
\hline DBCS & 139304 & 1.58 & warm & warm & summer & summer \\
\hline \multirow{5}{*}{ OBS1 } & 140215 & 2.81 & cool & cool & winter & winter \\
\hline & 244680 & 2.58 & cool & cool & winter & winter \\
\hline & 213021 & 1.80 & warm & warm & summer & spring \\
\hline & 210193 & 2.04 & NA & warm & NA & autumn \\
\hline & 207603 & 1.49 & NA & warm & NA & summer \\
\hline \multirow{8}{*}{ SADBS } & 139637 & 1.87 & cool & cool & spring & spring \\
\hline & 182249 & 1.86 & cool & cool & autumn & autumn \\
\hline & 131492 & 2.25 & cool & cool & autumn & winter \\
\hline & 131957 & 2.63 & cool & cool & winter & winter \\
\hline & 180529 & 1.64 & warm & warm & spring & spring \\
\hline & 180257 & 1.56 & warm & warm & autumn & autumn \\
\hline & 150901 & 1.79 & cool & warm & winter & autumn \\
\hline & 222164 & 1.73 & NA & cool & NA & autumn \\
\hline \multirow[t]{5}{*}{ ALBS } & 137285 & 2.04 & warm & cool & spring & spring \\
\hline & 215673 & 2.00 & cool & cool & autumn & autumn \\
\hline & 147194 & 1.71 & warm & warm & spring & spring \\
\hline & 141193 & 1.89 & NA & warm & NA & autumn \\
\hline & 136509 & 1.68 & NA & warm & NA & autumn \\
\hline \multirow[t]{5}{*}{ LBSR } & 130590 & 1.52 & cool & $\mathrm{cool}$ & autumn & autumn \\
\hline & 237233 & 0.91 & warm & warm & summer & summel \\
\hline & 243135 & 1.60 & cool & cool & autumn & winter \\
\hline & 228941 & 1.49 & $\mathrm{NA}$ & cool & $\mathrm{NA}$ & autumn \\
\hline & 248248 & 1.36 & NA & warm & NA & autumn \\
\hline
\end{tabular}


Table 6.4: Warm vs cool and interquartile seasonal determinations for the shells from Klasies River Main site, calculated using against the $\delta^{18} \mathrm{O}$ values from each shell (when sufficient to define an annual temperature range) and using averaged $\delta^{18} \mathrm{O}$ values for the period.

\begin{tabular}{|c|c|c|c|c|c|c|}
\hline Period & $\begin{array}{l}\text { Sample } \\
\text { ID }\end{array}$ & $\begin{array}{l}\text { Final } \\
\text { value }\end{array}$ & $\begin{array}{l}50: 50 \\
\text { (shell) }\end{array}$ & $\begin{array}{c}50: 50 \\
\text { (period) }\end{array}$ & $\begin{array}{l}\text { Season } \\
\text { (shell) }\end{array}$ & $\begin{array}{c}\text { Season } \\
\text { (period) }\end{array}$ \\
\hline \multirow[t]{7}{*}{ MSAII upper } & O50 BS3A & 2.08 & cool & cool & autumn & autumn \\
\hline & O50 SL5CP(i) & 1.56 & warm & warm & summer & summer \\
\hline & O50 SL4M(i) & 2.15 & NA & cool & NA & spring \\
\hline & O50 SL3i & - & cool & cool & spring & spring \\
\hline & O50 SL4M(ii) & 1.85 & warm & warm & autumn & autumn \\
\hline & O50 SL5CP (ii) & 2.27 & NA & cool & NA & winter \\
\hline & O50 BS3T & 2.24 & cool & cool & spring & spring \\
\hline \multirow[t]{8}{*}{ MSAII lower } & Z44 YS1B(ii) & 2.54 & cool & cool & spring & winter \\
\hline & Z45 BS2(i) & 1.98 & cool & warm & winter & spring \\
\hline & Z44 YS1B(i) & 1.08 & $\mathrm{NA}$ & warm & NA & summer \\
\hline & Z44 SM2 & 2.19 & warm & cool & autumn & autumn \\
\hline & Z44 SCB2AAF2 & 1.76 & warm & warm & spring & spring \\
\hline & Z45 BS2(ii) & 2.04 & cool & cool & autumn & autumn \\
\hline & Z44 BS2(i) & 1.26 & NA & warm & NA & summer \\
\hline & Z44 SM2(ii) & 2.26 & NA & cool & NA & autumn \\
\hline \multirow[t]{6}{*}{ MSA I } & Z44 SAS2S & 1.47 & warm & warm & summer & summer \\
\hline & Z44 SAS4SHC(i) & 1.46 & NA & warm & NA & summer \\
\hline & Z44 SAS4SHC(ii) & 1.74 & NA & warm & NA & autumn \\
\hline & Z44 SAS4SHC(iii) & 1.11 & NA & warm & NA & summer \\
\hline & Z44 SAS2SHAF2 & 1.82 & $\mathrm{cool}$ & warm & spring & spring \\
\hline & Z44 SAS4S & 2.32 & NA & cool & $\mathrm{NA}$ & winter \\
\hline
\end{tabular}



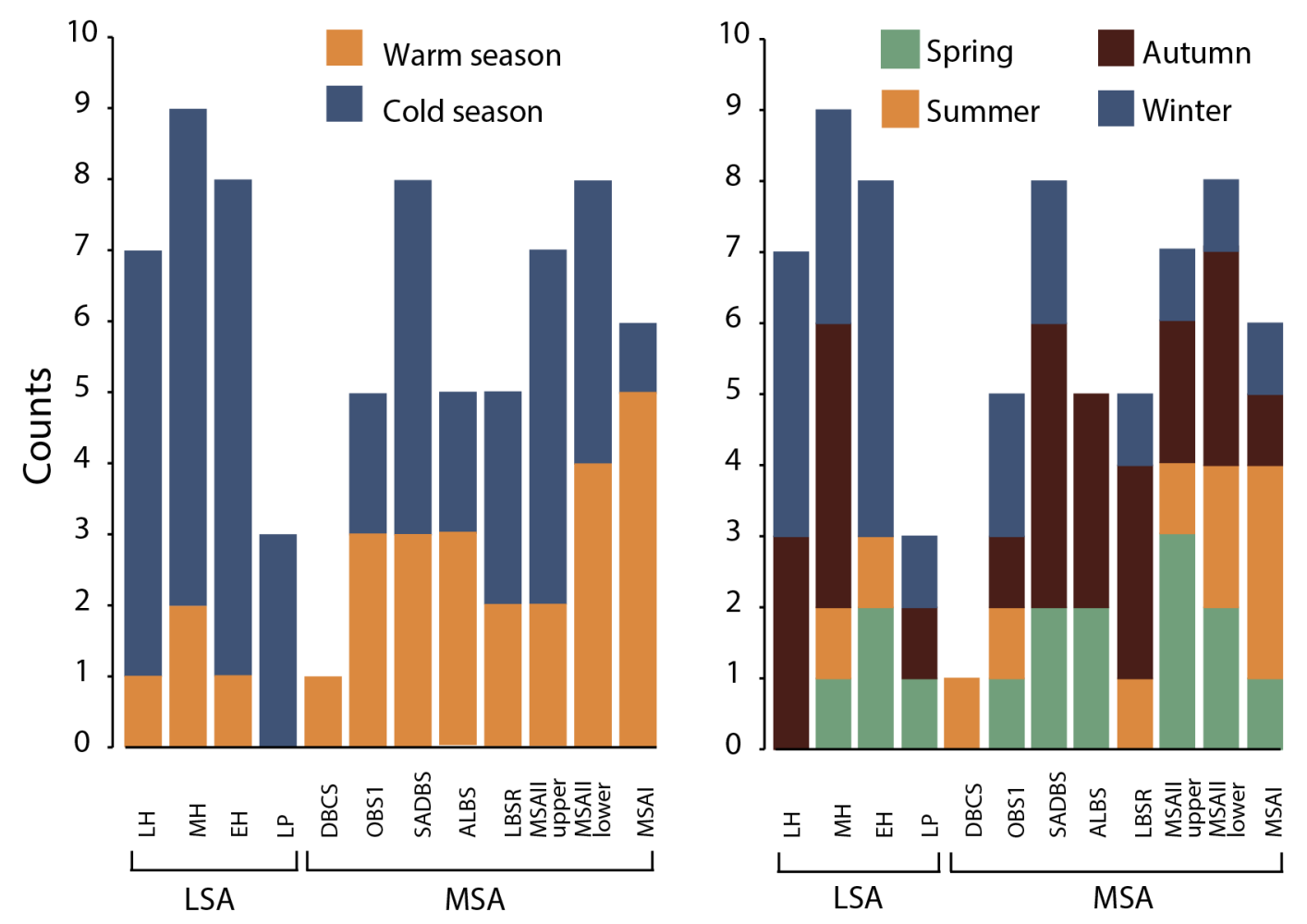

Figure 6.2.2: Warm vs cold and seasonal counts for each period considered in this study, see Tables 5.2, 5.6 and 5.7 for dates of each period.

Galimberti (2010) evaluated 13 shells from the MIS5 aged deposits of two sites, PP9B (114 $\pm 5 \mathrm{ka})$ and PP13B (LRS: 114-106ka, and URS and SBS: 98-92ka), within the Pinnacle Point complex of caves. In Figure 6.2.5 on page 162, the seasonal determinations of the shells measured by Galimberti are combined with the MIS5 shells from PP5-6 (i.e. those from level LBSR: $82 \pm 4 \mathrm{ka}$ ), so as to compare the MIS5 aged shells from Pinnacle Point to those of Klasies River Main site, situated in a subtly different ecosystem. The seasonal determinations for the MIS4 aged assemblage from PP5-6 and the Holocene aged assemblage from NBC are provided for comparative purposes. This plot shows how the MIS5 shells from PP were collected in a different season from the MIS5 shells at KRM or the MIS4 shells at PP5-6.

\subsection{Turbo growth rates during the MSA and LSA}

$\delta^{18} \mathrm{O}$ serial sampling results provide an additional means of assessing harvesting differences between the LSA and MSA, via growth rates. On the basis of significant declines in the average size of several mollusc species, including Turbo opercula, between MSA and 
Table 6.5: Growth rates in $\mathrm{mm} /$ cycle of annual seasonal cycles (peak to peak) in individual Turbo opercula as identified from serial $\delta^{18} \mathrm{O}$ analyses, with averages and standard deviations. Guide to sample names: B - Byneskranskop1; N - Nelson Bay Cave; PP - Pinnacle Point; K - Klasies River Main

\begin{tabular}{|c|c|c|c|c|c|c|c|c|}
\hline \multirow{2}{*}{\multicolumn{3}{|c|}{ LSA }} & \multicolumn{6}{|c|}{ MSA } \\
\hline & & & \multicolumn{3}{|c|}{ MIS4 } & \multicolumn{3}{|l|}{ MIS5 } \\
\hline Sample ID & Peak & $\mathrm{mm}$ & Sample ID & Peak & $\mathrm{mm}$ & Sample ID & Peak & $\mathrm{mm}$ \\
\hline BEI_34 & $2-5$ & 1.5 & PP139304 & $5-12$ & 4.1 & PP130590 & $6-11$ & 2.9 \\
\hline NIEIII_A5_10 & $7-15$ & 4.6 & & $12-18$ & 3.9 & & $11-19$ & 4.2 \\
\hline NIEIII_A5_7 & $3-9$ & 3.6 & PP244680 & $4-12$ & 3.4 & PP237233 & $6-15$ & 4.9 \\
\hline \multirow[t]{3}{*}{ BDud4_27 } & $3-6$ & 2.2 & & $12-19$ & 4.3 & KO50SL3i & $7-11$ & 2.7 \\
\hline & $6-10$ & 2.7 & PP213021 & $3-6$ & 1.8 & & $11-17$ & 3.5 \\
\hline & $10-14$ & 2.4 & & $6-12$ & 3.0 & KO50SL4M(ii) & $2-7$ & 2.5 \\
\hline \multirow[t]{2}{*}{ BI5_29 } & $4-9$ & 3.9 & PP210193 & $3-6$ & 2.0 & & $7-13$ & 3.7 \\
\hline & $9-13$ & 3.6 & & $6-9$ & 2.1 & KO50SL5CP(i) & $3-19$ & 7.9 \\
\hline NIA5_15 & $10-28$ & 8.7 & PP139637 & $4-7$ & 1.9 & KO50BS3T & $3-10$ & 3.3 \\
\hline BH6_34 & 6-11 & 3.1 & & $19-25$ & 4.0 & KO50BS3A & $3-18$ & 6.8 \\
\hline \multirow[t]{2}{*}{ BMort9_30 } & $4-9$ & 2.9 & PP182249 & $4-11$ & 4.1 & KZ44SM2 & $3-7$ & 1.9 \\
\hline & $9-14$ & 2.4 & & $11-18$ & 4.2 & & $7-11$ & 2.5 \\
\hline \multirow[t]{2}{*}{ NRB_B3_17 } & $2-10$ & 4.1 & PP131492 & $8-21$ & 7.0 & & $11-19$ & 3.5 \\
\hline & $10-22$ & 6.0 & PP131957 & $3-8$ & 2.3 & KZ45BS2(ii) & $7-13$ & 3.6 \\
\hline NRB_B3_18 & $9-18$ & 5.5 & & $8-15$ & 3.8 & KZ44YS1B(ii) & $2-5$ & 2.0 \\
\hline \multirow{2}{*}{ NJB_A4_9 } & $2-10$ & 4.9 & PP180529 & $3-6$ & 1.9 & & $5-8$ & 1.7 \\
\hline & $10-16$ & 3.4 & & $6-10$ & 2.7 & & $8-14$ & 3.3 \\
\hline NBSBJB4_2 & 6-15 & 5.4 & & $10-14$ & 2.8 & KZ44SCB2AAF2 & $5-14$ & 3.5 \\
\hline NBSBJB4_3 & $6-14$ & 3.4 & PP180257 & $5-17$ & 5.9 & KZ44SAS2S & $6-14$ & 4.0 \\
\hline NGB_B8B_17 & $7-20$ & 9.5 & PP137285 & $3-7$ & 2.3 & KZ44SAS2SHAF2 & $6-12$ & 3.5 \\
\hline \multirow[t]{2}{*}{ NGB_B8B_18 } & $4-13$ & 4.2 & & $7-12$ & 2.9 & & $12-19$ & 3.4 \\
\hline & $13-18$ & 3.3 & & $12-22$ & 4.4 & KZ44SAS4S & $3-8$ & 3.3 \\
\hline \multirow[t]{5}{*}{ NGB_B8B_15 } & $3-15$ & 6.3 & PP215673 & 3-12 & 4.8 & & & \\
\hline & & & & $12-21$ & 4.7 & & & \\
\hline & & & PP147194 & $3-8$ & 3.7 & & & \\
\hline & & & & $8-12$ & 3.0 & & & \\
\hline & $\mu$ & $\sigma$ & & $\mu$ & $\sigma$ & & $\mu$ & $\sigma$ \\
\hline LSA & 4.2 & 1.96 & MSA & 3.5 & 1.35 & MSAMIS5 & 3.6 & 1.45 \\
\hline Holocene & 3.9 & 1.66 & MSAMIS4 & 3.5 & 1.29 & $\mathrm{KRM}$ & 3.5 & 1.52 \\
\hline Late Pleistocene & 5.8 & 2.75 & $\mathrm{PP}$ & 3.6 & 1.26 & & & \\
\hline
\end{tabular}



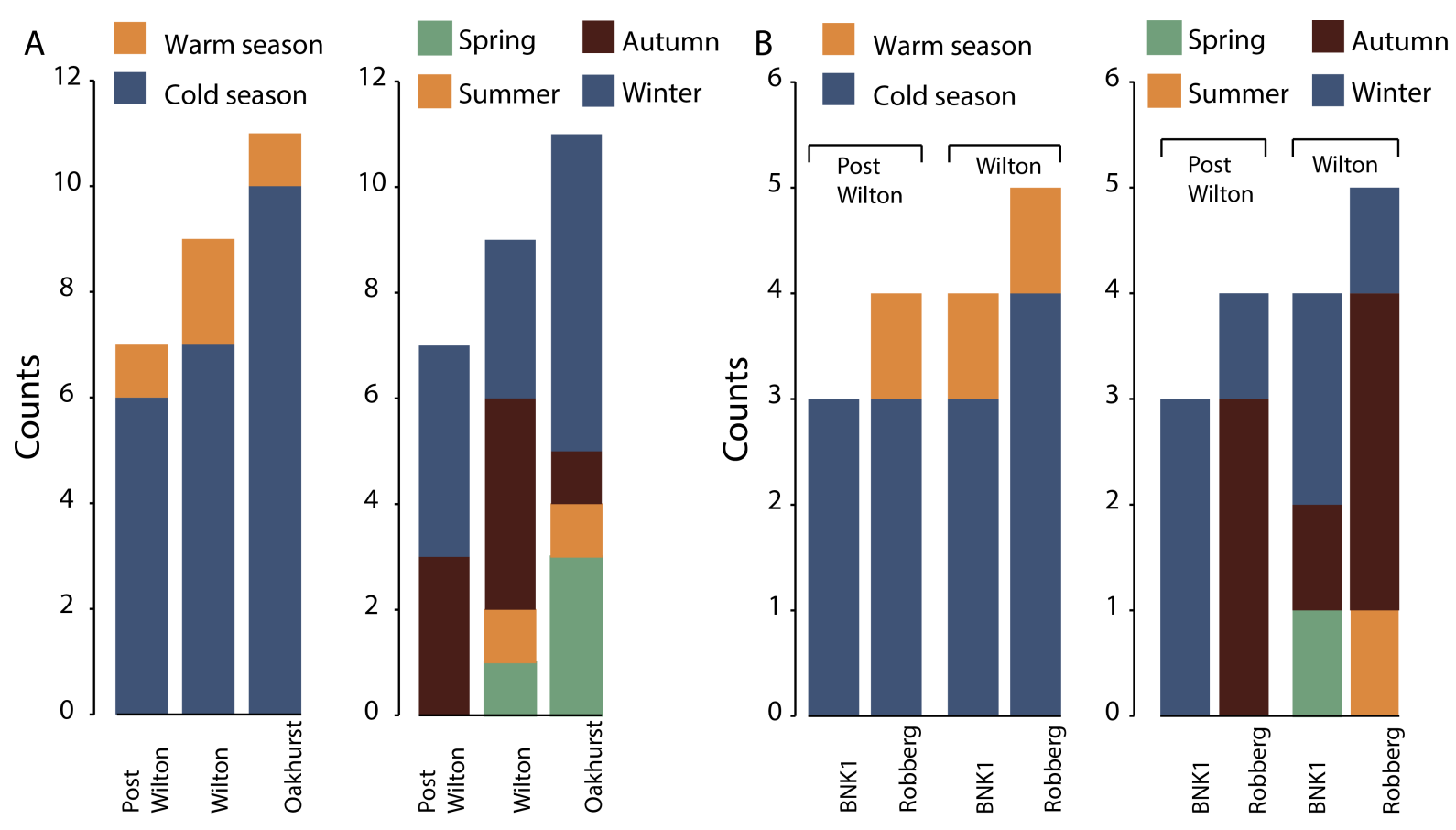

Figure 6.2.3: Warm vs cold and seasonal determinations A. for the entire LSA assemblage, according to cultural period, and B. separated according to site location for the post Wilton and Wilton periods.

LSA sites, Steele and Klein (2008; Klein and Steele, 2013) have argued that harvesting intensified during the LSA and that human populations were larger. Yet, a confounding factor is that all of the LSA assemblages date to within the Holocene, and reductions in size are also observed in other species such as crayfish and non-food molluscs, that should not be subject to the same harvesting pressures (Teske et al., 2007; Jerardino et al., 2008; Sealy and Galimberti, 2011). Thus, environmentally induced explanations for the size changes cannot be ruled out (Sealy and Galimberti, 2011). Klein and Steele (2013) have attempted to control for such differences by comparing LSA shells to MSA shells from the last interglacial, when global temperatures and sea-levels were similar to those during the Holocene. However, intertidal nutrient availability and primary productivity is likely to be affected by a complex, unknown set of factors beyond SST and these factors would certainly affect mollusc growth rates. Moreover, the interpretation that Turbo are smaller overall neglects alternative non-environmental reasons for smaller shells to be deposited in archaeological sites. Hypothetically, changes in transport decisions between the MSA and LSA, or in the gender division of labour, as women and children are less likely to take the higher risks associated with collecting larger Turbo living in the deeper waters, could also account for smaller average sizes in the LSA. Serial $\delta^{18} \mathrm{O}$ sequences can be used to evaluate growth rates directly, by measuring the amount of 


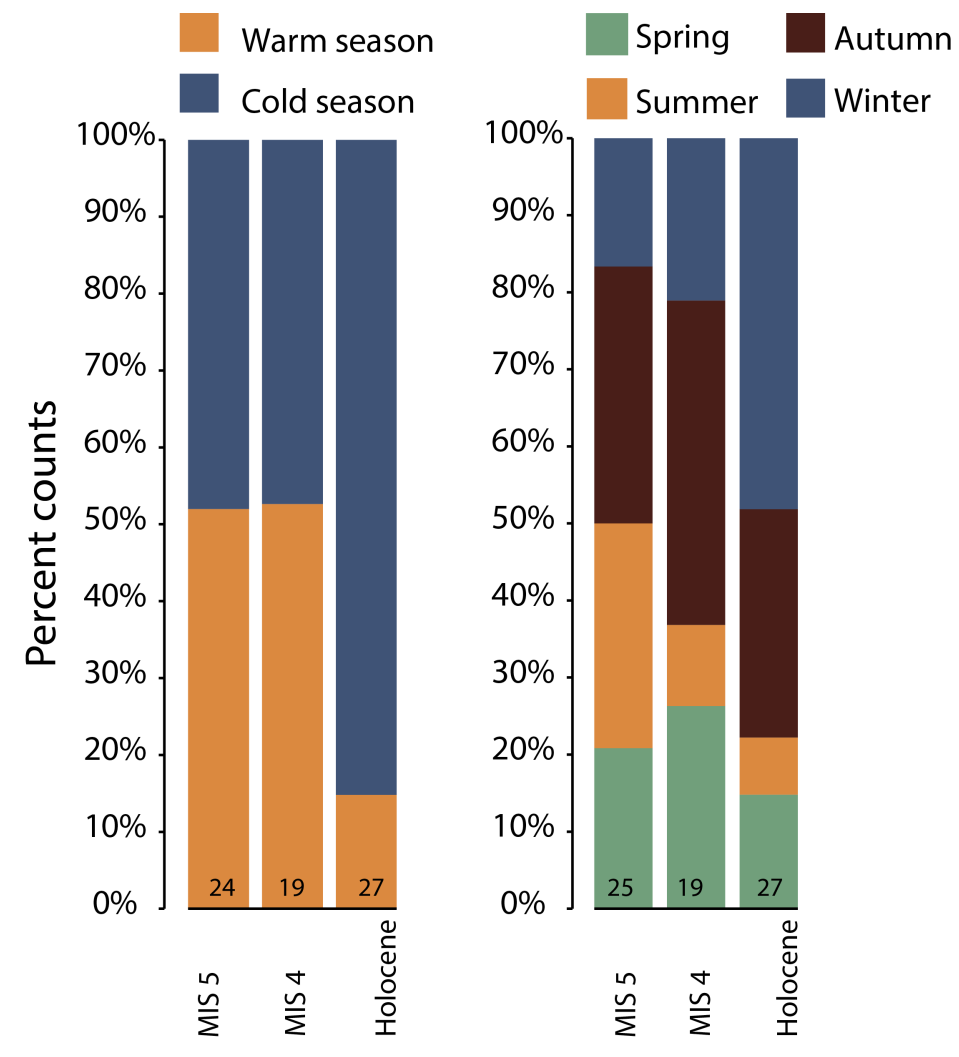

Figure 6.2.4: Percentage of warm vs cold season and interquartile seasonal determinations for the entire set of shells, according to broad age category, MIS5, MIS4 and the Holocene (including the three terminal Pleistocene shells from NBC). Sample sizes are shown at the base of each column. 

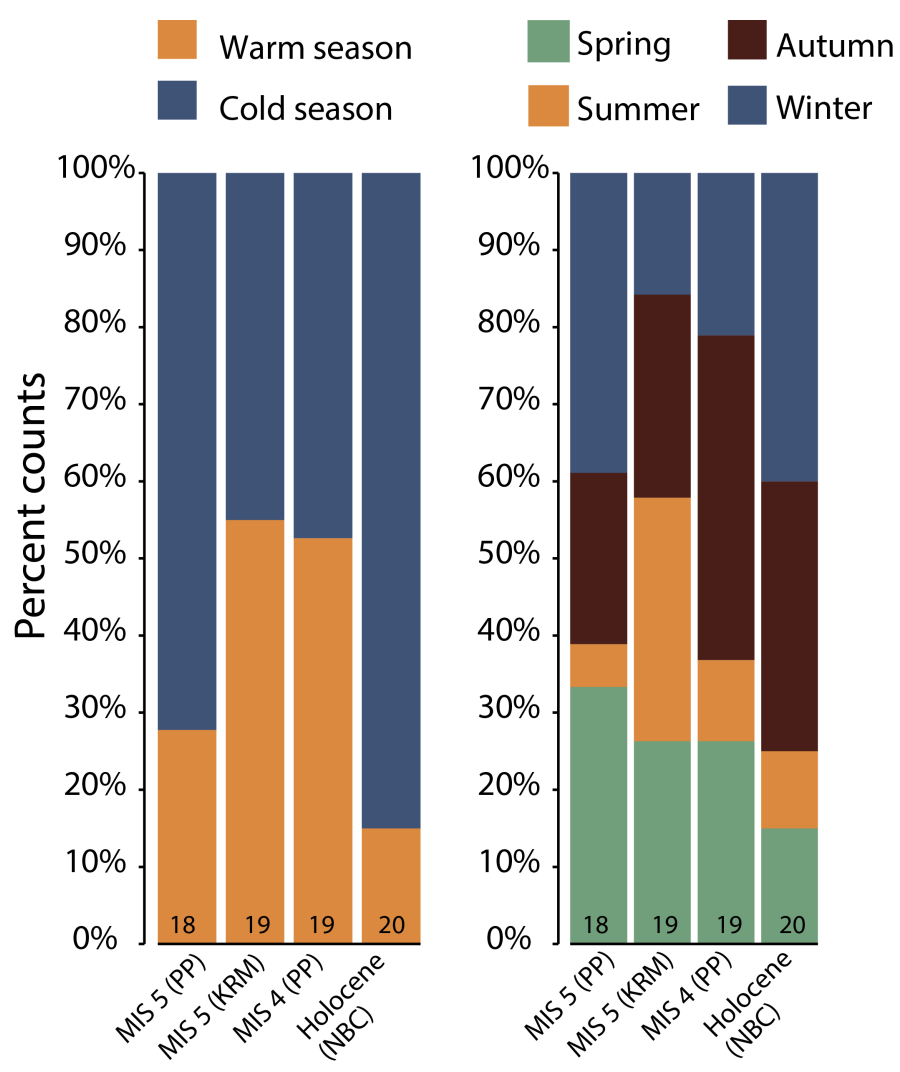

Figure 6.2.5: Percentage of warm versus cold season and interquartile seasonal determinations for MIS5, 4 and Holocene aged shells according to site location. Note that the MIS5 dataset from PP includes 13 shells measured by Galimberti, 2010 to increase the sample size. Sample sizes are shown at the base of each column. 
shell growth that corresponds with seasonal cycles evident in the $\delta^{18} \mathrm{O}$ sequence.

Identifying seasonal cycles in the $\delta^{18} \mathrm{O}$ sequences of Turbo opercula is not always straightforward, however - sometimes clearly sinusoidal curves are evident but frequently the series are more irregular. This is likely due to the resolution of sampling for this relatively slow growing shell. Yet to only measure the clearly sinusoidal series would risk biasing the results against older (and larger) animals with slower growth, where the cycles are below the level of the micromill sampling resolution. The strategy adopted here for identifying annual cycles has been to designate a cycle based on at least two ascending and descending values between peaks, so that single point fluctuations are not taken as representing seasonal peaks. Additionally, measured peaks are not permitted to overlap - i.e. either the summer-summer or the winter-winter annual cycle is measured, not both cycles. Once seasonal peaks were identified, the distance between the two micromilled samples was measured using a digital Vernier calliper, with the distance recorded to the first decimal. This analysis is intended to simply provide a assessment of growth rates between MSA and LSA molluscs, as this was the comparison addressed in the literature (Klein and Steele, 2013). The analysis is confounded by the complex, rotating growth pattern of the Turbo opercula and an assessment of growth rates utilising a different shell may prove easier.

The seasonal peaks measured here are indicated as black dots against the $\delta^{18} \mathrm{O}$ series plots in Appendix 2 (Figures B1, B2 and B3). Table 6.5 contains the measurements for seasonal cycles evident in particular shells, with the average values displayed at the bottom of the table. The averaged growth rate for the LSA shells is slightly higher at 4.2 $\mathrm{mm} /$ cycle than for the MSA shells $(3.5 \mathrm{~mm} /$ cycle), but the difference is not significant (Welsh Two Sample t-test; $t=1.62$, $\mathrm{p}$-value $=0.1143$ ). This suggests that growth rates did not differ between the LSA and MSA.

\subsection{Discussion}

There are few previous evaluations of the season of mollusc collection for the south coast and none which span such a long period as this study. In one of the first studies of its kind anywhere, Shackleton (1973) measured the season of collection for 15 Scutellastra tabularis shells from the mid Holocene Wilton levels of NBC, and concluded that all of the shells were collected in winter. However, although a valuable "proof-of-concept" study, some obvious sampling and validation limitations are evident - for example, the 
season of collection was evaluated against the annual range of temperatures recorded in a modern shell. Later, Cohen (1993) evaluated the potential of P. tabularis for palaeothermometry studies more thoroughly, and similarly concluded that the species does reliably record seasonal SSTs. Cohen also measured mid Holocene Wilton aged shells from NBC but when this dataset is re-evaluated using the Mannino interquartile method the shells record year-round collection. However, the Cohen study did not explicitly intend to evaluate season of collection, as the study was palaeoenvironmental in focus, and this may well affect the reliability of the final increment sampling (which is not explicitly detailed). In addition, it is far preferable to utilise a common food species for season of site occupation studies, and P. tabularis is uncommon at NBC and was not collected only for food.

Subsequently, Henshilwood (1995) evaluated the season of collection of Turbo sarmaticus shells from several Holocene sites located in the Garcia State Forest (also referred to as Blombosfontein), and found all seasons represented. But the sample sizes from each site are low, and Henshilwood evaluated seasonality by comparing the converted shell temperatures to the estimated annual SST ranges using an incorrect equation for calcitic carbonates. Moreover, diagenesis of the aragonite shells was not assessed. The most comprehensive study of Turbo thus far was that by Galimberti (2010), who undertook thorough modern validation and diagenetic assessments for a study of the archaeological shells from Pinnacle Point caves 9B and 13B, largely dating to MIS5. This record shows a dominant cool season signal for the season of collection (see Figure 6.2.5 on page 162).

The present study allows a comparison of shellfish harvesting strategies across a broader temporal and geographical range than has hitherto been possible, and several marked differences are evident between the sites and time periods. Conspicuous is the clear cool season signal in the LSA dataset, evident throughout the Holocene, versus the year round signal in the MSA data. This does point to a more structured use of the landscape and coastal resources during the LSA, consistent perhaps with a model of hunter-gatherer seasonal mobility. However, the pattern observed here does not fit neatly with expectations based upon the seasonal availability of resources. De Vynck et al. (2016) demonstrated that weather and tidal conditions markedly affect collecting yields for molluscs along the south coast, and, consequently, that summer was the optimal season for harvesting. Conversely, nutritious plant resources are available year round but most scarce from mid summer to early autumn (January - April) (De Vynck et al., 2015). These observations recommend a model of seasonal resource use whereby foragers exploit plant resources during the cooler months, turning to more accessible 
shellfish resources during summer. Yet, this is not supported by the seasonality estimates presented here and suggests that modern observational studies of resource availability need to be interpreted through the lens of the archaeological seasonality data. Without other lines of evidence, it is also currently impossible to know where people might have been when not at the coast, or gauge how widely people traversed the landscape.

A possible explanation for the apparent avoidance of shellfish during the warmer months might be the occurrence of toxic algal blooms which poison shellfish, which are more common during summer (Parkington, 1976). Yet, such "red tides" are rare on the south coast of South Africa, unlike on the more productive west coast, and are less dangerous when they do occur (Pitcher and Calder, 2000). Moreover, changes in water colour may well alert foragers to the harmful blooms and it is possible to remove those parts of the mollusc that concentrate the toxic plankton. Thus, red tides are not thought to have posed an insurmountable problem for foragers, such that they would avoid shellfish in summer (Bigalke, 1973; Jerardino, 2016).

The apparent lack of any major change in harvesting strategy between the earlier (Oakhurst) and middle (Wilton) Holocene levels is somewhat surprising, as other aspects of the archaeological record attest to marked changes in subsistence, population size and technology across this period. At NBC, for example, Klein (1972) observed a change in the faunal assemblage between the Oakhurst and Wilton levels, with increasing proportions of smaller browsing antelope throughout this period. Larger grazing and browsing antelope species, such as roan antelope and eland, are migratory, and their movement is dependant on seasonal rainfalls, while smaller browsing species are typically highly territorial, solitary, do not migrate seasonally and so are more easily caught through traps and snares (Deacon, 1984). Thus, the expectation is that hunting was more seasonally dependant during the Oakhurst, with anticipated effects for the reliance on other foods, including shellfish, throughout the year. However, no difference in the timing of shellfish harvesting is observed at NBC across this period. It should be said, however, that the Oakhurst faunal assemblage from NBC was deemed intermediate between the underlying Robberg, clearly dominated by large grazing species, and the Wilton, and equal numbers of the smaller browsers to the larger gregarious animals are indeed present during the Oakhurst (Klein, 1972). Thus, while hunting strategies changed between the two periods, they may not speak to changes in the seasonality of occupation. Unfortunately, no well-preserved shells are available from the Robberg levels to evaluate the season of harvest during these levels.

The LSA record may contain evidence of changes in shellfish harvesting across the 
LSA, although the small sample sizes for each level make this difficult to pinpoint. But the Oakhurst assemblage from NBC contains shells harvested in spring and summer, whereas the post Wilton assemblage, or that post-dating c. 4 kcal BP, contains only shells harvested in autumn and winter. This difference is consistent with evidence for substantial changes in social organisation and subsistence behaviour in the late Holocene, thought to reflect larger and increasingly settled, territorial populations (Hall, 2000; Sealy, 2006), and which arguably would have affected the harvesting of shellfish. Alternatively, Inskeep (1987) presents a model of seasonal landscape occupation after c. 6 kcalBP whereby year-round occupants of the southern Cape, who used Oakhurst type technologies, were joined by seasonal visitors from the interior regions, who used Wilton type technologies and who disrupted the year-round inhabitants shellfishing behaviours, during the "hot, dry summers" of the mid-Holocene climatic optimum. Indeed, the shift in seasonality, whether it occurs between the middle and later or middle and earlier Holocene, does not align with the expectation of more settled populations, which would presumably opportunistically harvest shellfish year-round. However, a confident conclusion regarding the season of shellfish harvesting is not yet possible due to the very small sample size (seven shells) for the late Holocene assemblage.

The marked differences in seasonality of shellfish collection between the MSA and LSA is consistent with interpretations that argue for a profound change in resource use between the two periods (Klein and Steele, 2013; Jerardino, 2016). This is further supported by the apparent lack of environmentally driven changes in the growth rates between the two periods. Yet, one interpretation of these differences, that MSA people were less efficient hunter-gatherers and thus not yet cognitively "modern" (Klein, 2008), is contradicted by numerous lines of evidence that demonstrate that MSA subsistence strategies and behaviours were generally as sophisticated as those observed in the LSA record (McBrearty and Brooks, 2000; Henshilwood et al., 2002; Henshilwood and Marean, 2003; D'Errico et al., 2005; Lombard, 2012; Wadley, 2013). Rather, the results presented here add greater nuance to discussions about the differences between MSA and LSA behaviour. The site-based comparison of the MSA assemblages shows unexpected patterning between the PP and KRM assemblages. While the MIS5 Turbo from KRM were harvested year round, both the MIS5 and MIS4 assemblages from PP show only a small summer signal, more similar to that seen during the LSA. This suggests that rather than indicating something profound about behavioural capacities of populations in the two periods, collection strategies were likely determined by the local availability of other seasonally varying resources at these particular localities. Moreover, depending on the method of evaluation, changes in seasonality are also observed between the 
interglacial MIS5 and glacial MIS4 aged assemblages in the PP caves. This supports other indications of behavioural change between MIS5 and MIS4, and suggests that the onset of glacial conditions caused people to adapt their subsistence strategies to cope with the new environmental constraints.

A possible confounding factor for conclusions about size differences between the two periods is evident when combining the growth rate estimates with the season of harvest data. The LSA samples show a very strong cool season signal for collection, and it is known that shellfishing returns are lowest during poor weather conditions when the seas are roughest (De Vynck et al., 2016). If, during the LSA, foragers predominantly harvested shellfish during the time of year when conditions were most dangerous, they may well have been more cautious about venturing into deeper waters inhabited by larger, older Turbo (Foster, 1997), and consequently, have collected smaller Turbo than MSA people who foraged more in the calmer summer months (C. Henshilwood, pers. comm.). It must be noted, however, that the size differences that Klein and Steele report are also seen across several species of limpets on both the southernmost and western coasts of South Africa, and season of harvest information for these species is unknown. However, the size differences between the MSA and LSA assemblages may indeed reflect human behaviour (as opposed to climatic or environmental variation) and not population increases per se. 


\section{Chapter 7}

\section{Discussion and conclusions}

\section{Contents}

7.1 Near-shore SSTs and regional climate patterns . . . . 170

7.2 Subsistence and cultural patterns . . . . . . . . 172

7.2 .1 Subsistence . . . . . . . . . . . . . . 172

7.2.2 Cultural and environmental change . . . . . . . . . . 176

7.3 Future research . . . . . . . . . . . . . 179

7.4 Summary of conclusions ............... 180

In this section, I compare the data presented in this thesis with a broader range of palaeoenvironmental and archaeological evidence. One of the core hypotheses for this research is that near-shore SST trends correlate with local and regional-scale precipitation conditions and so here I evaluate the limited evidence for local and regional climates across this period, especially for related evidence of changing precipitation seasonality (Research Objectives 1 and 2, in the Introduction: section 7.1). A further avenue for investigation is the intersection between climate change and the archaeological record - as Mitchell, (2002: 149) notes: "Orchestrating changes in environment, artefact assemblages and subsistence strategies into a coherent whole has been a major theme of LSA archaeology since the 1970's." Here I evaluate some of the major lines of archaeological evidence for technology and subsistence from each site, to better understand the intersections between these different dimensions of the past (Research Objectives 3 and 4, in the 
Introduction: section 7.2). I conclude the chapter by envisioning some promising areas for future research and describe some of the existing obstacles for this methodology.

Initially, it is important to note that the data in this thesis are aggregated by a combination of archaeological depositional phases and, at a higher level, by chronostratigraphic phases related to global climate schemes (i.e. the MIS, the subdivision of the Holocene). This aggregation assumes that these phases have a coherence or validity for southern African climate, and that any changes observed between the periods relate to the global climate changes. But there may well be trends operating outside of this structuring mechanism and, certainly, climate changes are likely to be continuous rather than discrete. The nature of this proxy record, however, with each shell representing only a few short years, and the large error ranges for the dates of each depositional context, demands the aggregation of the data according to some framework. Moreover, there is evidence that climatic and environmental changes in this region do move in concert with global climate changes (e.g. Bar-Matthews et al., 2010; Ziegler et al., 2013). Yet, additional shell isotope records will clearly be valuable in elucidating leads, lags and discrepancies in the climate and archaeological systems. The results presented in this thesis have laid the groundwork for future extensions of this approach by establishing baseline temperature ranges for each period - future applications will not require such intensive sampling for each shell, which will allow for more continuous examinations of subsistence and seasonal SST trends. For example, there are archaeological questions that require a higher degree of temporal resolution than is permitted by this study: a reduction in average femur length between 4-3 ka suggests a decline in food security at this time (Pfeiffer and Sealy, 2006), with possible implications for the exploitation of shellfish, but this period is not resolved by the present dataset. Similarly, the profound changes evident in the NBC archaeological sequence at c. 3.3 ka cannot be further explored from the perspective of shellfishing with these data (Inskeep, 1987). Yet, only a relatively small number of additional analyses upon the final growth increment of Turbo opercula may provide insights into subsistence across these relatively brief periods. In addition, the new dating framework for NBC and BNK1 (Loftus et al., 2016) demonstrates the chronological refinements that are possible with improved dating methods and modelling. Ongoing radiocarbon dating projects at other LSA sites will help in elucidating the nature and tempo of cultural change, enabling better assessments of the intersection between the environmental and archaeological records. 


\subsection{Near-shore SSTs and regional climate patterns}

Over a quarter of a century ago, van Andel (1989: 140) noted "the pervasive vagueness of descriptive terms" in palaeoclimate studies of the southernmost coast and the stubborn refusal of the "various interpretations... to coalesce into a coherent regional image." In subsequent decades, despite the accumulation of increasing amounts of palaeoenvironmental data, discerning the role of the various climate drivers and the precise nature of environmental change remains exceptionally challenging. Even over the Holocene, terrestrial climatic records for the year round and winter rainfall regions of the Cape present different interpretations of the climatic trends. For example, there is evidence for both drier and more mesic conditions during the mid Holocene altithermal, a global warm event between c. 9 - 5 kcalBP. Evidence for drying comes from sites situated in the winter rainfall zone, such as Klaarfontein (Meadows and Baxter, 2001) and Pakhuis Pass (Scott and Woodborne, 2007), or from sites located inland from the southernmost coast, such as Boomplaas (Scholtz, 1986) and Seweweekspoort (Chase et al., 2013). But other sites located at the boundary of the winter and year-round rainfall zone, such as Katbakkies Pass (Meadows et al., 2010; Chase et al., 2015) and Byneskranskop (Avery, 1993) record more summer rainfall and more mesic conditions for the mid Holocene altithermal. This corresponds with records that show moister conditions in the interior, summer rainfall region (Scott and Lee-Thorp, 2004; Scott et al., 2012). Yet, a near coastal record for the southernmost coast from Rietvlei tentatively interprets increased charcoal abundance during the mid Holocene as indicative of drier conditions from c. 7 5 kcal BP (Quick et al., 2015a). This might be explained by the decrease in near-shore summer SSTs caused by the upwelling trends, resulting in less moisture availability for the coastal strip, moderating any increases in summer rainfall. These apparent contradictions hint that reconstructions of precipitation trends in this region are confounded by the divergent trends in summer and winter rainfall dynamics in combination with the influence of highly localised coastal rainfall in response to near-shore SSTs.

In addition, large temperature shifts over this period complicate assessments of moisture availability - see the complex patterning in modern aridity that results from the intersection of these factors, especially along the south coast (Figure 7.1.1). Changes in aridity, rather than precipitation per se, are arguably a more useful parameter for understanding ecosystem and habitat change in the past (Chevalier and Chase, 2016). A long-sequence vlei archive from Vankervelsvlei near Plettenberg Bay provides some insights into changing vegetation patterning from MIS5 (Quick et al., 2015b). During MIS5d, pollen reflect an apparently aseasonal climate with substantial proportions of 


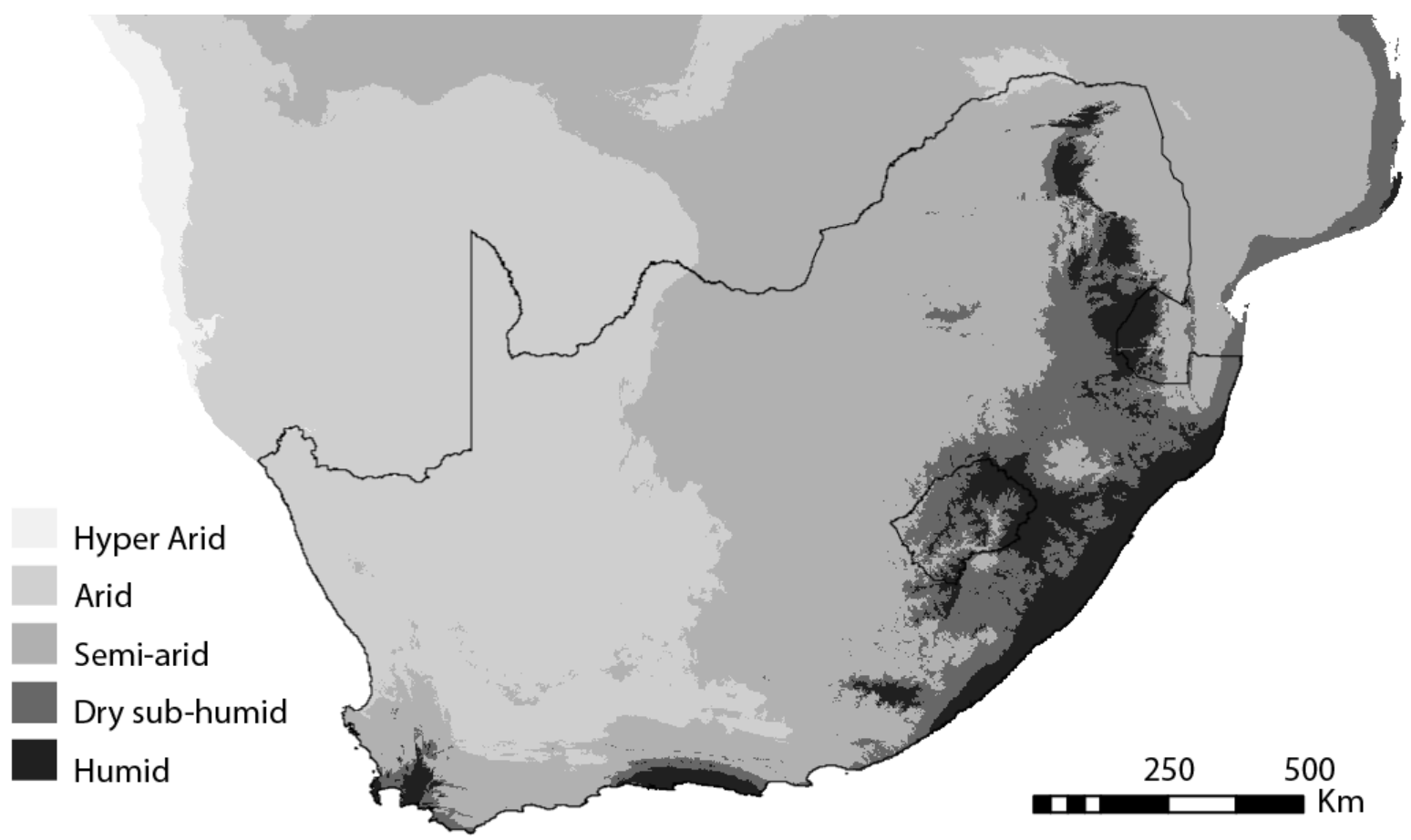

Figure 7.1.1: Map of modern (1950-2000) aridity index (Mean Annual Precipitation/Mean Annual Evaporation) across southern Africa (Zomer et al., 2007). Data available at www.cgiar-csi.org.

afrotemperate forest taxa, indicative of higher proportions of summer rainfall at this time. Within the latter part of MIS5 however, increased proportions of fynbos taxa suggest the emergence of a cooler, more seasonal climate system, likely the result of decreasing summer rainfall. However, further to the east, at KRM, faunal evidence shows conditions become progressively moister across MIS5 (Klein, 1976; Avery, 1987; van Pletzen, 2000), However, the shell SST data from KRM show little change across MIS5, suggesting that if the region was becoming more mesic, it was not directly due to oceanic influences: the trend may well be driven by the declining temperatures leading into the glacial. The similarity in near-shore SSTs between the periods may simply reflect the "snapshot" sampling, whereby the only shells available for sampling are from periods when people were occupying the site (ergo sea levels were similar between these periods).

MIS4 (71 - $57 \mathrm{ka}$ ) is thought to have been a generally humid period across the year round rainfall region due to the cooler temperatures and increased influence of the westerlies, although summer rainfall may have decreased (Chase, 2010; Truc et al., 2013). Yet, although afrotemperate forest taxa are still present at Vankervelsvlei, indicating that conditions remained generally mesic locally, the record also shows some suggestion of 
drought conditions at this time (Quick et al., 2015b). At KRM, MIS4 is apparently marked by increasingly open environments, possibly reflecting the differing influences of the summer and winter rainfall systems in the respective regions (Klein, 1976; Avery, 1987; van Pletzen, 2000). The MIS4 aged dataset of shells from level OBS1 at PP5-6 reflects the coolest temperatures but also an apparent reduction in upwelling. This record could suggest both less moisture availability locally, due to the low coastal SSTs and a suppression of the summer rainfall systems regionally. Thus, the apparent contradictions in the terrestrial datasets are very likely attributable to differences in the time resolution of the different records - continuous records indicate that the southern rainfall region experienced rapid shifts in climate during MIS4 (Ziegler et al., 2013) and to the competing influences of the shifting precipitation systems and the declining temperatures (Chevalier and Chase, 2016).

The near-shore SST records presented here point to a mechanism that accounts for the conflicting climate records recovered from the southern and western Cape. In addition to the sometimes confounding effects of the two main rain-bearing weather systems for the region, Agulhas SSTs likely influenced the precipitation of the coastal strip, as they do today (Jury et al., 1993; Jury, 2015). Increased SSTs anticipated to accompany periods of reduced upwelling may have offset the reductions in summer precipitation for the coastal region. However, near-shore SST shifts are obscured by the global trends in SST, which strongly affect Agulhas Current (Ziegler et al., 2013) and near-shore SST records. In this thesis I corrected for the global changes using a globally averaged record (Waelbroeck et al., 2002) but as more highly resolved, long-term records of Agulhas Current dynamics are recovered (e.g. Simon et al., 2013), and as the dating resolution of the archaeological deposits is improved, it will be increasingly possible to distinguish local SST shifts from the global record.

\subsection{Subsistence and cultural patterns}

\subsubsection{Subsistence}

Several lines of evidence suggest that ecosystems along the southernmost coast have been largely stable across the last interglacial cycle. Rector and Verrelli (2010) show that faunal communities did not "turnover" in line with glacial and interglacial periods, and they suggest that although the proportions of $\mathrm{C}_{3}$ plants and $\mathrm{C}_{4}$ grasses changed in 
response to shifting rainfall regimes, these vegetation changes occurred within generally predictable "mosaic" environments that continued to support the large mammal fauna from at least MIS5 (although see Faith, 2013). This accords with several pollen archives from the fynbos region that show little change in the vegetation at the biome level, even during periods of marked global climate change (Meadows et al., 2010; Quick et al., 2011; Valsecchi et al., 2013). Additionally, although the proportion of $\mathrm{C}_{3}$ plants and $\mathrm{C}_{4}$ grasses may well have changed, faunal isotope records show that grazers continued to consume $\mathrm{C}_{4}$ grasses throughout the LGM and Holocene, suggesting a persistence in the year-round rainfall regime under glacial conditions (Sealy, 1996). This resilience and overall stability within the vegetation structure has been proposed as an important factor in the apparent continued occupation of the southernmost coast during glacial and interglacial periods (Marean et al., 2014; De Vynck et al., 2015). Such stability hints that the marked differences in the harvesting strategies between the MSA and LSA (i.e. see Figure 6.2.4) are not readily attributable to climate driven changes in the resource base.

Yet, the evidence outlined above shows that there are still differences in environmental trends across the southernmost Cape region, largely driven by the shifting realms of influence of the summer and winter rainfall systems, and possibly also the varying importance of localised upwelling dynamics for coastal productivity. The MIS5 assemblages from PP13B in the west and KRM in the east reveal differences in the season of mollusc harvest from these two localities. This indicates that the economic strategies of people living in the two sites were organised differently, perhaps structured by the differing sets of seasonally available resources at each locality. This is consistent with previous research that finds ecologically-dependent flexibility in MSA foraging behaviours. Hutson (2016), for example, has shown differences in hunting and scavenging behaviours at open sites in the interior of the subcontinent, and suggested that part of the ambiguity in gauging the sophistication of MSA hunting practices is due to this behavioural flexibility. Ecological differences may have been most marked between the interior and coastal sites, but the season of harvest results here suggest that behavioural flexibility is evident even within the coastal zone. Indeed, Thompson (2010) showed that subtle differences are evident in the patterns of faunal exploitation between PP13B, Blombos Cave and Die Kelders Cave 1, all situated on the south coast.

At times of lowered sea level (for those periods covered in this thesis), the coastline adjacent to PP5-6 could have been up to c. $10 \mathrm{~km}$ away from Pinnacle Point (Fisher et al., 2010), while it would never have been further than a few kilometres at KRM 


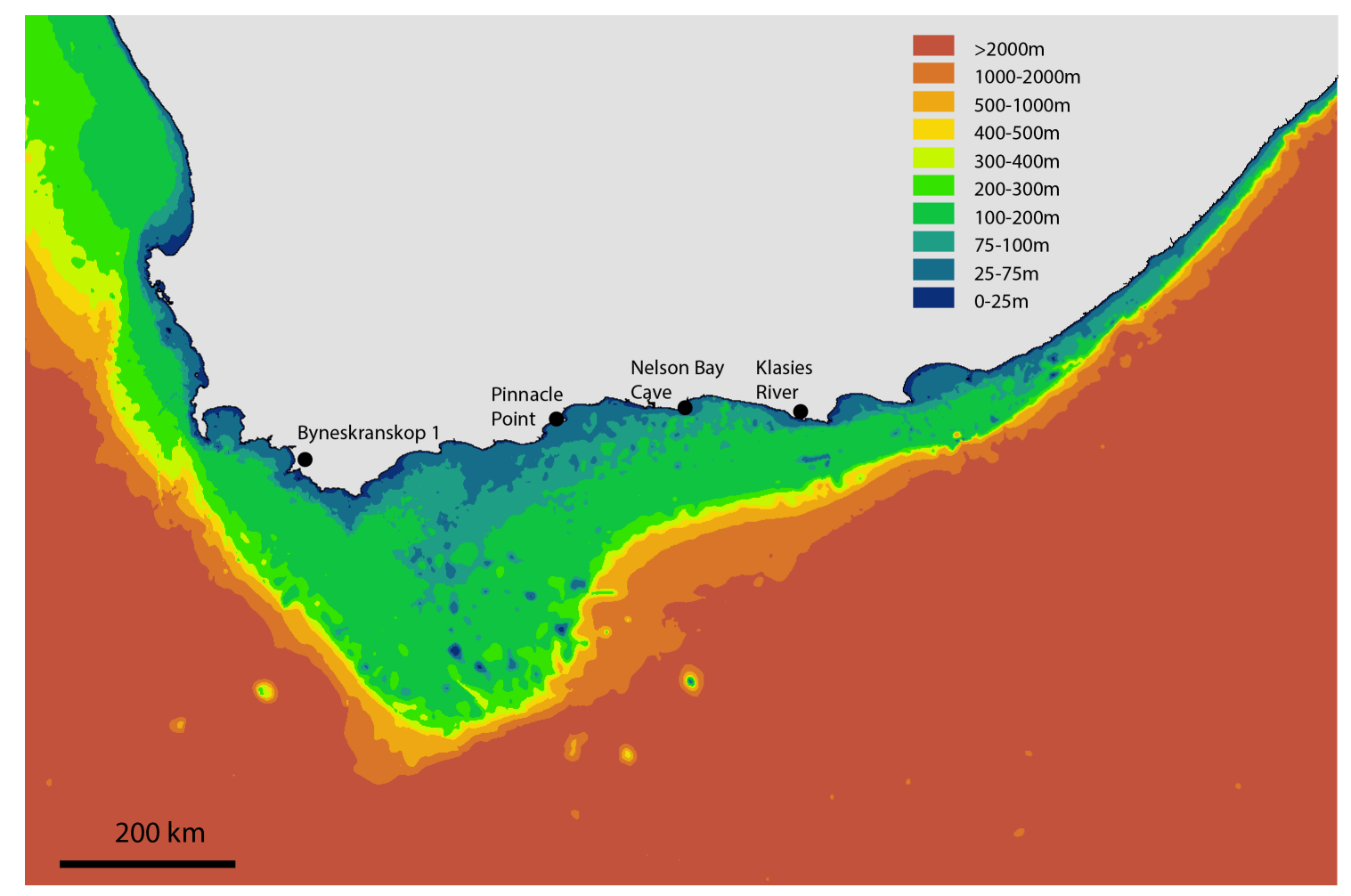

Figure 7.2.1: Bathymetric map of the southern coastal plain, South Africa. Data available from www.gebco.net.

where the coastal plain is much narrower (see Figure 7.2.1: van Andel, 1989; Dusseldorp and Langejans, 2013). The area around KRM today has more open grassland due to the higher proportion of summer rainfall - this may have favoured large grazing mammals, which may have migrated seasonally along the coastal plain. However, it is difficult to move from an acknowledgement of these regional ecological differences to understanding how these differences affected hunting and foraging behaviours. The MIS5 shell results for KRM show year-round harvesting (Figure 6.2.5), but this does not support a model whereby people switch between seasonally available resources, as is assumed if large herds are moving across the landscape seasonally. Moreover, Waselkov (1987) notes that few modern groups of hunter-gatherers collect shellfish year-round, and scheduling considerations mean that shellfishing is only undertaken when conditions are ideal. A more strongly seasonal harvesting signal is evident at PP during both MIS5 and 4, yet here too the results are contrary to expectations, which anticipate more shellfish collecting during the summer months when conditions are more favourable (De Vynck et al., 2016). Nevertheless, the ecological patterning along the coast has apparently influenced the foraging behaviour of the groups living at these sites, as manifested in the shellfish harvesting data. 
The shift from a more strongly cool season collection pattern evident in the MIS5 assemblage from PP13B (Galimberti, 2010) to the more year-round collection pattern in the MIS4 assemblage from PP5-6 (this study) is consistent with predictions of a change in societal organisation between MIS5 and 4, based upon assumptions of resource scarcity due to deteriorating environmental conditions of MIS4 (McCall, 2007; Henshilwood, 2008b), and the appearance of efficient projectile weaponry that accompanied increasing levels of territoriality across this period (Brown et al., 2012; Marean, 2014; 2016). Other lines of evidence have also shown intensification in resource acquisition behaviour or more focussed subsistence strategies at this time, including: an increase in large bovids at Blombos Cave, possibly related to more efficient hunting technologies (Dusseldorp, 2012), an increase in small ungulates and other mammals in MIS4 (Clark and Kandel, 2013), increases in the diversity of shellfish and more foccussed collection of particular species (Clark and Kandel, 2013; Langejans et al., 2012), an increase in the relative importance of marine mammals at Blombos Cave, and increases in the degree of fragmentation of faunal remains at Blombos Cave (Thompson and Henshilwood, 2011). Such evidence for intensification of hunting and foraging behaviours may then reflect wide-ranging shifts in foraging and hunting behaviour related to climate change at the onset of the glacial.

The marked difference in the timing of shellfish collection between the MSA and LSA is consistent with other lines of evidence that indicate different foraging behaviours between the two periods. But the nature of the difference in timing between the MSA and LSA is puzzling - numerous lines of evidence show the intensification of resource extraction, thought to reflect increasingly settled populations along the coast. This pattern of settlement might be expected to produce a year-round signal for shellfish collection, yet the Holocene shells show little evidence for summer harvesting, the season thought most suitable for shellfish foraging (De Vynck et al., 2016; Klein and Bird, 2016). Interestingly, the original formulation of the seasonal round model applied to the south west coast suggested shellfish was likely to have been collected during winter (Parkington, 1972; 1976), but this reflected a different ecological context, and other lines of evidence subsequently indicated that people likely lived year-round at the coast during at least the lattermost LSA (Sealy and van der Merwe, 1986). In the southern Cape, the mosaic nature of the vegetation and the generally year-round availability of terrestrial and marine resources (i.e. De Vynck et al., 2015; 2016) would arguably discourage any strongly seasonal harvesting strategy for just one resource unless overall those foraging behaviours were highly structured.

This evidence suggests that our understanding of the differences in LSA and MSA 
behaviour is still missing some key information, possibly related to the seasonal occurrence of other resources on the landscape, or to patterns of social organisation. Moreover, the results are indicative of changes in seasonal harvesting trends within the MSA and LSA (i.e. contrast the earliest and latest levels at KRM in Figure 6.2.2 and the trends within the Holocene) that cannot presently be resolved clearly, but which may become clearer with more analyses.

\subsubsection{Cultural and environmental change}

Linking specific stone tool technologies to particular subsistence practices is notoriously difficult, despite the "common-sense" appeal that relates these dimensions of the archaeological record. And while climate change is frequently postulated as a cause of technological change (e.g. Ziegler et al., 2013), given the enormous areas and disparate ecological settings across which certain of the southern African MSA and LSA lithic assemblages are found, direct environmental drivers can seem unlikely. Greater nuance is offered by models that seek to balance technological expediency and specialization as a means to limiting risk and maximising resource extraction under changing environmental conditions (e.g. Bousman, 2005; McCall, 2007; Lombard and Parsons, 2011; Mackay et al., 2014). A further consideration is the role of demographic factors. Powell et al. (2009), developing models by Shennan (2001) and Henrich (2004), predict increased technological complexity at times of population growth. Yet quantifying past population fluctuations is challenging, even during relatively recent periods (Sealy, 2016), and assumptions of deteriorating conditions throughout southern Africa during MIS4 (e.g. Powell et al., 2009) require further examination (Chase, 2010). Moreover, archaeological lines of evidence do not always bear out the modelled predictions of the Powell model (Collard et al., 2013; Sealy, 2016; Vaesen et al., 2016). This conflicting literature indicates that examples of climate-driven technological change still require explication and cannot be assumed from tenuous temporal coincidences. The climate record of the Turbo $\delta^{18} \mathrm{O}$ data is interbedded with the archaeological information and so provides more promising opportunities to test the covariance of climatic and social shifts.

Interpreting the functional and social significance of the changes in lithic dimensions, raw materials, production methods, etc., that lithic specialists quantify to track technological turnover is beyond the scope of this thesis. Yet, such measures of technological specialization reflect social organisation in ways that may well be expected to also intersect with the season of harvest results presented in Chapter 6, as a measure of coastal occupation 


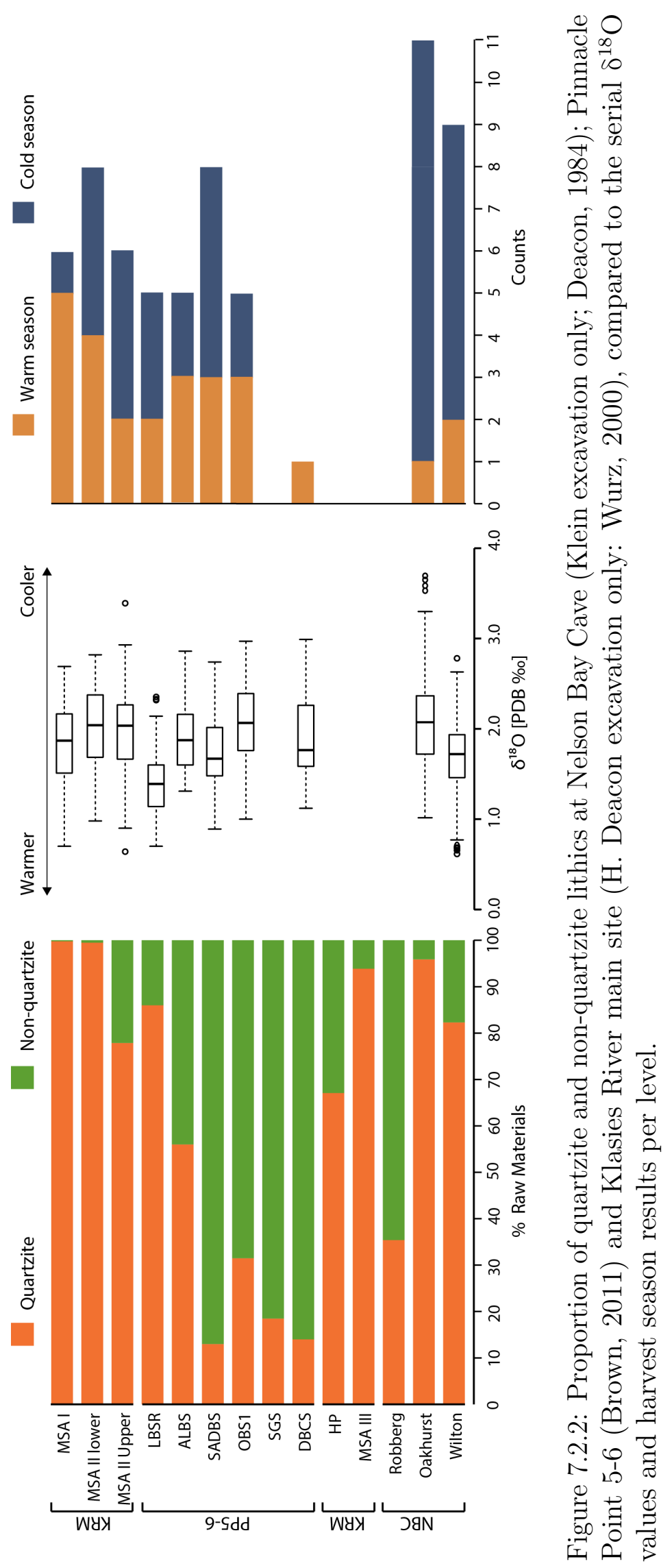


and resource exploitation. Presently, however, the sample sizes of shell harvest determinations are too small to track changes alongside the more detailed lithic information. Figure 7.2.2 shows one aspect of lithic characterization, the proportion of quartzite to non-quartzite raw materials (including fine-grained silcrete, chert, hornfels and quartz) from sites with associated shell $\delta^{18} \mathrm{O}$ data. This plot of raw material percentages reflects a pattern of the southernmost Cape MSA record observed at several sites including KRM, PP5-6, Diepkloof and Die Kelders, namely a shift from quartzite-dominated assemblages to the predominant usage of silcrete at about the time of the MIS5/4 transition. This trend is suggested, at least for the PP5-6 record, to reflect the availability of quartzite beach cobbles as driven by shifts in sea-level and the advance and regression of the shoreline, what Kyle Brown calls the Site Context Model (Brown, 2011).

According to Brown's model of quartzite usage, the proportion of silcrete should be higher in level OBS than in SADBS as the shore recedes away from the cave site. Yet, the proportion of silcrete in OBS1 is the lowest of all levels at PP5-6, and the assemblage is instead dominated by quartz. Further features mark a sharp change in lithic production between SADBS and the overlying OBS1 (Brown et al., 2012). While SADBS is characterised by short, narrow bladelets made of heat-treated silcrete and cherts, OBS1 has very few diagnostic tools, which the excavators attribute to the high proportion of quartz in the assemblage. OBS1 is a largely sterile horizon, with occasional thin lenses of archaeological material with low densities of finds, whereas SADBS has very high find density in a matrix of ash and combustion features. The underlying ALBS is similar to SADBS, although with less ash. The SADBS assemblage is shown to differ from the overlying Howiesons Poort assemblages both at this site and others, and is more similar in terms of size to LSA bladelet assemblages. The shell $\delta^{18} \mathrm{O}$ results from level OBS1 from PP5-6 record very low SSTs, on average $6{ }^{\circ} \mathrm{C}$ cooler year-round, presumably in response to a global decline in SSTs. The shells also record a high annual SST range and anomalously high $\delta^{13} \mathrm{C}$ values, which suggest reduced coastal upwelling. Thus, near-shore oceanographic conditions appear to have been markedly different from both the preceding SADBS level and the subsequent DBCS level (although based on analysis of a single operculum).

Unfortunately, faunal and other datasets from this site are not yet published and so cannot be evaluated across this period of apparent cultural and environmental change. And larger samples are needed to evaluate the possible shift in shellfish harvesting season between SADBS and OBS1 that is hinted at in Figure 7.2.2. Generally, however, combined SST and lithic evidence for level OBS1 (Brown et al., 2012) suggests an 
environmentally-driven relaxation in the constraints, whatever they were, that shaped the preceding highly-standardised SADBS lithic assemblage. The SST record from PP5-6 may then possibly demonstrate a local instance of technology and environmental changes occurring simultaneously. More nuanced studies that incorporate additional details of the lithic assemblages at these sites may well provide more productive insights into the relationship between these new climate records and the archaeological sequence.

\subsection{Future research}

Future research exploring near-shore SSTs and shellfish harvesting strategies will greatly benefit from a systematic study of modern seasonal and spatial isotopic variation along the coast. Although assumptions of minimal modern spatial variation along the coast are consistent with the available evidence, that evidence is still exceedingly sparse. A modern ecological study would allow for more robust conclusions about the size of errors associated with SST reconstructions in the past. On longer timescales, more highly resolved marine core records of carbon and oxygen isotope fluctuations will aid in distinguishing local and nearshore SST trends from global climate changes. While the Simon et al. (2013) dataset provides the best possibilities for such comparisons presently (see section 5.2), the temporal resolution is limiting. Ongoing work in this region will provide improved opportunities for adjusting near-shore records, especially as the palaeoclimate research community develops increasingly better platforms for data sharing.

Additional methodological research should evaluate the different sampling methods on the same operculum i.e. handheld drills vs the micromill, a continuous arc of samples vs discrete sets. It may well be that the lack of a seasonal signal in some of the $\delta^{18} \mathrm{O}$ series is due to the sampling resolution and direction, and potentially a small exploratory study would be able to establish the sampling method that provides the best possibilities for capturing the seasonal patterns, even amongst the larger, older animals with slower growth.

For development of the archaeological findings in this study, there are possibilities for extending this approach to other sites along the southernmost coast. Most notable among the MSA sites is Blombos Cave, about $100 \mathrm{~km}$ west of Pinnacle Point. This site boasts deposits dating from 75 to $>130$ ka (Jacobs et al., 2006), with abundant Turbo opercula (Langejans et al., 2012), and would allow for both temporal and spatial 
comparisons with the two MSA datasets presented here. There are numerous LSA sites with well-preserved shell assemblages, and the method employed in this thesis may provide helpful insights into societal level subsistence change, if deployed widely. Moreover, this thesis provides valuable baseline datasets, and additional data will be increasingly informative with fewer measurements. Further detailed comparisons of the faunal and lithic assemblages from these sites, in collaboration with specialists in these fields, will help to tease apart a fuller picture of technological and subsistence change.

There are also opportunities to extend this methodology to other mollusc species and to sites on the west coast. While Turbo is a promising species for palaeoenvironmental reconstructions because of the generally good preservation of the opercula, the growth spiral is more complex than most types of shell and it is not amenable to several of the standard methods in sclerochronology for establishing the timing of growth. There are encouraging results for the utility of Donax serra, the white mussel, for palaeotemperature reconstructions (Galimberti, 2010), and its shells are found wellpreserved in many old deposits. Additionally, Donax inhabits sandy beaches, and so can aid in the reconstruction of other types of environments than rocky shores - the same principle is true of other species, which may inhabit a range of tidal habitats.

A highly promising study would be a comparison of shellfishing trends along the southernmost and western Cape coastlines for both MSA and LSA assemblages. The two regions differ considerably in the available terrestrial resources, confounding comparisons of the subsistence behaviours observed in the two regions. Additional lines of evidence from mollusc collecting would perhaps enable better understanding of the occurrence of phenomena such as seasonal mobility through time. Additionally, resource availability is more seasonal on the winter-rainfall dominated west coast than in the year-round rainfall zone of the south coast - this is likely to have affected foraging and settlement behaviours in the two regions, which could be elucidated through comparable seasonality data.

\subsection{Summary of conclusions}

The conclusions to be drawn from this research are of methodological, palaeoclimatic and archaeological significance: 
1. Spatially resolved assessments of diagenesis are essential for deriving robust palaeotemperature records from Turbo sarmaticus opercula, which are prone to recrystallization.

(a) FTIR-ATR provides the best, minimally-destructive possibility for quantitatively establishing aragonitic conversion to calcite using small powdered samples.

2. New dating programs incorporating Bayesian modelling techniques can improve the existing chronologies of South African archaeological sites excavated decades ago.

(a) The application of AMS radiocarbon dates has extended the age range of the LSA sequences at both NBC and BNK1.

(b) Consideration of calibrated age estimates greatly affects the commonly accepted age ranges of the various lithic industries across southern Africa.

(c) More precise chronologies can identify stratigraphic inconsistencies that may not have been apparent to the excavator.

3. Utilising shell samples from several sites allows for comparative analyses that are more informative than projects based at single sites.

(a) The Holocene dataset is valuable for interpreting the older Pleistocene data and in uncoupling the global shifts in temperature from localized trends.

(b) Differences in nearshore SST trends along the southern coast are evident in the Holocene and Pleistocene, providing information to unravel the ecological differences at these localities.

4. Near-shore SSTs across the last interglacial responded closely to global SST and sea-level trends.

(a) The near-shore record captures larger, more representative seasonal ranges than marine core records based in the main stream of the Agulhas Current.

(b) The implication of changes in SST seasonality are unclear and require further investigation.

(c) The seasonal SST ranges observed in this study can be used to constrain Earth System Models, which, superficially, do not currently appear to capture SST seasonality accurately. 
5. The near-shore SST results highlight a likely mechanism accounting for the sometimes contradictory terrestrial palaeoenvironmental records, namely the localised climate effects of the warm Agulhas Current water for the southernmost coast.

(a) The Cohen and Tyson (1995) model is tentatively confirmed by comparison between the Holocene SST record and terrestrial precipitation records.

(b) The annual SST range at PP5-6 indicates increased summer rainfall in the interior and the coast at c. $82 \mathrm{ka}$, and drier conditions in both the interior and the coast at c. 69 ka.

6. The interbedded climate shell records at PP5-6 suggest climate and environmental shifts played a role in the marked cultural changes between LBSR and OBS1

(a) Inclusion of these palaeoclimatic findings may help explain lithic assemblages that do not align with the expectations of Brown's Site Context Model

(b) Drier conditions during OBS1 appear to coincide with a more unstandardized lithic assemblage, contrary to some models of greater levels of standardization during periods of environmental deterioration.

7. This project contributes to increasingly fine-scaled and nuanced understandings of foraging behaviours in the distant past.

(a) There is a marked distinction in the seasonal timing of shellfish harvesting between the MSA and LSA.

(b) The sites of PP and KRM reflect different seasonal foraging behaviours, even during the same broad time periods.

(c) The evidence is consistent with assertions of wide-ranging changes in forager behaviour at the onset of glacial MIS4.

(d) The data hint at a shift in the seasonal foraging across the Holocene but currently a clear identification of that trend is limited by small sample sizes.

8. No significant differences in growth rate are observed between the LSA and MSA but the analysis cannot be considered definitive given the complex growth pattern of the Turbo operculum and the pre-selection of shells during analysis.

(a) Consideration of the strong cool season of collection evident from LSA opercula hints that size differences may reflect a reduced intertidal range exploited due to the annual timing of collection. 


\section{Bibliography}

Adegoke, O., 1973. "Mineralogy and biogeochemistry of calcareous operculi and shells of some gastropods." Malacologia, 14:39-46.

Adler, H. H. and Kerr, P. F., 1962. "Infrared study of aragonite and calcite." The American mineralogist, 47:700-717.

Allan, E. L., Ambrose, S. T., Richoux, N. B., and Froneman, P. W., 2010. "Determining spatial changes in the diet of nearshore suspension-feeders along the South African coastline: Stable isotope and fatty acid signatures." Estuarine, Coastal and Shelf Science, 87(3):463-471.

Andrus, C. F. T., 2011. "Shell midden sclerochronology." Quaternary Science Reviews, 30(21):2892-2905.

Avery, D., 1982. "Micromammals as palaeoenvironmental indicators and an interpretation of the late Quaternary in the southern Cape Province, South Africa." Annals of the South African Museum, 85:183-377.

Avery, D., 1987. "Late Pleistocene coastal environment of the Southern Cape Province of South Africa: Micromammals from klasies river mouth." Journal of Archaeological Science, 14(4):405-421.

Avery, D., 1993. "Last interglacial and Holocene altithermal environments in South Africa and Namibia: micromammalian evidence." Palaeogeography, Palaeoclimatology, Palaeoecology, 101(3-4):221-228.

Avery, G., Halkett, D., Orton, J., Steele, T. E., Tusenius, M., and Klein, R. G., 2008. "The Ysterfontein 1 Middle Stone Age rock shelter and the evolution of coastal foraging." South African Archaeological Society Goodwin Series, 10:66-89.

Bailey, G. and Milner, N., 2002. "Coastal hunter-gatherers and social evolution: marginal or central?" Before Farming, 3-4:1-22.

Bar-Matthews, M., Marean, C. W., Jacobs, Z., Karkanas, P., Fisher, E., Herries, A., Brown, K. S., Williams, H. M., Bernatchez, J., Ayalon, A., and Nilssen, P., 2010. "A high resolution and continuous isotopic speleothem record of paleoclimate and paleoenvironment from 90 to 53 ka from Pinnacle Point on the south coast of South." 
Quaternary Science Reviews, 29:2131-2145.

Beal, L., De Ruijter, W., Biastoch, A., Zahn, R., Cronin, M., Hermes, J., Lutjeharms, J. R. E., Quartly, G., Tozuka, T., Baker-Yeboah, S., Bornman, T., Cipollini, P., Dijkstra, H., Hall, I., Park, W., Peeters, F. J. C., Penven, P., Ridderinkhof, H., and Zinke, J., 2011. "On the role of the Agulhas system in ocean circulation and climate." Nature, 471:429-436.

Behar, D. M., Villems, R., Soodyall, H., Blue-Smith, J., Pereira, L., Metspalu, E., Scozzari, R., Makkan, H., Tzur, S., Comas, D., Bertranpetit, J., Quintana-Murci, L., Tyler-Smith, C., Wells, R. S., and Rosset, S., 2008. "The dawn of human matrilineal diversity." American Journal of Human Genetics, 82(5):1130-40.

Berger, A. and Loutre, M., 1991. "Insolation values for the climate of the last 10 million years." Quaternary Science Reviews, 10(4):297-317.

Bigalke, E., 1973. "The exploitation of shellfish by coastal tribesmen of the Transkei." Annals of the Cape Province Museum, 9:159-175.

Bird, M. I., Ayliffe, L. K., Fifield, L., Turney, C. S. M., Cresswell, R. G., Barrows, T. T., and David, B., 1999. "Radiocarbon dating of "old" charcoal using a wet oxidation, stepped-combustion procedure." Radiocarbon, 41:127-140.

Blanchette, C. A., Broitman, B. R., and Gaines, S. D., 2006. "Intertidal community structure and oceanographic patterns around Santa Cruz Island, CA, USA." Marine Biology, 149(3):689-701.

Blome, M. W., Cohen, A. S., Tryon, C. A., Brooks, A. S., and Russell, J., 2012. "The environmental context for the origins of modern human diversity: a synthesis of regional variability in African climate 150,000-30,000 years ago." Journal of Human Evolution, 62(5):563-92.

Boiseau, M. and Juillet-Leclerc, A., 1997. "H2O2 treatment of recent coral aragonite: oxygen and carbon isotopic implications." Chemical Geology, 143(3-4):171-180.

Bousman, C. B., 2005. "Coping with risk: Later stone age technological strategies at Blydefontein Rock Shelter, South Africa." Journal of Anthropological Archaeology, 24(3):193-226.

Braconnot, P., Harrison, S. P., Kageyama, M., Bartlein, P. J., Masson-Delmotte, V., Abe-Ouchi, A., Otto-Bliesner, B., and Zhao, Y., 2012. "Evaluation of climate models using palaeoclimatic data." Nature Climate Change, 2(6):417-424.

Branch, G., Griffiths, C., Branch, M., and Beckley, L., 2007. Two oceans: a guide to the marine life of southern Africa. Cape Town: Struik Publishers, 2nd edition.

Brauer, G., Deacon, H. J., and Zipfel, F., 1992. "Comment on the new maxillary finds from Klasies River, South Africa." Journal of Human Evolution, 23:419-422. 
Brock, F., Higham, T. F. G., Ditchfield, P., and Bronk Ramsey, C., 2010. "Current pretreatment methods for AMS radiocarbon dating at the oxford radiocarbon accelerator unit (ORAU)." Radiocarbon, 52:103-112.

Bronk Ramsey, C., 1995. "Radiocarbon calibration and analysis of stratigraphy: the OxCal program." Radiocarbon, 37:425-430.

Bronk Ramsey, C., 2009a. "Bayesian analysis of radiocarbon dates." Radiocarbon, 51:337-360.

Bronk Ramsey, C., 2009b. "Dealing with outliers and offsets in radiocarbon dating." Radiocarbon, 51(3):1023-45.

Bronk Ramsey, C., Higham, T. F. G., and Leach, P., 2004. "Towards high-precision AMS: Progress and limitations." Radiocarbon, 46:17-24.

Brown, K., 2011. The Sword in the Stone: Lithic raw material exploitation in the Middle Stone at Pinnacle Point Site 5-6, Southern Cape, South Africa. Phd, University of Cape Town.

Brown, K. S., Marean, C. W., Herries, A. I., Jacobs, Z., Tribolo, C., Braun, D. R., Roberts, D. L., Meyer, M., and Bernatchez, J., 2009. "Fire as an engineering tool of early modern humans." Science, 325(5942):859-862.

Brown, K. S., Marean, C. W., Jacobs, Z., Schoville, B. J., Oestmo, S., Fisher, E. C., Bernatchez, J., Karkanas, P., and Matthews, T., 2012. "An early and enduring advanced technology originating 71,000 years ago in South Africa." Nature, 491(7425):590-3.

Brune, L., 2006. The examination of a method for determining palaeoclimates and seasonality: a study on the gastropod Turbo sarmaticus from Later Stone Age sites in the southern Cape, South Africa. Ma thesis, University of Oslo.

Bruton, J., Baird, D., and Coetzee, P. S., 1991. "Population structure and yield-perrecruit analysis of the giant periwinkle Turbo sarmaticus in the Cape St Francis region, South Africa." South African Journal of Marine Science, 11(1):345-356.

Buchanan, W., 1988. Shellfish in Prehistoric Diet: Elands Bay, S.W. Cape Coast, South Africa. Oxford: BAR International series 455.

Butler, P. G., Wanamaker Jr., A. D., Scourse, J. D., Richardson, C. A., and Reynolds, D. J., 2013. "Variability of marine climate on the North Icelandic Shelf in a 1357year proxy archive based on growth increments in the bivalve Arctica islandica." Palaeogeography, Palaeoclimatology, Palaeoecology, 373:141-151.

Caley, T., Kim, J.-H., Malaizé, B., Giraudeau, J., Laepple, T., Caillon, N., Charlier, K., Rebaubier, H., Rossignol, L., Castañeda, I. S., Schouten, S., and Sinninghe Damsté, J. S., 2011. "High-latitude obliquity as a dominant forcing in the Agulhas current system." Climate of the Past, 7(4):1285-1296. 
Carré, M., Klaric, L., and Lavallée, D., 2009. "Insights into early Holocene huntergatherer mobility on the Peruvian Southern Coast from mollusk gathering seasonality." Journal of Archaeological Science, 36(5):1173-1178.

Carter, J., 1990. Skeletal biomineralization: Patterns, processes and evolutionary trends. New York: Van Nostrand Reinhold.

Carto, S., Weaver, A., Hetherington, R., Lam, Y., and Wiebe, E., 2009. "Out of Africa and into an ice age: on the role of global climate change in the late Pleistocene migration of early modern humans out of Africa." Journal of Human Evolution, 56(2):139-151.

Cawthra, H. C., Bateman, M. D., Carr, A. S., Compton, J. S., and Holmes, P. J., 2014. "Understanding Late Quaternary change at the land-ocean interface: a synthesis of the evolution of the Wilderness coastline, South Africa." Quaternary Science Reviews, 99:210-223.

Cawthra, H. C., Compton, J. S., Fisher, E. C., MacHutchon, M. R., and Marean, C. W., 2016. "Submerged shorelines and landscape features offshore of Mossel Bay, South Africa." Geological Society, London, Special Publications, 411(1):219-233.

Chase, B. M., 2010. "South African palaeoenvironments during marine oxygen isotope stage 4: a context for the Howiesons Poort and Still Bay industries." Journal of Archaeological Science, 37(6):1359-1366.

Chase, B. M., Boom, A., Carr, A. S., Meadows, M. E., and Reimer, P. J., 2013. "Holocene climate change in southernmost South Africa: rock hyrax middens record shifts in the southern westerlies." Quaternary Science Reviews, 82:199-205.

Chase, B. M., Lim, S., Chevalier, M., Boom, A., Carr, A. S., Meadows, M. E., and Reimer, P. J., 2015. "Influence of tropical easterlies in southern Africa's winter rainfall zone during the Holocene." Quaternary Science Reviews, 107:138-148.

Chase, B. M. and Meadows, M. E., 2007. "Late Quaternary dynamics of southern Africa's winter rainfall zone." Earth-Science Reviews, 84(3-4):103-138.

Chase, B. M., Meadows, M. E., Scott, L., Thomas, D. S., Marais, E., Sealy, J. C., and Reimer, P. J., 2009. "A record of rapid Holocene climate change preserved in hyrax middens from southwestern Africa." Geology, 37:703-706.

Checa, A. and Jiménez-Jiménez, A., 1998. "Constructional morphology, origin, and evolution of the gastropod operculum." Paleobiology, 24:109-132.

Chevalier, M. and Chase, B. M., 2016. "Determining the drivers of long-term aridity variability: a southern African case study." Journal of Quaternary Science, 31(2):143151.

Clark, J. D., 1993. "African and Asian perspectives on the origins of modern hu- 
mans." Philosophical Transactions of the Royal Society of London. Series B: Biological Sciences., 337(1280):201-215.

Clark, J. L. and Kandel, A. W., 2013. "The Evolutionary Implications of Variation in Human Hunting Strategies and Diet Breadth during the Middle Stone Age of Southern Africa." Current Anthropology, 54(S8):S269-S287.

Climates Systems Analysis Group, U. o. C. T., 2016. "Climate Information Portal www.cip.csag.uct.ac.za/."

Cockcroft, M., Wilkinson, M., and Tyson, P. D., 1987. "The application of a presentday climatic model to the late Quaternary in southern Africa." Climate Change, 10:161-181.

Cohen, A., 1993. A Holocene Sea Surface Temperature Record in Molluscs Shells from the South African Coast. Phd, University of Cape Town.

Cohen, A. and Branch, G., 1992. "Environmentally controlled variation in the structure and mineralogy of Patella granularis shells from the coast of southern Africa: implications for." Palaeogeography, Palaeoclimatology, Palaeoecology, 91:49-57.

Cohen, A., Parkington, J. E., Brundrit, G. B., and van der Merwe, N. J., 1992. "A Holocene marine climate record in mollusc shells from the southwest African coast." Quaternary Research, 38:379-385.

Cohen, A. and Tyson, P. D., 1995. "Sea-surface temperature fluctuations during the Holocene off the south coast of Africa: implications for terrestrial climate and rainfall." The Holocene, 5:304-312.

Collard, M., Buchanan, B., O’Brien, M., and Scholnick, J., 2013. "Risk, mobiltiy of population size? Drivers of technological richness among contact-period western North American hunter-gatherers." Philosophical transactions of the Royal Society of London. Series B, Biological sciences, 368(1630):20120412.

Colonese, A., Mannino, M. A., Bar-Yosef Mayer, D., Fa, D., Finlayson, J., Lubell, D., and Stiner, M. C., 2011. "Marine mollusc exploitation in Mediterranean prehistory: An overview." Quaternary International, 239(1):86-103.

Compere, E. and Bates, J., 1973. "Determination of calcite: aragonite ratios in mollusc shells by infrared spectra." Limnology and Oceanography, 18:326-331.

Compton, J. S., 2011. "Pleistocene sea-level fluctuations and human evolution on the southern coastal plain of South Africa." Quaternary Science Reviews, 30:506-527.

Cooke, C., 1979. "Excavations at Diana's Vow Rock Shelter, Makoni District, Zimbabwe, Rhodesia." Occasional Papers of the National Museum of Rhodesia, 4:115-48.

Copeland, S. R., Cawthra, H. C., Fisher, E. C., Lee-Thorp, J. A., Cowling, R. M., le Roux, P. J., Hodgkins, J., and Marean, C. W., 2016. "Strontium isotope investigation 
of ungulate movement patterns on the Pleistocene Paleo-Agulhas Plain of the Greater Cape Floristic Region, South Africa." Quaternary Science Reviews, 141:65-84.

Coplen, T., 1993. "Normalization of oxygen and hydrogen isotope data." Chemical Geology: Isotope Geoscience, 72:293-297.

Cowling, R. M., Richardson, D., and Mustart, P., 1997a. "Fynbos." In Vegetation of Southern Africa, edited by R. Cowling, D. Richardson, and S. Pierce. Cambridge: Cambridge University Press.

Cowling, R. M., Richardson, D., and Pierce, S., 1997b. Vegetation of Southern Africa. Cambridge: Cambridge University Press.

Crétat, J., Richard, Y., Pohl, B., Rouault, M., Reason, C., and Fauchereau, N., 2012. "Recurrent daily rainfall patterns over South Africa and associated dynamics during the core of the austral summer." International Journal of Climatology, 32(2):261-273.

Cunnane, S. and Stewart, K., 2010. Human Brain Evolution: The Influence of Freshwater and Marine Food Resources. Hoboken, New Jersey: John Wiley \& Sons.

Dauphin, Y., Cuif, J.-P., and Massard, P., 2006. "Persistent organic components in heated coral aragonitic skeletons - Implications for palaeoenvironmental reconstructions." Chemical Geology, 231(1-2):26-37.

De Vynck, J., Anderson, R., Atwater, C., Cowling, R. M., Fisher, E. C., Marean, C. W., Walker, R. S., and Hill, K., 2016. "Return rates from intertidal foraging from Blombos Cave to Pinnacle Point: Understanding early human economies." Journal of Human Evolution, 92:101-115.

De Vynck, J., Cowling, R. M., Potts, A., and Marean, C. W., 2015. "Seasonal availability of edible underground and aboveground carbohydrate resources to human foragers on the Cape south coast, South Africa." PeerJ PrePrints.

Deacon, H. J., 1976. Where hunters gathered: a study of Holocene Stone Age people in the Eastern Cape. Claremont: South African Archaeological Society, monograph edition.

Deacon, H. J., 1979. "Excavations at Boomplaas cave - a sequence through the upper Pleistocene and Holocene in South Africa." World Archaeology, 10:241-257.

Deacon, H. J., 1993. "Planting an idea: an archaeology of Stone Age gatherers in South Africa." The South African Archaeological Bulletin, 48(158):86-93.

Deacon, H. J., 1995. "Two Late Pleistocene-Holocene archaeological depositories from the southern Cape, South Africa." South African Archaeological Bulletin, 50:121:131.

Deacon, H. J. and Geleijnse, V. B., 1988. "The stratigraphy and sedimentology of the main site sequence, Klasies River, South Africa." South African Archaeological Bulletin, 43:5-14. 
Deacon, H. J. and Thackeray, J. F., 1984. "Late Pleistocene environmental changes and implications for the archaeological record in southern Africa." In Late Cainozoic palaeoclimates of the southern hemisphere, edited by J. C. Vogel, 375-390. Rotterdam: Balkema.

Deacon, J., 1978. "Changing patterns in the late Pleistocene/early Holocene prehistory of Southern Africa as seen from the Nelson Bay Cave Stone artifact sequence." Quaternary Research, 10(1):84-111.

Deacon, J., 1984. The Later Stone Age of Southernmost Africa (Vol. 213). Oxford: British Archaeological Reports.

Deacon, J. and Lancaster, N., 1988. Late Quaternary palaeoenvironments of southern Africa. Oxford: Clarendon Press.

D'Errico, F., Henshilwood, C. S., Vanhaeren, M., and van Niekerk, K. L., 2005. "Nassarius kraussianus shell beads from Blombos Cave: evidence for symbolic behaviour in the Middle Stone Age." Journal of Human Evolution, 48(1):3-24.

D'Errico, F., Moreno, R. G., and Rifkin, R. F., 2012. "Technological, elemental and colorimetric analysis of an engraved ochre fragment from the Middle Stone Age levels of Klasies River Cave 1, South Africa." Journal of Archaeological Science, 39:942-952.

Dewar, G. I., Reimer, P. J., Sealy, J. C., and Woodborne, S., 2012. "Late-Holocene marine radiocarbon reservoir correction $(\{$ Delta $\} \mathrm{R})$ for the west coast of South Africa." The Holocene, 22(12):1481-1489.

Dickinson, S. R. and McGrath, K. M., 2001. "Quantitative determination of binary and tertiary calcium carbonate mixtures using powder X-ray diffraction." The Analyst, 126(7):1118-1121.

Douka, K., Hedges, R., and Higham, T. F. G., 2010. "Improved AMS 14C Dating of Shell Carbonates Using High-Precision X-Ray Diffraction and a Novel Density Separation Protocol (CarDS)." Radiocarbon, 52:735-751.

Dusseldorp, G. L., 2012. "Tracking the influence of technological change on Middle Stone Age hunting strategies in South Africa." Quaternary International, 270:70-79.

Dusseldorp, G. L. and Langejans, G. H., 2013. "Carry that weight: coastal foraging and transport of marine resources during the South African Middle Stone Age." Southern African Humanities, 25:105-135.

Dyez, K. A., Zahn, R., and Hall, I. R., 2014. "Multicentennial Agulhas leakage variability and links to North Atlantic climate during the past 80000 years." Paleoceanography, 29(12):1238-1248.

Emiliani, C., Cardini, L., Mayeda, T., McBurney, C., and Tongiorgi, E., 1964. "Paleotemperature analysis of fossil shells of marine mollusks (food refuse) from the Arene 
Candide Cave, Italy, and the Haua Fteah Cave, Cyrenaica." Isotopic and cosmic chemistry, 11:133-156.

Emiliani, C. and Mayeda, T., 1964. "Oxygen isotopic analysis of some molluscan shells from fossil littoral deposits of Pleistocene age." American Journal of Science, 262(1):107-113.

Epstein, S., Buchsbaum, R., Lowenstam, H. A., and Urey, H., 1951. "Carbonate-water isotopic temperature scale." Geological Society of America Bulletin, 62:417-426.

Epstein, S., Buchsbaum, R., Lowenstam, H. A., and Urey, H., 1953. "Revised carbonatewater isotopic temperature scale." Geological Society of America Bulletin, 64:13151326.

Epstein, S. and Lowenstam, H. A., 1953. "Temperature-Shell-Growth Relations of Recent and Interglacial Pleistocene Shoal-Water Biota from Bermuda." The Journal of Geology, 61:424-438.

Epstein, S. and Mayeda, T., 1953. "Variation of O18 content of waters from natural sources." Geochimica et Cosmochimica Acta, 4(5):213-224.

Erlandson, J. M., 2001. "The Archaeology of Aquatic Adaptations: Paradigms for a New Millennium." Journal of Archaeological Research, 9(4):287-350.

Fairhall, A., Young, A., and Erickson, J., 1976. "University of Washington Dates IV." Radiocarbon, 18:221-239.

Faith, J. T., 2013. "Ungulate diversity and precipitation history since the Last Glacial Maximum in the Western Cape, South Africa." Quaternary Science Reviews, 68:191199.

Fauchereau, N., Pohl, B., Reason, C., Rouault, M., and Richard, Y., 2008. "Recurrent daily OLR patterns in the Southern Africa/Southwest Indian Ocean region, implications for South African rainfall and teleconnections." Climate Dynamics, $32(4): 575-591$.

Faylona, M. G. P. G., Lazareth, C. E., Sémah, A.-M., Caquineau, S., Boucher, H., and Ronquillo, W. P., 2011. "Preliminary study on the preservation of giant clam (Tridacnidae) shells from the Balobok Rockshelter archaeological site, south Philippines." Geoarchaeology, 26(6):888-901.

Feathers, J., 2002. "Luminescence dating in less than ideal conditions: case studies from Klasies River main site and Duinefontein, South Africa." Journal of Archaeological Science, 29:177-194.

Fenger, T., Surge, D., Schöne, B. R., and Milner, N., 2007. "Sclerochronology and geochemical variation in limpet shells (Patella vulgata): A new archive to reconstruct coastal sea surface temperature." Geochemistry, Geophysics, Geosystems, 8(7). 
Ferguson, J. E., Fa, D., Atkinson, T., Barton, R., Ditchfield, P., Henderson, G., and Finlayson, J., 2006. "High resolution climate records from stable isotopes and trace metals in mollusc shells from Gibraltar." Geochimica et Cosmochimica Acta, 70(18):A170.

Ferguson, J. E., Henderson, G. M., Fa, D. A., Finlayson, J. C., and Charnley, N. R., 2011. "Increased seasonality in the Western Mediterranean during the last glacial from limpet shell geochemistry." Earth and Planetary Science Letters, 308(3):325-333.

Fisher, E. C., Akkaynak, D., Harris, J., Herries, A. I., Jacobs, Z., Karkanas, P., Marean, C. W., and McGrath, J. R., 2015. "Technical considerations and methodology for creating high-resolution, color-corrected, and georectified photomosaics of stratigraphic sections at archaeological sites." Journal of Archaeological Science, 57:380-394.

Fisher, E. C., Bar-Matthews, M., Jerardino, A., and Marean, C. W., 2010. "Middle and Late Pleistocene paleoscape modeling along the southern coast of South Africa." Quaternary Science Reviews, 29(11):1382-1398.

Fitzhugh, B., 2001. "Risk and Invention in Human Technological Evolution." Journal of Anthropological Archaeology, 20(2):125-167.

Foster, G., 1997. Growth, reproduction and feeding biology of Turbo sarmaticus (Mollusca: Vetigastropoda) along the coast of the Eastern Cape Province of South Africa. Phd, Rhodes University.

Foster, L. C., Andersson, C., Hoie, H., Allison, N., Finch, A. A., and Johansen, T., 2008. "Effects of micromilling on d $18 \mathrm{O}$ in biogenic aragonite." Geochemistry, Geophysics, Geosystems, 9(4).

Galimberti, M., 2010. Investigating the use of oxygen and carbon isotopes and sclerochronology on Turbo sarmaticus and Donax serra for palaeoenvironment reconstruction at Pinnacle Point, South Africa. Phd, University of Cape Town.

Gasse, F., Chalié, F., Vincens, A., Williams, M. A. J., and Williamson, D., 2008. "Climatic patterns in equatorial and southern Africa from 30,000 to 10,000 years ago reconstructed from terrestrial and near-shore proxy data." Quaternary Science Reviews, 27(25-26):2316-2340.

Gill, I., Olson, J. J., and Hubbard, D. K., 1995. "Corals, paleotemperature records, and the aragonite-calcite transformation." Geology, 23(4):333-336.

Gillikin, D. P., De Ridder, F., Ulens, H., Elskens, M., Keppens, E., Baeyens, W., and Dehairs, F., 2005. "Assessing the reproducibility and reliability of estuarine bivalve shells (Saxidomus giganteus) for sea surface temperature reconstruction: Implications for paleoclimate studies." Palaeogeography, Palaeoclimatology, Palaeoecology, 228(12):70-85.

Goodwin, A. and van Riet Lowe, C., 1929. "The Stone Age Cultures of South Africa." 
Annals of the South African Museum, (27):1-146.

Green, C., 2011. "It's about time: temporality and intra-site GIS." In Proceedings of the 36th CAA Conference 2008, edited by E. Jerem, F. Redo, and V. Szeverenyi, 213-218. Budapest: Archaeolingua.

Griffiths, C. and Branch, G., 1997. "The exploitation of coastal invertebrates and seaweeds in South Africa: historical trends, ecological impacts and implications for management." Transactions of the Royal Society of South Africa, 52(1):121-148.

Griffiths, P. and de Haseth, J., 2007. Fourier Transform Infrared Spectroscopy. Hoboken, New Jersey: Wiley \& Sons, Inc., 2nd edition.

Gröcke, D. R. and Gillikin, D. P., 2008. "Advances in mollusc sclerochronology and sclerochemistry: tools for understanding climate and environment." Geo-Marine Letters, 28(5-6):265-268.

Grossman, E. and Ku, T., 1986. "Oxygen and carbon isotope fractionation in biogenic aragonite: temperature effects." Chemical Geology: Isotope Geoscience Section, 59:5974 .

Grottoli, A. G., Rodrigues, L. J., Matthews, K. A., Palardy, J. E., and Gibb, O. T., 2005. "Pre-treatment effects on coral skeletal d13C and d18O." Chemical Geology, 221(3-4):225-242.

Grün, R. and Beaumont, P., 2001. "Border Cave revisited: a revised ESR chronology." Journal of Human Evolution, 40(6):467-82.

Gulley-Stahl, H. J., Haas, J. A., Schmidt, K. A., Evan, A. P., and Sommer, A. J., 2009. "Attenuated total internal reflection Fourier transform infrared spectroscopy: a quantitative approach for kidney stone analysis." Applied spectroscopy, 63(7):759-66.

Hall, S., 2000. "Burial and sequence in the Later Stone Age of the Eastern Cape Province, South Africa." The South African Archaeological Bulletin, 55(172):137-146.

Helmy, R., Zhou, G. X., Chen, Y. W., Crocker, L., Wang, T., Wenslow, R. M., and Vailaya, A., 2003. "Characterization and Quantitation of Aprepitant Drug Substance Polymorphs by Attenuated Total Reflectance Fourier Transform Infrared Spectroscopy." Analytical Chemistry, 75(3):605-611.

Henrich, J., 2004. "Demography and Cultural Evolution: How Adaptive Cultural Processes can Produce Maladaptive Losses: The Tasmanian Case." American Antiquity, $69(2): 197-214$.

Henshilwood, C. S., 1995. Holocene archaeology of the coastal Garcia State Forest, southern Cape, South Africa. Dphil thesis, University of Cambridge.

Henshilwood, C. S., 1996. "A revised chronology for pastoralism in southernmost Africa: new evidence of sheep at c. 2000 b.p. from Blombos Cave, South Africa." Antiquity, 
$70(270): 945-949$.

Henshilwood, C. S., 2008a. Holocene prehistory of the southern Cape. Excavations at Blombos Cave and Blombosfontein Nature Reserve. BAR International Series 1860. Cambridge: Cambridge Monographs in African Archaeology, 75.

Henshilwood, C. S., 2008b. "Winds of Change: Palaeoenvironments, Material Culture and Human Behaviour In The Late Pleistocene ( 77 ka-48 ka ago) in the Western Cape Province, South Africa." Goodwin Series, 10:35-51.

Henshilwood, C. S., D’Errico, F., Vanhaeren, M., van Niekerk, K. L., and Jacobs, Z., 2004. "Middle stone age shell beads from South Africa." Science, 304:404.

Henshilwood, C. S., D'Errico, F., Yates, R., Jacobs, Z., Tribolo, C., Duller, G. A., Mercier, N., Sealy, J. C., Valladas, H., Watts, I., and Wintle, A. G., 2002. "Emergence of Modern Human Behavior: Middle Stone Age Engravings from South Africa." Science, 295:1278-1280.

Henshilwood, C. S. and Marean, C. W., 2003. "The origin of modern human behavior." Current anthropology, 44(5):627-51.

Henshilwood, C. S. and Sealy, J. C., 1997. "Bone artefacts from the Middle Stone Age at Blombos Cave, Southern Cape, South Africa." Current Anthropology, 38:890-895. Henshilwood, C. S., Sealy, J. C., Yates, R., Cruz-Uribe, K., Goldberg, P., Grine, F. E., Poggenpoel, C., van Niekerk, K. L., and Watts, I., 2001. "Blombos Cave, southern Cape, South Africa: preliminary report on the 1992 - 1999 excavations of the Middle Stone Age levels." Journal of Archaeological Science, 28:421-448.

Higham, T. F. G., Douka, K., Wood, R., Ramsey, C. B., Brock, F., Basell, L., Camps, M., Arrizabalaga, A., Baena, J., Barroso-Ruíz, C., Bergman, C., Boitard, C., Boscato, P., Caparrós, M., Conard, N. J., Draily, C., Froment, A., Galván, B., Gambassini, P., Garcia-Moreno, A., Grimaldi, S., Haesaerts, P., Holt, B., Iriarte-Chiapusso, M.J., Jelinek, A., Jordá Pardo, J. F., Maíllo-Fernández, J.-M., Marom, A., Maroto, J., Menéndez, M., Metz, L., Morin, E., Moroni, A., Negrino, F., Panagopoulou, E., Peresani, M., Pirson, S., de la Rasilla, M., Riel-Salvatore, J., Ronchitelli, A., Santamaria, D., Semal, P., Slimak, L., Soler, J., Soler, N., Villaluenga, A., Pinhasi, R., and Jacobi, R., 2014. "The timing and spatiotemporal patterning of Neanderthal disappearance." Nature, 512(7514):306-9.

Higham, T. F. G., Jacobi, R., and Ramsey, C., 2006. "AMS radiocarbon dating of ancient bone using ultrafiltration." Radiocarbon.

Hill, J. M., McQuaid, C., and Kaehler, S., 2006. "Biogeographic and nearshore-offshore trends in isotope ratios of intertidal mussels and their food sources around the coast of southern Africa." Marine Ecology Progress Series, 318:63-73. 
Hill, J. M. and McQuaid, C. D., 2008. " $\delta 13 \mathrm{C}$ and $\delta 15 \mathrm{~N}$ biogeographic trends in rocky intertidal communities along the coast of South Africa: Evidence of strong environmental signatures." Estuarine, Coastal and Shelf Science, 80(2):261-268.

Hoell, A., Funk, C., Magadzire, T., Zinke, J., and Husak, G., 2014. "El Niño-Southern Oscillation diversity and Southern Africa teleconnections during Austral Summer." Climate Dynamics, 45(5-6):1583-1599.

Hogg, A. G., Hua, Q., Blackwell, P. G., Niu, M., Buck, C. E., Guilderson, T. P., Heaton, T. J., Palmer, J. G., Reimer, P. J., Reimer, R. W., Turney, C. S. M., and Zimmerman, S. R. H., 2013. "SHCal13 Southern Hemisphere Calibration, 0-50,000 Years cal BP." Radiocarbon, 55(4):1889-1903.

Horsburgh, K., 2008. The origins of Southwestern African pastoralism: Addressing classic debates using ancient DNA. Phd, Stanford University.

Hudson, J. D. and Anderson, T. F., 1989. "Ocean temperatures and isotopic compositions through time." Transactions of the Royal Society of Edinburgh: Earth Sciences, 80(34):183-192.

Hutson, J. M., 2016. "The faunal remains from Bundu Farm and Pniel 6: Examining the problematic Middle Stone Age archaeological record within the southern African interior." Quaternary International.

Inskeep, R. R., 1987. Nelson Bay Cave, Cape Province, South Africa: the Holocene levels (Vol. 357). Oxford: British Archaeological Reports.

Inskeep, R. R. and Vogel, J. C., 1985. "Radiocarbon dates from the Holocene levels at Nelson Bay Cave, and an interim report on their associations." The South African Archaeological Bulletin, 40:103-105.

Jacobs, Z., Duller, G. A. T., Wintle, A. G., and Henshilwood, C. S., 2006. "Extending the chronology of deposits at Blombos Cave, South Africa, back to 140 ka using optical dating of single and multiple grains of quartz." Journal of Human Evolution, 51(3):255-73.

Jacobs, Z. and Roberts, R. G., 2008. "Testing times: old and new chronologies for the Howieson's Poort and Still Bay industries in environmental context." South African Archaeological Society Goodwin Series, 10:9-34.

Jacobs, Z. and Roberts, R. G., 2015. "An improved single grain OSL chronology for the sedimentary deposits from Diepkloof Rockshelter, Western Cape, South Africa." Journal of Archaeological Science, 63:175-192.

Jacobs, Z., Roberts, R. G., Galbraith, R. F., Deacon, H. J., Grün, R., Mackay, A., Mitchell, P., Vogelsang, R., and Wadley, L., 2008. "Ages for the Middle Stone Age of southern Africa: implications for human behavior and dispersal." Science, 
322(5902):733-5.

Janssen, C. I. F. and Kiliaan, A. J., 2014. "Long-chain polyunsaturated fatty acids (LCPUFA) from genesis to senescence: the influence of LCPUFA on neural development, aging, and neurodegeneration." Progress in lipid research, 53:1-17.

Jasco. "Application Note 02-03. Quantitative Analysis of Powdered Solids with FTIRATR."

Jerardino, A., 2010a. "Large shell middens in Lamberts Bay, South Africa: a case of hunter-gatherer resource intensification." Journal of Archaeological Science, 37:22912302.

Jerardino, A., 2010b. "Prehistoric Exploitation of Marine Resources in Southern Africa with Particular Reference to Shellfish Gathering: Opportunities and Continuities." Pyrenae, 41:7-52.

Jerardino, A., 2015. "Shell density as proxy for reconstructing prehistoric aquatic resource exploitation, perspectives from southern Africa." Journal of Archaeological Science: Reports, 6:637-644.

Jerardino, A., 2016. "On the origins and significance of Pleistocene coastal resource use in southern Africa with particular reference to shellfish gathering." Journal of Anthropological Archaeology, 41:213-230.

Jerardino, A., Branch, G., and Navarro., R., 2008. "Human impact on precolonial West Coast marine environments of South Africa." In Human impacts on marine environments, edited by J. Erlandson and T. Rick, 279-96. Berkeley: University of California Press.

Jerardino, A. and Marean, C. W., 2010. "Shellfish gathering, marine paleoecology and modern human behavior: perspectives from cave PP13B, Pinnacle Point, South Africa." Journal of Human Evolution, 59:412-424.

Jochelson, W., 1933. "History, ethnology and anthropology of the Aleut." In Carneige Institute of Washington No. 432. Washington, D.C.: W.F. Roberts.

Jury, M. R., 2015. "Passive Suppression of South African Rainfall by the Agulhas Current." Earth Interactions, 19(13):1-14.

Jury, M. R., Valentine, H. R., and Lutjeharms, J. R. E., 1993. "Influence of the Agulhas Current on Summer Rainfall along the Southeast Coast of South Africa." Journal of Applied Meteorology, 32(7):1282-1287.

Karkanas, P., Brown, K. S., Fisher, E. C., Jacobs, Z., and Marean, C. W., 2015. "Interpreting human behavior from depositional rates and combustion features through the study of sedimentary microfacies at site Pinnacle Point 5-6, South Africa." Journal of Human Evolution, 85:1-21. 
Keatings, K., Holmes, J., and Heaton, T. J., 2006. "Effects of pre-treatment on ostracod valve chemistry." Chemical Geology, 235(3-4):250-261.

Keith, M. and Parker, R., 1965. "Local variation of $13 \mathrm{C}$ and $18 \mathrm{O}$ content of mollusk shells and the relatively minor temperature effect in marginal marine environments." Marine Geology, 3(1):115-129.

Kelly, R., 1995. The foraging spectrum: Diversity in hunter-gatherer lifeways. Washington, D.C.: Smithsonian Institution Press.

Kendall, C. and Caldwell, E. A., 1998. "Fundamentals of Isotope Geochemistry." In Isotope Tracers in Catchment Hydrology, edited by C. Kendall and J. J. McDonnell, 51-86. Amsterdam: Elsevier B.V.

Kilburn, R. and Rippey, E., 1982. Sea Shells of Southern Africa. Johannesburg: Macmillan South Africa.

Klein, R. G., 1972. "The late quaternary mammalian fauna of Nelson Bay Cave (Cape Province, South Africa): Its implications for megafaunal extinctions and environmental and cultural change." Quaternary Research, 2(2):135-142.

Klein, R. G., 1976. "The mammalian fauna of the Klasies River Mouth sites, Southern Cape Province, South Africa." The South African Archaeological Bulletin, 31:75-98.

Klein, R. G., 2000. "Archeology and the evolution of human behavior." Evolutionary Anthropology: Issues, News, and Reviews, 9(1):17-36.

Klein, R. G., 2001. "Southern Africa and Modern Human Origins." Journal of Anthropological Research, 57(1):1-16.

Klein, R. G., 2008. "Out of Africa and the evolution of human behavior." Evolutionary Anthropology, 17(6):267-281.

Klein, R. G. and Bird, D., 2016. "Shellfishing and human evolution." Journal of Anthropological Archaeology, In Press.

Klein, R. G. and Cruz-Uribe, K., 2000. "Middle and Later Stone Age large mammal and tortoise remains from Die Kelders Cave 1, Western Cape Province, South Africa." Journal of Human Evolution, 38(1):169-95.

Klein, R. G. and Steele, T. E., 2013. "Archaeological shellfish size and later human evolution in Africa." Proceedings of the National Academy of Sciences of the United States of America, 110(27):10910-5.

Kristen, I., Fuhrmann, A., Thorpe, J., Rohl, U., Wilkes, H., and Oberhansli, H., 2007. "Hydrological changes in southern Africa over the last $200 \mathrm{Ka}$ as recorded in lake sediments from the Tswaing impact crater." South African Journal of Geology, 110:311-326.

Kuman, K., Inbar, M., and Clarke, R., 1999. "Palaeoenvironments and Cultural 
Sequence of the Florisbad Middle Stone Age Hominid Site, South Africa." Journal of Archaeological Science, 26(12):1409-1425.

Kyriacou, K., 2009. The reinvestigation of Hoffman's/Robberg Cave - the artefactual and shellfish assemblages. Mphil, University of Cape Town.

Kyriacou, K., Parkington, J. E., Marais, A. D., and Braun, D. R., 2014. "Nutrition, modernity and the archaeological record: Coastal resources and nutrition among Middle Stone Age hunter-gatherers on the western Cape coast of South Africa." Journal of Human Evolution, 77:64-73.

Kyriacou, K., Parkington, J. E., Will, M., Kandel, A. W., and Conard, N. J., 2015. "Middle and Later Stone Age shellfish exploitation strategies and coastal foraging at Hoedjiespunt and Lynch Point, Saldanha Bay, South Africa." Journal of Archaeological Science, 57:197-206.

Lambeck, K., Esat, T. M., and Potter, E.-K., 2002. "Links between climate and sea levels for the past three million years." Nature, 419(6903):199-206.

Lange, K., Perlès, C., Vanhaeren, M., and Reiche, I., 2008. "Heat-induced modification of marine shells used as personal ornaments at the prehistoric site of Franchthi Cave, Greece: first results of a multianalytical approach." In 9th International Conference on NDT of Art. Jerusalem, Israel.

Langejans, G. H., Dusseldorp, G. L., and Thackeray, J. F., 2016. "Pleistocene molluscs from Klasies River (South Africa): Reconstructing the local coastal environment." Quaternary International, In Press.

Langejans, G. H., Dusseldorp, G. L., van Niekerk, K. L., and Henshilwood, C. S., 2013. "A hazy shade of winter: Late Pleistocene environments and behavioural adaptations at Blombos Cave, South Africa." New Studies on Former and Recent Landscape Changes in Africa: Palaeoecology of Africa, 32:19 -44.

Langejans, G. H., van Niekerk, K., Dusseldorp, G. L., and Thackeray, J. F., 2012. "Middle Stone Age shellfish exploitation: Potential indications for mass collecting and resource intensification at Blombos Cave and Klasies River, South Africa." Quaternary International, 270:80-94.

LeGrande, A. N. and Schmidt, G., 2006. "Global gridded data set of the oxygen isotopic composition in seawater." Geophysical Research Letters, 33:L12604.

Lisiecki, L. E. and Raymo, M. E., 2005. "A Pliocene-Pleistocene stack of 57 globally distributed benthic $\delta 180$ records." Paleoceanography, 20(1):na-na.

Loftus, E., Rogers, K., and Lee-Thorp, J. A., 2015. "A simple method to establish calcite:aragonite ratios in archaeological mollusc shells." Journal of Quaternary Science, $30(8): 731-735$. 
Loftus, E., Sealy, J. C., and Lee-Thorp, J. A., 2016. "New Radiocarbon Dates and Bayesian Models for Nelson Bay Cave and Byneskranskop 1: Implications for the South African Later Stone Age Sequence." Radiocarbon, 58(2):365-381.

Lombard, A., Strauss, T., Harris, J., Sink, K., Attwood, C., and Hutchings, L., 2004. South African National Spatial Biodiversity Assessment 2004: Technical Report. Volume 4: Marine component. Pretoria: South African National Biodiversity Institute.

Lombard, M., 2012. "Thinking through the Middle Stone Age of sub-Saharan Africa." Quaternary International, 270:140-155.

Lombard, M. and Parsons, I., 2011. "What happened to the human mind after the Howiesons Poort?" Antiquity, 85:1433-1443.

Lombard, M., Wadley, L., Deacon, J., Wurz, S., Parsons, I., Mohapi, M., Swart, J., and Mitchell, P., 2012. "South African and Lesotho Stone Age sequence updated (I)." South African Archaeological Bulletin, 67:120-144.

Louisfert, J. and Pobbequin, T., 1952. "Differentiation of calcium carbonate by means of infrared absorption spectroscopy." Comptes Rendus de l'Académie des Sciences, 235:287-289.

Low, A. and Rebelo, A., 1996. Vegetation of South Africa, Lesotho and Swaziland.

Lowenstam, H. A., 1981. "Minerals formed by organisms." Science, 211(4487):1126-1131.

Lutjeharms, J. R. E., 2006. The Agulhas Current. Berlin, Heidelberg: Springer.

Mackay, A., 2009. History and selection in the in the Late Pleistocene archaeology of the Western Cape, South Africa. Phd, Australian National University.

Mackay, A., Stewart, B. A., and Chase, B. M., 2014. "Coalescence and fragmentation in the late Pleistocene archaeology of southernmost Africa." Journal of Human Evolution, $72: 26-51$.

Mannino, M. A., Spiro, B., and Thomas, K. D., 2003. "Sampling shells for seasonality: oxygen isotope analysis on shell carbonates of the inter-tidal gastropod Monodonta lineata (da Costa) from populations across its." Journal of Archaeological Science, 30(6):667-679.

Mannino, M. A., Thomas, K. D., and Leng, M., 2007. "Marine resources in the Mesolithic and Neolithic at the Grotta dell'Uzzo (Sicily): evidence from isotope analyses of marine shells." Archaeometry, 49(1):117-133.

Mannino, M. A., Thomas, K. D., Leng, M. J., and Sloane, H. J., 2008. "Shell growth and oxygen isotopes in the topshell Osilinus turbinatus: resolving past inshore sea surface temperatures." Geo-Marine Letters, 28(5-6):309-325.

Marean, C. W., 2010a. "Introduction to the Special Issue - The Middle Stone Age at 
Pinnacle Point Site 13B, a Coastal Cave near Mossel Bay (Western Cape Province, South Africa)." Journal of Human Evolution, 59:231-233.

Marean, C. W., 2010b. "Pinnacle point cave 13B (Western Cape Province, South Africa) in context: The cape floral kingdom, shellfish, and modern human origins." Journal of Human Evolution, 59:425-443.

Marean, C. W., 2011. "Coastal South Africa and the Coevolution of the Modern Human Lineage and the Coastal Adaptation." In Trekking the Shore: Changing Coastlines and the Antiquity of Coastal Settlement, edited by N. F. Bicho, J. A. Haws, and L. G. Davis. New York: Springer.

Marean, C. W., 2014. "The origins and significance of coastal resource use in Africa and Western Eurasia." Journal of Human Evolution, 77:17-40.

Marean, C. W., 2015. "An Evolutionary Anthropological Perspective on Modern Human Origins." Annual Review of Anthropology, 44(1):533-556.

Marean, C. W., 2016. "The transition to foraging for dense and predictable resources and its impact on the evolution of modern humans." Philosophical Transactions of the Royal Society of London. Series B: Biological Sciences., 371(1698):20150239.

Marean, C. W., Anderson, R. J., Bar-Matthews, M., Braun, K., Cawthra, H. C., Cowling, R. M., Engelbrecht, F., Esler, K. J., Fisher, E., Franklin, J., Hill, K., Janssen, M., Potts, A. J., and Zahn, R., 2015. "A new research strategy for integrating studies of paleoclimate, paleoenvironment, and paleoanthropology." Evolutionary Anthropology: Issues, News, and Reviews, 24(2):62-72.

Marean, C. W., Bar-Matthews, M., Bernatchez, J., Fisher, E., Goldberg, P., Herries, A. I. R., Jacobs, Z., Jerardino, A., Karkanas, P., Minichillo, T., Nilssen, P. J., Thompson, E., Watts, I., and Williams, H. M., 2007. "Early human use of marine resources and pigment in South Africa during the Middle Pleistocene." Nature, 449(7164):905-8.

Marean, C. W., Cawthra, H. C., Cowling, R. M., Esler, K. J., and De Vynck, J., 2014. "Stone Age people in a changing South African Greater Cape Floristic Region." In Fynbos: Ecology, Evolution, and Conservation of a Megadiverse Region, edited by N. Allsopp, J. F. Colville, and G. A. Verboom, 164. Oxford University Press.

Marean, C. W., Goldberg, P., Avery, G., Grine, F. E., and Klein, R. G., 2000. "Middle Stone Age stratigraphy and excavations at Die Kelders Cave 1 (Western Cape Province, South Africa): the 1992, 1993, and 1995 field seasons." Journal of Human Evolution, 38:7-42.

Mason, S. J., 1995. "Sea-surface temperature - South African rainfall associations, 1910-1989." International Journal of Climatology, 15(2):119-135.

Mayewski, P. A., Rohling, E. E., Curt Stager, J., Karlén, W., Maasch, K. A., David 
Meeker, L., Meyerson, E. A., Gasse, F., van Kreveld, S., Holmgren, K., Lee-Thorp, J. A., Rosqvist, G., Rack, F., Staubwasser, M., Schneider, R. R., and Steig, E. J., 2004. "Holocene climate variability." Quaternary Research, 62(3):243-255.

McBrearty, S. and Brooks, A. S., 2000. "The revolution that wasn't: a new interpretation of the origin of modern human behavior." Journal of Human Evolution, 39(5):453-563.

McCall, G. S., 2007. "Behavioral ecological models of lithic technological change during the later Middle Stone Age of South Africa." Journal of Archaeological Science, 34(10):1738-1751.

McGrath, J. R., Cleghorn, N., Gennari, B., Henderson, S., Kyriacou, K., Nelson-Viljoen, C., Nilssen, P., Richardson, L., Shelton, C., Wilkins, J., and Marean, C. W., 2015. "The pinnacle point shell midden complex: A mid-to late holocene record of later stone age coastal foraging along the Southern Cape Coast of South Africa." South African Archaeological Bulletin, 70(202):209-219.

McLachlan, A. and Lombard, H., 1980. "Seasonal variations in energy and biochemical components of an edible gastropod, Turbo sarmaticus (Turbinidae)." Aquaculture, 19:117-125.

Meadows, M. E. and Baxter, A., 2001. "Holocene vegetation history and palaeoenvironments at Klaarfontein Springs, Western Cape, South Africa." The Holocene, 11(6):699-706.

Meadows, M. E., Chase, B. M., and Seliane, M., 2010. "Holocene palaeoenvironments of the Cederberg and Swartruggens mountains, Western Cape, South Africa: Pollen and stable isotope evidence from hyrax dung middens." Journal of Arid Environments, $74(7): 786-793$.

Miller, G., Beaumont, P., Deacon, H. J., Brooks, A. S., Hare, P., and a.J.T. Jull, 1999.

"Earliest modern humans in southern Africa dated by isoleucine epimerization in ostrich eggshell." Quaternary Science Reviews, 18(13):1537-1548.

Milner, N., 2005. "Can seasonality studies be used to identify sedentism in the past?" In (Un)settling the Neolithic, edited by D. Bailey, V. Cummings, and A. Whittle, 32-37. Oxford: Oxbow Books.

Milo, R. G., 1998. "Evidence for Hominid Predation at Klasies River Mouth, South Africa, and its Implications for the Behaviour of Early Modern Humans." Journal of Archaeological Science, 25:99-133.

Mitchell, P., 1988. "The late Pleistocene early microlithic assemblages of southern Africa." World Archaeology, 20(1):27-39.

Mitchell, P., 1995. "Revisiting the Robberg: New results and a revision of old ideas at Sehonghong rock-shelter, Lesotho." South African Archaeological Bulletin, 50:28-38. 
Mitchell, P., 2000. "The organization of Later Stone Age lithic technology in the Caledon Valley, southern Africa." African archaeological review, 17:141-176.

Mitchell, P., 2002. The archaeology of southern Africa. Cambridge: Cambridge University Press.

Mitchell, P. and Vogel, J. C., 1994. "New radiocarbon dates from Sehonghong rock-shelter, Lesotho." South African Journal of Science, 90:284-288.

Oestmo, S., Schoville, B. J., Wilkins, J., and Marean, C. W., 2014. "A Middle Stone Age Paleoscape near the Pinnacle Point caves, Vleesbaai, South Africa." Quaternary International, 350:147-168.

Orton, J., 2006. "The Later Stone Age lithic sequence at Elands Bay, Western Cape, South Africa: raw materials, artefacts and sporadic change." Southern African Humanities, 18:1-28.

Pargeter, J. "Lithic miniaturization in Late Pleistocene southern Africa." Journal of Archaeological Science: Reports, In press.

Parkington, J. E., 1972. "Seasonal mobility in the late Stone Age." African Studies, 31:223-244.

Parkington, J. E., 1976. "Coastal settlement between the mouths of the Berg and Olifants Rivers, Cape Province." The South African Archaeological Bulletin, 31:127-140.

Parkington, J. E., 2003. "Middens and moderns: shellfishing and the Middle Stone Age of the Western Cape, South Africa." South African Journal of Science, 99(5/6):243.

Parkington, J. E., 2010. "Coastal diet, encephalization, and innovative behaviors in the late Middle Stone Age of southern Africa." In Human Brain Evolution: The Influence of Freshwater and Marine Food Resources, edited by S. Cunnane and K. Stewart. Hoboken, New Jersey: Wiley \& Sons, Inc.

Parkington, J. E., 2012. "Mussels and mongongo nuts: logistical visits to the Cape west coast, South Africa." Journal of Archaeological Science, 39(5):1521-1530.

Partridge, T. C., Demenocal, P. B., Lorentz, S., Paiker, M., and Vogel, J. C., 1997. "Orbital forcing of climate over South Africa: a 200,000-year rainfall record from the Pretoria Saltpan." Quaternary Science Reviews, 16:1125-1133.

Pfeiffer, S. and Sealy, J. C., 2006. "Body size among Holocene foragers of the Cape Ecozone, southern Africa." American Journal of Physical Anthropology, 129(1):1-11.

Pitcher, G. and Calder, D., 2000. "Harmful algal blooms from the southern Benguela Current: a review and appraisal of monitoring from 1989 to 1997." South African Journal of Marine Science, 22(1):255-271.

Planinsek, O., Planinsek, D., Zega, A., Breznik, M., and Srcic, S., 2006. "Surface analysis of powder binary mixtures with ATR FTIR spectroscopy." International Journal of 
Pharmaceutics, 319(1-2):13-9.

Pohl, B., Fauchereau, N., Richard, Y., Rouault, M., and Reason, C., 2008. "Interactions between synoptic, intraseasonal and interannual convective variability over Southern Africa." Climate Dynamics, 33(7-8):1033-1050.

Powell, A., Shennan, S., and Thomas, M. G., 2009. "Late Pleistocene demography and the appearance of modern human behavior." Science (New York, N. Y.), 324(5932):1298301.

Prendergast, A., Stevens, R. E., O’Connell, T., Fadlalak, A., Touati, M., Al-Mzeine, A., Schöne, B. R., Hunt, C., and Barker, G., 2015. "Changing patterns of eastern Mediterranean shellfish exploitation in the Late Glacial and Early Holocene: Oxygen isotope evidence from gastropod in Epipaleolithic to Neolithic human occupation layers at the Haua Fteah cave, Libya." Quaternary International, 407(Part B):80-93.

Proudfoot, L., 2006. Population structure, growth and recruitment of two exploited infralittoral molluscs (Haliotis midae and Turbo sarmaticus) along the south east coast, South Africa. Msc dissertation, Rhodes University.

Quick, L. J., Carr, A. S., Meadows, M. E., Boom, A., Bateman, M. D., Roberts, D. L., Reimer, P. J., and Chase, B. M., 2015a. "A late Pleistocene-Holocene multi-proxy record of palaeoenvironmental change from Still Bay, southern Cape Coast, South Africa." Journal of Quaternary Science, 30(8):870-885.

Quick, L. J., Chase, B. M., Meadows, M. E., Scott, L., and Reimer, P. J., 2011. "A 19.5kyr vegetation history from the central Cederberg Mountains, South Africa: Palynological evidence from rock hyrax middens." Palaeogeography, Palaeoclimatology, Palaeoecology, 309(3-4):253-270.

Quick, L. J., Meadows, M. E., Bateman, M. D., Kirsten, K. L., Mäusbacher, R., Haberzettl, T., and Chase, B. M., 2015b. "Vegetation and climate dynamics during the last glacial period in the fynbos-afrotemperate forest ecotone, southern Cape, South Africa." Quaternary International, 404(Part B):136-149.

Reason, C., 2001a. "Evidence for the Influence of the Agulhas Current on Regional Atmospheric Circulation Patterns." Journal of Climate, 14(12):2769-2778.

Reason, C., 2001b. "Subtropical Indian Ocean SST dipole events and southern African rainfall." Geophysical Research Letters, 28(11):2225-2227.

Rector, A. L. and Reed, K. E., 2010. "Middle and late Pleistocene faunas of Pinnacle Point and their paleoecological implications." Journal of Human Evolution, 59(3-4):340-57.

Rector, A. L. and Verrelli, B. C., 2010. "Glacial cycling, large mammal community composition, and trophic adaptations in the Western Cape, South Africa." Journal of Human Evolution, 58(1):90-102. 
Reimer, P. J., Baillie, M. G., Bard, E., Warren Beck, J., Blackwell, P. G., Buck, C. E., Burr, G. S., Lawrence Edwards, R., Friedrich, M., Guilderson, T. P., Hogg, A. G., Hughen, K. A., Kromer, B., McCormac, G., Manning, S., Reimer, R. W., Southon, J. R., Stuiver, M., van der Plicht, J., and Weyhenmeyer, C. E., 2006. "Comment on "Radiocarbon calibration curve spanning 0 to 50,000 years BP based on paired $230 \mathrm{Th} / 234 \mathrm{U} / 238 \mathrm{U}$ and $14 \mathrm{C}$ dates on pristine corals" by R.G. Fairbanks et al. (Quaternary Science Reviews 24 (2005) 1781-1796)." Quaternary Science Reviews, 25(7-8):855-862.

Reimer, P. J., Baillie, M. G. L., Bard, E., Bayliss, A., Beck, J. W., Blackwell, P. G., Bronk Ramsey, C., Buck, C. E., Burr, G. S., Edwards, R. L., Friedrich, M., Grootes, P. M., Guilderson, T. P., Hajdas, I., Heaton, T. J., Hogg, A. G., Hughen, K. A., Kaiser, K. F., Kromer, B., McCormac, F. G., Manning, S. W., Reimer, R. W., Richards, D. A., Southon, J. R., Talamo, S., Turney, C. S. M., van der Plicht, J., and Weyhenmeyer, C. E., 2009. "IntCal09 and Marine09 radiocarbon age calibration curves, 0-50,000 years cal BP." Radiocarbon, 51:1111-1150.

Reynolds, D. J., Richardson, C. A., Scourse, J. D., Butler, P. G., Wanamaker, A. D., Ridgway, I., Sayer, M. D., and Gulliver, P., 2013. "The potential of the marine bivalve mollusc Glossus humanus (L.) as a sclerochronological archive." The Holocene, 23(12):1711-1720.

Rightmire, P. and Deacon, H. J., 1991. "Comparative studies of Late Pleistocene human remains from Klasies River Mouth, South Africa." Journal of Human Evolution, 20:131-156.

Rightmire, P. and Deacon, H. J., 2001. "New human teeth from Middle Stone Age deposits at Klasies River, South Africa." Journal of Human Evolution, 41:535-544.

Roberts, P., Henshilwood, C. S., van Niekerk, K. L., Keene, P., Gledhill, A., Reynard, J., Badenhorst, S., and Lee-Thorp, J. A., 2016. "Climate, Environment and Early Human Innovation: Stable Isotope and Faunal Proxy Evidence from Archaeological Sites (98-59ka) in the Southern Cape, South Africa." PloS one, 11(7):e0157408.

Rohling, E. J., 2000. "Paleosalinity: Confidence limits and future applications." Marine Geology, 163:1-11.

Sampson, C. G., 1974. The stone age archaeology of Southern Africa. New York: Academic Press.

Sarkar, A., Ramesh, R., and Bhattacharya, S., 1990. "Effect of sample pretreatment and size fraction on the d18 O and d13 C values of foraminifera in Arabian Sea sediments." Terra Nova, 2(5):488-493.

Sauer, C., 1961. "Sedentary and mobile bents in early societies." In Social life of early 
man, edited by S. Washburn. Chicago: Aldine.

Scholtz, A., 1986. Palynological and Palaeobotanical Studies in the Southern Cape. Ma thesis, University of Stellenbosch.

Scholz, C., Johnson, T., Cohen, A. S., King, J. W., Peck, J. A., Overpeck, J. T., Talbot, M. R., Brown, E. T., Kalindekafe, L., Amoako, P. Y. O., Lyons, R. P., Shanahan, T. M., Castañeda, I. S., Heil, C. W., Forman, S. L., McHargue, L. R., Beuning, K. R., Gomez, J., and Pierson, J., 2007. "East African megadroughts between 135 and 75 thousand years ago and bearing on early-modern human origins." Proceedings of the National Academy of Sciences, 104:16416-16421.

Schöne, B. R., 2008. "The curse of physiology - challenges and opportunities in the interpretation of geochemical data from mollusk shells." Geo-Marine Letters, 28(56):269-285.

Schöne, B. R., Fiebig, J., Pfeiffer, M., Gle $\beta$, R., Hickson, J., Johnson, A. L., Dreyer, W., and Oschmann, W., 2005. "Climate records from a bivalved Methuselah (Arctica islandica, Mollusca; Iceland)." Palaeogeography, Palaeoclimatology, Palaeoecology, 228:130-148.

Schumann, E., 1999. "Wind-driven mixed layer and coastal upwelling processes off the south coast of South Africa." Journal of Marine Research, 57:671-691.

Schumann, E., Cohen, A., and Jury, M. R., 1995. "Coastal sea surface temperature variability along the south coast of South Africa and the relationship to regional and global climate." Journal of Marine Research, 53(2):231-248.

Schumann, E., Perrins, L., and Hunter, I., 1982. "Upwelling along the south coast of the Cape Province, South Africa." South African Journal of Science, 78:238-242.

Schweitzer, F. R. and Wilson, M., 1978. "A preliminary report on excavations at Byneskranskop, Bredasdorp District, Cape." South African Archaeological Bulletin, 33(128):134-140.

Schweitzer, F. R. and Wilson, M., 1982. "Byneskranskop 1: A Late Quaternary living site in the southern Cape Province." The Annals of the South African Museum, 88:1-102.

Scott, L. and Lee-Thorp, J. A., 2004. "Holocene climatic trends and rhythms in Southern Africa." In Past Climate Variability through Europe and Africa, edited by R. W. Battarbee, F. Gasse, and C. E. Stickley, 69-91. Amsterdam: Springer Netherlands.

Scott, L., Neumann, F., Brook, G., Bousman, C. B., Norström, E., and Metwally, A., 2012. "Terrestrial fossil-pollen evidence of climate change during the last 26 thousand years in Southern Africa." Quaternary Science Reviews, 32:100-118.

Scott, L. and Woodborne, S., 2007. "Vegetation history inferred from pollen in Late 
Quaternary faecal deposits (hyraceum) in the Cape winter-rain region and its bearing on past climates in South Africa." Quaternary Science Reviews, 26(7-8):941-953.

Sealy, J. C., 1996. "Seasonality of rainfall around the Last Glacial Maximum as reconstructed from carbon isotope analyses of animal bones from Nelson Bay Cave." South African Journal of Science, 92:441-444.

Sealy, J. C., 2006. "Diet, Mobility, and Settlement Pattern among Holocene HunterGatherers in Southernmost Africa." Current Anthropology, 47(4):569-595.

Sealy, J. C., 2016. "Cultural Change, Demography, and the Archaeology of the Last 100 kyr in Southern Africa." In Africa from MIS 6-2: Population Dynamics and Paleoenvironments, edited by S. Jones and B. A. Stewart. Dordrecht: Springer.

Sealy, J. C. and Galimberti, M., 2011. "Shellfishing and the interpretation of shellfish sizes in the Middle and Later Stone Ages of South Africa." In Trekking the Shore, 405-419. Springer.

Sealy, J. C. and van der Merwe, N. J., 1986. "Isotope Assessment and the SeasonalMobility Hypothesis in the Southwestern Cape of South Africa." Current Anthropology, $27(2): 135-150$.

Serrano, O., Serrano, L., and Mateo, M. A., 2008. "Effects of sample pre-treatment on the $\delta 13 \mathrm{C}$ and $\delta 18 \mathrm{O}$ values of living benthic foraminifera." Chemical Geology, 257(3-4):218-220.

Shackleton, N., 1967. "Oxygen isotope analyses and Pleistocene temperatures re-assessed." Nature, 215:15-17.

Shackleton, N., 1969. "Marine mollusca in archaeology." In Science in Archaeology, edited by D. Brothwell and E. Higgs, 407-414. New York, USA: Thames and Hudson.

Shackleton, N., 1973. "Oxygen isotope analysis as a means of determining season of occupation of prehistoric midden sites." Archaeometry, 38:133-141.

Shackleton, N., 1974. "Attainment of isotopic equilibrium between ocean water and the benthic foraminifera genus Uvigerina: isotopic changes in the ocean during the last glacial." Colloques Internationaux du C.N.R.S, 219:203-209.

Shackleton, N., 1982. "Stratigraphy and chronology of the KRM deposits: oxygen isotope evidence." In The Middle Stone Age at Klasies River Mouth in South Africa, edited by R. Singer and J. J. Wymer, 192-199. Chicago: University of Chicago.

Shackleton, N., 1987. "Oxygen isotopes, ice volume and sea level." Quaternary Science Reviews, 6:183-190.

Shackleton, N. and Opdyke, N., 1973. "Oxygen isotope and palaeomagnetic stratigraphy of Equatorial Pacific core V28-238: Oxygen isotope temperatures and ice volumes on a 105 year and 106 year scale." Quaternary research, 3:39-55. 
Shakun, J., Lea, D., Lisiecki, L., and Raymo, M., 2015. "An 800-kyr record of global surface ocean $\delta 18 \mathrm{O}$ and implications for ice volume-temperature coupling." Earth and Planetary Science Letters, 426:58-68.

Shennan, S., 2001. "Demography and Cultural Innovation: a Model and its Implications for the Emergence of Modern Human Culture." Cambridge Archaeological Journal, 11(0):5-16.

Simon, M. H., Arthur, K. L., Hall, I. R., Peeters, F. J., Loveday, B. R., Barker, S., Ziegler, M., and Zahn, R., 2013. "Millennial-scale Agulhas Current variability and its implications for salt-leakage through the Indian-Atlantic Ocean Gateway." Earth and Planetary Science Letters, 383:101-112.

Simon, M. H., Gong, X., Hall, I. R., Ziegler, M., Barker, S., Knorr, G., van der Meer, M. T. J., Kasper, S., and Schouten, S., 2015. "Salt exchange in the Indian-Atlantic Ocean Gateway since the Last Glacial Maximum: A compensating effect between Agulhas Current changes and salinity variations?" Paleoceanography, 30(10):1318-1327.

Singels, E., Potts, A. J., Esler, K. J., Cowling, R. M., Marean, C. W., and Vynck, J. C. D., 2015. "Foraging potential of underground storage organ plants in the southern Cape, South Africa." PeerJ PrePrints, 3:e1962.

Singer, R. and Wymer, J. J., 1982. The Middle Stone Age at Klasies River Mouth in South Africa. Chicago: University of Chicago.

Sire, J. and Bonnet, P., 1984. "Growth and structure of the calcified operculum of the Polynesian gastropod Turbo setosus(Prosobranchia: Turbinidae): Determination of individual age." Marine Biology, 79:75-87.

Slack, M., Fullagar, R., Field, J., and Border, A., 2004. "New Pleistocene ages for backed artefact technology in Australia." Archaeology in Oceania, 39:131-137.

South African Weather Service, 2014. "Climate data available on request: www.weathersa.co.za/climate."

Spragg, R., 2011. "Contact and Orientation Effects in FT-IR ATR Spectra." Spectroscopy Magazine, 28:s18-s27.

Steele, T. and Klein, R. G., 2008. "Intertidal shellfish use during the middle and later stone age of South Africa." Archaeofauna, 17:63-76.

Steele, T. E. and Klein, R. G., 2009. "Late Pleistocene subsistence strategies and resource intensification in Africa." In The evolution of hominin diets: integrating approaches to the study of Palaeolithic subsistence, edited by J.-J. Hublin and M. P. Richards. Dordrecht: Springer.

Stephens, M., Mattey, D., Gilbertson, D. D., and Murray-Wallace, C. V., 2008. "Shellgathering from mangroves and the seasonality of the Southeast Asian Monsoon using 
high-resolution stable isotopic analysis of the tropical estuarine bivalve (Geloina erosa) from the Great Cave of Niah, Sarawak: methods and reconnaissance of molluscs." Journal of Archaeological Science, 35(10):2686-2697.

Stiner, M. C. and Kuhn, S. L., 2006. "Changes in the 'Connectedness' and Resilience of Paleolithic Societies in Mediterranean Ecosystems." Human Ecology, 34(5):693-712.

Stiner, M. C., Munro, N. D., and Surovell, T. A., 2000. "The Tortoise and the Hare: Small-Game Use, the Broad-Spectrum Revolution, and Paleolithic Demography." Current Anthropology, 41(1):39-79.

Stringer, C., 2000. "Palaeoanthropology. Coasting out of Africa." Nature, 405(6782):24-5, 27.

Surge, D. and Barrett, J., 2012. "Marine climatic seasonality during medieval times (10th to 12th centuries) based on isotopic records in Viking Age shells from Orkney, Scotland." Palaeogeography, Palaeoclimatology, Palaeoecology, 350:236-246.

Swart, P. K., Leder, J., Gill, I., Olson, J. J., and Hubbard, D. K., 1996. "Corals, paleotemperature records, and the aragonite-calcite transformation: Comment and Reply." Geology, 24(1):91-93.

Talma, S. A., Donner, J., and Ellis, S., 1992. "Stable isotopic composition of marine shells along the Southern African coast." South African Journal of Science, 88:499-504.

Tarutani, T., Clayton, R. N., and Mayeda, T. K., 1969. "The effect of polymorphism and magnesium substitution on oxygen isotope fractionation between calcium carbonate and water." Geochimica et Cosmochimica Acta, 33(8):987-996.

Taylor, R. and Bar-Yosef, O., 2014. Radiocarbon Dating: an Archaeological Perspective. Walnut Creek, CA: Left Coast Press, 2nd edition.

Teske, P. R., Papadopoulos, I., McQuaid, C. D., Newman, B. K., and Barker, N. P., 2007. "Climate change, genetics or human choice: why were the shells of mankind's earliest ornament larger in the Pleistocene than in the Holocene?" PloS one, 2(7):e614. Thackeray, J. F., 1988. "Molluscan fauna from Klasies River, South Africa." The South African Archaeological Bulletin, 43:27-32.

Thomas, D. S. and Shaw, P., 2002. "Late Quaternary environmental change in central southern Africa: new data, synthesis, issues and prospects." Quaternary Science Reviews, 21(7):783-797.

Thomas, K. D., 2015a. "Molluscs emergent, Part I: themes and trends in the scientific investigation of mollusc shells as resources for archaeological research." Journal of Archaeological Science, 56:133-140.

Thomas, K. D., 2015b. "Molluscs emergent, Part II: themes and trends in the scientific investigation of molluscs and their shells as past human resources." Journal of 
Archaeological Science, 56:159-167.

Thompson, J. C., 2010. "Variability in Middle Stone Age faunal exploitation and use of the physical and social landscapes in the southwestern Cape, South Africa." In Settlement dynamics of the Middle Paleolithic and Middle Stone Age, Vol. 3, edited by A. Delagnes and N. J. Conard. Tuebingen: Kerns Verlag.

Thompson, J. C. and Henshilwood, C. S., 2011. "Taphonomic analysis of the Middle Stone Age larger mammal faunal assemblage from Blombos Cave, southern Cape, South Africa." Journal of Human Evolution, 60(6):746-67.

Tierney, J. E., Lewis, S. C., Cook, B. I., LeGrande, A. N., and Schmidt, G. A., 2011. "Model, proxy and isotopic perspectives on the East African Humid Period." Earth and Planetary Science Letters, 307(1-2):103-112.

Tobin, T. S., Schauer, A. J., and Lewarch, E., 2011. "Alteration of micromilled carbonate $\delta 180$ during Kiel Device analysis." Rapid communications in mass spectrometry, 25(15):2149-52.

Trauth, M., Larrasoaña, J., and Mudelsee, M., 2009. "Trends, rhythms, and events in Plio-Pleistocene African climate." Quaternary Science Reviews, 28:399-411.

Tribolo, C., Mercier, N., Douville, E., Joron, J.-L., Reyss, J.-L., Rufer, D., Cantin, N., Lefrais, Y., Miller, C., Porraz, G., Parkington, J. E., Rigaud, J.-P., and Texier, P.-J., 2013. "OSL and TL dating of the Middle Stone Age sequence at Diepkloof Rock Shelter (South Africa): a clarification." Journal of Archaeological Science, 40(9):3401-3411.

Tribolo, C., Valladas, N. M. H., Joron, J., Guibert, P., Lefrais, Y., Selo, M., Texier, P.-J., Rigaud, J.-P., Porraz, G., Poggenpoel, C., Parkington, J. E., Texier, J.-P., and Lenoble, A., 2009. "Thermoluminescence dating of a Stillbay-Howiesons Poort sequence at Diepkloof Rock Shelter (Western Cape, South Africa)." Journal of Archaeological Science, 36(3):730-739.

Truc, L., Chevalier, M., Favier, C., Cheddadi, R., Meadows, M. E., Scott, L., Carr, A. S., Smith, G. F., and Chase, B. M., 2013. "Quantification of climate change for the last 20,000years from Wonderkrater, South Africa: Implications for the long-term dynamics of the Intertropical Convergence Zone." Palaeogeography, Palaeoclimatology, Palaeoecology, 386:575-587.

Tyson, P. D., 1986. Climatic Change and Variability in Southern Africa. Cape Town: Oxford University Press.

Tyson, P. D. and Preston-Whyte, R., 2000. The weather and climate of southern Africa. Cape Town: Oxford University Press.

Urey, H., 1948. "Oxygen isotopes in nature and in the laboratory." Science, 108:489-496. Urey, H., Lowenstam, H. A., Epstein, S., and McKinney, C. R., 1951. "Measurement of 
paleotemperatures and temperatures of the Upper Cretaceous of England, Denmark, and the southeastern United States." Geological Society of America Bulletin, 62(4):399. Vaesen, K., Collard, M., Cosgrove, R., and Roebroeks, W., 2016. "Population size does not explain past changes in cultural complexity." Proceedings of the National Academy of Sciences of the United States of America, 113(16):E2241-2247.

Valsecchi, V., Chase, B. M., Slingsby, J., Carr, A. S., Quick, L. J., Meadows, M. E., Cheddadi, R., and Reimer, P. J., 2013. "A high resolution 15,600- year pollen and microcharcoal record from the Cederberg Mountains, South Africa." Palaeogeography, Palaeoclimatology, Palaeoecology, 387:6-16.

van Andel, T. H., 1989. "Late Pleistocene Sea Levels and the Human Exploitation of the Shore and Shelf of Southern South Africa." Journal of Field Archaeology, $16(2): 133-155$.

van Pletzen, L., 2000. The large mammal fauna from Klasies River. Ma, University of Stellenbosch.

Van Zinderen Bakker, E., 1967. "Upper Pleistocene and Holocene stratigraphy and ecology on the basis of vegetation changes in sub-Saharan Africa." In Background to Evolution in Africa, edited by W. Bishop and J. Clark, 125-147. Chicago: University of Chicago.

Villa, P., Soriano, S., Teyssandier, N., and Wurz, S., 2010. "The Howiesons Poort and MSA III at Klasies River main site, Cave 1A." Journal of Archaeological Science, 37:630-655.

Villa, P., Soriano, S., Tsanova, T., Degano, I., Higham, T. F. G., D’Errico, F., Backwell, L., Lucejko, J. J., Comas, D., and Beaumont, P., 2012. "Border Cave and the beginning of the Later Stone Age in South Africa." Proceedings of the National Academy of Sciences of the United States of America, 109:13208-13213.

Vogelsang, R., Richter, J., Jacobs, Z., Eichhorn, B., Linseele, V., and Roberts, R. G., 2010. "New excavations of Middle Stone Age deposits at Apollo 11 Rockshelter, Namibia: stratigraphy, archaeology, chronology and past environments." Journal of African Archaeology, 8(2):185-218.

Voigt, E., 1973. "Stone Age molluscan utilization at Klasies River mouth caves." South African Journal of Science, 69(10):306-309.

Voigt, E., 1982. "The molluscan fauna." In The Middle Stone Age at Klasies River Mouth in South Africa, edited by R. Singer and J. J. Wymer, 155-186. Chicago: University of Chicago.

Volman, T. P., 1978. "Early Archaeological Evidence for Shellfish Collecting." Science, 201(4359):911-913. 
Wadley, L., 1996. "The Robberg Industry of Rose Cottage Cave: The technology, spatial patterns and environment." South African Archaeological Bulletin, 51(164):64-74.

Wadley, L., 2013. "Recognizing Complex Cognition through Innovative Technology in Stone Age and Palaeolithic Sites." Cambridge Archaeological Journal, 23(2):163-183. Waelbroeck, C., Labeyrie, L., Michel, E., Duplessy, J. C., McManus, J. F., Lambeck, K., Balbon, E., and Labracherie, M., 2002. "Sea-level and deep water temperature changes derived from benthic foraminifera isotopic records." Quaternary Science Reviews, 21:295-305.

Walker, M., Berkelhammer, M., Björck, S., Cwynar, L. C., Fisher, D. A., Long, A. J., Lowe, J. J., Newnham, R. M., Rasmussen, S. O., and Weiss, H., 2012. "Formal subdivision of the Holocene Series/Epoch: a Discussion Paper by a Working Group of INTIMATE (Integration of ice-core, marine and terrestrial records) and the Subcommission on Quaternary Stratigraphy (International Commission on Stratigraphy)." Journal of Quaternary Science, 27(7):649-659.

Walker, N. D., 1986. "Satellite observations of the Agulhas Current and episodic upwelling south of Africa." Deep Sea Research Part A. Oceanographic Research Papers, 33(8):1083-1106.

Walker, N. D., 1990. "Links between South African summer rainfall and temperature variability of the Agulhas and Benguela Current systems." Journal of Geophysical Research, 95(C3):3297.

Walter, R. C., Buffler, R. T., Bruggemann, J. H., Guillaume, M. M., Berhe, S. M., Negassi, B., Libsekal, Y., Cheng, H., Edwards, R. L., von Cosel, R., Néraudeau, D., and Gagnon, M., 2000. "Early human occupation of the Red Sea coast of Eritrea during the last interglacial." Nature, 405(6782):65-9.

Wanner, H., Beer, J., Bütikofer, J., Crowley, T. J., Cubasch, U., Flückiger, J., Goosse, H., Grosjean, M., Joos, F., Kaplan, J. O., Küttel, M., Müller, S. A., Prentice, I. C., Solomina, O., Stocker, T. F., Tarasov, P., Wagner, M., and Widmann, M., 2008. "Mid- to Late Holocene climate change: an overview." Quaternary Science Reviews, 27(19-20):1791-1828.

Wanner, H., Solomina, O., Grosjean, M., Ritz, S. P., and Jetel, M., 2011. "Structure and origin of Holocene cold events." Quaternary Science Reviews, 30(21-22):3109-3123.

Waselkov, G., 1987. "Shellfish Gathering and Shell Midden Archaeology." Advances in Archaeological Method and Theory, 10:97-210.

Watanabe, T., Minagawa, M., Oba, T., and Winter, A., 2001. "Pretreatment of coral aragonite for $\mathrm{Mg}$ and $\mathrm{Sr}$ analysis: Implications for coral thermometers." Geochemical Journal, 35:265-269. 
Weiner, S. and Dove, P., 2003. "An overview of biomineralization processes and the problem of the vital effect." Reviews in Mineralogy and Geochemistry, 54:1-29.

Wendt, W., 1976. "'Art Mobilier'from the Apollo 11 Cave, South West Africa: Africa's Oldest Dated Works of Art." The South African Archaeological Bulletin, 31:5-11.

Wierzbowski, H., 2007. "Effects of pre-treatments and organic matter on oxygen and carbon isotope analyses of skeletal and inorganic calcium carbonate." International Journal of Mass Spectrometry, 268(1):16-29.

Will, M., Bader, G., and Conard, N. J., 2014a. "Characterizing the Late Pleistocene MSA Lithic Technology of Sibudu, KwaZulu-Natal, South Africa." PLoS One, 9(5):e98359. Will, M., Kandel, A. W., and Conard, N. J., 2014b. "Coastal adaptations and settlement systems on the Cape and Horn of Africa during the Middle Stone Age." In Settlement dynamics of the Middle Paleolithic and Middle Stone Age, edited by N. J. Conard and A. Delagnes, volume 4, 61-89. Tuebingen: Kerns Verlag.

Will, M., Kandel, A. W., Kyriacou, K., and Conard, N. J., 2015. "An evolutionary perspective on coastal adaptations by modern humans during the Middle Stone Age of Africa." Quaternary International, 404(Part B):68-86.

Woillez, M.-N., Levavasseur, G., Daniau, A.-L., Kageyama, M., Urrego, D. H., SánchezGoñi, M.-F., and Hanquiez, V., 2014. "Impact of precession on the climate, vegetation and fire activity in southern Africa during MIS4." Climate of the Past, 10(3):1165-1182.

Wrangham, R. W., Jones, J. H., Laden, G., Pilbeam, D., and Conklin-Brittain, N., 1999. "The Raw and the Stolen: Cooking and the Ecology of Human Origins." Current Anthropology, 40(5):567-594.

Wurz, S., 1999. "The Howiesons Poort backed artefacts from Klasies River: an argument for symbolic behaviour." The South African Archaeological Bulletin, 54(169):38-50.

Wurz, S., 2000. The Middle Stone Age at Klasies River, South Africa. Phd thesis, University of Stellenbosch.

Wurz, S., 2002. "Variability in the middle stone age lithic sequence, 115,000-60,000 years ago at Klasies river, South Africa." Journal of Archaeological Science, 29:1001-1015.

Wurz, S., 2013. "Technological Trends in the Middle Stone Age of South Africa between MIS 7 and MIS 3." Current Anthropology, 54(S8):S305-S319.

Yesner, D., 1980. "Maritime Hunter-Gatherers: Ecology and Prehistory." Current Anthropology, 21(6):727-750.

Ziegler, M., Simon, M., Hall, I., Barker, S., Stringer, C. B., and Zahn, R., 2013. "Development of Middle Stone Age innovation linked to rapid climate change." Nature Communications, 4:1905.

Zomer, R., Bossio, D., Trabucco, A., Yuanjie, L., Gupta, D., and Singh, V., 2007. "Trees 
and Water: Smallholder Agroforestry on Irrigated Lands in Northern India, Colombo, Sri Lanka." Technical report, International Water Management Institute. 
Appendix A

\section{Raw data}




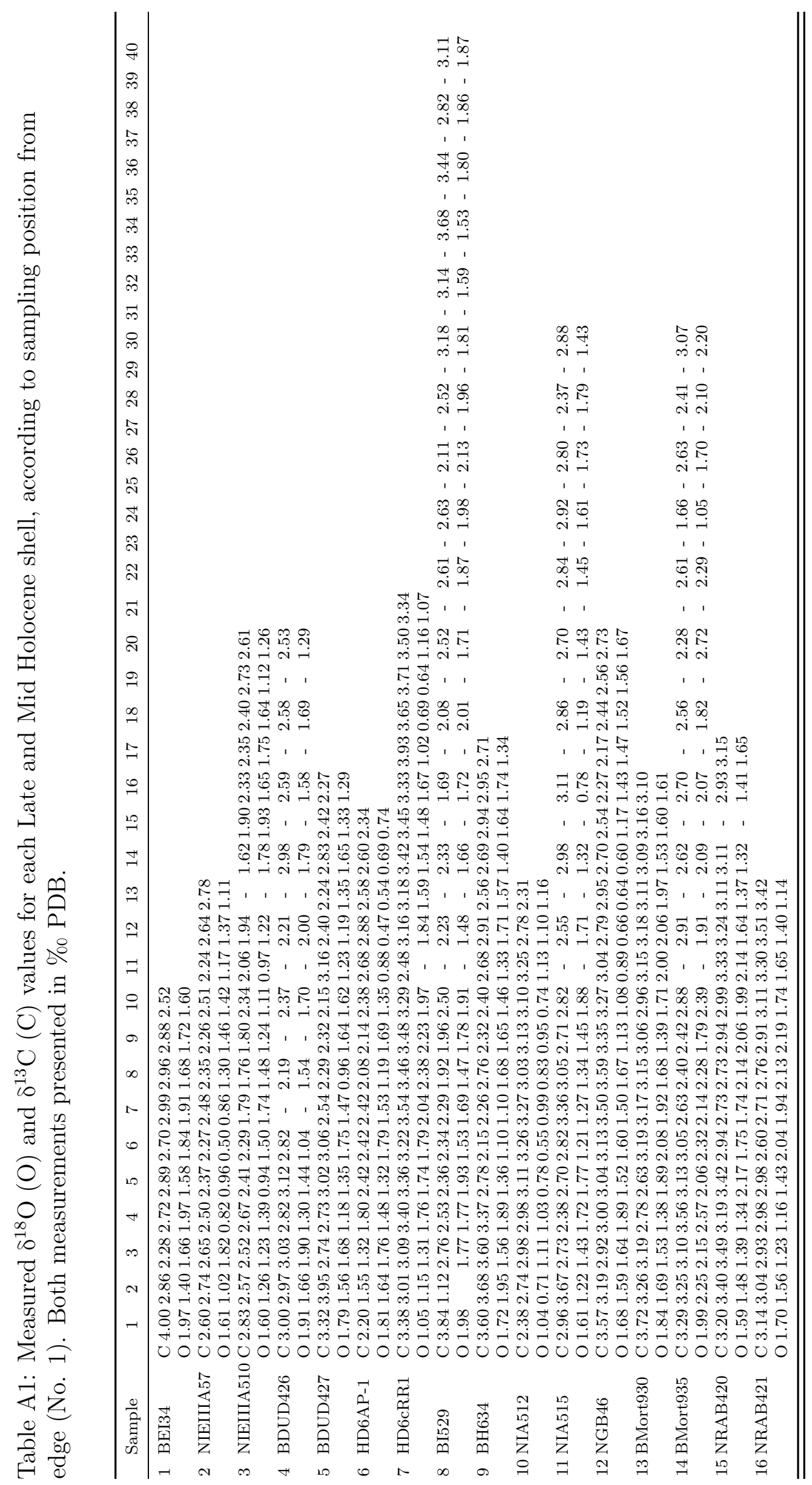




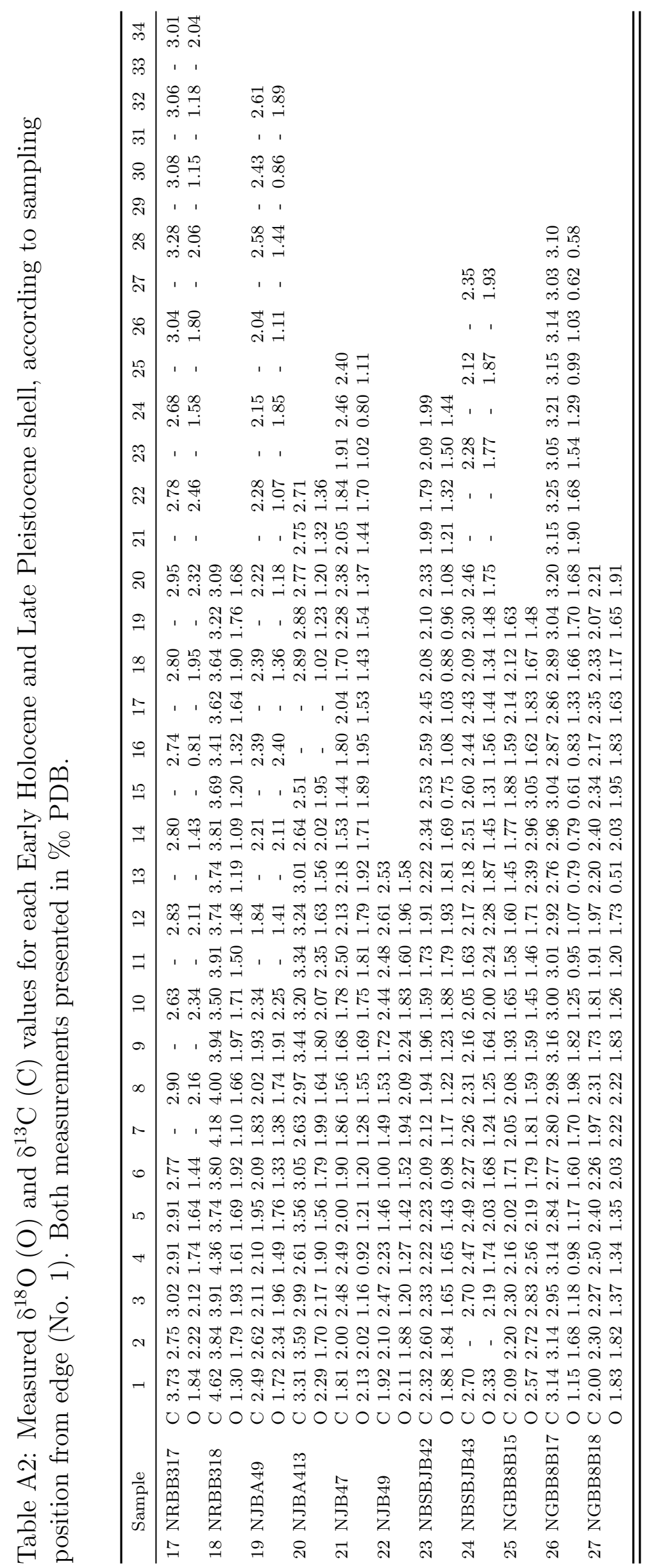




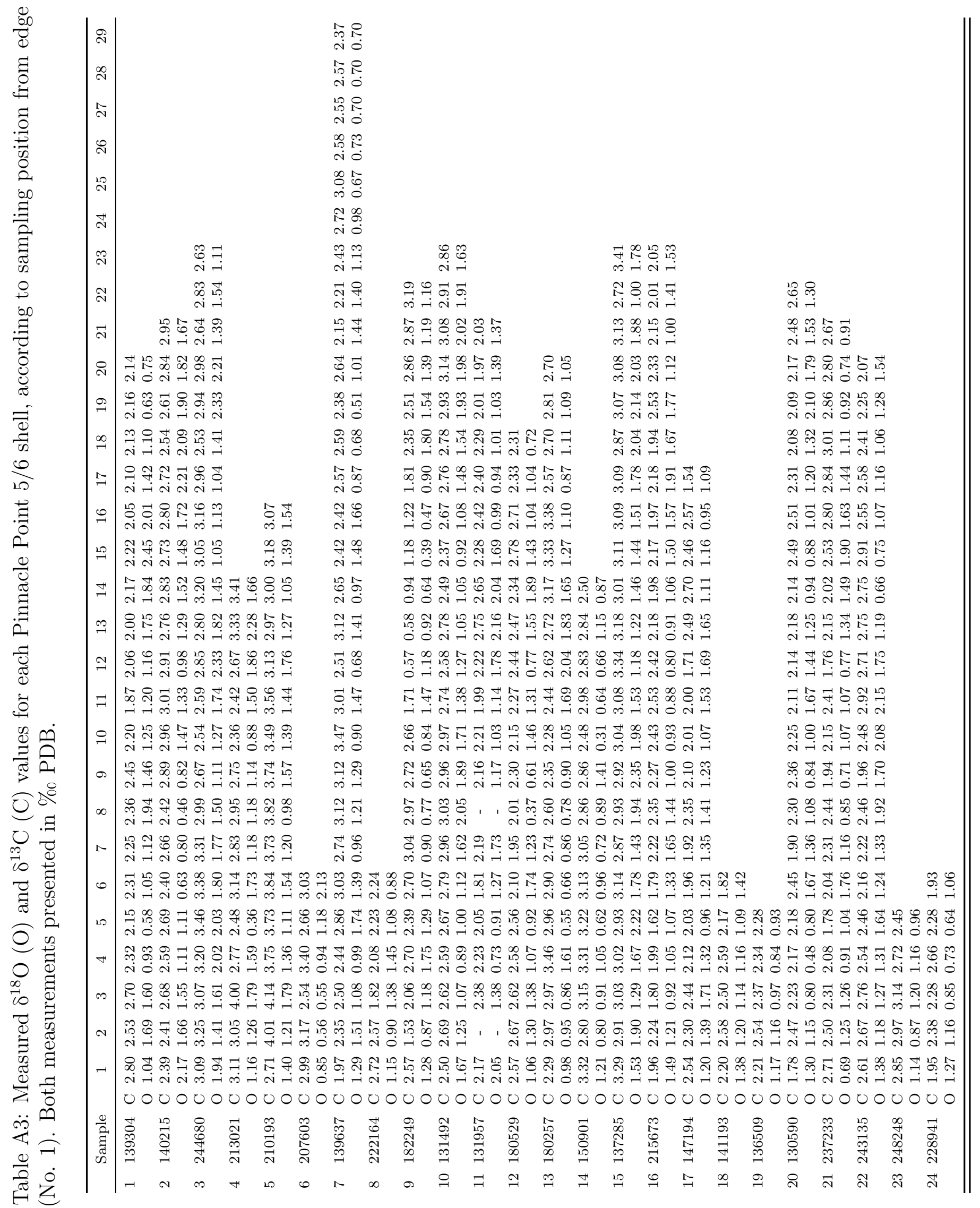




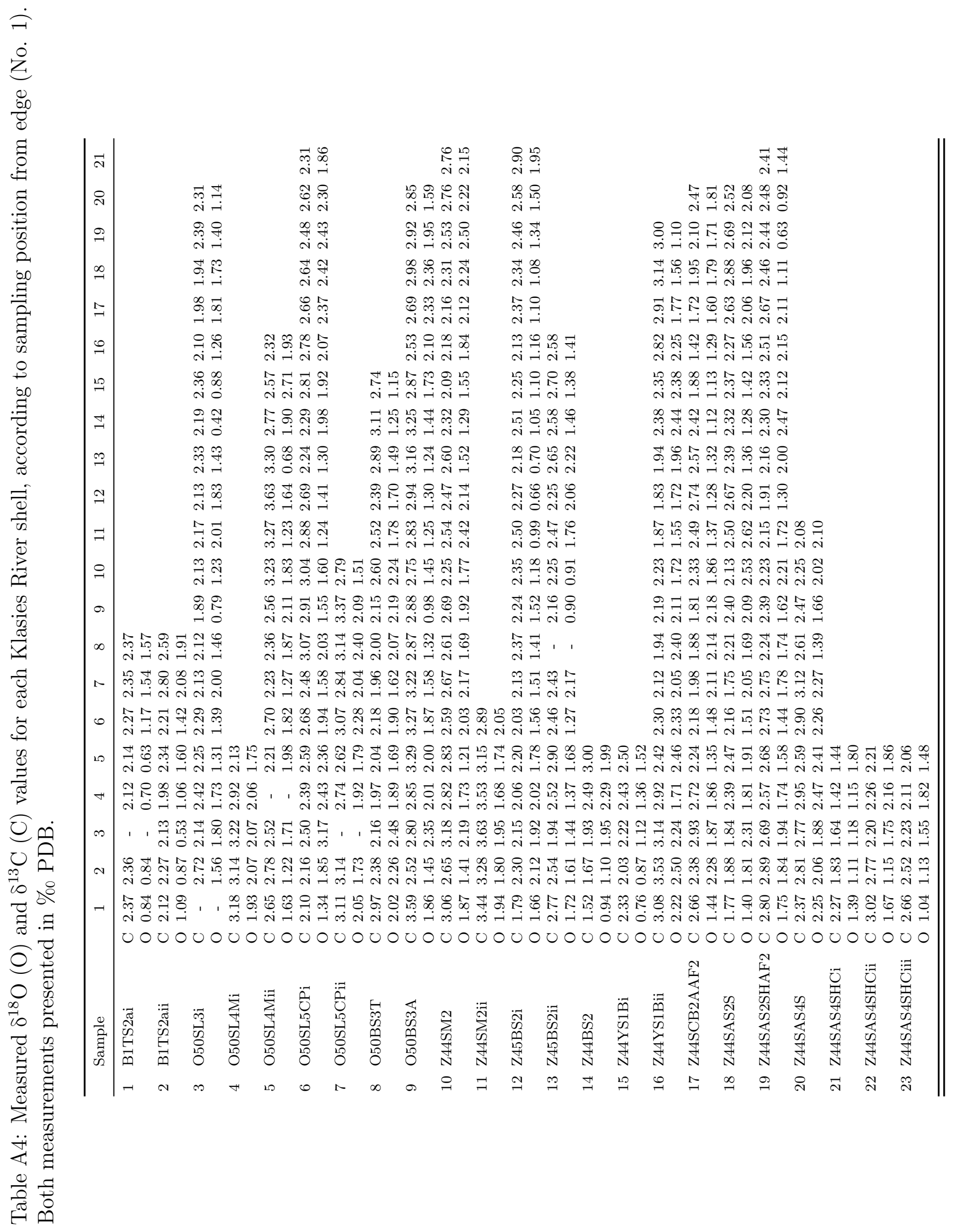




\section{Appendix B}

\section{Line plots and shell photographs}

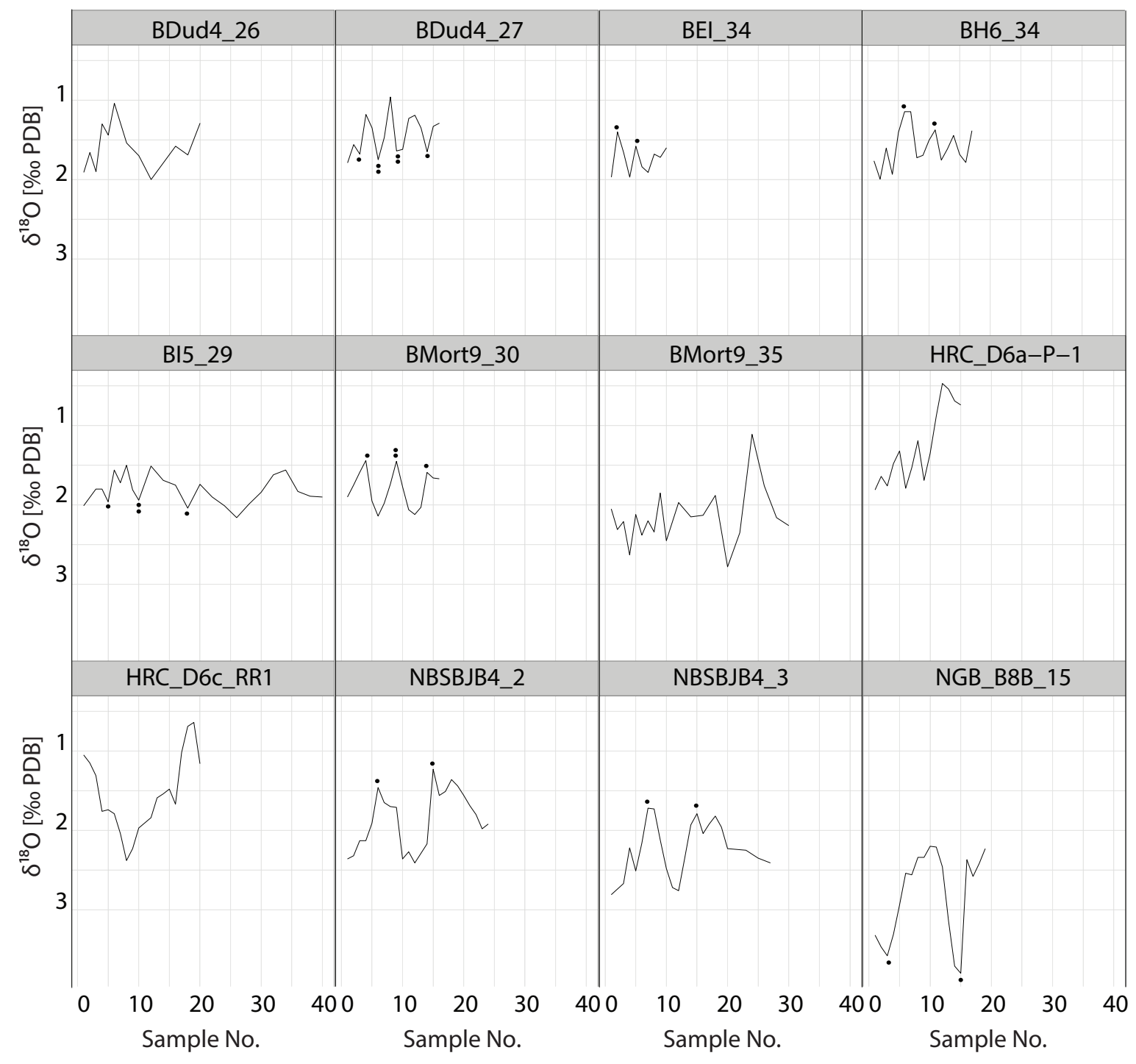




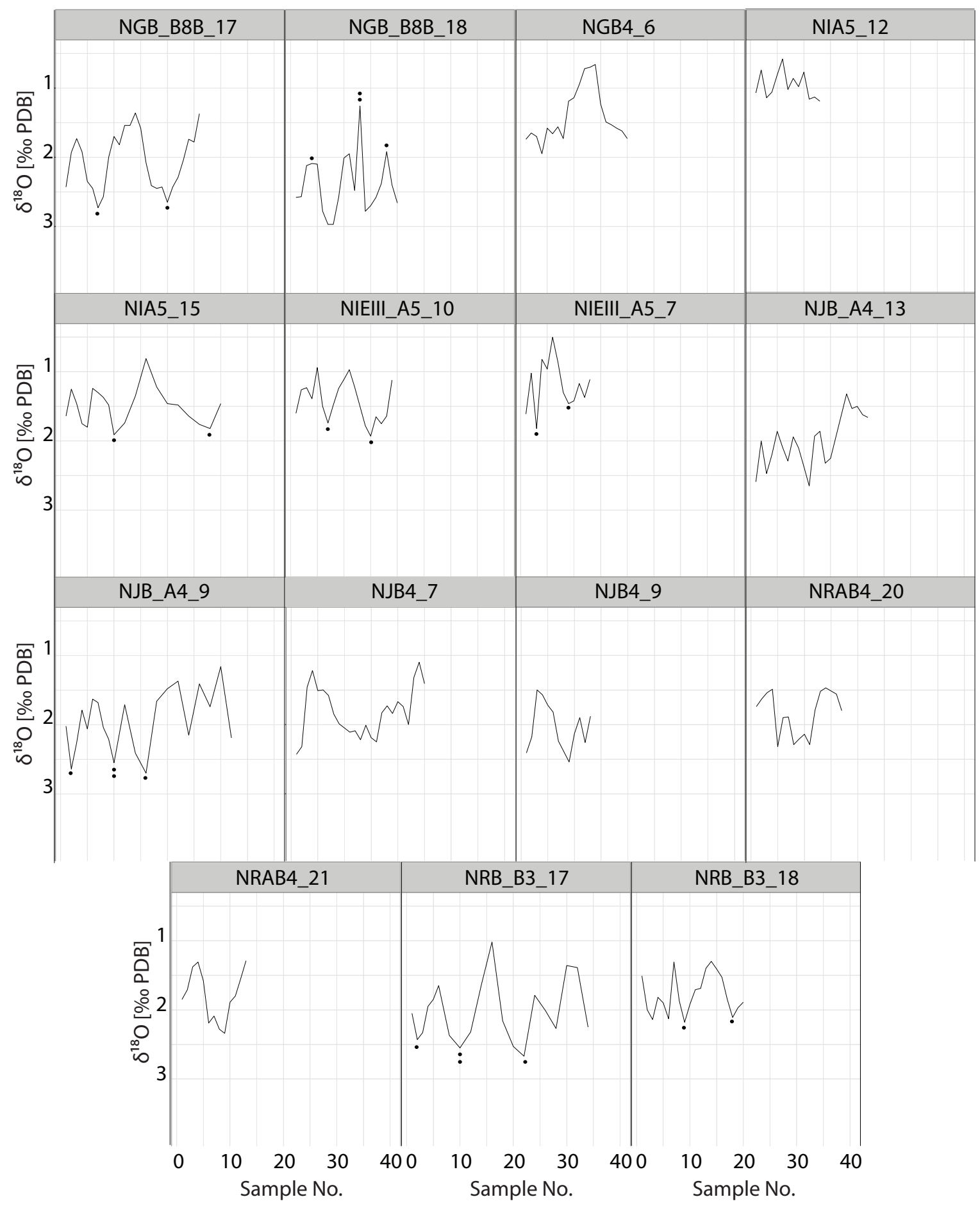

Figure B1: Individual line plots of $\delta^{18} \mathrm{O}$ measurements from the outer edge of the operculum for each Holocene aged operculum in alphabetical order. Black dots show the seasonal peaks that are measured in section 6.3 . 


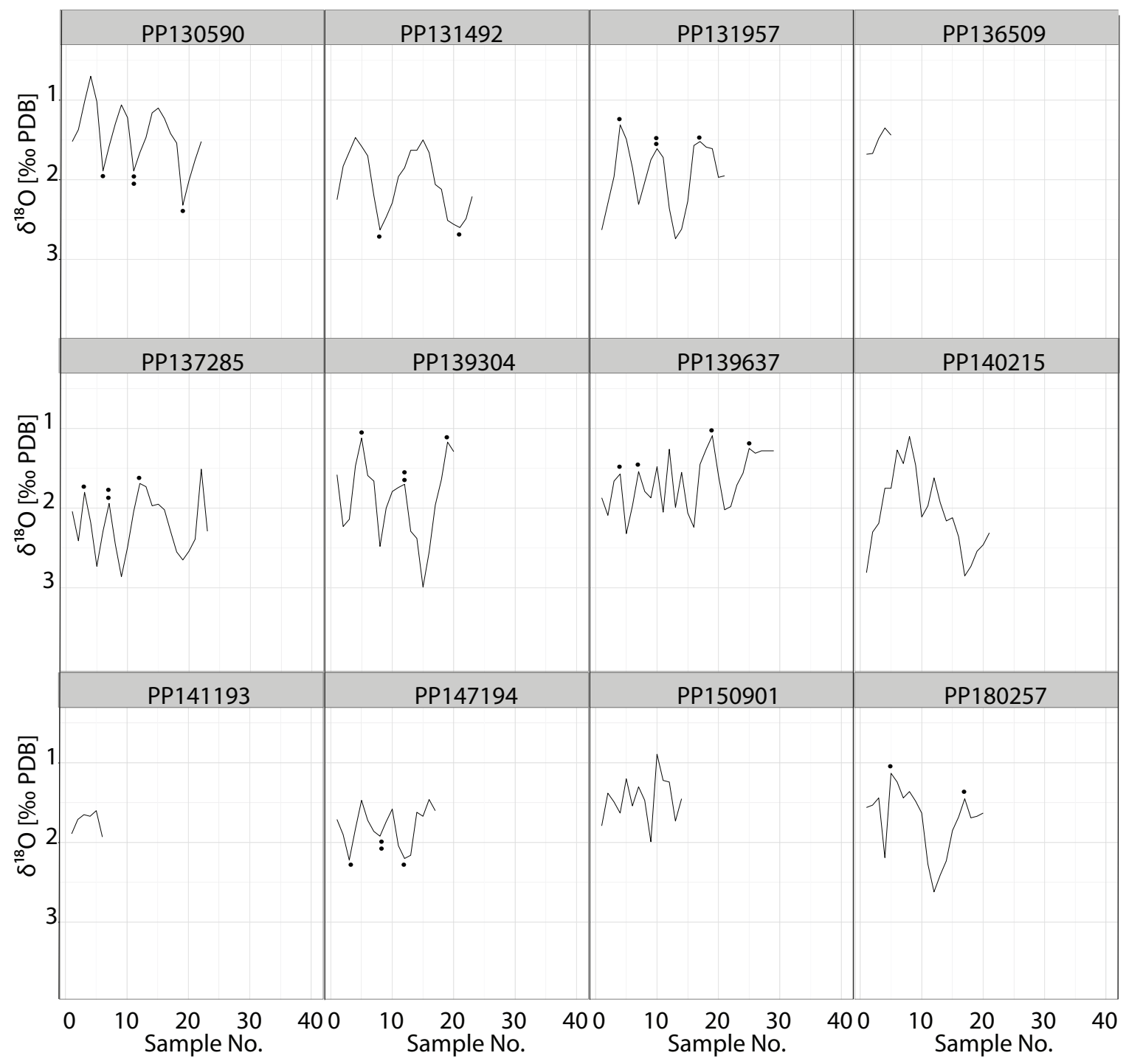




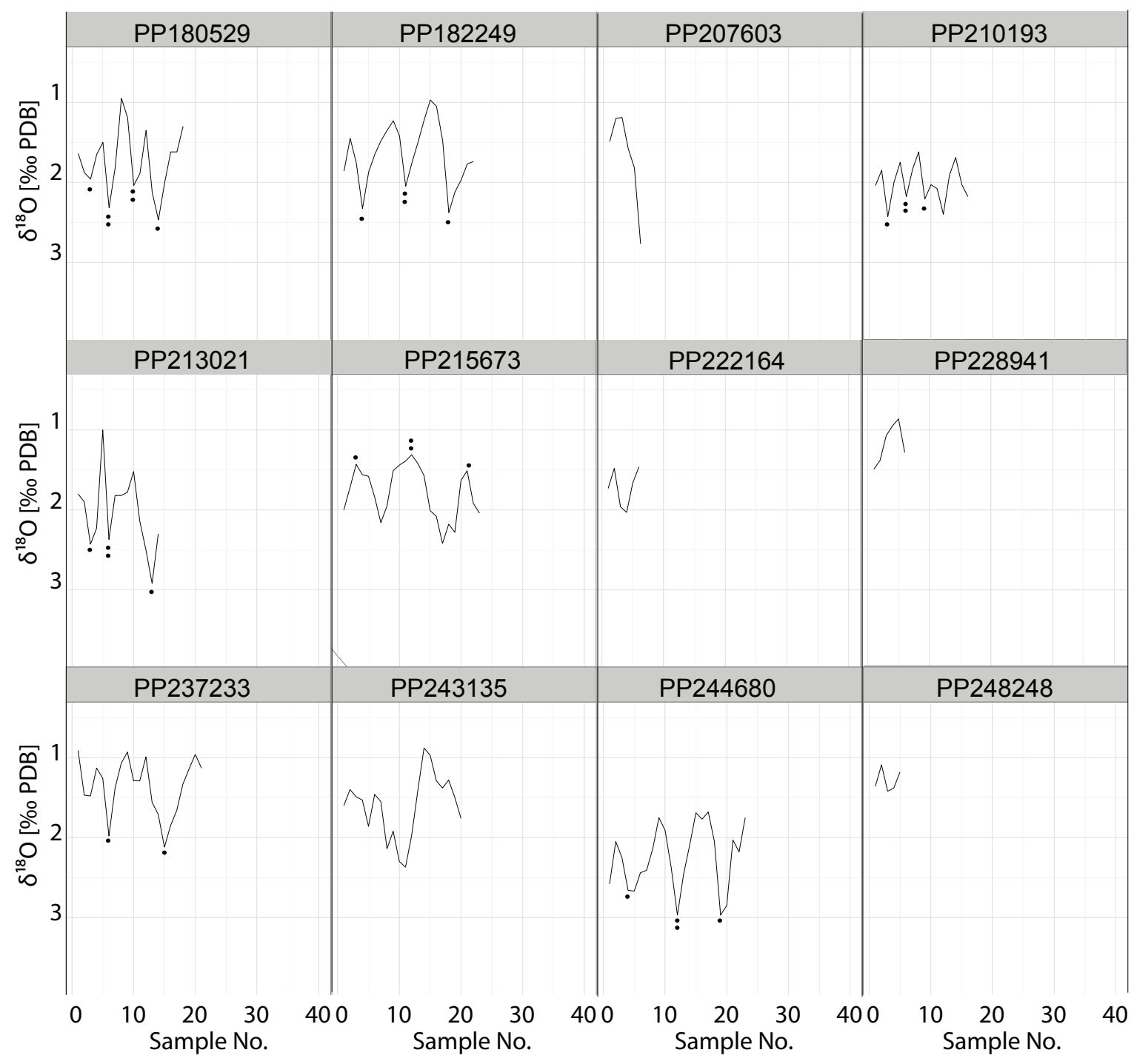

Figure B2: Individual line plots of $\delta^{18} \mathrm{O}$ measurements from the outer edge of each operculum from Pinnacle Point 5-6 in alphabetical order. Black dots show the seasonal peaks that are measured in section 6.3 . 


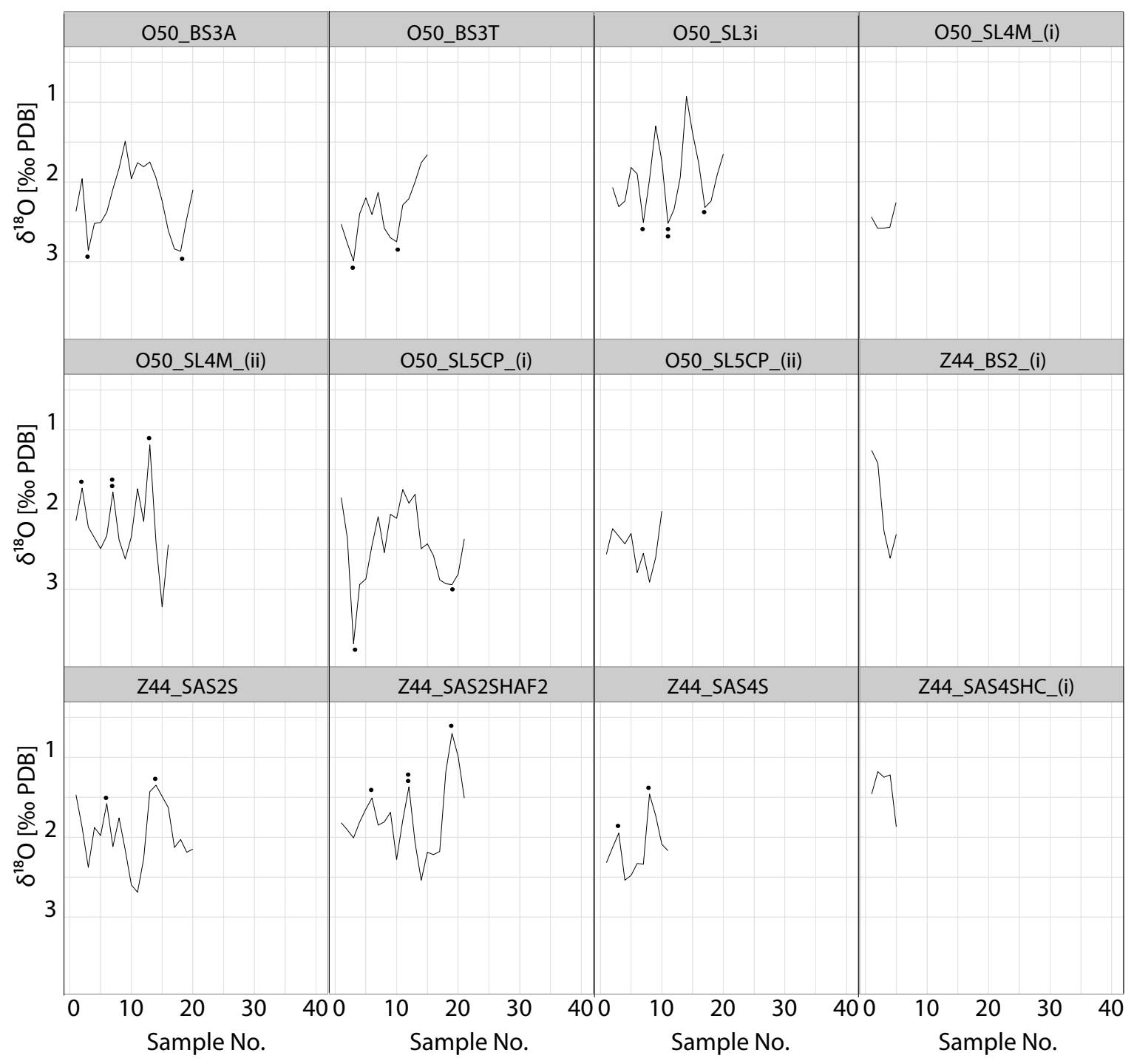




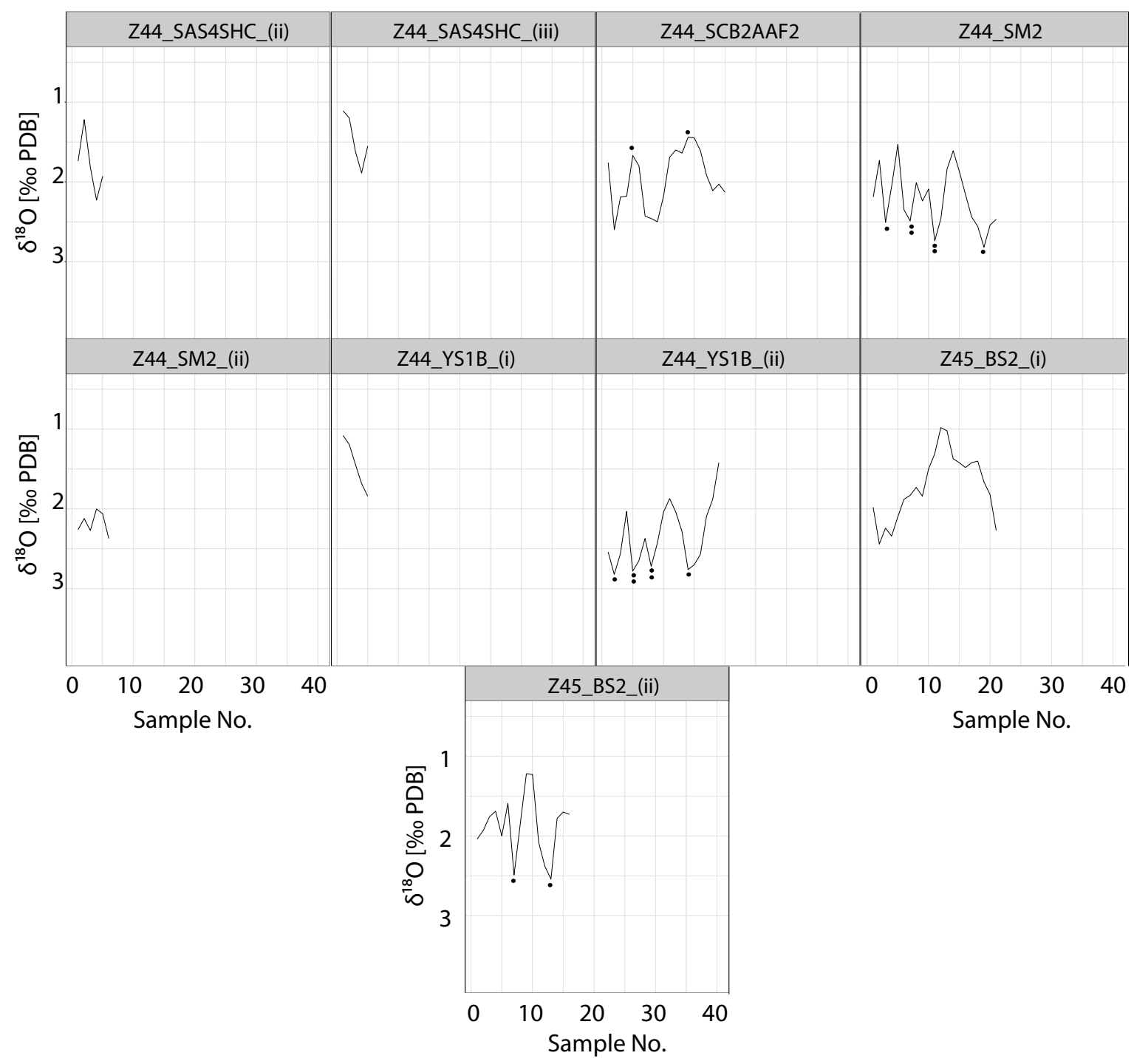

Figure B3: Individual line plots of $\delta^{18} \mathrm{O}$ measurements from the outer edge of each operculum from Klasies River in alphabetical order. Black dots show the seasonal peaks that are measured in section 6.3. 


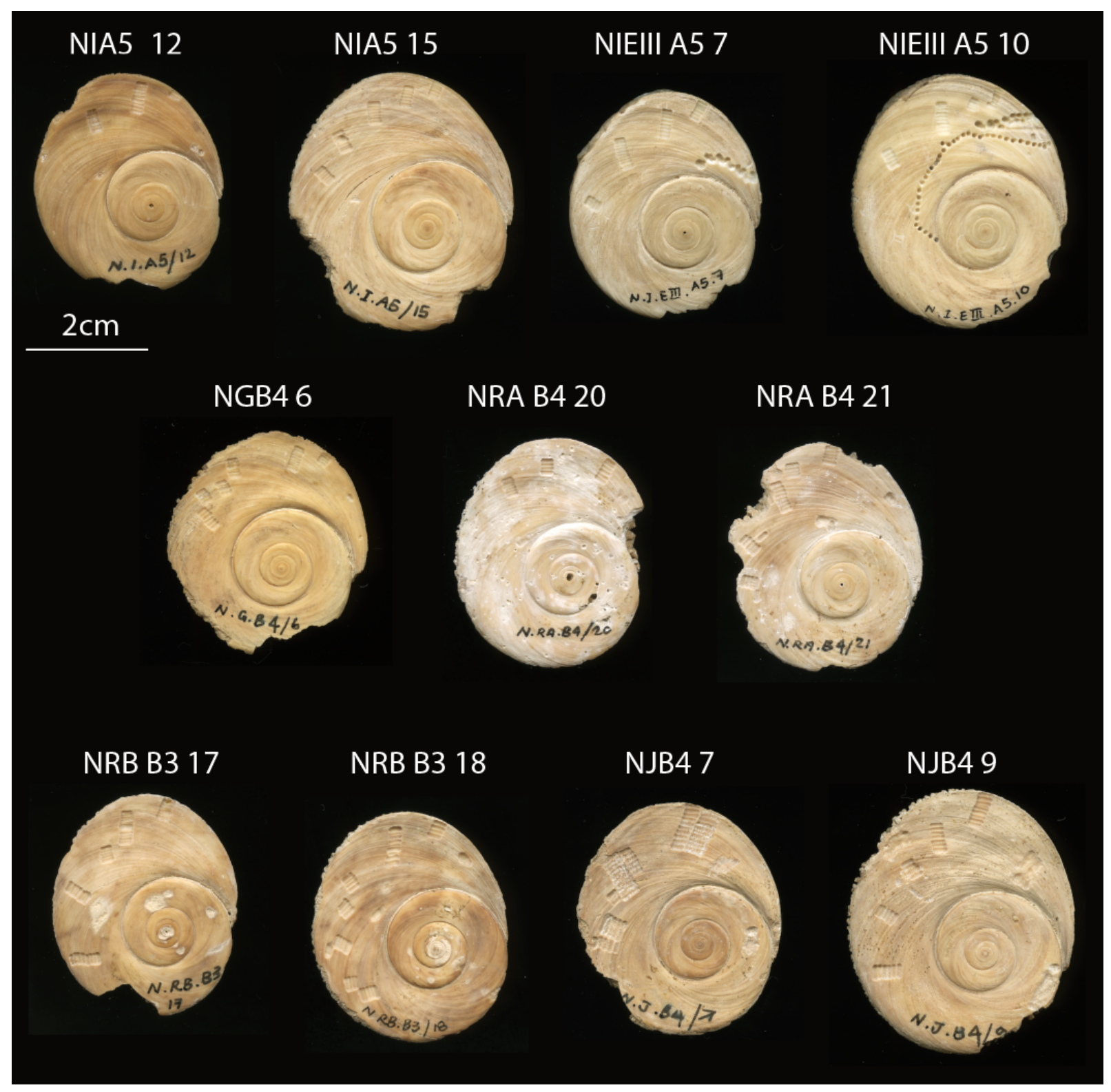




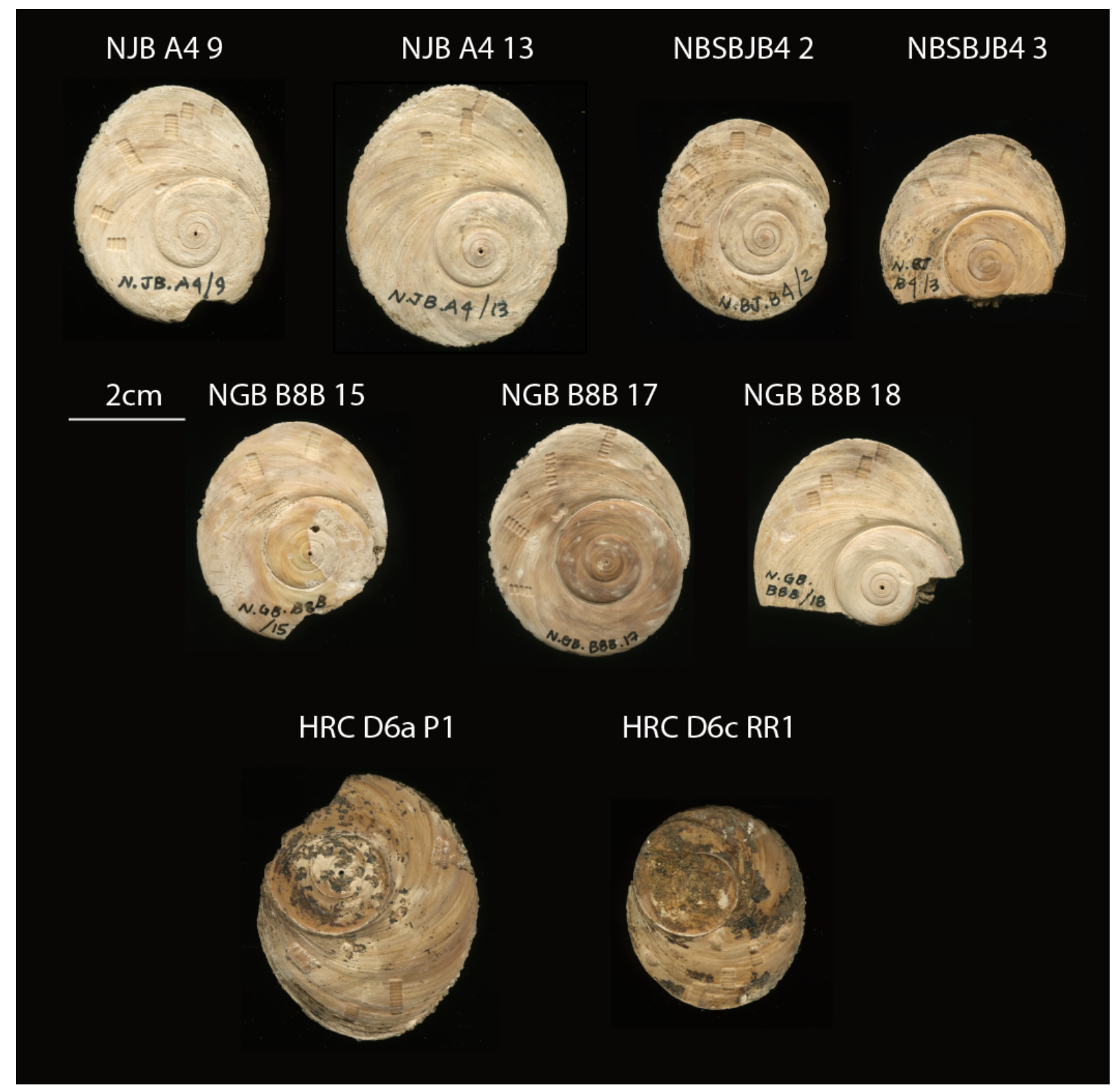

Figure B4: Individual photographs of each sampled shell from NBC and HRC (holes on shells from NIEIII A5 were made by a previous researcher. 


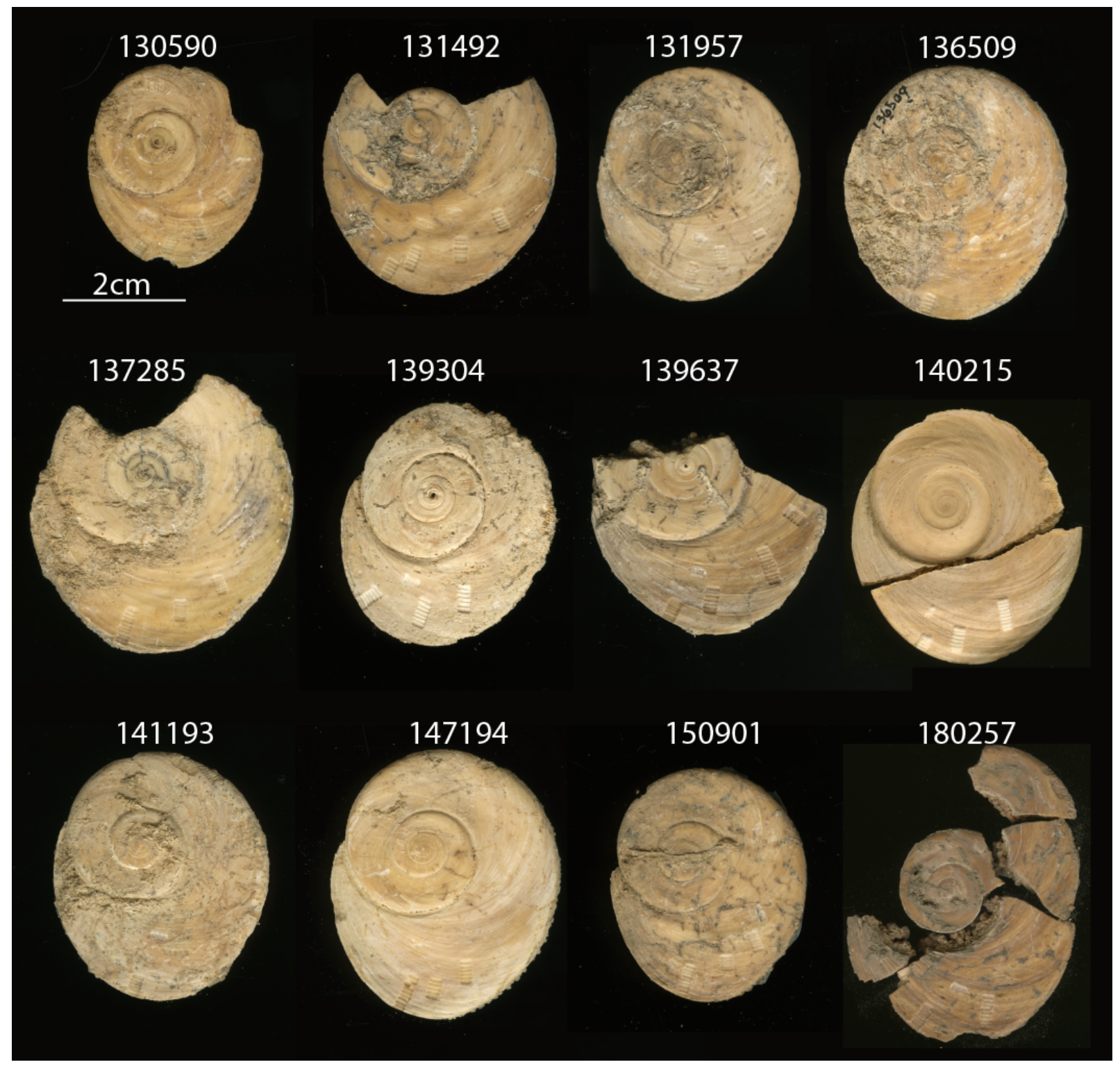




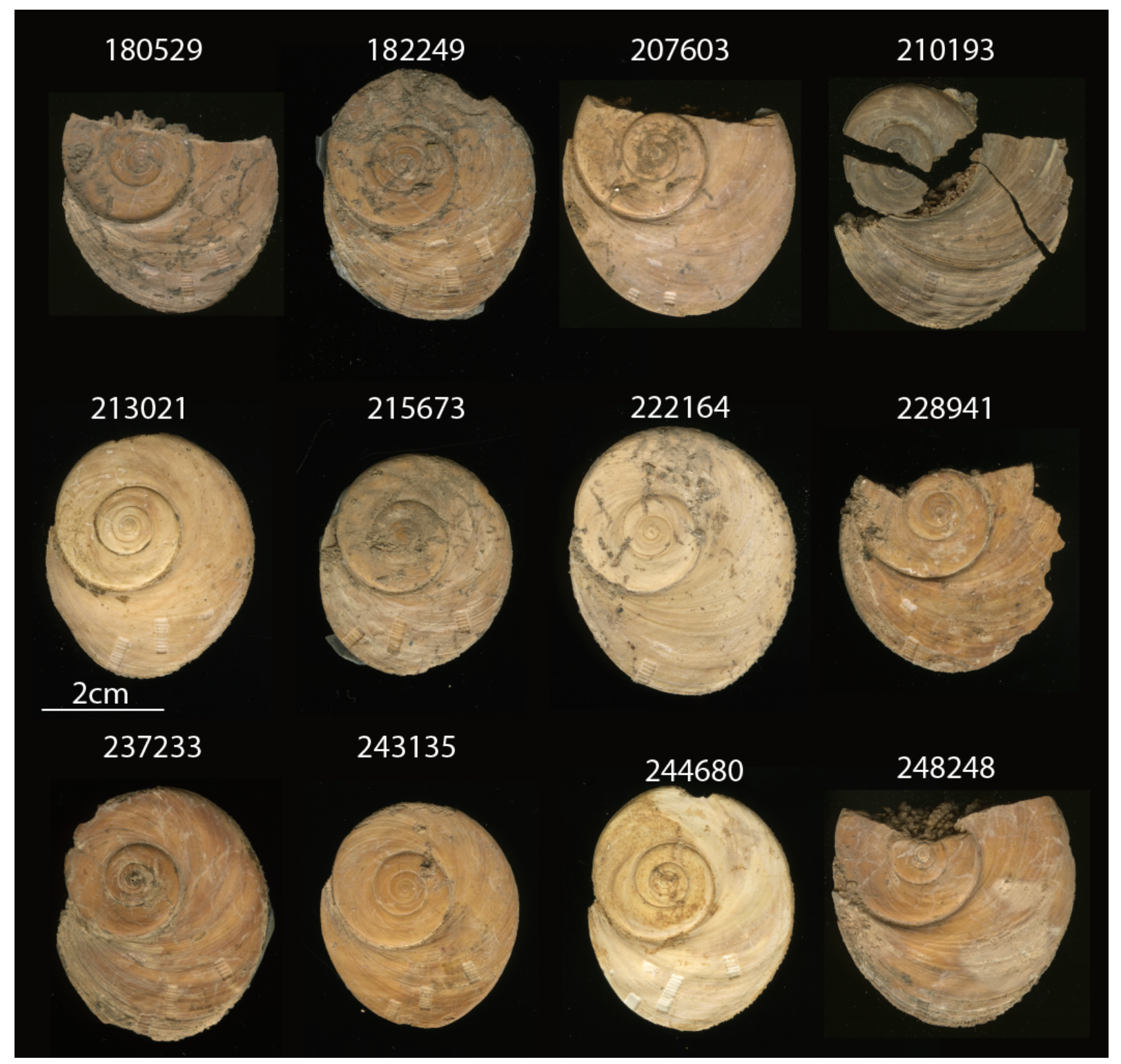

Figure B5: Individual photographs of each sampled shell from PP5-6. 


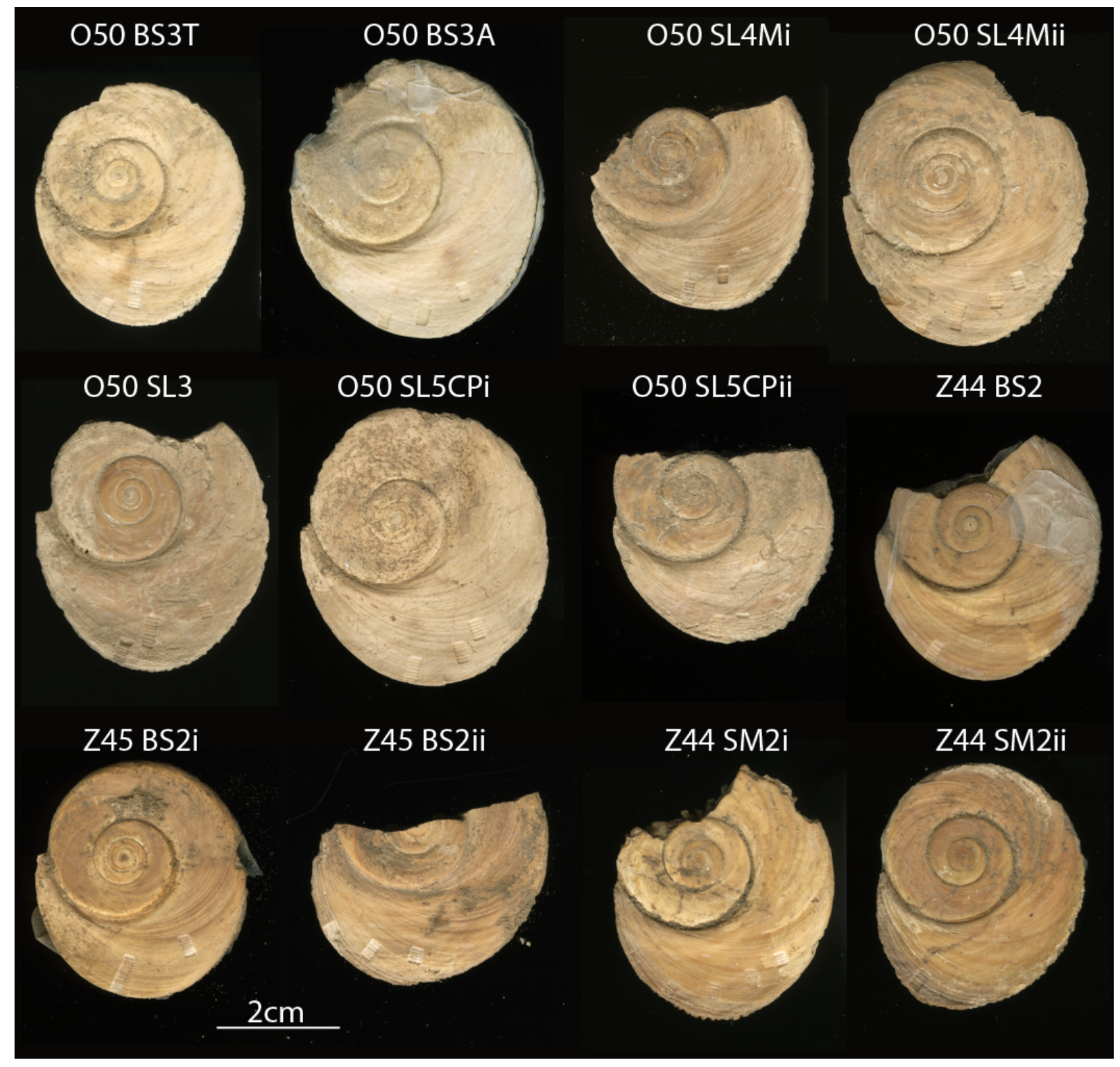




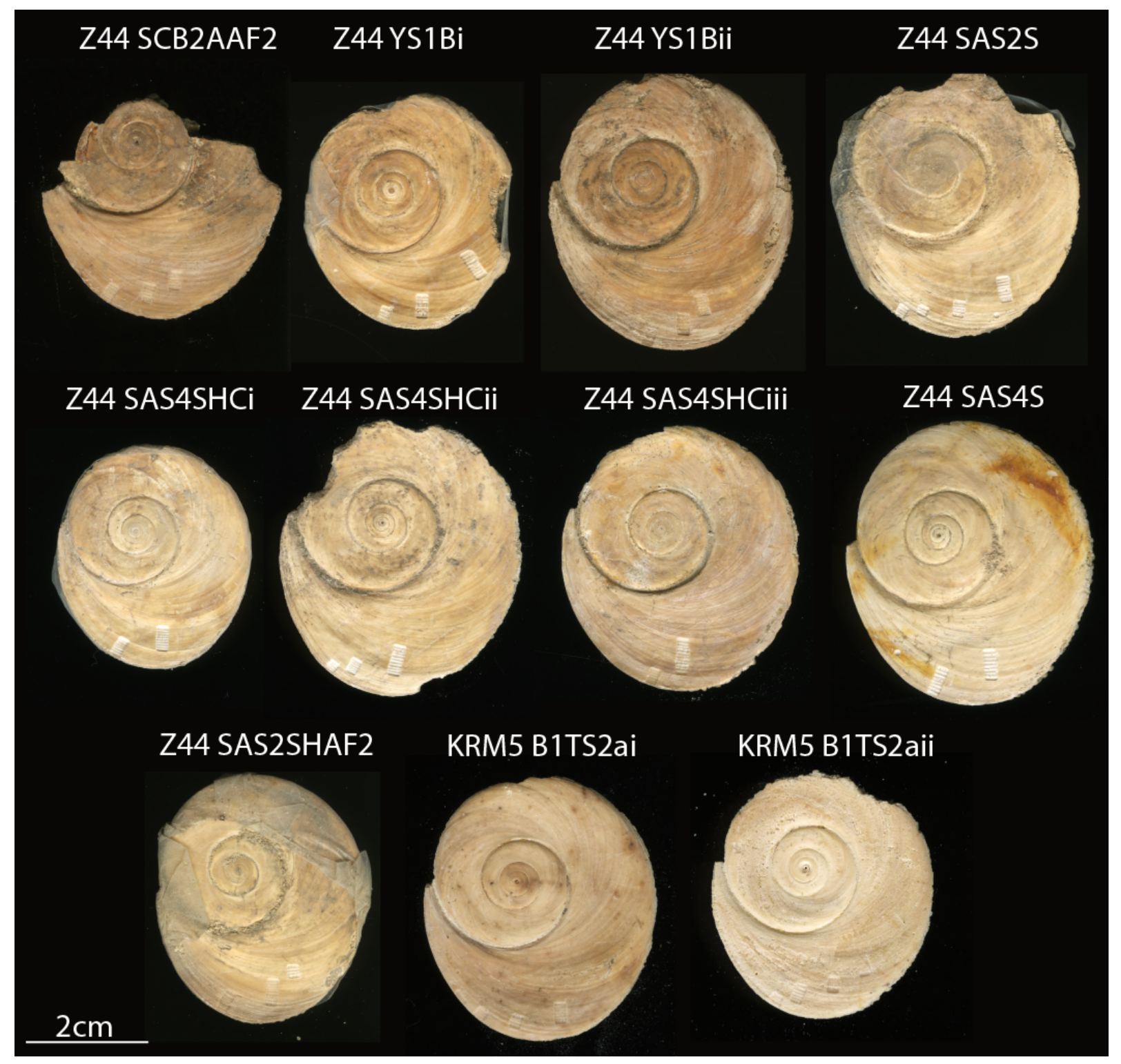

Figure B6: Individual photographs of each sampled shell from KRM. 


\section{Appendix C}

\section{Statistical test results}

Table C1: Post-hoc TukeyHSD multiple comparisons test results for raw Holocene $\delta^{18} \mathrm{O}$ results, grouped into four periods (late Holocene, mid Holocene, early Holocene and terminal Pleistocene). Significant results in bold font.

\begin{tabular}{lcccc}
\hline & diff & lwr & upr & p adj \\
\hline LateHolo-EarlyHolo & -0.188695221 & -0.32406711 & -0.05332334 & $\mathbf{0 . 0 0 2 0 3 2 4}$ \\
LatePleis-EarlyHolo & -0.001752914 & -0.16008767 & 0.15658184 & 0.9999916 \\
MidHolo-EarlyHolo & -0.024261864 & -0.14441717 & 0.09589344 & 0.9541430 \\
LatePleis-LateHolo & 0.186942308 & 0.01598763 & 0.35789698 & $\mathbf{0 . 0 2 5 7 3 2 7}$ \\
MidHolo-LateHolo & 0.164433358 & 0.02807755 & 0.30078916 & $\mathbf{0 . 0 1 0 6 8 3 0}$ \\
MidHolo-LatePleis & -0.022508950 & -0.18168574 & 0.13666784 & 0.9834219 \\
\hline \hline
\end{tabular}

Table C2: ANOVA results for corrected Holocene $\delta^{18} \mathrm{O}$ results, grouped into four periods (late Holocene, mid Holocene, early Holocene and terminal Pleistocene).

\begin{tabular}{lccccc}
\hline & Df & Sum Sq & Mean Sq & F value & $\operatorname{Pr}(>\mathrm{F})$ \\
\hline Period & 3 & 41.91 & 13.969 & 78.36 & $<\mathbf{2 e - 1 6}$ \\
Residuals & 489 & 87.18 & 0.178 & & \\
\hline \hline
\end{tabular}


Table C3: Post-hoc TukeyHSD multiple comparisons test results for corrected Holocene $\delta^{18} \mathrm{O}$ results, grouped into four periods (late Holocene, mid Holocene, early Holocene and terminal Pleistocene). Significant results in bold font.

\begin{tabular}{lcccc}
\hline & diff & lwr & upr & p adj \\
\hline LateHolo-EarlyHolo & -0.5170589 & -0.6533364 & -0.3807813 & $\mathbf{0 . 0 0 0 0 0 0 0}$ \\
LatePleis-EarlyHolo & 0.4198834 & 0.2604894 & 0.5792775 & $\mathbf{0 . 0 0 0 0 0 0 0}$ \\
MidHolo-EarlyHolo & -0.2891035 & -0.4100627 & -0.1681443 & $\mathbf{0 . 0 0 0 0 0 0 0}$ \\
LatePleis-LateHolo & 0.9369423 & 0.7648439 & 1.1090407 & $\mathbf{0 . 0 0 0 0 0 0 0}$ \\
MidHolo-LateHolo & 0.2279554 & 0.0906873 & 0.3652234 & $\mathbf{0 . 0 0 0 1 3 1 4}$ \\
MidHolo-LatePleis & -0.7089869 & -0.8692287 & -0.5487452 & $\mathbf{0 . 0 0 0 0 0 0 0}$ \\
\hline \hline
\end{tabular}

Table C4: Post-hoc TukeyHSD multiple comparisons test results for corrected Holocene $\delta^{18} \mathrm{O}$ results, grouped into six groups (late Holocene BNK1 and Robberg, mid Holocene BNK1 and Robberg, early Holocene and terminal Pleistocene). Significant results in bold font.

\begin{tabular}{lcccc}
\hline & diff & lwr & upr & p adj \\
\hline LateHoloBNK-EarlyHolo & -0.39093706 & -0.59932276 & -0.18255137 & $\mathbf{0 . 0 0 0 0 0 1 8}$ \\
LateHoloRobb-EarlyHolo & -0.59273193 & -0.76412465 & -0.42133922 & $\mathbf{0 . 0 0 0 0 0 0 0}$ \\
LatePleis-EarlyHolo & 0.41988345 & 0.24849073 & 0.59127617 & $\mathbf{0 . 0 0 0 0 0 0 0}$ \\
MidHoloBNK-EarlyHolo & -0.11185281 & -0.27338068 & 0.04967505 & 0.3546085 \\
MidHoloRobb-EarlyHolo & -0.45554619 & -0.61368071 & -0.29741168 & $\mathbf{0 . 0 0 0 0 0 0 0}$ \\
LateHoloRobb-LateHoloBNK & -0.20179487 & -0.43885296 & 0.03526322 & 0.1461610 \\
LatePleis-LateHoloBNK & 0.81082051 & 0.57376242 & 1.04787860 & $\mathbf{0 . 0 0 0 0 0 0 0}$ \\
MidHoloBNK-LateHoloBNK & 0.27908425 & 0.04905746 & 0.50911104 & $\mathbf{0 . 0 0 7 4 0 9 4}$ \\
MidHoloRobb-LateHoloBNK & -0.06460913 & -0.29226589 & 0.16304763 & 0.9652944 \\
LatePleis-LateHoloRobb & 1.01261538 & 0.80731706 & 1.21791371 & $\mathbf{0 . 0 0 0 0 0 0 0}$ \\
MidHoloBNK-LateHoloRobb & 0.48087912 & 0.28374163 & 0.67801661 & $\mathbf{0 . 0 0 0 0 0 0 0}$ \\
MidHoloRobb-LateHoloRobb & 0.13718574 & -0.05718109 & 0.33155257 & 0.3327309 \\
MidHoloBNK-LatePleis & -0.53173626 & -0.72887376 & -0.33459877 & $\mathbf{0 . 0 0 0 0 0 0 0}$ \\
MidHoloRobb-LatePleis & -0.87542964 & -1.06979648 & -0.68106281 & $\mathbf{0 . 0 0 0 0 0 0 0}$ \\
MidHoloRobb-MidHoloBNK & -0.34369338 & -0.52941966 & -0.15796710 & $\mathbf{0 . 0 0 0 0 0 2 7}$ \\
\hline \hline
\end{tabular}


Table C5: Post-hoc TukeyHSD multiple comparisons test results for Holocene $\delta^{13} \mathrm{C}$ results, grouped into four periods (late Holocene, mid Holocene, early Holocene and terminal Pleistocene). Significant results in bold font.

\begin{tabular}{lcccc}
\hline & diff & lwr & upr & p adj \\
\hline Late Holo-Early Holo & 0.16412864 & -0.006053978 & 0.33431126 & 0.0633280 \\
Late Pleisto-Early Holo & -0.06988586 & -0.269785907 & 0.13001418 & 0.8042631 \\
Mid Holo-Early Holo & 0.36172794 & 0.210532682 & 0.51292320 & $\mathbf{0 . 0 0 0 0 0 0 0}$ \\
Late Pleisto-Late Holo & -0.23401451 & -0.452740082 & -0.01528893 & $\mathbf{0 . 0 3 0 6 0 4 6}$ \\
Mid Holo-Late Holo & 0.19759930 & 0.022268593 & 0.37293001 & $\mathbf{0 . 0 1 9 9 7 4 3}$ \\
Mid Holo-Late Pleisto & 0.43161381 & 0.227313147 & 0.63591447 & $\mathbf{0 . 0 0 0 0 0 0 5}$ \\
\hline \hline
\end{tabular}

Table C6: Post-hoc TukeyHSD multiple comparisons test results for uncorrected Pinnacle Point 5/6 $\delta^{18} \mathrm{O}$ results, according to stratigraphic unit (DBCS, OBS1, SADBS, ALBS and LBSR). Significant results in bold font.

\begin{tabular}{lcccc}
\hline & diff & lwr & upr & p adj \\
\hline DBCS-ALBS & -0.04055405 & -0.32043559 & 0.239327478 & 0.9947419 \\
LBSR-ALBS & -0.17783784 & -0.36041242 & 0.004736743 & 0.0604264 \\
OBS1-ALBS & 0.04319595 & -0.13592265 & 0.222314544 & 0.9645218 \\
SADBS-ALBS & -0.21455074 & -0.37214054 & -0.056960945 & $\mathbf{0 . 0 0 2 0 3 1 3}$ \\
LBSR-DBCS & -0.13728378 & -0.41716532 & 0.142597748 & 0.6636801 \\
OBS1-DBCS & 0.08375000 & -0.19388945 & 0.361389454 & 0.9222957 \\
SADBS-DBCS & -0.17399669 & -0.43825932 & 0.090265944 & 0.3724529 \\
OBS1-LBSR & 0.22103378 & 0.04191519 & 0.400152381 & $\mathbf{0 . 0 0 7 0 5 4 1}$ \\
SADBS-LBSR & -0.03671290 & -0.19430270 & 0.120876893 & 0.9686892 \\
SADBS-OBS1 & -0.25774669 & -0.41131927 & -0.104174103 & $\mathbf{0 . 0 0 0 0 5 6 0}$ \\
\hline \hline
\end{tabular}

Table C7: ANOVA results for corrected Pinnacle Point 5/6 $\delta^{18} \mathrm{O}$ results, according to stratigraphic unit (DBCS, OBS1, SADBS, ALBS and LBSR).

\begin{tabular}{lccccc}
\hline & Df & Sum Sq & Mean Sq & F value & $\operatorname{Pr}(>\mathrm{F})$ \\
\hline Period & 4 & 17.16 & 4.291 & 26.13 & $<\mathbf{2 e - 1 6}$ \\
Residuals & 394 & 64.70 & 0.164 & & \\
\hline \hline
\end{tabular}


Table C8: Post-hoc TukeyHSD multiple comparisons test results for corrected Pinnacle Point 5/6 $\delta^{18} \mathrm{O}$ results, according to stratigraphic unit (DBCS, OBS1, SADBS, ALBS and LBSR). Significant results in bold font.

\begin{tabular}{lcccc}
\hline & diff & lwr & upr & p adj \\
\hline DBCS-ALBS & -0.01055405 & -0.290435586 & 0.26932748 & 0.9999742 \\
LBSR-ALBS & -0.46783784 & -0.650412418 & -0.28526326 & $\mathbf{0 . 0 0 0 0 0 0 0}$ \\
OBS1-ALBS & 0.17319595 & -0.005922652 & 0.35231454 & 0.0635868 \\
SADBS-ALBS & -0.14455074 & -0.302140541 & 0.01303906 & 0.0896349 \\
LBSR-DBCS & -0.45728378 & -0.737165316 & -0.17740225 & $\mathbf{0 . 0 0 0 0 9 6 5}$ \\
OBS1-DBCS & 0.18375000 & -0.093889454 & 0.46138945 & 0.3670547 \\
SADBS-DBCS & -0.13399669 & -0.398259321 & 0.13026594 & 0.6347404 \\
OBS1-LBSR & 0.64103378 & 0.461915186 & 0.82015238 & $\mathbf{0 . 0 0 0 0 0 0 0}$ \\
SADBS-LBSR & 0.32328710 & 0.165697297 & 0.48087689 & $\mathbf{0 . 0 0 0 0 0 0 4}$ \\
SADBS-OBS1 & -0.31774669 & -0.471319274 & -0.16417410 & $\mathbf{0 . 0 0 0 0 0 0 3}$ \\
\hline \hline
\end{tabular}

Table C9: Post-hoc TukeyHSD multiple comparisons test results for uncorrected Klasies River Main site $\delta^{18} \mathrm{O}$ values, according to stratigraphic unit (MSA II upper, MSA II lower and MSA I).

\begin{tabular}{lcccc}
\hline & diff & lwr & upr & p adj \\
\hline MSAIIlow-MSAI & -0.077997068 & -0.2397055 & 0.08371136 & 0.4924352 \\
MSAIIupp-MSAI & -0.003168772 & -0.1671887 & 0.16085112 & 0.9988582 \\
MSAIIupp-MSAIIlow & 0.074828297 & -0.0677501 & 0.21740670 & 0.4326151 \\
\hline \hline
\end{tabular}

Table C10: ANOVA results for corrected Klasies River Main site $\delta^{18} \mathrm{O}$ values, according to stratigraphic unit (MSA II upper, MSA II lower and MSA I).

\begin{tabular}{lccccc}
\hline & Df & Sum Sq & Mean Sq & F value & $\operatorname{Pr}(>\mathrm{F})$ \\
\hline Period & 2 & 1.34 & 0.6707 & 3.397 & $\mathbf{0 . 0 3 4 9}$ \\
Residuals & 280 & 55.29 & 0.1975 & & \\
\hline \hline
\end{tabular}


Table C11: Post-hoc TukeyHSD multiple comparisons test results for corrected Klasies River Main site $\delta^{18} \mathrm{O}$ values, according to stratigraphic unit (MSA II upper, MSA II lower and MSA I). Significant results in bold font.

\begin{tabular}{lcccc}
\hline & diff & lwr & upr & p adj \\
\hline MSAIIlow-MSAI & 0.1720029 & 0.01029451 & 0.3337114 & $\mathbf{0 . 0 3 4 0 3 6 6}$ \\
MSAIIupp-MSAI & 0.1468312 & -0.01718867 & 0.3108511 & 0.0897636 \\
MSAIIupp-MSAIIlow & -0.0251717 & -0.16775010 & 0.1174067 & 0.9090664 \\
\hline \hline
\end{tabular}

Table C12: Post-hoc TukeyHSD multiple comparisons test results for Pinnacle Point 5-6 and Klasies River $\delta^{13} \mathrm{C}$ results, by site and according to depositional or technological unit. Significant results in bold font.

\begin{tabular}{lcccc}
\hline & diff & lwr & upr & p adj \\
\hline Pinnacle Point 5-6 & & & & \\
DBCS-ALBS & -0.213797297 & -0.6131194629 & 0.18552487 & 0.8608542 \\
LBSR-ALBS & -0.065270270 & -0.3257593291 & 0.19521879 & 0.9998083 \\
OBS1-ALBS & 0.535702703 & 0.2801444821 & 0.79126092 & 0.0000000 \\
SADBS-ALBS & 0.080020583 & -0.1448213308 & 0.30486250 & 0.9939841 \\
LBSR-DBCS & 0.148527027 & -0.2507951386 & 0.54784919 & 0.9910841 \\
OBS1-DBCS & 0.749500000 & 0.3533767284 & 1.14562327 & 0.0000000 \\
SADBS-DBCS & 0.293817881 & -0.0832199536 & 0.67085572 & 0.3193733 \\
OBS1-LBSR & 0.600972973 & 0.3454147523 & 0.85653119 & 0.0000000 \\
SADBS-LBSR & 0.145290854 & -0.0795510605 & 0.37013277 & 0.6317319 \\
SADBS-OBS1 & -0.455682119 & -0.6747924585 & -0.23657178 & 0.0000000 \\
Klasies River sites & & & & \\
MSAI-KRM_Holo & 0.087273632 & -0.3653260496 & 0.53987331 & 0.9999886 \\
MSAII_lower-KRM_Holo & 0.155333333 & -0.2803165160 & 0.59098318 & 0.9938828 \\
MSAII_upper-KRM_Holo & 0.339371795 & -0.0982526069 & 0.77699620 & 0.3272027 \\
MSAII_lower-MSAI & 0.068059701 & -0.1766608549 & 0.31278026 & 0.9994389 \\
MSAII_upper-MSAI & 0.252098163 & 0.0038795567 & 0.50031677 & 0.0425212 \\
MSAII_upper-MSAII_lower & 0.184038462 & -0.0317317777 & 0.39980870 & 0.1891493 \\
\hline \hline
\end{tabular}

